
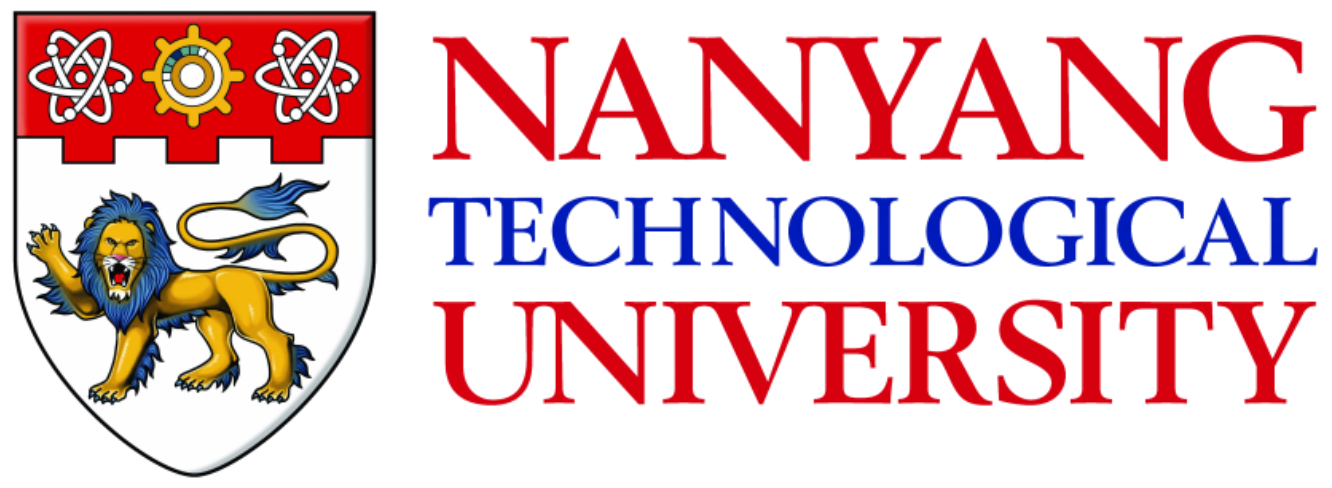

HYBRID MATERIALS FOR REMOVAL OF BISPHENOL-A FROM AQUEOUS SOLUTION

MARIA REGINA HARTONO

SCHOOL OF MATERIALS SCIENCE AND ENGINEERING 



\section{HYBRID MATERIALS FOR REMOVAL OF BISPHENOL-A FROM AQUEOUS SOLUTION}

MARIA REGINA HARTONO

SCHOOL OF MATERIALS SCIENCE \& ENGINEERING

A thesis submitted to the Nanyang Technological University in partial fulfilment of the requirement for the degree of Doctor of Philosophy 



\section{Abstract}

Noxious pollutants such as endocrine disrupting compounds (EDCs) are associated with rapid industrial and urban development. They are difficult to remove using conventional wastewater treatments and thus pose new challenges in environmental remediation. These concerns necessitate more effective and efficient approaches for emerging pollutant removal from wastewater treatment units. (Aim) This study evaluated various strategies for the removal of one of these emerging endocrine disruptor compounds, bisphenol A (BPA). (Scope) In particular, to improve the removal of BPA from aqueous environments, we investigated processes of physical separation of BPA from an aqueous solution through adsorption and then investigated the subsequent integration of adsorption with biological degradation.

Among the emerging adsorbent materials, biosorbents predominate due to their low cost and abundance. However, these products have low adsorption capacity. Therefore, to improve these abilities, amphiphilic surfactant treated biosorbent was developed and studied, and the factors affecting its ability to remove BPA were assessed. In the first study, we evaluated pre-treatment of bamboo powder waste, a kind of biosorbents, to remove BPA. Despite the marked increase in removal capacity after treatment with cationic surfactant, its kinetics and adsorption capacity are still considered inferior in comparison to other emerging adsorbent materials. A comparison study was conducted among treated bamboo powder, commercial graphene nanoplatelets, and single- and multi-walled carbon nanotubes (MWCNTs) for the removal of BPA. Our study deduced that carbon nanomaterial (CNM) variants in general possess faster adsorption capacities and kinetics for BPA removal.

Indeed, CNM variants have gained tremendous interest as adsorbents due to their high adsorption capacity and improved re-usability through multiple regeneration cycles. However, there are concerns regarding their environmental toxicity, which brings into question about their application as environmentally safe and sustainable adsorbent 
materials. To overcome this, the second part of our study focused on the development of composite sorbents such as entrapped MWCNTs and $\mathrm{TiO}_{2}$ inside alginate beads to reduce environmental toxicity and to facilitate the recovery of the used sorbent. Because wastewater treatment plants are operated in continuous mode with limited contact time to reach equilibrium, it was necessary to assess the capability of a sorbent during continuous flow mode to assess its practical application. BPA removal from the composite beads in the column reactors was affected by the feed flow rate, bed depth and initial inlet concentrations. The BPA sorption performance was predicted with good correlation using a dose-response model. We showed that photolytic degradation of BPA desorbed from the beads, and thus the regeneration of the spent adsorbent beads can be achieved simultaneously.

Results showed that the alginate beads alone, however, were easily abraded and susceptible to destruction by phosphate, rendering their use in their pure form unsuitable for the containment of MWCNTs in water treatment. Therefore, in the next part of our study, we designed a macro-bead platform comprised of a calcium-alginate core and a polysulfone (Psf) layer as an immobilization matrix for MWCNTs. We hypothesized that the additional Psf layer would improve BPA removal and reduce the percentage of MWCNTs that leaked from the beads. We tested these fabricated beads for adsorption of BPA in a batch reactor and tested their re-usability in a column reactor. The physical and chemical properties of the fabricated beads were characterized using electron microscopy, zeta potential, BET surface area, FTIR and Instron microtester. Bioluminescence assay was used as a means to detect the leakage of MWCNTs from the beads. Several accepted kinetic and isotherm models were utilized to characterize the adsorption behavior of the hybrid beads. Our observations show that BPA removal increased with the content of MWCNTs. Also, the addition of the Psf layer improved the amount of adsorbed BPA at lower MWCNT amounts but was less significant with higher counts of MWCNTs. Moreover, the hybrid beads were relatively stable over a wide range of pHs. The BPA adsorption profile of the hybrid beads correlates well with the pseudo-second order kinetic model and the Langmuir isotherm monolayer adsorption model. Addition of a Psf layer on composite beads that contained MWCNTs improved the compressive load 
capacity of the composite beads up to twelvefold at $40 \%$ compression. The improved compressive load capacity in beads layered in Psf could be applicable to both shield and improve the stability of the composite calcium alginate-MWCNT beads in reactors, where the bead sorbents may be subjected to abrasion that could affect bead integrity.

Building from our previous studies, in the last part of our work, we attempted to integrate the biodegrading component into the hybrid bead. We used a novel BPA tolerant bacteria strain $\mathrm{PBPA}_{2}$ that was isolated from the environment and embedded it within the calcium-alginate/MWCNT/Psf beads with the purpose of integrating the adsorption performance of MWCNTs and the biodegradation capability of the $\mathrm{PBPA}_{2}$ strain. The effects of enrichment and mineral media composition, bead diameter and cell loading were studied in a batch reactor. It was observed that the addition of $0.05 \%$ yeast extract into the mineral medium and the reduction of the bead's diameter enhanced the removal of BPA. Subsequent experiments in continuous-flow column reactors resulted in enhanced BPA removal, reinforcing the potential of integrating biodegrading bacteria with CNTs.

In summary, this work reveals the development of a novel composite sorbent platform for the removal of BPA and elucidates upon its sorption mechanisms and efficiencies. 


\section{Acknowledgements}

I would like to thank my supervisors, namely Professor Ariel Kushmaro and Professor Robert S. Marks from Ben-Gurion University of the Negev (BGU) as well as Professor Chen Xiaodong from Nanyang Technological University (NTU), for their insightful advices and kind assistances throughout this journey. I am also grateful to my cosupervisors during research attachment at University of Nantes, Professor Marie Jose Durand-Thouand and Professor Gerald Thouand.

I would also like to thank my mentors and colleagues for their continuous support despite various adversities. In no particular order:

- Dr. Eitan Ben-Dov for his contribution in microbial encapsulation technique and BLAST characterization

- Dr. Evgeny Eltzov for his contribution in biosensing

- Dr. Valentina Pavlov for isolating the bisphenol A tolerant bacteria

- Dr. Ali Assaf for his expertise in principle component analysis

- Ms. Olivia Wijaya, Dr. Ronn Goei and Dr. Yap Pow Seng for their networking expertise and assistance in securing chemicals and equipment

- Ms. Hilla Ben Hamo, Ms. Kulchaya Tanong and Ms. Marina de Leew for their exceptional hospitality while I was overseas

- My project manager, Dr. Ma Bing, as well as colleagues at NEW-CREATE

- $\quad$ Technical staffs at NTU and ERI@N for equipment training and support

Lastly, I would like to thank my family and friends for their constant encouragement. This thesis is dedicated to my departed parents, for the debts that I could never repay.

\section{Dominus Illuminatio Mea}




\section{Table of Contents}

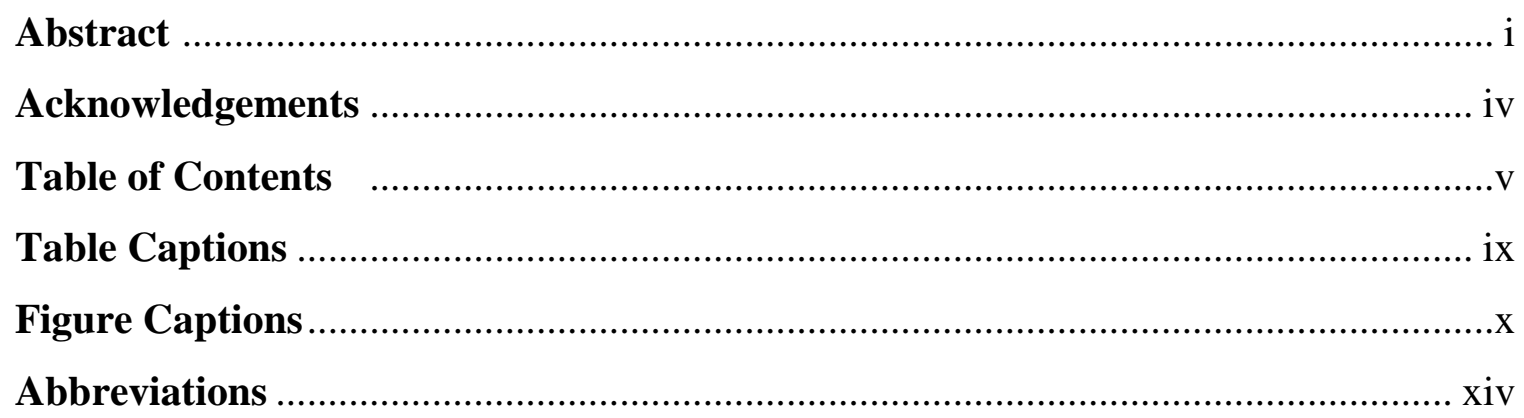

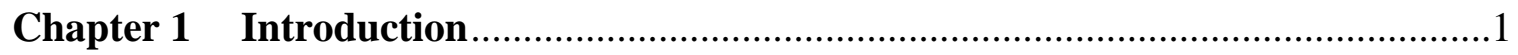

1.1 Adsorption for Removal of Emerging Pollutants .............................................

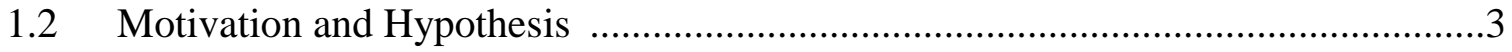

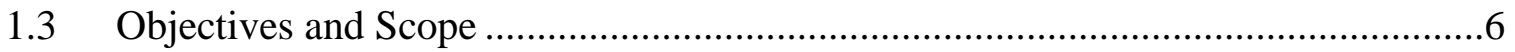

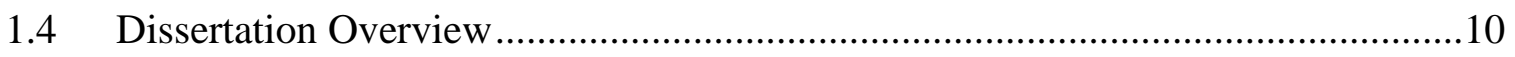

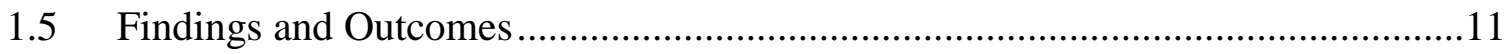

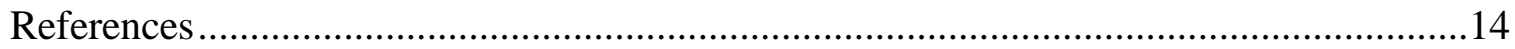

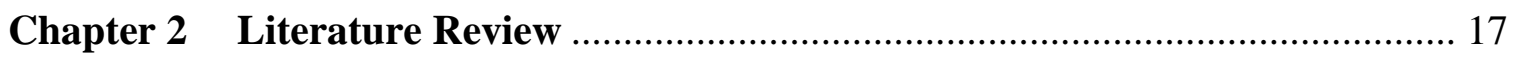

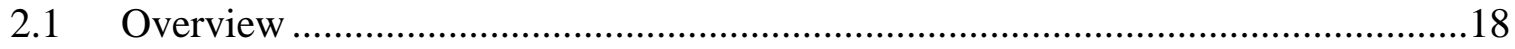

2.1.1 Adsorption process...................................................................... 19

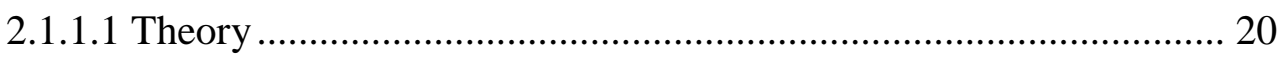

2.1.1.2 Batch Reactor - Sorption kinetics ..........................................21

2.1.1.3 Batch Reactor - Sorption isotherm ........................................ 22

2.1.1.4 Continuous Flow Reactor - Column modeling ......................... 24

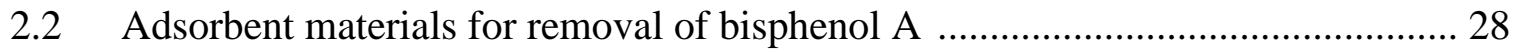

2.2.1 CNMs as emerging adsorbent materials: benefits and challenges .............34

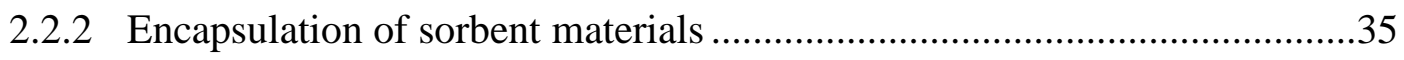

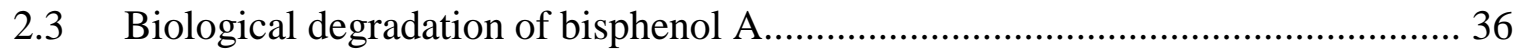

2.3.1 Integration of biodegradation with CNMs adsorption ..............................38

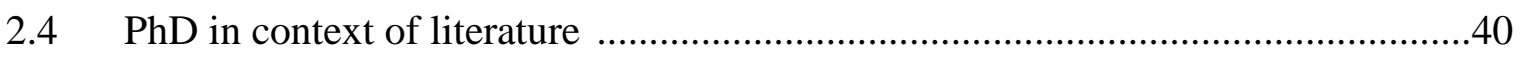

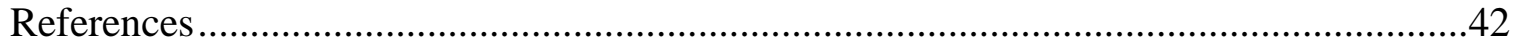




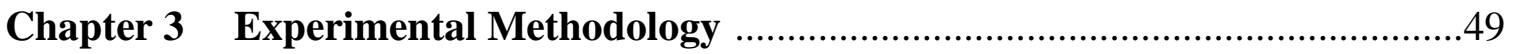

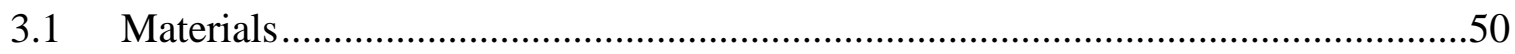

3.1.1 Reagents and Solvents .......................................................................50

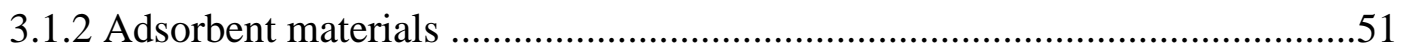

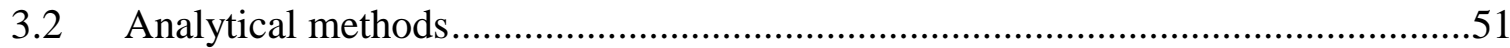

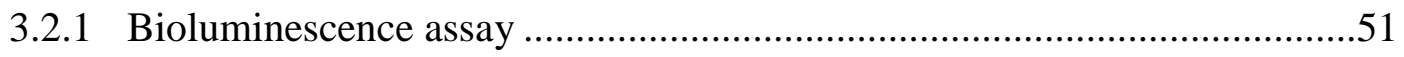

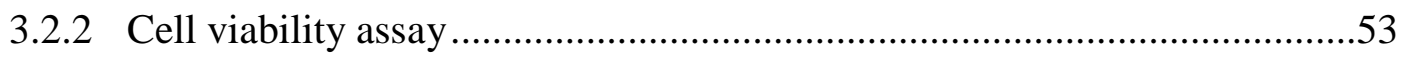

3.2.3 Fourier Transforms Infrared Spectroscopy Analysis...................................54

3.2.4 High Performance Liquid Chromatography ..............................................54

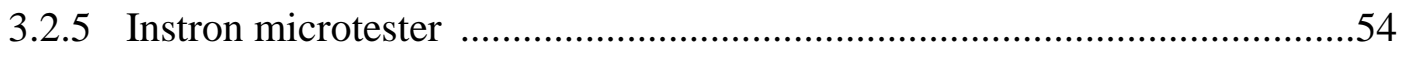

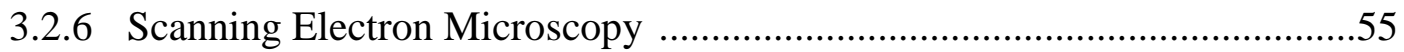

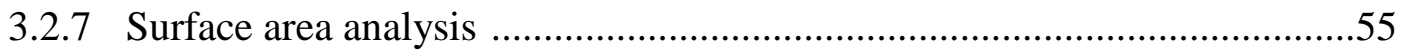

3.2.8 Ultraviolet-Visible Spectrophotometer ....................................................55

3.2.9 Zeta potential measurement ………………......................................56

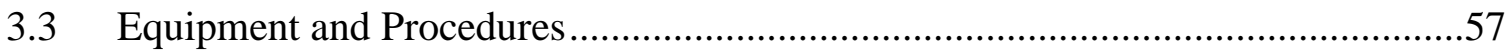

3.3.1 Preparation of Adsorbent Materials ………………...............................57

3.3.1.1 Modification of Bamboo Fiber Powder ……………………….....57

3.3.1.2 Fabrication of Hybrid Beads ........................................................57

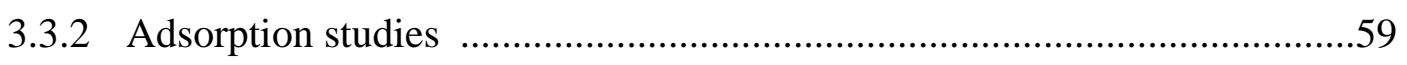

3.3.2.1 Batch reactor - adsorption ............................................................59

3.3.2.2 Batch reactor - desorption ......................................................59

3.3.2.3 Column reactor ...........................................................................6

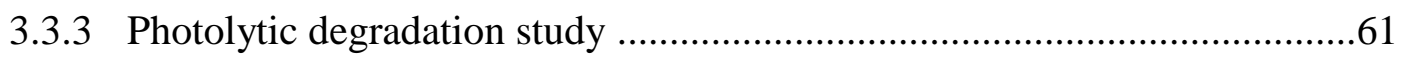

3.3.4 Combined biodegradation - adsorption ……….........................................62

3.3.4.1 Microorganism isolation and enrichment culture condition ...........62

3.3.4.2 Batch Reactor - Biodegradation by PBPA2 strain .........................62

3.3.4.3 Immobilization of PBPA2 within hybrid bead ................................64

3.3.4.4 Batch Reactor - BPA removal by immobilized PBPA2 strain.........64

3.3.4.5 Column Reactor ............................................................................65

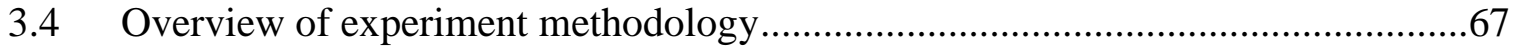

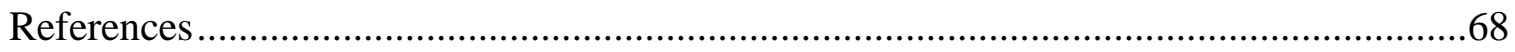




\section{Chapter 4 Characterization and BPA removal performance by}

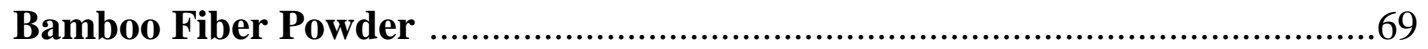

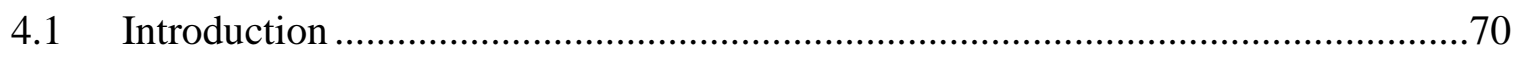

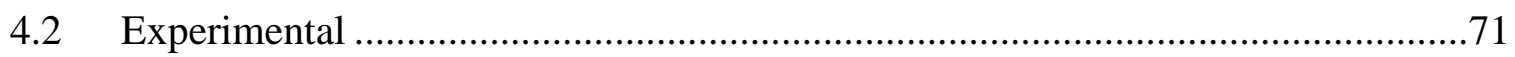

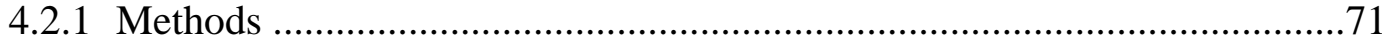

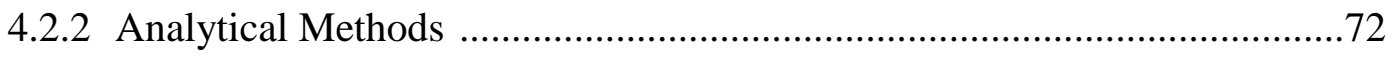

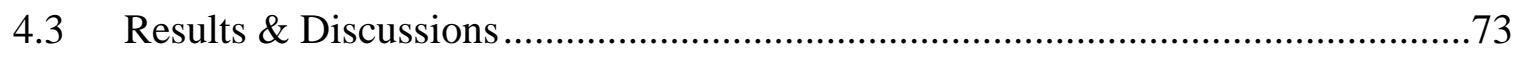

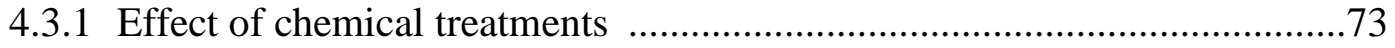

4.3.2 Effect of bamboo powders dosage ................................................... 73

4.3.3 Sorption isotherm at different particle sizes .........................................74

4.3.4 Proposed mechanism .................................................................... 77

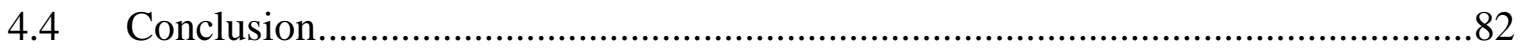

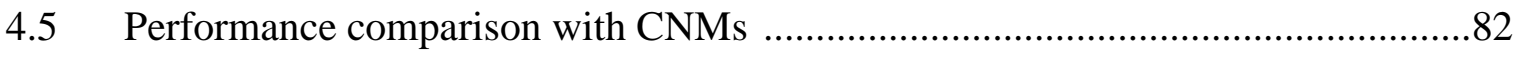

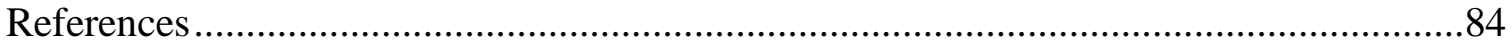

\section{Chapter 5 Characterization and BPA removal performance by}

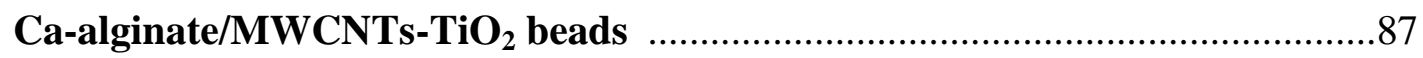

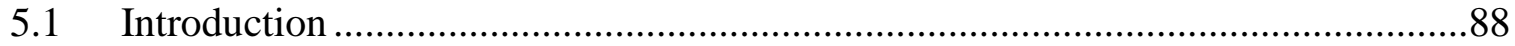

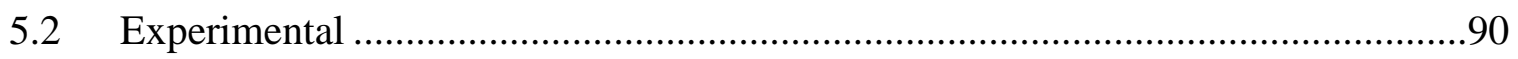

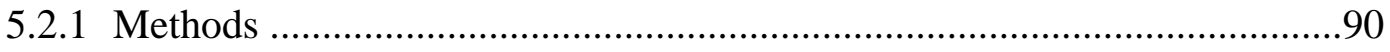

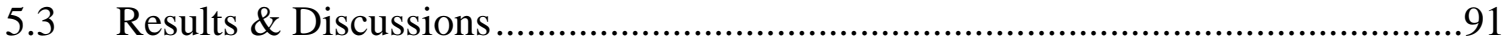

5.3.1 Influence of design parameters on bisphenol A removal..........................91

5.3.2 Photolytic degradation and byproducts............................................96

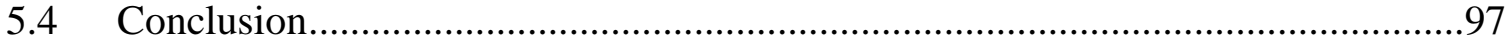

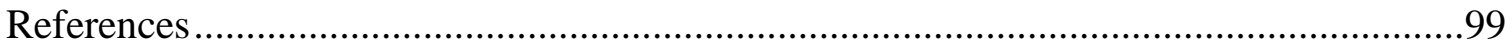

\section{Chapter 6 Characterization and BPA removal performance by}

Ca-alginate/MWCNTs/Polysulfone beads ...............................................101

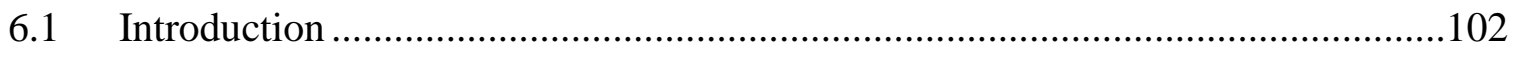

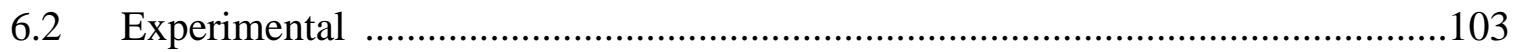

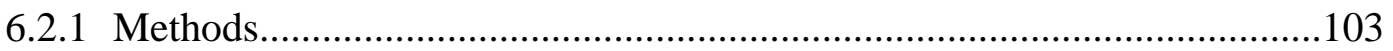




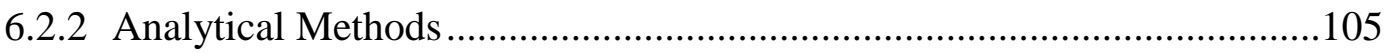

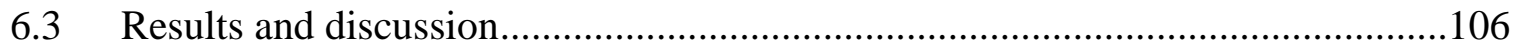

6.3.1 Characterization of the hybrid beads .................................................106

6.3.2 Influence of experiment parameters................................................... 108

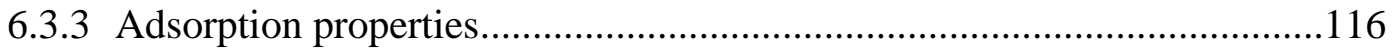

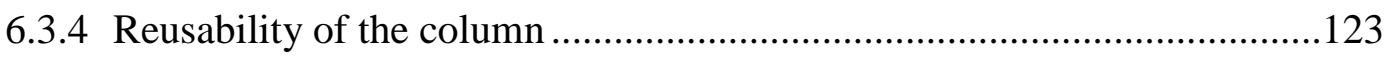

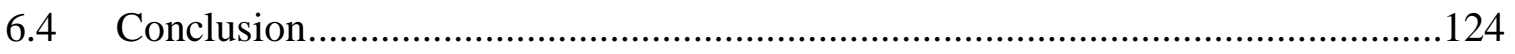

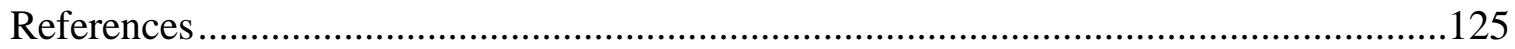

\section{Chapter 7 Characterization and BPA removal performance by}

Ca-alginate/MWCNTs-Bacteria/Polysulfone beads ..................................127

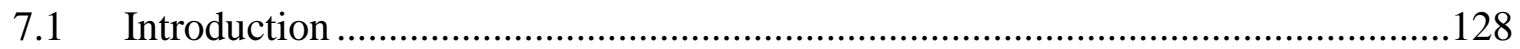

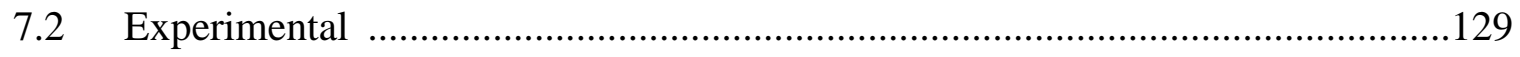

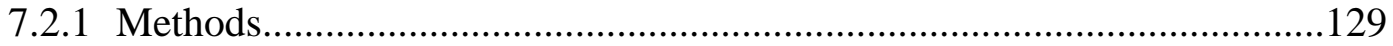

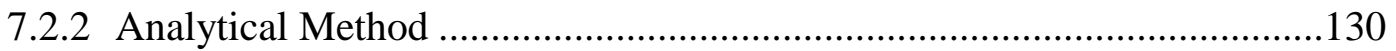

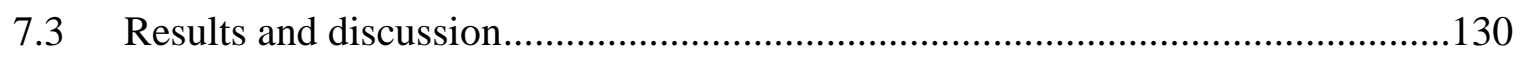

7.3.1 Characterization of the isolated strain PBPA2 .....................................130

7.3.2 BPA removal by immobilized PBPA2 in batch reactor..........................134

7.3.3 BPA removal by immobilized PBPA2 in column reactor .......................136

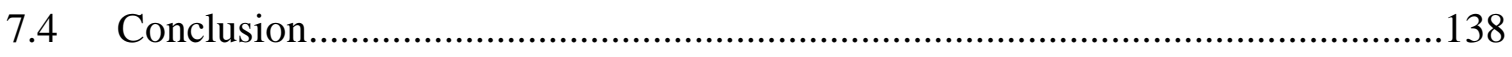

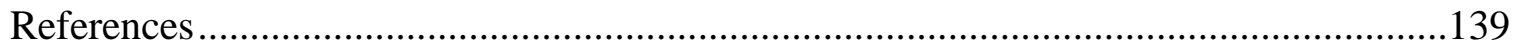

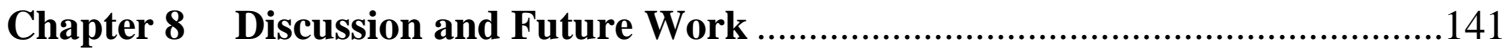

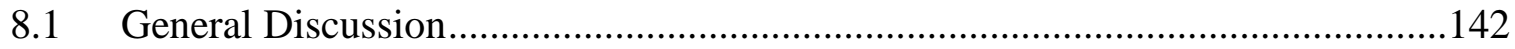

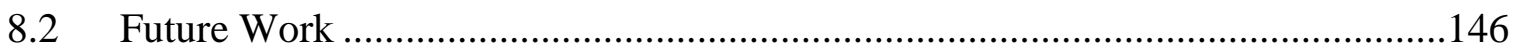

8.2.1 Structural characterization of surfactant treated fiber ...........................146

8.2.2 Optimization of integrated MWCNTs-bacteria bead..............................147

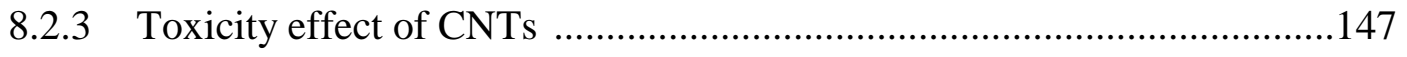

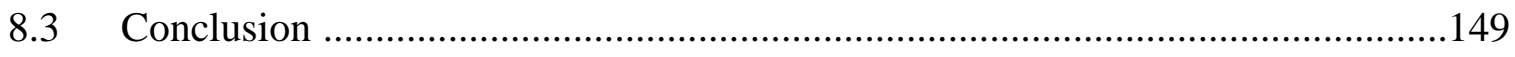

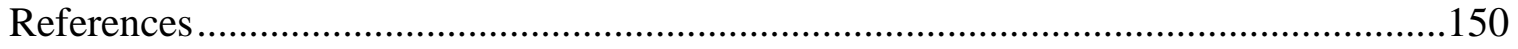

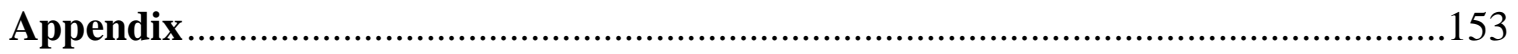




\section{Table Captions}

Table 1.1 Properties of bisphenol A ..................................................................2

Table 2.1 Comparison of tertiary treatments in removal of emerging pollutants .......19

Table 2.2 Typical operating conditions of GAC column ......................................24

Table 2.3 Several reported BPA sorbents and their sorption capacity ........................32

Table 3.1 List of chemicals and products used in the study .....................................50

Table 3.2 Key characteristics of CNMs used in this study .....................................51

Table 3.3 Recipes of the media used in BPA degradation study .............................63

Table 4.1 Parameters of Linear and Freundlich isotherm models .............................75

Table 4.2 Surface analysis measurements of treated bamboo powders of $300 \mu \mathrm{m}$

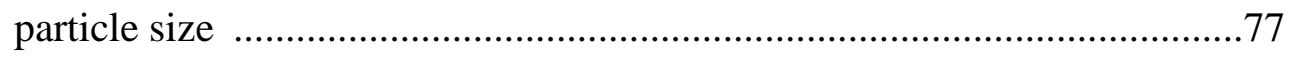

Table 5.1(a) Experimental setting in the breakthrough study ..................................93

Table 5.1(b) Parameters of sorption models at different initial BPA concentrations ......95

Table 6.1 Summary of experimental conditions for bead fabrication ......................104

Table 6.2 Comparisons of BET surface area values of the hybrid beads ................108

Table 6.3 Description of MWCNTs dispersion into alginate at different concentration .109

Table 6.4 Physical properties of the hybrid beads …........................................113

Table 6.5 Kinetic parameters for BPA adsorption by $\mathrm{Ca}-\mathrm{Alg} / 22 \%-\mathrm{MWCNTs} / \mathrm{Psf}$ at different initial BPA concentrations ...................................................118

Table 6.6 Langmuir and Freundlich parameters for BPA adsorption by $\mathrm{Ca}-\mathrm{Alg} / 22 \%$ MWCNTs/Psf at equilibrium

Table 7.1 Dose-response model parameters .136 


\section{Figure Captions}

Figure 1.1 Chemical structure of bisphenol A …................................................2

Figure 1.2(a) The scope of the two studies included in the project in relevance to the qualitative price comparison of reported adsorbents for removal of BPA .8

Figure 1.2(b) Flow diagrams showing the three main parts which constitutes the second study. Effects of different parameters on each part were optimized in order to improve the BPA removal efficiency …...........................................9

Figure 2.1 Illustration of breakthrough curve in a fixed-bed column reactor .............25

Figure 2.2 The qualitative price comparison of reported adsorbent materials for removal of BPA 34

Figure 2.3 The amount of works published under "bisphenol A" and "toxicity" terms as retrieved from Scopus

Figure 3.1 The bioluminescence patterns produced by DPD2511 (a) after 1.5h incubation at different monitoring temperatures and (b) against negative control after different incubation time at ambient monitoring temperature

Figure 3.2 Absorbance spectra of BPA at different concentrations (top-down: 100, 80, 60, 40 and $20 \mathrm{mg} . \mathrm{L}^{-1}$ ) showing characteristic peaks at the wavelength of $225 \mathrm{~nm}$ and $276 \mathrm{~nm}$ .56

Figure 3.3 The hybrid bead fabrication process (a) alginate-MWCNT mixture was dropped into stirred calcium chloride solution, (b) the swollen composite bead was touched to filter paper; (c) the dried bead was dropped into Psf solution; (d) phaseinversion process caused Psf layer to be formed; (e) immersion into distilled water completed the polymerization and (f) the resultant hybrid beads

Figure 3.4 Illustration of up-flow packed bed column set-up used in the column experiment

Figure 3.5 Set-up of photolytic degradation study .61

Figure 3.6 (a) Illustration on the setup of column study: (1) column filled with hybrid beads; (2) sterile air purging; (3) filter; (4) peristaltic pump; (5) feed and (6) outlet and (b) its corresponding experimental setup 
Figure 4.1 Removal of BPA by chemically treated bamboo powders .73

Figure 4.2 Effect of CBPs dosage on removal of BPA .74

Figure 4.3 Sorption isotherm of BPA on the CTAB treated bamboo powder at equilibrium .75

Figure 4.4 (a) Principal component analysis showing the distribution of spectra, (b) ANOVA showing the distribution of different groups, ANOVA table: pvalue $=1.77 \times 10-5$ indicating that the samples are statistically different, $(\mathrm{c})$ First loading of PCA scores .79

Figure 4.5 Zeta-potential measurements of untreated and CTAB-treated BPs .80

Figure 4.6 Illustration on the possible interactions involved during the chemical treatment of BPs with (a) Cationic surfactant CTAB and (b) untreated .....81

Figure 4.7 BPA adsorption capacity and initial sorption rate of CBPs and tested CNMs

Figure 5.1 Simplified illustration on the pollutant sorption and subsequent regeneration of the spent composite carbon nanotube-TiO2 hydrogel beads

Figure 5.2 BPA sorption curves by the column under different (a) flow rates and (b) bed depths .93

Figure 5.3 BPA sorption curves by the column subjected to different (a) inlet BPA concentrations and (b) Predicted concentration-time profile based on sorption models for $10 \mathrm{mg} . \mathrm{L}^{-1}$ inlet BPA concentration

Figure 5.4 (a) Adsorption-desorption-photocatalytic removal of BPA by the composite calcium-alginate/MWCNTs/TiO2 beads (b) Adsorption performance of the beads after 5 cycles of adsorption-desorption- irradiation .97

Figure 6.1 Simplified illustration of the composite bead with Psf layer 102

Figure 6.2 FTIR spectrum of (a) MWCNTs (b) Ca-Alg (c) Ca-Alg/22\%MWCNTs .106

Figure 6.3 SEM photographs of (a) surface of Ca-Alg bead (b) Ca-Alg/ 22\%MWCNTs, (c) Psf surface, (d) Cross section of Psf layer 107

Figure 6.4 Structures formed after cross linking of alginate/MWCNTs mixture with calcium chloride .109 
Figure 6.5 Effect of amount of MWCNTs immobilized in alginate beads on BPA removal

Figure 6.6 Induction factor produced by DPD2511 after being subjected to (a) MWCNTs solutions at different concentrations and (b) aliquots taken before and after vortex for $\mathrm{Ca}-\mathrm{Alg} / 22 \%-\mathrm{MWCNTs}$ and $\mathrm{Ca}-\mathrm{Alg} / 22 \%-\mathrm{MWCNTs} / \mathrm{Psf}$ beads

Figure 6.7 SEM photographs of (a) surface of Ca-Alg/22\%-MWCNTs beads (a) before and (b) after vortex

Figure 6.8 Equilibrium amounts of BPA adsorbed to $\mathrm{Ca}-\mathrm{Alg} / \mathrm{MWCNTs}$ and $\mathrm{Ca}-$ $\mathrm{Alg} / \mathrm{MWCNTs} / \mathrm{Psf}$

Figure 6.9 (a) The effect of $\mathrm{pH}$ on BPA removal using Ca-Alg/ 22\%-MWCNTs/Psf beads (b) Zeta-potential curves vs. pH of Ca-alginate( $\Delta)$ and $\operatorname{MWCNTs}(\bullet)$

Figure 6.10 The effect of adsorbent dosage on the adsorption of BPA onto Ca-Alg/ 22\%MWCNTs/Psf beads at equilibrium .116

Figure 6.11 Effect of contact time on the adsorption of BPA on the Ca-Alg/ 22\%MWCNTs/Psf beads

Figure 6.12 Pseudo-second order kinetic plots for the adsorption of BPA on Ca-Alg/ 22\%-MWCNTs/Psf beads at BPA concentrations of (ם) $20 \mathrm{mg} \cdot \mathrm{L}^{-1},(\mathbf{O}) 60$ mg. $\mathrm{L}^{-1}$ and $(\mathbf{\Delta}) 100 \mathrm{mg} . \mathrm{L}^{-1}$ 118

Figure 6.13 (a) Weber-Morris graph and (b) Plot of Bt against time for the adsorption of BPA on Ca-Alg/22\%-MWCNTs/Psf beads .119

Figure 6.14 Isotherm of BPA adsorption onto Ca-Alg/22\%-MWCNTs/Psf beads .....121

Figure 6.15 (a) Breakthrough curve in continuous-flow column reactor for adsorption of 100 mg.L ${ }^{-1}$ BPA on Ca-Alg/22\%-MWCNTs/Psf beads and (b) Illustration of up-flow packed bed column set-up used in the continuous flow experiment

Figure 7.1 Illustration of the proposed hybrid beads. Both bacteria and MWCNTs are embedded inside the calcium alginate bead and finally coated with a layer of polysulfone .129 
Figure 7.2 (a) $\mathrm{OD}_{600 \mathrm{~nm}}$ of PBPA2 against incubation time in acclimatization medium supplied with high amount of glucose and yeast extract and (b) Percentage of BPA removal and $\mathrm{OD}_{600 \mathrm{~nm}}$ of PBPA2 in mineral media with addition of different concentrations of yeast extract

Figure 7.3 Percentage of BPA removed by strain PBPA2 in the free culture form ...132

Figure 7.4 Effect of MWCNTs dosages towards viability of PBPA2 ......................134

Figure 7.5 Percentage of BPA removed by Ca-alginate/MWCNTs-PBPA2/Psf beads 135

Figure 7.6 BPA removed by hybrid Ca-alginate/MWCNTs-PBPA2/Psf beads (•) in continuous column reactor in comparison to beads without PBPA2 (०)...136

Figure 7.7 Amount of BPA extracted from the hybrid beads after solvent extraction using ethanol .137

Figure 8.1 Nanoparticles such as CNMs may impart toxicity to prokaryotic cells (bacteria) through a variety of cellular pathways 148

Figure S1 (a) Adsorption-desorption-photocatalytic removal of BPA by the composite calcium-alginate/MWCNTs/TiO 2 beads at different $\left[\mathrm{Alg} / \mathrm{TiO}{ }_{2}\right]$ loading ratio at 2 g. $\mathrm{L}^{-1}$ beads dosage and $50 \mathrm{mg} . \mathrm{L}^{-1}$ initial BPA concentration and (b) the corresponding beads structure

Figure S2 BPA adsorption onto $\mathrm{Ca}-\mathrm{Alg} / 22 \%-\mathrm{MWCNTs}-\mathrm{TiO}_{2}$ beads in static incubation and its corresponding predicted adsorption capacity based on Langmuir model 154 


\section{Abbreviations}

$\begin{array}{ll}\text { BPA } & \text { Bisphenol A } \\ \text { BPs } & \text { Bamboo fiber powders } \\ \text { CBPs } & \text { Cationic surfactant treated bamboo fiber powders } \\ \text { CNMs } & \text { Carbon Nano Materials } \\ \text { CNTs } & \text { Carbon Nano Tubes } \\ \text { EDCs } & \text { Endocrine Disruptor Compounds } \\ \text { FTIR } & \text { Fourier Transform Infrared Spectroscopy } \\ \text { HPLC } & \text { High Performance Liquid Chromatography } \\ \text { MOF } & \text { Metal Organic Framework } \\ \text { SWCNTs } & \text { Single Walled Carbon Nanotubes } \\ \text { MWCNTs } & \text { Multi Walled Carbon Nanotubes } \\ \text { Psf } & \text { Polysulfone } \\ \text { SEM } & \text { Scanning Electron Microscopy } \\ \text { UV-Vis } & \text { Ultraviolet Visible } \\ \text { XGnPs } & \text { Graphene Nanoplatelets }\end{array}$

The following nomenclatures are used frequently in this work:

Ca-Alg beads

Ca-Alg/MWCNTs beads

Ca-Alg/MWCNTs-TiO 2 beads

Ca-Alg/MWCNTs/Psf beads

Ca-Alg/MWCNTs-PBPA2/Psf beads
Calcium alginate beads

Calcium alginate beads with embedded MWCNTs

Calcium alginate beads with embedded MWCNTs and $\mathrm{TiO}_{2}$

Calcium alginate beads with embedded MWCNTs and Psf coating Calcium alginate beads with embedded MWCNTs and PBPA2 bacteria, coated with Psf 


\section{Chapter 1}

\section{Introduction}

The emergence of new varieties of recalcitrant pollutants is one of the consequences of rapid industrial and urban development. These concerns necessitate more effective approaches towards emerging pollutant removal from water bodies. Among several available removal methods for recalcitrant pollutants, adsorption is a simpler and more adaptable process compared to other tertiary treatments ${ }^{I}$. The central aim of this thesis is to optimize the removal of a persistent endocrine disruptor compound, BPA, using tailored adsorbent materials for water remediation. Several approaches, such as (1) development of chemically treated bamboo powder, (2) fabrication of a hybrid bead platform incorporating highly adsorptive MWCNTs and the subsequent (3) integration of a novel pollutant-degrading bacteria strain into the hybrid beads have been investigated. 


\subsection{Adsorption for Removal of Emerging Pollutants}

With the rising concern of water pollution resulting from rapid industrialization, numerous pollutant-removal methods have been researched and created. The scarcity of clean water in many parts of the world ${ }^{2}$ calls for efforts to improve water reclamation processes, which rely on the ability to remove diverse types of water pollutants and contaminants.

Bisphenol A (BPA, $\mathrm{C}_{15} \mathrm{H}_{16} \mathrm{O}_{2}$ ) is one of the endocrine disruptor compounds (EDCs) commonly used as an industrial chemical to make polycarbonate, a hard and clear plastic. The selected properties of BPA are listed in Table 1.1. It is widely used in numerous consumer products including the lining of food and beverage containers in order to prevent contamination and to extend shelf life ${ }^{3}$.

Table 1.1 Properties of bisphenol $\mathrm{A}^{4}$

\begin{tabular}{cc}
\hline Characteristic & bisphenol A \\
\hline Molecular weight $\left(\mathrm{g} \cdot \mathrm{mol}^{-1}\right)$ & 228.31 \\
Molar volume $\left(\mathrm{cm}^{3} \cdot \mathrm{mol}^{-1}\right)$ & 191.1 \\
Width $(\mathrm{nm})$ & 0.94 \\
Depth $(\mathrm{nm})$ & 0.53 \\
Thickness $(\mathrm{nm})$ & 0.43 \\
\hline
\end{tabular}

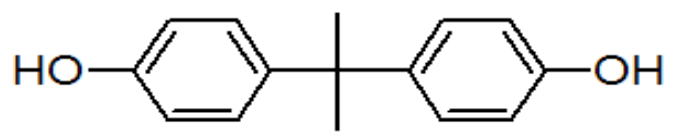

Fig. 1.1 Chemical structure of bisphenol A

Acute toxicity of BPA within the concentration of $1-10 \mathrm{mg} . \mathrm{L}^{-1}$ towards aquatic organisms has been reported ${ }^{5}$. It is also suspected to affect human health ${ }^{6,7}$, with mutagenecity in human RSa cells detected within concentrations of $10^{-7}-10^{-5} \mathrm{M}^{8}$. BPA is often released by factories or leaks out from waste thrown into water bodies. BPA found in wastewater treatment plant effluents and waste landfill leachates also eventually transfer into the aquatic system ${ }^{9}$. Statistics show BPA concentrations of up to $17.2 \mathrm{mg}$. $\mathrm{L}^{-1}$ 
in untreated leachate at Japanese landfills ${ }^{10}$ while treated leachate concentrations reached $5.1 \mu \mathrm{g} . \mathrm{L}^{-111}$. Concentrations of BPA within the range of $2 \mathrm{ng} \cdot \mathrm{L}^{-1}-0.23 \mu \mathrm{g} . \mathrm{L}^{-1}$ have been detected in river water and require 8 days to be eliminated under aerobic conditions ${ }^{12}$. This signifies the demand for a safe, simple and practical way to remove BPA from aqueous solutions to reduce environmental contamination and pollution.

A variety of methods for removal of recalcitrant EDCs in water and wastewater treatment units were formulated. The strategies considered were physical separation such as membrane filtration and adsorption, chemical treatment with an advanced oxidation process or biological degradation using a microorganism ${ }^{13-17}$.

Among these methods, adsorption is a straightforward and more adaptable process when compared to membrane filtration or advanced oxidation processes ${ }^{1}$, as it requires less capital investment with fewer procedures involved in the treatment. Besides operating as a stand-alone process in a column reactor, the adsorption system has also been adapted as a membrane pre-treatment method to remove organic and inorganic contaminants in order to reduce the likelihood of fouling ${ }^{18}$.

\subsection{Motivation and Hypothesis}

Rapid industrialization on a global scale has drawn attention to the need for developing new purification technologies for emerging pollutants. Therefore, the development of novel, non-toxic methodologies for purifying water is imperative, and cost-effective and advanced wastewater treatment protocols are required ${ }^{19}$. It is estimated that a new molecule is isolated or synthesized every 2.6 seconds $^{20}$. BPA has been chosen as the model emerging organic pollutant in our study due to its endocrine disruptive nature and widespread use in consumer products ${ }^{21}$.

Currently, the widely used sorbent material for the elimination of organic compounds is activated carbon (AC). However, this presents several drawbacks such as flammability, regeneration difficulty and the presence of impurities which render AC weakly hydrophilic $^{22}$. Efforts to develop alternative sorbent materials to handle the limitations of 
$\mathrm{AC}$ in the removal of organic aromatic micro-pollutants such as BPA were investigated, among these materials are $\mathrm{CNMs}^{23,24}$, metal organic frameworks (MOFs) ${ }^{25,26}$, silicatebased mesoporous materials ${ }^{27,28}$, clay or mineral materials ${ }^{29}$ and zeolite ${ }^{30,31}$. Exorbitant preparative charges for most of these novel sorbents propelled the research towards the use of waste products of biological origin (or biosorbents) as they are versatile, inexpensive, abundant and attainable ${ }^{32}$. Due to their inferior adsorptive nature, these wastes often require physical and chemical pre-processing prior to application to become efficient sorbent materials ${ }^{33,34}$. However, there are still too few studies dedicated to the comparison of different treatments for the sorption enhancement of biosorbents for the removal of organic pollutants.

When compared to $\mathrm{AC}, \mathrm{CNMs}$ are one of the most promising emerging adsorbent materials, which have gained attention due to their high adsorption capacity and reusability through a large number of cycles ${ }^{35}$. However, there are concerns that they are prone to accumulation and may induce harmful effects in cells. To date, there are only a few reports in the literature that address the immobilization of CNMs in porous matrices in a manner that prevents their elution with regard to their application as an adsorbent ${ }^{36}$. There is also a lack of research on the adsorption behavior of BPA on encapsulated CNMs.

In parallel, biodegradation of noxious pollutants is of importance to ensure that effluents are safely released into the environment. Although it is cost-effective, the biological treatment is hindered by its toxicity and slow degradation process with high concentrations of noxious waste. In the past, the biological activated carbon process (which combines the adsorption capability of activated carbon with bacteria for the removal of organic pollutants) was developed with greater pollutant removal capability as compared to their independent performance ${ }^{37,38}$. Despite significant efforts in the utilization of pristine CNMs as sorbent materials, there is a lack of research dedicated to addressing the interaction and possible combination of CNMs with bacteria degradation for organic pollutant removal. Indeed, the relatively expensive cost of CNMs and the reported bactericidal capability of $\mathrm{CNMs}^{39}$ may have discouraged such early attempts. 
Although the actual mechanisms governing CNMs' toxicity towards bacteria cells is still debated, current opinions can be generally divided to membrane damage due to direct piercing of bacteria cells by $\mathrm{CNMs}^{40}$ or oxidative stress caused by agglomeration of $\mathrm{CNMs}^{41}$. To date, only one study has investigated the effect of combining CNMs with degrading bacteria with reported concentration-dependent improvement in atrazine removal beyond which the CNMs are deemed toxic ${ }^{42}$. Taking into consideration the possible toxicity mechanisms, minimizing the "active piercing motion" of CNMs with regard to bacteria may improve its concentration threshold for CNM toxicity. Here, immobilization of CNMs and bacteria may serve to reduce the instances of piercing due to the static nature of the interaction, while at the same time, minimizing the likelihood of CNMs and bacteria being released into the effluent. Moreover, immobilization of bacteria in a porous matrix also protects the cells from predation, water and nutrient stresses, allows larger bacterial population, and reduces excessive sludge ${ }^{43}$. A platform for immobilizing these entities therefore needs to be developed. The desired properties of the chosen matrix include the capability to prevent entrapped materials from being washed out, high porosity to allow inflow and outflow of analytes, mechanical stability and ease of fabrication.

In summary, at the core of this thesis is the aspiration to develop a low-toxicity sorbent with high BPA retention capability. This goal is attempted by means of:

(1) Chemical treatment of low-capacity but non-toxic and cost-effective biosorbent waste materials

(2) Encapsulation of high-capacity but arguably toxic CNMs and subsequent effort to increase its removal performance via integration with bacteria degradation.

Our hypothesis is that:

(a) Chemical pre-treatment of the low-sorption sorbent materials will modify their properties and improve their sorption capacity; in particular, pre-treatment with surfactant solutions will generally increase their BPA sorption capability due to an increase in the hydrophobic interaction introduced by the long-aliphatic chain of the surfactants and 
(b) Integration of CNMs with biodegrading bacteria through immobilization will enhance their pollutant removal performance whilst minimizing leakage.

\subsection{Objectives and Scope}

To address the gaps in the literature and knowledge, the main objectives of this thesis may be summarized as follows:

\subsubsection{Modification, characterization and assessment of BPA removal performance by low-cost, pre-treated bamboo fiber powder as waste from construction industry}

The utilization of bamboo fiber powders, frequently generated as construction waste, as an alternative, affordable biosorbent for the removal of organic contaminants such as BPA is still largely unexplored. The raw bamboo fiber powders were sieved and chemically modified through treatment with cationic, an-ionic, non-ionic surfactants, alkali and acid solutions. The treated powders were characterized, and their sorption performance for the removal of BPA was studied in a batch reactor. It was postulated that treatment with cationic surfactant would provide the best improvement in BPA removal due to the positively charged head group which enables higher surfactant attachment with negatively charged bamboo powder during pre-treatment. The adsorption behavior of BPA onto the treated bamboo fiber powder under the influence of different parameters, such as BPA concentrations, particle size and dosage of the bamboo fiber powder were investigated.

\subsubsection{Develop a platform for encapsulation of CNMs and bacteria to remove BPA} which will allow controlled study in non-sterile batch and column reactor

In the proposed study, encapsulation of CNMs in an alginate matrix and their adsorption behavior towards BPA will be explored. Although the adsorption capacities of CNM variants have been reported, only a few attempts ${ }^{36}$ to encapsulate these nanomaterials inside a porous bead matrix have been reported to date. MWCNTs were subsequently selected among the CNM variants tested due to their high BPA sorption capacity. We proposed composite beads, comprised of MWCNTs and P25 titanium dioxide encapsulated in calcium alginate macro beads. Using these composite beads, the 
adsorption behavior of BPA was analyzed in a column reactor. The effects of flow rate, bed height and initial pollutant concentration were studied and an appropriate removal model was selected. The design of hybrid beads comprised of composite calcium alginate-MWCNTs core with a secondary Psf layer was proposed, and its performance for the removal of BPA in a batch reactor, as well as its containment capability for MWCNTs, were tested. Considering the potential for harnessing the superior adsorption property of CNMs, we assessed the integration of MWCNTs with degrading bacteria, isolated from environmental samples, for pollutant removal. The isolation of BPA tolerant and BPA degrading bacteria strain $\mathrm{PBPA}_{2}$ and its integration into the hybrid beads was assessed in batch and column reactors. Using the selected removal model depicted in Chapter 5 for a column reactor, the performance of the modified bead in a column reactor was qualitatively inferred.

The scope of the project is outlined in Fig. 1.2(a) and (b). In this project, we will focus on further development of two types of potential BPA adsorbents at the high- and lowcost end of the spectrum, namely CNMs and biosorbents, in order to tackle their respective inferiority. 


\section{Aim: Develop novel adsorbent materials for BPA removal}

Metal
Organic
Silicamework

Fig. 1.2(a) The scope of the two studies included in the project in relevance to the qualitative price comparison of reported adsorbents for removal of BPA (Sources: Cheaptubes Inc, Purolite, Sigma-Aldrich) 


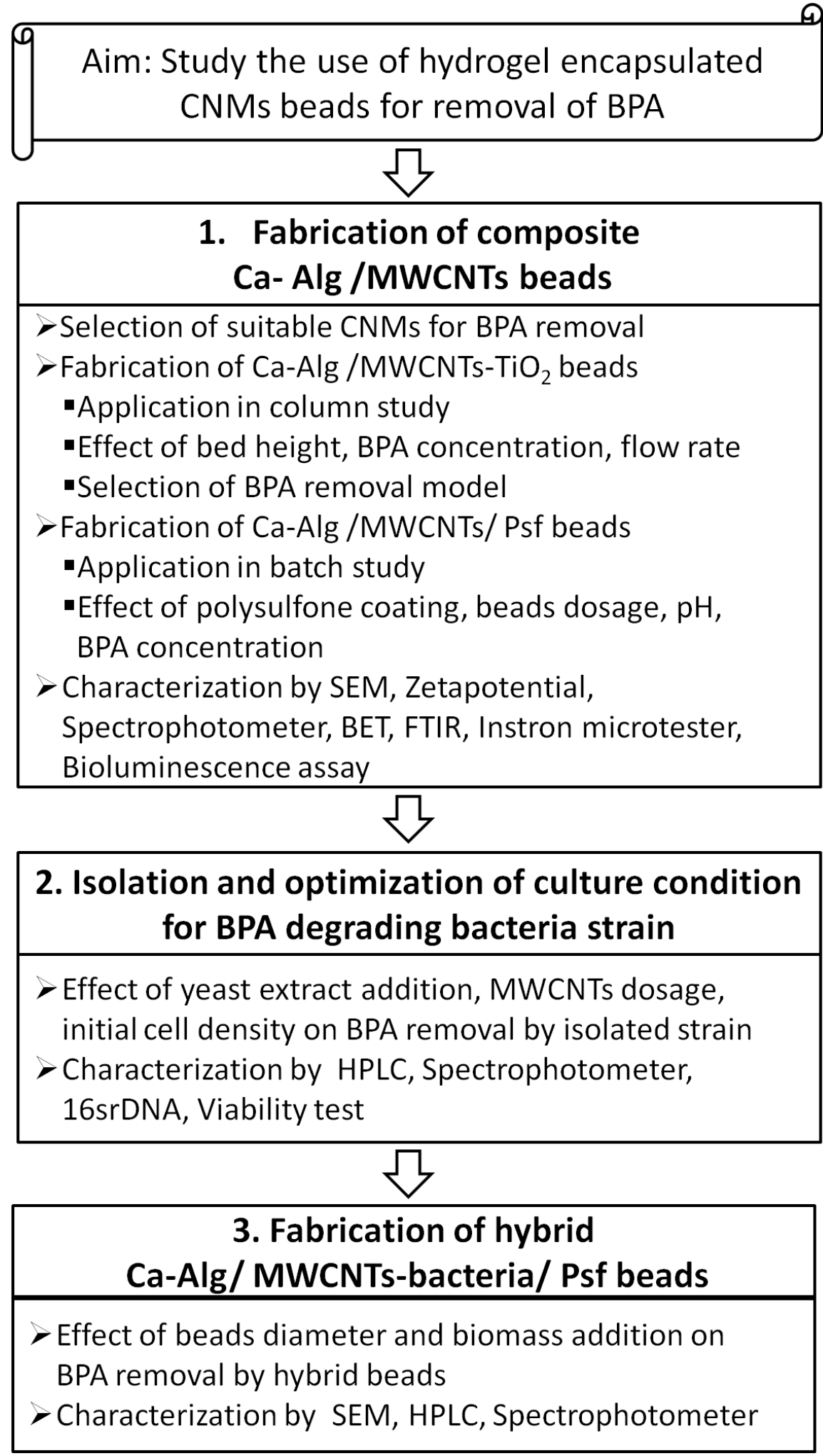

Fig. 1.2(b) Flow diagrams showing the three main parts, which constitute the second study. Effects of different parameters on each part were optimized in order to improve the efficiency of BPA removal. 


\subsection{Dissertation Overview}

This thesis is organized into eight chapters:

Chapter 1 comprises the motivation and the objective of the study. The scope, novelty and summary of significant findings are discussed.

Chapter 2 presents general background on wastewater treatment units based on pollutant removal by adsorption and the benefit of immobilization. The overview of the adsorption process, the factors influencing adsorption, current progress on a variety of adsorbents being developed for the removal of BPA and an assessment of recent publications describing the removal of pollutants through adsorption processes using bead immobilized adsorbent material are presented. Finally, the untapped potential of integrating biodegradation with CNM-based adsorption for the removal of BPA is discussed.

Chapter 3 details the experimental techniques utilized in the fabrication, characterization and application of modified bamboo fiber powders and hybrid composite beads in batch and column reactors. The rationale behind the selection of materials, medium recipes and experimental parameters is presented.

Chapter 4 presents the characterization of modified bamboo powder and its performance for removal of BPA in a batch reactor. The comparison of its removal performance with respect to CNMs is discussed.

Chapter 5 contains the results and discussion inferred from the performance evaluation of $\mathrm{Ca}-\mathrm{Alg} / \mathrm{MWCNTs}-\mathrm{TiO}_{2}$ beads application in a continuous-flow column reactor.

Chapter 6 and 7 discuss the results from the characterization and performance evaluation of $\mathrm{Ca}-\mathrm{Alg} / \mathrm{MWCNTs} / \mathrm{Psf}$ and $\mathrm{Ca}-\mathrm{Alg} / \mathrm{MWCNTs}$-bacteria/Psf beads in batch and column reactors.

Chapter 8 provides summary, conclusion and overview on future works. 


\subsection{Findings and Outcomes}

In the first part of the project, the following findings were observed in the modification and evaluation of bamboo fiber powder (BP) waste as an alternative biosorbent for the removal of BPA:

(a) Pre-treatment of the raw BPs with alkali, non-ionic and ionic surfactant solutions were observed to enhance the BPA sorption performance in comparison to untreated BPs based on the order: cationic surfactant-treated BPs > anionic surfactant-treated BPs > alkali-treated BPs $\approx$ non-ionic surfactant-treated BPs > acid-treated BPs $\approx$ untreated BPs

(b) After pre-treatment of BPs with cationic surfactant (CBPs), their efficiency in the removal of BPA was enhanced up to 3x higher than untreated BPs. FTIR and BET surface area analysis supported the notion that this improvement was contributed by both the increase in surface area after treatment and the hydrophobic aliphatic chain introduced by the surfactant.

(c) The BPA removal decreases with an increase in particle size, higher BPA concentration and lower adsorbent dosage. The adsorption behavior in this system is best described by the Linear and Freundlich adsorption isotherm models, indicating the significant role of hydrophobic, multi-layered partitioning in the system.

(d) Despite improvements in BPA removal, sorption capacities and rates estimated from the pseudo-second order kinetic model indicated that CBPs are still inferior in comparison to CNMs such as MWCNTs.

For the second part of the study, the following findings were observed regarding encapsulation of $\mathrm{MWCNTs}-\mathrm{TiO}_{2}$ in calcium-alginate and its application for BPA removal in a column reactor:

(a) It was observed that maximum sorption was achieved at the lowest flow rate and highest bed height tested. The breakthrough time was extended with higher bed height, lower flow rate and lower initial BPA concentration in the feed.

(b) The sorption capacity of the composite sorbent at $10 \mathrm{mg} \cdot \mathrm{L}^{-1}$ inlet BPA concentration, $2.0 \mathrm{~mL} \cdot \mathrm{min}^{-1}$ flow rate and $20 \mathrm{~cm}$ bed height was $5.46 \mathrm{mg} \cdot \mathrm{g}^{-1}$. 
(c) The modelling study shows that the experimental breakthrough curve could be depicted with satisfactory correlation using the dose-response model.

(d) Photolytic removal of BPA desorbed from the beads is possible under irradiation. Thus, the re-generation of the spent adsorbent beads and eventual photolytic removal of BPA can be achieved simultaneously.

(e) Despite the ease in fabrication, the fragility of the beads may lead to the potential release of MWCNTs.

An extension of this project was performed by encapsulation of MWCNTs in hybrid calcium-alginate (Ca-Alg) bead with a polysulfone (Psf) outer layer to aid as an additional barrier in minimizing the leakage of the MWCNTs. The following findings were obtained:

(a) The addition of the Psf outer layer on composite Ca-Alg encapsulated MWCNTs (Ca-Alg/MWCNTs) beads enhanced the compressive load capacity of the beads up to twelvefold at $40 \%$ compression. This mechanical improvement is favourable in maintaining the integrity of the beads in a reactor.

(b) The addition of a Psf layer onto the Ca-Alg/MWCNTs composite bead increased the total surface area. The availability of additional sorption sites may have explained the enhancement in the amount of BPA adsorbed at lower MWCNTs loading. However the improvement in BPA removal was less significant at higher MWCNTs loading. A bioluminescence bacteria assay was utilized as a means to qualitatively probe the leakage of MWCNTs from the hybrid bead (Ca-Alg/MWCNTs/Psf) before and after rigorous vortex into the solution. The calculated induction ratio suggested the Psf layer assisted in reducing the leakage of encapsulated MWCNTs.

(c) The devised hybrid beads were stable at a wide range of pHs. The BPA adsorption capacity by hybrid beads increased with initial BPA concentration with faster kinetics obtained by higher bead dosage. The adsorption behavior fitted both the pseudo-second order kinetic and the Langmuir isotherm models with high correlation.

The following findings were obtained for the next part of this project - the isolation of a BPA-degrading bacteria strain and the optimization of the culture condition: 
(a) BPA tolerant biodegrading bacteria were successfully isolated from wastewater using BPA-enriched media. The 16s rDNA genes from isolated strain PBPA2 were sequenced and identified with a $100 \%$ homology match as Pseudomonas aeruginosa, based on screening with the Basic Local Alignment Search Tool (BLAST).

(b) The increase in yeast extract concentration in culture media appeared to correlate with the increase in PBPA2 cell growth and the percentage of BPA removal.

(c) No significant toxic effect was observed after exposure to 0.1 g.L $\mathrm{L}^{-1}$ MWCNTs. Interestingly, a $17 \%$ increase in viable cell count in comparison to the control was recorded. A noticeable decrease in viable cells was seen upon exposure to higher MWCNT concentrations. This observation indicated the toxic effect of MWCNTs at high concentrations towards PBPA2.

(d) $\sim 18 \%$ removal of 20 mg.L $\mathrm{L}^{-1}$ BPA was observed after 5 weeks of incubation irrespective of starting cell density tested $\left(\mathrm{OD}_{600 \mathrm{~nm}}=0.04-1\right)$.

The following findings were derived for the last part of this project - the integration of the isolated PBPA2 strain into the hybrid Ca-Alg./MWCNTs/Psf beads:

(a) Entrapment of PBPA2 within the hybrid bead increased the BPA removal at an early incubation period in comparison to free cells.

(b) Continued incubation showed that removal by hybrid Ca-alginate/22\%MWCNTs PBPA2/Psf beads reached to more than $\sim 18 \%$ after 4 weeks of incubation irrespective of the bead's size. The prolonged incubation appeared to produce similar results, in terms of BPA removal, as those achieved by free cells.

(c) Exhaustion time for the Ca-alginate/MWCNTs-PBPA2/Psf column was longer than the hybrid beads without PBPA2. Application of the dose-response model for BPA removal by the column suggested that the $80 \%$ breakthrough time for $\mathrm{Ca}$ alginate/MWCNTs-PBPA2/Psf is stipulated to be 11 days in comparison to 5 days for beads without PBPA2. The discrepancy suggests that the adsorbed BPA is available for degradation by PBPA2, hence extending the lifetime of the beads.

(d) Preliminary work indicates the possibility of bacterial regeneration of the hybrid beads by exposing them into medium devoid of BPA for a prolonged period. 


\section{References}

1 Grassi, M., Kaykioglu, G., Belgiorno, V. \& Lofrano, G. in Emerging compounds removal from wastewater SpringerBriefs in Molecular Science (ed Giusy Lofrano) Ch. 2, 15-37 (Springer Netherlands, 2012).

2 OhIsson, L. Water conflicts and social resource scarcity. Physics and Chemistry of the Earth, Part B: Hydrology, Oceans and Atmosphere 25, 213-220 (2000).

3 Krishnan, A. V., Stathis, P., Permuth, S. F., Tokes, L. \& Feldman, D. Bisphenol-A: an estrogenic substance is released from polycarbonate flasks during autoclaving. Endocrinology (Philadelphia) 132, 2279-2279 (1993).

4 Bautista-Toledo, I., Ferro-García, M. A., Rivera-Utrilla, J., Moreno-Castilla, C. \& Vegas Fernández, F. J. Bisphenol A Removal from water by activated carbon. effects of carbon characteristics and solution chemistry. Environmental Science \& Technology 39, 6246-6250 (2005).

5 Alexander, H. C., Dill, D. C., Smith, L. W., Guiney, P. D. \& Dorn, P. Bisphenol A: acute aquatic toxicity. Environmental toxicology and chemistry 7, 19-26 (1988).

6 Rubin, B. S. \& Soto, A. M. Bisphenol A: Perinatal exposure and body weight. Molecular and Cellular Endocrinology 304, 55-62 (2009).

7 Vandenberg, L. N., Hauser, R., Marcus, M., Olea, N. \& Welshons, W. V. Human exposure to bisphenol A (BPA). Reproductive Toxicology 24, 139-177 (2007).

8 Takahashi, S. et al. Mutagenicity of bisphenol A and its suppression by interferon$\alpha$ in human RSa cells. Mutation Research/Genetic Toxicology and Environmental Mutagenesis 490, 199-207 (2001).

9 Kang, J.-H., Aasi, D. \& Katayama, Y. Bisphenol A in the aquatic environment and its endocrine-disruptive effects on aquatic organisms. Critical Reviews in Toxicology 37, 607-625 (2007).

10 Yamamoto, T., Yasuhara, A., Shiraishi, H. \& Nakasugi, O. Bisphenol A in hazardous waste landfill leachates. Chemosphere 42, 415-418 (2001).

11 Crain, D. A. et al. An ecological assessment of bisphenol-A: evidence from comparative biology. Reproductive Toxicology 24, 225-239 (2007).

12 Suzuki, T., Nakagawa, Y., Takano, I., Yaguchi, K. \& Yasuda, K. Environmental fate of bisphenol A and its biological metabolites in river water and their xenoestrogenic activity. Environmental Science \& Technology 38, 2389-2396 (2004).

13 Masuda, M., Yamasaki, Y., Ueno, S. \& Inoue, A. Isolation of bisphenol Atolerant/degrading Pseudomonas monteilii strain N-502. Extremophiles 11, 355362 (2007).

14 Yamanaka, H., Moriyoshi, K., Ohmoto, T., Ohe, T. \& Sakai, K. Degradation of bisphenol A by Bacillus pumilus isolated from kimchi, a traditionally fermented food. Appl Biochem Biotechnol 136, 39-51 (2007).

15 Oshiman, K.-i., Tsutsumi, Y., Nishida, T. \& Matsumura, Y. Isolation and characterization of a novel bacterium, Sphingomonas bisphenolicum strain AO1, that degrades bisphenol A. Biodegradation 18, 247-255 (2007).

16 Sasaki, M., Maki, J.-i., Oshiman, K.-i., Matsumura, Y. \& Tsuchido, T. Biodegradation of bisphenol A by cells and cell lysate from Sphingomonas sp. strain AO1. Biodegradation 16, 449-459 (2005).

17 Matsumura, Y. et al. Isolation and characterization of novel bisphenol-A-degrading bacteria from soils. Biocontrol science 14, 161-169 (2009). 
18 Tsujimoto, W., Kimura, H., Izu, T. \& Irie, T. Membrane filtration and pretreatment by GAC. Desalination 119, 323-326 (1998).

19 El Rahman, A. M. A. \& Gepreel, M. A. Nanotechnology Applications in Water Treatment: Future Avenues and Challenges: A review. Proceeding of the 6th International Perspective on Water Resources \& the Environment conference (IPWE). Turkey (2013)

20 Bradley, C. P. 50 Millionth Unique Chemical Substance Recorded in CAS REGISTRY,

<http://www.acs.org/content/acs/en/pressroom/newsreleases/2009/september/50-

millionth-unique-chemical-substance-recorded-in-cas-registry.html> (2009).

21 Liao, C. \& Kannan, K. Widespread occurrence of bisphenol A in paper and paper products: implications for human exposure. Environmental Science \& Technology 45, 9372-9379 (2011).

22 Blocki, S. W. Hydrophobic zeolite adsorbent: A proven advancement in solvent separation technology. Environmental Progress 12, 226-230, doi:10.1002/ep.670120312 (1993).

23 Lin, D. \& Xing, B. Adsorption of phenolic compounds by carbon nanotubes: role of aromaticity and substitution of hydroxyl groups. Environmental Science \& Technology 42, 7254-7259 (2008).

24 Zhao, W., Tang, Y., Xi, J. \& Kong, J. Functionalized graphene sheets with poly(ionic liquid)s and high adsorption capacity of anionic dyes. Applied Surface Science 326, 276-284 (2015).

25 Park, E. Y., Hasan, Z., Khan, N. A. \& Jhung, S. H. Adsorptive removal of bisphenol-a from water with a metal-organic framework, a porous chromiumbenzenedicarboxylate. Journal of Nanoscience and Nanotechnology 13, 27892794 (2013).

26 Qin, F. X., Jia, S. Y., Liu, Y., Li, H. Y. \& Wu, S. H. Adsorptive removal of bisphenol A from aqueous solution using metal-organic frameworks. Desalination and Water Treatment 54, 93-102 (2015).

27 Kim, Y. H., Lee, B., Choo, K. H. \& Choi, S. J. Selective adsorption of bisphenol A by organic-inorganic hybrid mesoporous silicas. Microporous and Mesoporous Materials 138, 184-190 (2011).

28 Fan, X., Tu, B., Ma, H. \& Wang, X. Adsorption behavior of environmental hormone Bisphenol A onto mesoporous silicon dioxide. Bulletin of the Korean Chemical Society 32, 2560-2564 (2011).

29 Wang, Z. M. et al. Matrix-enhanced adsorption removal of trace BPA by controlling the interlayer hydrophobic environment of montmorillonite. Applied Clay Science 104 (2015).

30 Tsai, W. T., Hsien, K. J. \& Hsu, H. C. Adsorption of organic compounds from aqueous solution onto the synthesized zeolite. Journal of Hazardous Materials 166, 635-641 (2009).

31 Dong, Y., Wu, D., Chen, X. \& Lin, Y. Adsorption of bisphenol A from water by surfactant-modified zeolite. Journal of colloid and interface science 348, 585-590 (2010). 
$32 \mathrm{Wu}$, Y.-n. et al. Facile fabrication of photonic MOF films through stepwise deposition on a colloid crystal substrate. Chemical Communications 47, 1009410096 (2011).

33 Zhou, Y., Lu, P. \& Lu, J. Application of natural biosorbent and modified peat for bisphenol a removal from aqueous solutions. Carbohydrate Polymers 88, 502-508 (2012).

34 Zhao, R.-S. et al. Preconcentration and determination of polybrominated diphenyl ethers in environmental water samples by solid-phase microextraction with $\mathrm{Fe}_{3} \mathrm{O}_{4}$-coated bamboo charcoal fibers prior to gas chromatography-mass spectrometry. Analytica Chimica Acta 769, 65-71 (2013).

35 Lu, C., Chiu, H. \& Bai, H. Comparisons of adsorbent cost for the removal of zinc (II) from aqueous solution by carbon nanotubes and activated carbon. Journal of Nanoscience and Nanotechnology 7, 4-5 (2007).

36 Fugetsu, B. et al. Encapsulation of multi-walled carbon nanotubes (MWCNTs) in $\mathrm{Ba} 2+$-alginate to form coated micro-beads and their application to the preconcentration/elimination of dibenzo-p-dioxin, dibenzofuran, and biphenyl from contaminated water. Analyst 129, 565-566 (2004).

37 Sirotkin, A. S., Koshkina, L. Y. \& Ippolitov, K. G. The BAC-process for treatment of waste water containing non-ionogenic synthetic surfactants. Water Research 35 , 3265-3271 (2001).

38 Martin, M. J., Serra, E., Ros, A., Balaguer, M. D. \& Rigola, M. Carbonaceous adsorbents from sewage sludge and their application in a combined activated sludge-powdered activated carbon (AS-PAC) treatment. Carbon 42, 1389-1394 (2004).

39 Young, Y.-F. et al. Toxicity mechanism of carbon nanotubes on Escherichia coli. Materials Chemistry and Physics 134, 279-286 (2012).

40 Liu, S. et al. Sharper and faster "nano darts" kill more bacteria: a study of antibacterial activity of individually dispersed pristine single-walled carbon nanotube. Acs Nano 3, 3891-3902 (2009).

41 Liu, S. et al. Antibacterial activity of graphite, graphite oxide, graphene oxide, and reduced graphene oxide: membrane and oxidative stress. Acs Nano 5, 69716980 (2011).

42 Zhang, C., Li, M., Xu, X. \& Liu, N. Effects of carbon nanotubes on atrazine biodegradation by Arthrobacter sp. Journal of Hazardous Materials 287, 1-6 (2015).

43 Cassidy, M., Lee, H. \& Trevors, J. Environmental applications of immobilized microbial cells: a review. Journal of Industrial Microbiology 16, 79-101 (1996). 


\section{Chapter 2}

\section{Literature Review}

The background on adsorption process, models and parameters affecting adsorption are elaborated in this chapter. In particular, isotherm and kinetic models frequently used in batch and column reactors are described. Varieties of adsorbent materials being developed for removal of BPA and their corresponding reported adsorption capacities are briefly presented with focus on CNMs. Recent researches on microbial mediated biological degradation of BPA are summarized. Finally, the possibility of integration of CNMs adsorption with biodegradation for enhancement in the removal of BPA while preventing their leakage through encapsulation is postulated. 


\subsection{Overview}

Industrial and sewage wastewater treatment plants are comprised of several basic compartments, namely preliminary, primary and secondary treatments. Preliminary treatment removes materials such as physical debris which may interfere with mechanical, chemical or biological processes in the subsequent compartments. Secondary treatment typically includes aerobic biological process which use microbial consortia found in the vessels to remove dissolved materials in wastewater. Secondary treatment is commonly designed to attain efficient removal of ammonia and nutrient such as nitrogen and phosphorus. Depending on the intended application, these biological reactors could be designed as plug-flow, arbitrary or complete mix reactors.

EDCs such as BPA are not readily removed by regular a physicochemical treatment which is based on coagulation and flocculation. Removal of EDCs by adsorption, absorption and degradation by activated sludge in secondary treatment is also hindered due to the required operating conditions of the plant such as sludge age and hydraulic retention time which vary from one compound to another ${ }^{1}$. Therefore, installment of tertiary treatment has become necessary with increase in discharge of emerging pollutants from municipal or industry sources. Tertiary treatment options include membrane filtration, advanced oxidation process and adsorption. Compared to other methods, adsorption is relatively simpler in terms of design and operation, does not produce undesirable by-products, less expensive than membrane filtration with better adaptability than ion-exchange and insensitive to toxic substance. Table 2.1 shows the advantages of adsorption compared to other methods in removal of emerging compounds ${ }^{2}$. 
Table 2.1 Comparison of tertiary treatments in removal of emerging pollutants

\begin{tabular}{|c|c|c|}
\hline Method & Advantage(s) & Disadvantage(s) \\
\hline $\begin{array}{l}\text { Membrane } \\
\text { filtration and } \\
\text { Advanced } \\
\text { Oxidation } \\
\text { Process } \\
\text { (AOP) }\end{array}$ & - $\quad$ Effective removal & $\begin{array}{ll}- & \text { AOP may lead to formation of unknown } \\
\text { - } & \text { High investment costs } \\
- & \text { Require high maintenance } \\
- & \text { Complicated operation procedures } \\
- & \text { Secondary pollution (i.e. toxic } \\
\text { byproducts) }\end{array}$ \\
\hline Adsorption & $\begin{array}{ll}\text { - } & \text { No additional } \\
\text { - } & \text { byproducts } \\
\text { - } & \text { Simple design } \\
\text { - } & \text { Simple operation } \\
& \text { Insensitive to toxic } \\
\text { compounds }\end{array}$ & $\begin{array}{ll}- & \text { Regeneration problem } \\
- & \text { Release of adsorbent materials }\end{array}$ \\
\hline
\end{tabular}

Commonly used adsorbent materials are granular or powdered activated carbon, natural clays and minerals ${ }^{3}$.

\subsubsection{Adsorption process}

Adsorption is a mass transfer process, which involves the accumulation of compounds (adsorbate) at the interface of an adsorbing material (adsorbent). Their interactions could be categorized as physisorption (exothermic, weak and reversible physical attractions due to dispersive van der Waals or electrostatic forces, characterized by decrease in free energy and entropy) or chemisorption (stronger monolayer adsorption resulting from chemical bonding). Under certain conditions, both interactions may occur in simultaneous or alternate fashion.

In a solid-liquid system, adsorption results in the removal of solutes from aqueous media and the accumulation of the solute on solid surface, which reaches equilibrium after sufficient contact time. Among the main factors influencing the adsorption process are $(i)$ surface area, (ii) temperature, (iii) molecular size and structure of sorbate-sorbent, (iv) pH and $(v)$ concentration of sorbate. 
The extent of adsorption is proportional to the specific surface area available for adsorption. A high amount of adsorption per unit weight of solid can be achieved with a porous adsorbent. Adsorption capacity (determined by a balance of the rate of adsorption and desorption) is inversely proportional with temperature as a fraction of molecules leaving the surface increases with the increase in temperature. In a solid-liquid adsorption, an increase in temperature improves the solubility of the adsorbate, which decreases its adsorption capability. Large molecules are more strongly adsorbed than small molecules since the adsorption binding energy of a molecule on the adsorbent surface is proportional to the area covered by the molecule. Thereby, in the case of a high molecular weight polymer, the adsorption may be irreversible. However, if the adsorbent pores are smaller than the molecules, molecular sieving behavior is observed as the large molecules become barred from the smallest pores. Different substituent groups in a molecule confer different adsorption behavior: the nitro group often increases adsorbability, hydroxyl and amino groups generally reduce adsorbability, and carbonyl, halogen groups or the presence of a double bond give a variable effect on adsorption ${ }^{4}$. In general, low polarity molecules are better adsorbed than highly polar molecules. A solution's $\mathrm{pH}$ affects the distribution of a charge on the surface of the adsorbent, and hence, can vary the degree of adsorption according to the functional groups conferred in the sorbate ${ }^{5}$. In addition, the mixture of many compounds affects the adsorption process. These compounds may act independently, enhance adsorption or interfere with one another. Finally, the adsorption is affected by the concentration of the adsorbate and the dosage of adsorbent. Regeneration of previously adsorbed materials includes thermal, steam, solvent extraction, acid/base treatment and chemical oxidation.

\subsubsection{Theory}

Adsorption isotherm and kinetic models were developed in order to better understand and predict the behavior of specific adsorbate-adsorbent systems. The ability to envisage the adsorption behavior eases the scaling up of the system. In the following sections, the commonly used adsorption isotherm and kinetic models in batch and fixed-bed continuous column reactors, which are relevant to our studies, are described. 


\subsubsection{Batch Reactor - Sorption kinetics}

Pseudo-first order and second order rate equations ${ }^{6,7}$ have been used to model adsorption kinetics. The pseudo-first order model is formulated as:

$$
\ln \left(\mathrm{q}_{\mathrm{e}, \exp }-\mathrm{q}_{\mathrm{t}}\right)=\ln \mathrm{q}_{\mathrm{e}, \mathrm{cal}}-\mathrm{k}_{1} \mathrm{t}
$$

where $\mathrm{q}_{\mathrm{e}, \exp }\left(\mathrm{mg} \cdot \mathrm{g}^{-1}\right)$ is the experimental adsorption capacity of the sorbent for BPA at equilibrium; $\mathrm{q}_{\mathrm{t}}\left(\mathrm{mg} \cdot \mathrm{g}^{-1}\right)$ is the amount of BPA adsorbed after incubation time $\mathrm{t}(\mathrm{h})$; $\mathrm{q}_{\mathrm{e}, \mathrm{cal}}$ $\left(\mathrm{mg} \cdot \mathrm{g}^{-1}\right)$ is the adsorption capacity of the sorbent calculated using the models; $\mathrm{k}_{1}\left(\mathrm{~h}^{-1}\right)$ is the rate constant for the pseudo-first order model. Values of $\mathrm{q}_{\mathrm{e}, \mathrm{cal}}$ and $\mathrm{k}_{1}$ are obtained from the slope and intercept of the linear plot $\ln \left(\mathrm{q}_{\mathrm{e}, \exp }-\mathrm{q}_{\mathrm{t}}\right)$ over time.

The pseudo-second order model is presented as:

$$
\begin{gathered}
\mathrm{t} / \mathrm{q}_{\mathrm{t}}=1 /\left(\mathrm{k}_{2} \mathrm{q}_{\mathrm{e}, \mathrm{cal}}{ }^{2}\right)+\mathrm{t} / \mathrm{q}_{\mathrm{e}, \mathrm{cal}} \\
\mathrm{h}=\mathrm{k}_{2} \mathrm{q}_{\mathrm{e}}^{2}
\end{gathered}
$$

where $\mathrm{q}_{\mathrm{e}, \exp }\left(\mathrm{mg} \cdot \mathrm{g}^{-1}\right), \mathrm{q}_{\mathrm{t}}\left(\mathrm{mg} \cdot \mathrm{g}^{-1}\right)$ and $\mathrm{q}_{\mathrm{e}, \text { cal }}\left(\mathrm{mg} \cdot \mathrm{g}^{-1}\right)$ are the same as described in the pseudo-first order model with $\mathrm{h}\left(\mathrm{mg} \cdot \mathrm{g}^{-1} \cdot \mathrm{h}^{-1}\right)$ and $\mathrm{k}_{2}\left(\mathrm{~g} \cdot \mathrm{mg}^{-1} \cdot \mathrm{h}^{-1}\right)$ being the initial sorption rate and rate constants for the pseudo-second order model. In this kinetic model, the values for $\mathrm{q}_{\mathrm{e}, \mathrm{cal}}$ and $\mathrm{k}_{2}$ are derived from the slope and intercept of plot $\mathrm{t} / \mathrm{q}_{\mathrm{t}}$ versus $\mathrm{t}$.

The rate-controlling process on the specific sorbate-sorbent system can be determined using the Weber-Morris kinetic model ${ }^{8}$. The model is described as follows:

$$
\mathrm{q}_{\mathrm{t}}=\mathrm{K}_{\mathrm{d}} \mathrm{t}^{0.5}+\mathrm{I}
$$

where $K_{d}\left(m g \cdot g^{-1} \cdot h^{-0.5}\right)$ represents the rate constant for the intra-particle diffusion and value of I (mg. $\left.\mathrm{g}^{-1}\right)$ gives insight on the effect of the boundary layer. The linearity of the plot of $\mathrm{q}_{\mathrm{t}}$ vs $\mathrm{t}^{0.5}$ suggests the involvement of intra-particle diffusion in the adsorption process. In addition, if the plot intercepts through the origin, the intra-particle diffusion can be regarded as a rate-determining step. 
Besides the Weber-Morris model, the Boyd plot further helps to identify whether the ratecontrolling steps are external mass transfer or intra-particle diffusion. The Boyd model ${ }^{9}$ is expressed as follows:

$$
\mathrm{B}_{\mathrm{t}}=-\ln \left(1-\mathrm{q}_{\mathrm{t}} / \mathrm{q}_{\mathrm{e}}\right)-0.4977
$$

If the plot of $\mathrm{B}_{\mathrm{t}}$ against time passes through the origin, the intra-particle diffusion controls the adsorption; otherwise, external mass transfer is the rate-controlling step in the adsorption system.

\subsubsection{Batch Reactor - Sorption isotherms}

Several isotherm models have been developed to predict the behavior of adsorbateadsorbent systems. Each model was constructed based on different assumptions with the compatibility of a model being assessed by comparison of goodness of fit constant, or $\mathrm{r}^{2}$, between the data gained through the experiment and the data generated by the model.

Commonly used empirical models to describe adsorption in a sorbate-sorbent system at a constant temperature in the batch reactor are the Langmuir ${ }^{10}$ with the assumption of a single layer of coverage on a homogenous surface with no subsequent interaction between adsorbed species, and the Linear and Freundlich models for multilayer adsorption on a heterogeneous surface ${ }^{11}$.

\section{Linear model}

The simplest sorption isotherm model typically indicates that the energies involved in the sorption are uniform with the increase in solute concentrations. This model is generally associated with a system with either a very low solute concentration or a sorbent with low sorption potential ${ }^{12}$. The linear model is described as follows:

$$
q_{e, \exp }=K_{d} C_{e, \exp }
$$

where $\mathrm{q}_{\mathrm{e}, \exp }\left(\mathrm{mg} \cdot \mathrm{g}^{-1}\right)$ is adsorption of a sorbate by a sorbent at equilibrium, $\mathrm{C}_{\mathrm{e}, \exp }\left(\mathrm{mg}^{\mathrm{L}} \mathrm{L}^{-1}\right)$ is the equilibrium concentration of a sorbate in an aqueous solution and $K_{d}\left(L \cdot g^{-1}\right)$ is the linear partition or distribution coefficient of a sorbate in the aqueous solution and sorbent. 


\section{Langmuir isotherm}

It is referred to as the ideal monolayer model as it assumes that the adsorbate molecules form a monolayer on the energetically identical and structurally homogenous adsorbent sites with an absence of subsequent interactions between adsorbed molecules. The Langmuir model for a solid-liquid system is described as ${ }^{10}$ :

$$
\begin{gathered}
\frac{C_{e, \text { exp }}}{q_{e, \text { exp }}}=\frac{C_{e, \text { exp }}}{q_{m}}+\frac{1}{K_{L}} \\
R_{L}=\frac{1}{\left(1+\alpha_{L} C_{o}\right)}
\end{gathered}
$$

where $\mathrm{C}_{\mathrm{e}, \mathrm{exp}}\left(\mathrm{mg} \cdot \mathrm{L}^{-1}\right)$ is the equilibrium concentration of sorbate in a solution; $\mathrm{q}_{\mathrm{e}, \mathrm{exp}}\left(\mathrm{mg} \cdot \mathrm{g}^{-}\right.$ $\left.{ }^{1}\right)$ is the adsorption of a sorbate by the composite beads at equilibrium; $\mathrm{q}_{\mathrm{m}}\left(\mathrm{mg}_{\mathrm{g}} \mathrm{g}^{-1}\right)$ is the maximum adsorption capacity of the beads derived from the Langmuir model; $\mathrm{R}_{\mathrm{L}}$ is the dimensionless equilibrium constant, which indicates the shape of the isotherm; $\mathrm{K}_{\mathrm{L}}\left(\mathrm{L} \cdot \mathrm{g}^{-1}\right)$ and $\alpha_{\mathrm{L}}\left(\mathrm{L}_{\mathrm{mg}}{ }^{-1}\right)$ are the Langmuir coefficients with $\alpha \mathrm{L}$ defined as the ratio of $\mathrm{K}_{\mathrm{L}}$ over $\mathrm{q}_{\mathrm{m}}$. The Langmuir coefficients, $\mathrm{q}_{\mathrm{m}}$ and $\mathrm{K}_{\mathrm{L}}$, are obtained by plotting $\mathrm{C}_{\mathrm{e}, \exp } / \mathrm{q}_{\mathrm{e}, \exp }$ over $\mathrm{C}_{\mathrm{e}, \exp \text {. }}$.

\section{Freundlich isotherm}

Freundlich $^{13}$ is the other commonly used isotherm model. The isotherm model is based on the assumption that multilayer adsorption on heterogeneous surfaces governs the interaction between the equilibrium concentration of an adsorbate in both liquid and solid phase. The Freundlich model is given as ${ }^{13}$ :

$$
\log q_{e, \exp }=\frac{1}{n} \log C_{e, \exp }+\log K_{F}
$$

where the definition for $\mathrm{C}_{\mathrm{e}, \exp }\left(\mathrm{mg} \cdot \mathrm{L}^{-1}\right), \mathrm{q}_{\mathrm{e}, \exp }\left(\mathrm{mg} \cdot \mathrm{g}^{-1}\right)$ is the same as described in the Langmuir model; $\mathrm{K}_{\mathrm{F}}\left(\mathrm{mg}^{1-1 / \mathrm{n}} \cdot \mathrm{L}^{1 / \mathrm{n}} \cdot \mathrm{g}^{-1}\right)$ is the Freundlich constant representing multilayer adsorption capacity, and $\mathrm{n}$ is a constant representing adsorption strength. The Freundlich coefficients, $\mathrm{K}_{\mathrm{F}}$ and $\mathrm{n}$, are obtained by plotting $\log \mathrm{q}_{\mathrm{e}}$ over $\log \mathrm{C}_{\mathrm{e}, \mathrm{exp}}$. 


\subsubsection{Continuous Flow Reactor - Column modeling}

Continuous flow studies using bead reactors could yield useful applicative information for the adaption of the adsorbent in wastewater treatment. Three common types of bead reactors are fixed bed with gravity (down-flow), fixed bed with pressure (up-flow) and fluidized bed (up-flow). In general, up-flow configuration is favored due to fewer issues with blockages. Typical operating parameters for granulated activated carbon (GAC) adsorbent are presented in Table $\mathbf{2 . 2}$ with parameters relevant to our study written in italics.

Table 2.2 Typical operating conditions of GAC column ${ }^{14}$

\begin{tabular}{cc}
\hline Parameter & $\begin{array}{c}\text { Typical } \\
\text { values }\end{array}$ \\
Bed height $(\mathrm{m})$ & $2-4$ \\
Area $\left(\mathrm{m}^{2}\right)$ & $5-30$ \\
Empty bed contact time $(\mathrm{min})$ & $5-30$ \\
Effective contact time $(\mathrm{min})$ & $2-10$ \\
Particle diameter $(\mathrm{mm})$ & $0.5-4$ \\
Bed volume $\left(\mathrm{m}^{3}\right)$ & $10-50$ \\
Bed porosity & $0.35-0.45$ \\
\hline
\end{tabular}

An illustration of a typical breakthrough curve in a fixed-bed adsorption column is shown in Fig. 2.1. In this case, the polluted water feed is introduced at the top (down-flow); however, the same principle still applies for an up-flow reactor. The curved lines refer to the concentration of the sorbate at various times as it moves through the column, with $\mathrm{C}_{\mathrm{o}}$ referring to the initial sorbate concentration in the influent. The assumption follows that the volume of the bed above the curve at $t_{1}$ is the exhausted bed with the clean bed below the curve.

Breakthrough occurs when the front of the clean zone reaches the bottom of the bed, in which the adsorbent is saturated and the effluent concentration approaches $\mathrm{C}_{\mathrm{o}}$. This concentration is usually defined when $\mathrm{C}_{t}=0.90 \mathrm{C}_{\mathrm{o}}$. Among the main parameters affecting the adsorption process in column reactors are the influent sorbate concentration, bed 
depth and feed flow rate. These parameters affect dispersion, diffusion and the channeling processes of the sorbate through the column.
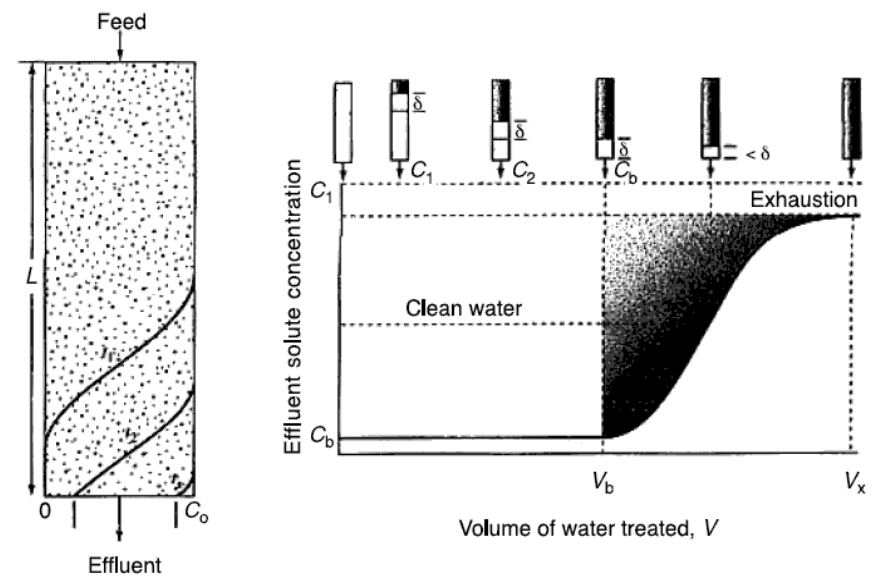

Volume of water treated, $V$

Fig. 2.1. Illustration of breakthrough curve in a fixed-bed column reactor ${ }^{15}$

The dynamic performance of the column is generally described using the following parameters $^{14}$ :

$$
\begin{gathered}
q_{\text {total }}=v \int_{t=0}^{t=t s}\left(C_{i}-C_{t}\right) d t \\
q_{e, t s}=\frac{q_{\text {total }}}{m_{\text {ads }}} \\
\mathrm{V}=v \Delta t \\
\mathrm{~m}_{\text {total }}=\mathrm{V} \mathrm{C}_{\mathrm{i}} \\
\text { Removal }(\%)=\frac{\mathrm{q}_{\text {total }}}{\mathrm{m}_{\text {total }}}
\end{gathered}
$$

Where $\mathrm{q}_{\mathrm{total}}(\mathrm{mg})$ is the total amount of sorbate adsorbed, $\mathrm{m}_{\text {total }}(\mathrm{mg})$ is the total amount of pollutant injected into the column, $\mathrm{q}_{\mathrm{e}, \mathrm{ts}}\left(\mathrm{mg} \cdot \mathrm{g}^{-1}\right)$ refers to the sorption capacity of the column up to saturation or total amount of sorbate adsorbed by the column until the end of operation per unit weight of sorbent added, $v\left(\mathrm{~L}^{-\mathrm{h}^{-1}}\right)$ refers to the volumetric influent flow rate, $m_{a d s}(g)$ is the dry weight of the sorbent in the column while $C_{i}\left(m g . L^{-1}\right)$ and $C_{t}$ $\left(\mathrm{mg} . \mathrm{L}^{-1}\right)$ represent the initial inlet and outlet concentrations after operation time $t(\mathrm{~h})$ respectively, V (L) represents the total volume of the effluent treated. 
The concentration-time profile in a continuous flow column sorption reactor is commonly represented through the breakthrough curve which is defined as the ratio of pollutant concentration at the outlet at time $t$ to inlet concentration $\left(\mathrm{C}_{t} / \mathrm{C}_{\mathrm{i}}\right)$ as a function of time or volume at specified bed height ${ }^{16}$. The operation time required until the outlet concentration reaches a certain breakthrough concentration is defined as breakthrough time $^{17}$. It is inherently difficult to ascertain the breakthrough curve profile in a continuous flow column reactor as the solute concentration dynamically changes across the bed. Moreover, the shape of the breakthrough curve is affected by the transport mechanism within the adsorbent and the column ${ }^{18}$. It is therefore favorable to predict the shape of the curve under defined operating conditions. Since it was considered tedious to perform a multitude of experiments under different process variables to obtain the breakthrough time, mathematical dynamic sorption models were generated to lessen the amount of time for experiments and repetitions. These models were built upon the probable assumption of a chief mechanism governing the sorption process such as mass transfer, diffusion or surface reaction. Some of the commonly used models are listed below:

\section{Adams-Bohart model}

The Adams-Bohart model ${ }^{19}$ has been used in many column sorption studies and is generally applicable to interpret the initial part (10\%-50\%) of the breakthrough curve in the presence of one contaminant ${ }^{20}$. In this study, the model is applied to predict BPA removal using experimental data of up to $50 \%$ breakthrough time $\left(C_{t} / C_{i}=0-0.5\right)$. The formula can be expressed as follows ${ }^{19}$ :

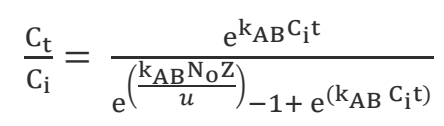

where $\mathrm{k}_{\mathrm{AB}}\left(\mathrm{L} \cdot \mathrm{mg}^{-1} \cdot \mathrm{h}^{-1}\right)$ represents the kinetic coefficient, No $\left(\mathrm{mg} \cdot \mathrm{L}^{-1}\right)$ is the volumetric sorption capacity, $u\left(\mathrm{~cm} \cdot \mathrm{min}^{-1}\right)$ is the linear influent flow rate which can be obtained by dividing volumetric flow rate with the cross-section area of the column and $\mathrm{Z}$ is the bed height of the column. 


\section{Yoon-Nelson model}

Another frequently used model in the fixed-bed sorption system is the Yoon-Nelson model $^{21-23}$, which was originally developed to describe the adsorption of gases on solid sorbents. The equation is described as follows:

$$
\frac{C_{t}}{C_{i}}=\frac{1}{1+e^{k_{Y N}(\tau-t)}}
$$

where $k_{y n}\left(\mathrm{~h}^{-1}\right)$ is the Yoon-Nelson rate constant and $\tau$ is the total operation time at $\mathrm{C}_{\mathrm{t}}=$ $0.5 \mathrm{C}_{\mathrm{i}}$.

Dose-response model

Originally used in pharmacological studies, this model has been applied in biosorption column studies for the removal of heavy metals with good correlation irrespective of the length of operational time ${ }^{22,24}$. The derived model is represented as follows:

$$
\frac{C_{t}}{C_{i}}=1-\frac{1}{1+\left(\frac{v t}{\text { Veff } 50 \%}\right)^{a}}
$$

where $a$ is a constant of the dose-response model, $\mathrm{V}_{\text {eff50\% }}(\mathrm{L})$ is the total volume of treated effluent when $\mathrm{C}_{\mathrm{t}}=0.5 \mathrm{C}_{\mathrm{i}}$. 


\subsection{Adsorbent materials for removal of BPA}

Activated carbon

Activated carbon (AC) has been commonly used as an adsorbent because it is capable of removing BPA rapidly and effectively due its high surface area and adsorptive capacity $^{25,26}$. However, the preparation process of activated carbon is costly. Comprehensive reviews on preparation of activated carbon and its application for removal of phenolic organic compounds can be found elsewhere ${ }^{27-29}$. Several limitations of AC include flammability, regeneration difficulty and the presence of impurities, which render it weakly hydrophilic in character ${ }^{30}$.

\section{Biosorbent}

The higher preparative cost of common adsorbent activated carbon has driven the research on sorbent materials towards low cost, abundant and environmentally friendly waste. However, few studies have been done on the utilization of wastes for the removal of BPA. Due to their inferior adsorptive nature, these wastes often require physical and chemical pre-processing prior to application in order to increase their efficiency as adsorbent materials $^{31}$. Reports show that agricultural wastes such as coir pith, coconut shell and durian peel, which have been treated with concentrated $98 \%$ sulfuric acid, demonstrate enhanced BPA adsorption with maximum adsorption capacity in the range of $\sim 4 \mathrm{mg} . \mathrm{g}_{-}{ }^{132}$. Inspired by a prior study, which used cationic surfactant pre-treatment of zeolite to enhance the retention of $\mathrm{BPA}^{33}$, peat waste has been modified with a high concentration of hexadecyltrimethylammonium bromide with a maximum sorption capacity of $31.40 \mathrm{mg} \cdot \mathrm{g}^{-134}$. These results indirectly indicate that the surfactant modification introduced hydrophobic sites, which increased the sorbent affinity towards those compounds with higher octanol-water partitioning coefficients ${ }^{31}$. In previous studies, chemical treatments of biomass with surfactants have been reported to improve their adsorption performance towards heavy metals ${ }^{35,36}$. However, there is a lack of research in comparison studies regarding the effects of treatments on biomass using different types of surfactants for the removal of organic pollutants. 
It is postulated that treatment of the biosorbent with surfactant will improve sorption of $B P A$.

\section{Carbon nanomaterials (CNMs)}

Carbon nanomaterials are one of the emerging adsorbent materials seen in recent years $^{37,38}$ with graphene, multi-walled carbon nanotubes (MWCNTs), and single-walled carbon nanotubes (SWCNTs) variants ${ }^{38}$ among the most reported promising adsorbents in water treatment. Graphene is a crystalline form of carbon, where carbon atoms are arranged in a regular hexagonal pattern. Graphene is a one-atom thick layer of graphite; it is very strong, light, nearly transparent, and an excellent conductor of heat and electricity. Its interaction with other materials and with light, and its inherently two-dimensional nature, produce a number of interesting, unique properties. Since the discovery of multiwalled and single-walled carbon nanotubes ${ }^{39,40}$, CNTs have attracted considerable interest due to their desirable mechanical, thermal and electrical properties ${ }^{41}$.

In recent years, CNTs have garnered attention in the field of wastewater treatment as potential sorbent materials, particularly in the removal of organic aromatic compounds. The adsorption capacities of CNMs, such as CNTs and graphene towards various organic pollutants ${ }^{42,43}$, have been reported in a myriad of studies, which in some cases showed higher adsorption than activated carbon especially for aromatic organic compounds ${ }^{44}$. This excellent adsorption property may be attributed to the strong hydrophobicity and high surface area of CNMs. In addition, modification of CNTs, which induced a more positive charge appeared to enhance BPA removal ${ }^{42}$.

\section{Metal Organic Framework}

Metal organic frameworks (MOFs) are a family of porous crystalline materials constructed through the self-assembly of nitrogen- or oxygen-bearing organic ligands comprised of aligned benzene rings with metal ions. The fabrication procedure generally involves hydrothermal synthesis which requires additional purification. The facile fabrication of MOFs, however, enables the selection of potential MOF-based adsorbent materials with a variety of tunable structures such as pore size, surface structure, porosity 
and surface area ${ }^{45,46}$. Among the myriad of MOF varieties, the MIL series are a popular choice for adsorption of BPA, partly due to their large pore size and surface area ${ }^{47}$. MIL$53(\mathrm{Cr})\left(\mathrm{Cr}(\mathrm{OH})\left[\mathrm{O}_{2} \mathrm{C}-\mathrm{C}_{6} \mathrm{H}_{4}-\mathrm{CO}_{2}\right]\right)$ was first reported for the removal of BPA with a high adsorption capacity of $421 \mathrm{mg} \cdot \mathrm{g}^{-148}$. The utilization of MIL-MOFs containing the toxic Chromium, however, has raised concern regarding potential pollution. Synthesis of MIL$53(\mathrm{Al})\left(\mathrm{Al}(\mathrm{OH})\left[\mathrm{O}_{2} \mathrm{C}-\mathrm{C}_{6} \mathrm{H}_{4}-\mathrm{CO}_{2}\right]\right)$ and mesostructured MIL-53(Al) (which eliminated Chromium) was attempted. It was observed that higher adsorption capacity was obtained by the mesostructured MIL-53(Al) in comparison to microporous MIL-53(Al). A high pH was detrimental to the adsorption of BPA on these structures because adsorption capacity decreases with an increase in $\mathrm{pH}$, with almost negligible adsorption at $\mathrm{pH} 12$. The interactions of $\pi-\pi$ bonds, hydrogen bonding and breathing phenomena ${ }^{49}$ have been suggested as factors influencing the affinity with $\mathrm{BPA}^{50}$.

MIL-101(Cr) and MIL-100(Fe), which possess higher pore size and greater surface area in comparison to MIL-53, have been utilized for the adsorption of BPA. In this case MIL$100(\mathrm{Fe})$ shows inferior adsorption capacity in comparison to MIL-101(Cr) presumably due to its lower porosity and pore size. Based on their performance under different concentrations of $\mathrm{NaCl}$, it was postulated that BPA was adsorbed to MIL-101(Cr) mainly through free diffusion; whereas, adsorption to MIL-100(Fe) occurred mainly through electrostatic interaction ${ }^{51}$.

\section{Silicates}

Mesoporous silica has been tested for its ability to remove BPA. The porous structure was obtained through synthesis, using cationic surfactant as a structure-directing template, followed by calcination at a high temperature of $\sim 550^{\circ} \mathrm{C}$. A maximum BPA adsorption capacity of $353.4 \mathrm{mg} \cdot \mathrm{g}^{-1}$ was reported ${ }^{52}$. Similarly, an organic-inorganic hybrid mesoporous silica structure, constructed by attachment of phenyl groups onto mesoporous silica materials via co-condensation methods, also showed favorable BPA retention, with a maximum adsorption capacity of $351 \mathrm{mg} \cdot \mathrm{g}^{-153}$. It appears that the interplay of hydrogen-bonding interaction between hydrophilic hydroxyl groups in 
phenyl and hydroxyl groups in BPA, as well as $\pi-\pi$ interaction between benzene rings in BPA and hydrophobic phenyl lead to relatively strong BPA affinity.

\section{Zeolites}

Zeolites are crystalline tecto-aluminosilicates composed of hydrated $\mathrm{TO}_{4}$ atoms with $\mathrm{T}$ being tetrahedral atoms with a framework ratio of $\mathrm{O} / \mathrm{T}=2^{54}$. Zeolite structures are attractive for molecular sieving and inorganic membrane separation applications due to their uniformity in pore size. This property enables it to recognize, selectively distinguish, as well as organize a molecule with up to $1 \AA$ precision. Approximately 75 types of both natural and synthetic zeolite structures of small (i.e. $0.3-0.4 \mathrm{~nm}$ of $6-8$-member ring), medium (i.e. $0.5-0.6 \mathrm{~nm}$ of 10 -member ring) and large (i.e. $0.7-0.8 \mathrm{~nm}$ of 12-member ring) pore size categories have been reported ${ }^{55}$. Typical synthesis for zeolite structures involves the usage of high pressure hydrothermal reactors.

The physical and chemical properties of zeolites could be altered by means of adjusting the $\mathrm{Si} / \mathrm{Al}$ ratio. For instance, increasing the ratio of $\mathrm{Si} / \mathrm{Al}$ would produce more hydrophobic silica structures with different pores size and orientation; whereas, decreasing the Si/Al ratio would improve its hydrophilic nature. BPA adsorption studies with hydrophobic zeolite (high $\mathrm{Si} / \mathrm{Al}$ ratio) exhibited high BPA removal despite the relatively lower surface area in comparison to activated carbon. This behavior indicates the crucial role of hydrophobicity in the zeolite-BPA adsorption systems ${ }^{56,57}$. For instance, adsorption, using commercial Y-type zeolite with $\mathrm{Si} / \mathrm{Al}$ ratio of $\sim 100$ and BET surface area $504.5 \mathrm{~m}^{2} \cdot \mathrm{g}^{-1}$, attained a maximum BPA adsorption capacity of $141 \mathrm{mg} \cdot \mathrm{g}^{-1}$. It was noted that the effect on particle size below $0.3 \mathrm{~mm}$ with regard to adsorption performance was not considerable ${ }^{58}$. In contrast, adsorption of BPA with novel synthesized zeolite, possessing Si/Al ratio of $\sim 5$ and similar BET surface area of $400 \mathrm{~m}^{2} \cdot \mathrm{g}^{-1}$, showed a limited BPA adsorption capacity of below $0.5 \mathrm{mg} \cdot \mathrm{g}^{-1}$. It was suggested that the low adsorption was due to repulsive action between hydrophilic zeolite and the non-polar BPA compound $^{59}$. Pre-treatment of zeolite with cationic surfactant also has been reported to improve the retention of organic pollutants due to the hydrophobic partitioning onto the long chain of surfactants ${ }^{33}$. 


\section{Other adsorbent materials}

Other materials have been tested for their adsorption of BPA such as mineral and polymeric materials, which include cross-linked $\beta$-cyclodextrin polymer, chitosanbearing $\beta$-cyclodextrin, esterified carboxyl cotton and alpha-ketoglutaricacid-modified chitosan resins with a maximum adsorption capacity of $84,85,87.7$ and $60.7 \mathrm{mg} \mathrm{g}^{-1}$ respectively ${ }^{60,61}$.

Table 2.3 summarizes the reported adsorption capacity of several adsorbent materials in relation to their BET surface area measurement. It is evident that high surface area does not always correlate with high BPA affinity, with the highest BPA sorption capacity of 465 mg.g ${ }^{-1}$ reported for mesoporous MIL-53(Al)-F127 $7^{50}$.

Table 2.3 Several reported BPA sorbents and their sorption capacity

\begin{tabular}{|c|c|c|c|c|}
\hline Adsorbent type & Group & $\begin{array}{l}\text { BET Surface } \\
\text { Area } \\
\left(\mathbf{m}^{2} \cdot \mathrm{g}^{-1}\right)\end{array}$ & $\begin{array}{l}\text { Adsorption } \\
\text { capacity }\left(\mathrm{mg.g}^{-1}\right)\end{array}$ & Ref. \\
\hline AC commercial & $\mathrm{AC}$ & 2535 & 137 & 51 \\
\hline AC commercial, granular & $\mathrm{AC}$ & 1068 & 399 & 48 \\
\hline $\begin{array}{l}\text { AC commercial-coconut } \\
\text { based }\end{array}$ & $\mathrm{AC}$ & 916 & 263.2 & 62 \\
\hline $\begin{array}{l}\text { AC commercial-bituminous } \\
\text { coal based }\end{array}$ & $\mathrm{AC}$ & 916 & 328.3 & 62 \\
\hline $\begin{array}{l}\text { Nitric acid modified } \\
\text { commercial AC (W20) }\end{array}$ & $\mathrm{AC}$ & 1777 & 382.1 & 25 \\
\hline $\begin{array}{l}\text { Thermal modified } \\
\text { commercial AC (W20N) }\end{array}$ & $\mathrm{AC}$ & 1760 & 432.3 & 25 \\
\hline $\begin{array}{l}\text { Surfactant modified fibric } \\
\text { peat }\end{array}$ & Biosorbent & 0.547 & 31.40 & 34 \\
\hline Acid treated coir pith & Biosorbent & 5.79 & 4.308 & 32 \\
\hline Acid treated coconut shell & Biosorbent & 4.75 & 4.159 & 32 \\
\hline Acid treated durian peel & Biosorbent & N.D & 4.178 & 32 \\
\hline Acid treated banana bunches & Biosorbent & N.D & 4.532 & 32 \\
\hline $\begin{array}{l}\text { Acid treated coconut } \\
\text { bunches }\end{array}$ & Biosorbent & N.D & 4.662 & 32 \\
\hline
\end{tabular}




\begin{tabular}{|c|c|c|c|c|}
\hline $\begin{array}{l}\text { Graphene } \\
\text { (reduced graphene oxide) }\end{array}$ & CNMs & 327 & 182 & 63 \\
\hline Graphene Oxide & CNMs & 32 & 87.8 & 64 \\
\hline $\begin{array}{l}\text { Microwave modified multi- } \\
\text { walled carbon nanotubes }\end{array}$ & CNMs & 94.8 & 60.98 & 42 \\
\hline $\begin{array}{l}\text { Multi-walled carbon } \\
\text { nanotubes } \\
\text { (inner diameter }=3.8 \mathrm{~nm}, \\
\text { outer diameter }=10-30 \mathrm{~nm} \text {, } \\
\text { length }=10 \mu \mathrm{m} \text { ) }\end{array}$ & CNMs & N.D & 111 & 65 \\
\hline $\begin{array}{l}\text { Multi-walled carbon } \\
\text { nanotubes } \\
\text { (outer diameter }=<8 \mathrm{~nm} \text {, } \\
\text { length }=10-30 \mu \mathrm{m} \text { ) }\end{array}$ & CNMs & 301.20 & 18.72 & 66 \\
\hline $\begin{array}{l}\text { Multi-walled carbon } \\
\text { nanotubes }-\mathrm{COOH} \\
\text { (outer diameter }=<8 \mathrm{~nm} \text {, } \\
\text { length }=10-30 \mu \mathrm{m} \text { ) }\end{array}$ & $\mathrm{CNMs}$ & 238.68 & 21.42 & 66 \\
\hline $\begin{array}{l}\text { Single-walled carbon } \\
\text { nanotubes } \\
\text { (inner diameter }=0.8-1.1 \\
\mathrm{~nm} \text {, outer diameter }=1-2 \mathrm{~nm} \text {, } \\
\text { length }=10 \mu \mathrm{m} \text { ) }\end{array}$ & CNMs & N.D & 71 & 65 \\
\hline $\begin{array}{l}\text { Single-walled carbon } \\
\text { nanotubes } \\
\text { (outer diameter }=1-2 \mathrm{~nm} \text {, } \\
\text { length }=5-30 \mu \mathrm{m} \text { ) }\end{array}$ & CNMs & 467.38 & 58.67 & 66 \\
\hline qMOF, MIL-53Cr & MOF & 1438 & 421 & 48 \\
\hline $\begin{array}{l}\text { MOF, microporous MIL- } \\
53(\mathrm{Al})\end{array}$ & MOF & 931.3 & 325 & 50 \\
\hline $\begin{array}{l}\text { MOF, mesoporous MIL- } \\
\text { 53(Al)-F127 }\end{array}$ & MOF & 1008.3 & 465 & 50 \\
\hline MIL-101 (Cr) & MOF & 3711 & 252.5 & 51 \\
\hline MIL-100 (Fe) & MOF & 1754 & 55.6 & 51 \\
\hline Mesoporous silica MCM-41 & Silica & 1030 & 9 & 53 \\
\hline
\end{tabular}




\begin{tabular}{|c|c|c|c|c|}
\hline $\begin{array}{l}\text { Phenyl-functionalized } \\
\text { mesoporous silica }\end{array}$ & Silica & 750 & 351 & 53 \\
\hline Mesoporous silicon dioxide & Silica & N.D & 353.4 & 52 \\
\hline $\begin{array}{l}\text { Commercial Y-type Zeolite, } \\
\text { Degussa }(\mathrm{Si} / \mathrm{Al}=100\end{array}$ & Zeolite & 504.5 & 141 & 58 \\
\hline $\begin{array}{l}\text { Novel synthesized zeolite } \\
(\mathrm{Si} / \mathrm{Al}=5)\end{array}$ & Zeolite & 402.96 & $<0.5$ & 59 \\
\hline $\begin{array}{l}\text { SMZFA F prepared from } \\
\text { coal fly ash }\end{array}$ & Zeolite & N.D & $114.9(\mathrm{pH}>9)$ & 33 \\
\hline $\begin{array}{l}\text { SMZFA L prepared from } \\
\text { coal fly ash }\end{array}$ & Zeolite & N.D & $56.8(\mathrm{pH}>9)$ & 33 \\
\hline $\begin{array}{l}\text { SMZFA prepared from coal } \\
\text { fly ash }\end{array}$ & Zeolite & N.D & $90.9(\mathrm{pH}=\sim 10.3)$ & 57 \\
\hline
\end{tabular}

\subsubsection{CNMs as emerging adsorbent materials: benefits and challenges}

CNMs, in particular CNT variants, can effectively remove low concentrations of toxic recalcitrant pollutants over a wide range of $\mathrm{pHs}^{43,67}$ and were reported to be a more effective adsorbent than $\mathrm{AC}^{68}$ owing to their greater surface area, short equilibrium times $^{69,70}$, hydrophobicity and selective adsorption for aromatic compounds through $\pi-\pi$ electron donor-acceptor interaction ${ }^{63}$. The use of CNTs as a new generation sorbent may reduce the cost of water conditioning due to shorter contact time and smaller volume tank required for treatment ${ }^{71}$. Price-wise, CNTs are in the middle of the range between MOFs and biosorbents (Fig. 2.2). However, the increase in market demand for CNTs, due to emerging applications across different fields, is expected to cause the price of CNTs to decrease in the future ${ }^{72}$.

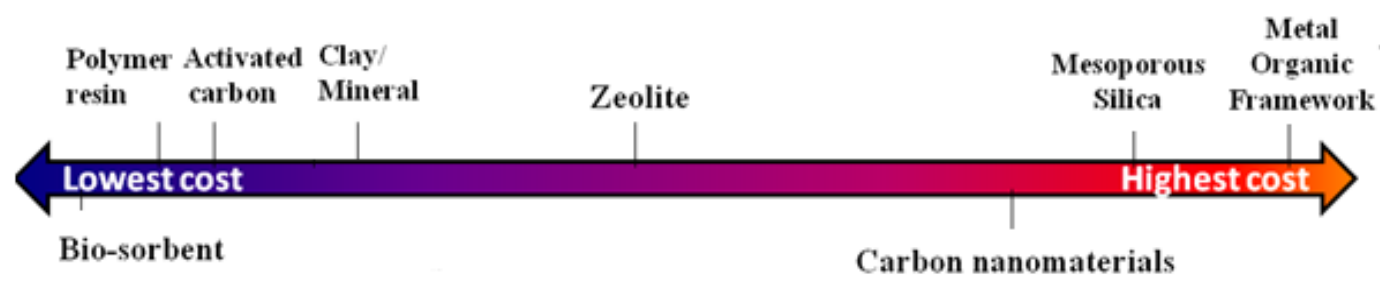

Fig. 2.2 The qualitative price comparison of reported adsorbent materials for removal of BPA (Sources: Cheaptubes Inc, Purolite, Sigma-Aldrich) 
Due to their small size, there is concern regarding the eco-toxicity impact when CNTs are released into the environment ${ }^{73}$. CNTs have also been reported to be capable of entering the human body through water bodies, thus disturb the intracellular metabolic pathways in humans, causing oxidative stress and membrane damage ${ }^{74}$. It could also act as an anchor for contaminants due to its strong affinity for pollutants, which would lead to accumulation in vivo ${ }^{75}$. It is therefore essential to prevent the release of CNT adsorbents into the effluent during water treatment processing. Frequently used methods for the separation of CNTs are centrifugation and filtration, which can be deemed timeconsuming and inefficient. A nanocomposite of MWCNTs with $\mathrm{Fe}_{3} \mathrm{O}_{4}$ has been developed for the separation of spent adsorbent from the aqueous phase through the application of a magnetic field ${ }^{76}$. Another possible solution is the encapsulation of CNTs to aid in their recovery and reduce leakage as discussed in section 2.2.2.

\subsubsection{Encapsulation of sorbent materials}

In order to prevent the release of sorbent materials into the environment, many studies have investigated the containment of sorbent materials through encapsulation. The materials used for encapsulation are commonly based on alginate. Alginate is defined as a family of biopolymers comprised of a-L-guluronic acid and 1,4-linked p-D-mannuronic unit groups, which are arranged in a linear manner ${ }^{77}$. The carboxylate groups in alginate undergo a rapid cross-linking reaction upon exposure to divalent ions, which results in the construction of solid hydrogels. The pliable character of alginate makes it a preferred option as an encapsulation matrix for a variety of materials ${ }^{78}$.

Alginate encapsulated AC has been studied for the removal of heavy metals ${ }^{79}$, phenol $^{80}$ and other organic compounds ${ }^{81,82}$. It was observed that AC impregnated alginate beads adsorbed both positively charged compounds and neutral-low molecular weight compounds. In this composite system, AC is responsible for the adsorption of toxic organics, whereas the alginate component is responsible for the removal of heavy metals.

Besides activated carbon, encapsulation of magnetic nanoparticles has been widely done as it could facilitate the recovery of alginate beads using an external magnetic field. 
Ngomsik et al $^{83,84}$ encapsulated Cyanex $272^{\circledR}$, a commercial sorbent, within magnetic maghemite impregnated alginate beads for the removal of Cobalt and Nickel divalent ions from aqueous solutions. Li et al $^{85}$ developed magnetic beads comprised of Rhizopus cohnii powder and magnetite particles coated with alginate and poly-vinyl alcohol to remove $\mathrm{Cr}(\mathrm{VI})$ ions. Bee et $\mathrm{al}^{86}$ encapsulated magnetic maghemite nanoparticles functionalized with citrate ions in calcium-alginate for the adsorption of $\mathrm{Pb}$ (II) ions. The preparation of composite beads comprised of activated carbon and magnetic nanoparticles has also been investigated. Rocher et $\mathrm{al}^{87}$ encapsulated alginate beads with iron-oxide magnetic nanoparticles and AC for the removal of dye molecules.

In comparison to AC, very few studies have focused on assessing the adsorption performance of alginate encapsulated carbon nanomaterials ${ }^{88,89}$. In particular, due to its recent classification as an emerging contaminant, adsorption properties of BPA on encapsulated CNMs have not been thoroughly explored.

\subsection{Biological degradation of bisphenol A}

Microbial-mediated degradation of BPA has been investigated for the removal of BPA. In the past three decades, BPA tolerant and degrading strains have been isolated from various sources in the environment. Most of the identified strains belong to Sphingomonas sp., Pseudomonas sp. and Bacillus sp.. The Achromobacter xylosoxidans strain B-16 degraded up to $10 \mathrm{mg} . \mathrm{L}^{-1}$ BPA in a basal mineral medium following the firstorder kinetic model, with a half time of 3.1 days at $35^{\circ} \mathrm{C}$, pH of 7.0 and initial inoculums $\mathrm{OD}_{600 \mathrm{~nm}}$ of $\sim 0.317$. It was noted that the BPA-degrading activity was disturbed by an increase in BPA toxicity at high concentrations above $10 \mathrm{mg} . \mathrm{L}^{-1}$, and slow growth was seen after 7 days of incubation in a mineral medium, achieving final $\mathrm{OD}_{600 \mathrm{~nm}}$ of $\sim 0.359^{90}$.

Masuda et $\mathrm{al}^{91}$ isolated the Pseudomonas monteilii strain N-502, which is able to grow in a medium containing 0.5 g. $\mathrm{L}^{-1}$ yeast extract and 0.5 g.L $\mathrm{L}^{-1}$ polypeptone and degrade 500 mg. $\mathrm{L}^{-1} \mathrm{BPA}$ in 10 days at $30^{\circ} \mathrm{C}$ with initial inoculums $\mathrm{OD}_{660 \mathrm{~nm}}$ of $\sim 0.05$. The strain exhibits tolerance towards BPA at concentrations of up to 20 g. $\mathrm{L}^{-1}$. Masuda also reported the growth inhibition of several commercial strains at low BPA concentrations of less 
than 1.0 g.L. $\mathrm{L}^{-1}$. Due to availability of other carbon sources, BPA degradation appeared to be significantly higher in the nutrient-rich medium than the basal mineral medium with BPA as the sole carbon source. Yamanaka et $\mathrm{al}^{92}$ reported the efficiency of three Bacillus pumilus strains isolated from fermented kimchi to degrade BPA up to $50 \mathrm{mg} . \mathrm{L}^{-1}$, starting inoculums $\mathrm{OD}_{660 \mathrm{~nm}}$ of 0.2 at $27^{\circ} \mathrm{C}$ in a medium containing nutrients such as peptone, beef and yeast extracts, with no trace of estrogenic 4-hydroxyacetophenone present as intermediate metabolites. After $20 \mathrm{~h}$ incubation, final $\mathrm{OD}_{660 \mathrm{~nm}}$ reached $\sim 3.0$. The strains were not able to grow in a mineral medium containing only BPA or glucose as the sole carbon source with minimum value of $0.1 \%, 0.05 \%$ and $0.1 \%$ respectively for peptone, beef and yeast extracts required for degradation to proceed. Neither cell growth nor BPA degradation was seen at BPA concentration of $100 \mathrm{mg} \cdot \mathrm{L}^{-1}$. Sphingomonas sp. strain $\mathrm{AO}^{93,94}$ isolated from soil was reported to degrade $100 \mathrm{mg} \cdot \mathrm{L}^{-1} \mathrm{BPA}$ within $6 \mathrm{~h}$ in a MYPG medium containing 3.0 g.L $\mathrm{L}^{-1}$ malt extract, 3.0 g.L $\mathrm{L}^{-1}$ yeast, 5.0 g.L $\mathrm{L}^{-1}$ peptone and 10 g. $\mathrm{L}^{-1}$ glucose, and within $48 \mathrm{~h}$ in a minimum medium with $1 \%$ glucose at $30^{\circ} \mathrm{C}$, at starting inoculums density $\mathrm{OD}_{600 \mathrm{~nm}}=0.05$. The presence of $0.1 \%-1.0 \%$ glucose shortened the degradation time of BPA. The estrogenic activity of strain AO1 metabolite products increased after $4 \mathrm{~h}$ incubation but diminished afterwards. Matsumura et $\mathrm{al}^{95}$ reported the ability of 25 soil isolated strains, 22 strains belonging to proteobacteria and 4 strains belonging to Bacillus sp. to completely degrade $115 \mathrm{mg} . \mathrm{L}^{-1} \mathrm{BPA}$ in nutrient-rich L medium containing 10 g. $\mathrm{L}^{-1}$ tryptone, 5 g.L $\mathrm{L}^{-1}$ yeast extract and 5 g.L $\mathrm{L}^{-1} \mathrm{NaCl}$ at starting $\mathrm{OD}_{650 \mathrm{~nm}}$ of $\sim 0.01$ at $30^{\circ} \mathrm{C}$ within $48 \mathrm{~h}$. In addition, isolated Bacillus sp YA27 and three Spinghomonas sp. strains were able to grow in a basal mineral media with BPA as the sole carbon source. They noted the different metabolism pathways between Pseudomonas sp. SU1 and SU4 and Bacillus sp YA27 isolates based on the monitored metabolic products.

Facultative anaerobic bacteria belonging to the strain Bacillus sp. GZB are able to fully degrade $5 \mathrm{mg} . \mathrm{L}^{-1}$ BPA in a mineral medium with $51 \%$ mineralization efficiency, the starting $\mathrm{OD}_{600 \mathrm{~nm}}$ for inoculums used for the degradation test was estimated to be 0.04 0.11 . BPA degradation follows pseudo-first order kinetic at $0.030-0.013 / \mathrm{h}$ with half lives of 22.6-52.7 h within concentrations of $10-30 \mathrm{mg} . \mathrm{L}^{-1}$, at an optimum temperature of 
$37^{\circ} \mathrm{C}$ and a $\mathrm{pH}$ range within 7.0-8.5. For this strain, the inhibition effect of BPA was evident at concentrations higher than $30 \mathrm{mg} . \mathrm{L}^{-196}$. Recently, Kamaraj et al reported the isolation of three bacteria strains belong to Pseudomonas sp. and Bacillus sp. capable of degrading more than $70 \%$ of $1000 \mathrm{mg} . \mathrm{L}^{-1} \mathrm{BPA}$ in a mineral medium prepared with seawater at a $\mathrm{pH}$ range of $7.0-8.0,37^{\circ} \mathrm{C}$ after 12 days, and the starting inoculums density was not stated. Among different tested co-substrates such as glucose, maltose, mannitol and sodium glutamate, the best improvement in BPA degradation was obtained in the presence of $0.5 \%$ sodium glutamate ${ }^{97}$. It is apparent from these reports that BPA tolerant and degrading bacteria are widely available in the natural environment and not

restricted to polluted areas ${ }^{98,99}$. Moreover, the BPA degradation performance is generally enhanced by the addition of external nutrients and limited by the toxicity of BPA beyond certain concentrations.

\subsubsection{Integration of biodegradation with CNMs adsorption via alginate encapsulation for pollutant decontamination}

In general, only a few studies have touched upon the integration of microbial degradation with an adsorption component in hydrogel beads, with most of these studies performed using $\mathrm{AC}$ as the adsorbent material. For instance, Sheeja et al ${ }^{100}$ studied the biodegradation of phenol using Pseudomonas pictorum immobilized on alginate and AC/alginate composite beads. The protective effect of the alginate matrix alone was perceived to increase the tolerance at concentrations where survival is not possible with free cells. Further addition of an adsorption component in the form of AC within the alginate matrix improved the removal of phenol ${ }^{101}$. One of the drawbacks of immobilization is the relatively slower kinetics for the pollutants to reach the cells or adsorbents due to a diffusion barrier introduced by the matrix. It is therefore promising to integrate CNMs, which have exhibited superior adsorption kinetics performance in comparison to $\mathrm{AC}$, into the immobilization matrix.

A combination of bacterial biodegradation with CNM's adsorption in a single system, however, may provide additional complexity due to the perceived antimicrobial nature of CNMs. The antimicrobial property of highly purified single-walled carbon nanotubes 
(SWCNTs) was first reported by Kang et $\mathrm{al}^{74}$ and appears to be affected by their concentrations $^{102}$, length ${ }^{103}$, environment of the bacterial growth, surface functional group, shapes of the bacteria ${ }^{104}$ and the electronic structure ${ }^{105}$ but are less influenced by charges on the CNT's surface ${ }^{106}$. MWCNTs have been reported to posses relatively weaker antibacterial properties in comparison to SWCNTs, with thinner SWCNTs postulated to be more effective in piercing the membrane of the bacteria than MWCNTs ${ }^{104}$.

Despite this reported bacterial toxicity, it is presumed that the immobilization of CNTs, which limits direct interaction with the bacteria cells, reduces antibacterial toxicity. For instance, a lack of antibacterial capacity was exhibited by SWCNTs blendedpolyvinylchloride ultrafiltration membrane, which suggests that polymer wrapping may reduce the antibacterial property of $\mathrm{SWCNTs}^{107}$. Moreover, a recent study with Arthrobacter $s p$. in its free cell form shows that below their toxic concentration, MWCNTs improved the biodegradation rate of atrazine up to $20 \%$ through the promotion of bacterial growth and expression of degradation genes ${ }^{108}$. These studies imply that immobilization of bacteria in a matrix containing adsorbent material improves the tolerance of bacteria towards pollutants beyond toxic concentrations. Depending on the concentration of CNTs and the starting cell density of the bacteria, CNTs may improve the rate of pollutant removal and that the toxicity of CNTs towards bacteria may be lessened by the prevention of direct contact through immobilization. 


\subsection{PhD in context of literature}

A screening of the literature using the terms "bisphenol A" and "toxicity" in Scopus retrieved numerous articles with a major increase seen within the past two decades (Fig. 2.3). This remarkable increase in reports regarding BPA toxicity started in the 1990s, which coincides with the first report regarding the endocrine disrupting nature of BPA in $1993^{109,110}$. This upward trend has continued over the past two decades with the subsequent detection of BPA in wastewater treatment plants ${ }^{111}$ further highlighting the importance and significance of this issue.

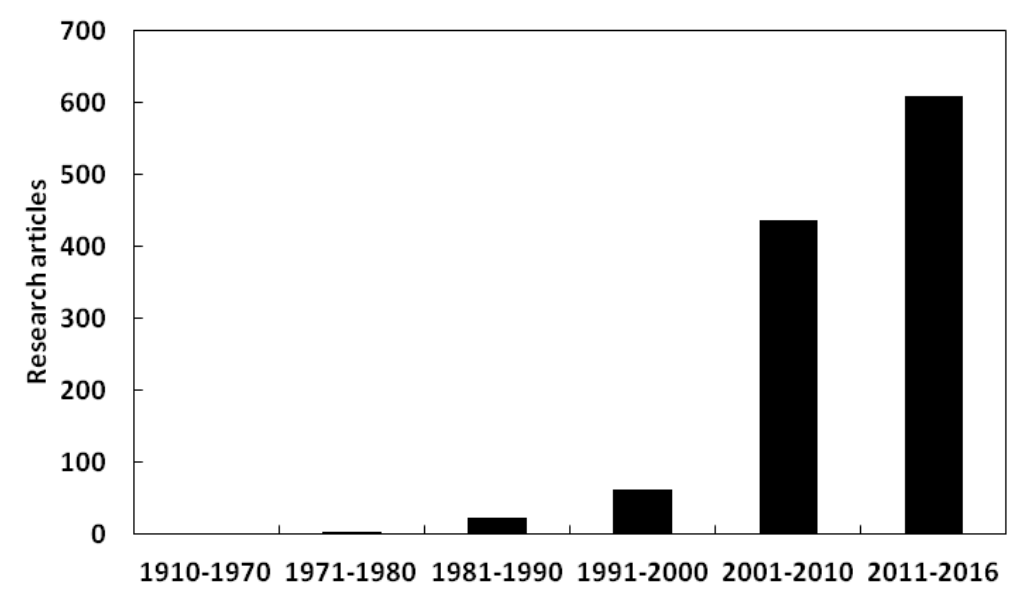

Fig. 2.3 The amount of works published under "bisphenol A" and "toxicity" terms as retrieved from Scopus

Due to its bio-refractory nature, the removal of BPA through the adsorption process has gained a lot of interests in recent years with the emergence of various adsorbent materials as described in section 2.2. Among these emerging adsorbents, biosorbents offer cheap and abundant resources with the potential for improvement in their sorption capability through chemical pre-treatment. At the other end, CNMs offer superior adsorption performance in comparison to AC. However, several challenges still need to be addressed in order to realize the practical application of $\mathrm{CNM}$ as an adsorbent material. One of the difficulties corresponds to CNM's "nanometer scale" which imposes possible ecotoxicity risk, hence the need to encapsulate CNMs in a robust compartment is of importance to prevent accidental release into the treated effluent. Presently, the data on 
the kinetics and mechanism of BPA adsorption on CNMs, in particular immobilized CNM beads whether in continuous-flow column or batch reactors, are still scarce.

This project is divided into two sections. In the first section, we studied the effect of chemical pre-treatment of bamboo fiber powder waste as a biosorbent for BPA. Despite the improvement, when compared to untreated bamboo powder, kinetic studies show that their sorption performance is still inferior to other emerging adsorbents such as CNM variants. Among the CNMs tested, MWCNTs exhibit the best sorption capacity with a similar initial sorption rate as SWCNTs. Thereafter, we dedicated the rest of the thesis to the application of MWCNTs as a sorbent material for BPA removal through encapsulation in hydrogel beads. First, we investigated (1) the encapsulation of MWCNTs in alginate beads and tested their performance in a continuous-flow column reactor. Considering the fragile nature of alginate and eventual release of CNTs, in the next stage (2) the incorporation of an additional layer of polysulfone for better containment of MWCNTs was proposed, and the sorption behavior was tested in a batchscale reactor. In the last part of our work, (3) we assessed the feasibility of incorporating this new compartment with biodegradation of a novel isolated BPA tolerant strain in order to improve BPA removal. Little is known about the possibility of combining the adsorption capability of CNTs with microbial biodegradation within an encapsulated system. With regard to the insidious nature of BPA in the environment, it appears to be important to improve the knowledge of different alternatives for its removal. 


\section{References}

1 Ternes, T. A., Joss, A. \& Siegrist, H. The complexity of these hazards should not be underestimated. Environmental Science and Technology 38, 392-399A (2004).

2 Grassi, M., Kaykioglu, G., Belgiorno, V. \& Lofrano, G. in Emerging Compounds Removal from Wastewater SpringerBriefs in Molecular Science (ed Giusy Lofrano) Ch. 2, 15-37 (Springer Netherlands, 2012).

3 Gupta, V., Carrott, P., Ribeiro Carrott, M. \& Suhas. Low-cost adsorbents: growing approach to wastewater treatment-a review. Critical Reviews in Environmental Science and Technology 39, 783-842 (2009).

4 Eckenfelder, W. W. Industrial water pollution control. (McGraw-Hill, NY., 1989).

5 Weber, W. J. J. Physicochemical processes for water quality control. (Wiley, 1972).

6 Ho, Y.-S. \& McKay, G. The kinetics of sorption of divalent metal ions onto sphagnum moss peat. Water Research 34, 735-742 (2000).

7 Blanchard, G., Maunaye, M. \& Martin, G. Removal of heavy metals from waters by means of natural zeolites. Water Research 18, 1501-1507 (1984).

8 Weber, W. J. \& Morris, J. C. Kinetics of adsorption on carbon from solution. Journal of the Sanitary Engineering Division 89, 31-60 (1963).

9 Boyd, G. E., Adamson, A. W. \& Myers, L. S. The exchange adsorption of ions from aqueous solutions by organic zeolites. II. Kinetics1. Journal of the American Chemical Society 69, 2836-2848 (1947).

10 Langmuir, I. The constitution and fundamental properties of solids and liquids. II. Liquids. 1. Journal of the American Chemical Society 39, 1848-1906 (1917).

11 Freundlich, H. Concerning adsorptions in solutions. Journal of Physical Electrochemistry 57, 1100-1107 (1906).

12 Site, A. D. Factors affecting sorption of organic compounds in natural sorbent/water systems and sorption coefficients for selected pollutants. A review. Journal of Physical and Chemical Reference Data 30, 187-439 (2001).

13 Freundlich, H. Over the adsorption in solution. J. Phys. Chem 57, 1100-1107 (1906).

14 Worch, E. Adsorption Technology in Water Treatment. (Walter de Gruyter GmbH \& Co., 2012).

15 Sincero, A. P. \& Sincero, G. A. Physical-chemical treatment of water and wastewater. (CRC Press, 2002).

16 Aksu, Z. \& Gönen, F. Biosorption of phenol by immobilized activated sludge in a continuous packed bed: prediction of breakthrough curves. Process Biochemistry 39, 599-613 (2004).

17 Goel, J., Kadirvelu, K., Rajagopal, C. \& Garg, V. K. Removal of lead (II) by adsorption using treated granular activated carbon: batch and column studies. Journal of Hazardous Materials 125, 211-220 (2005).

18 Vázquez, G., Alonso, R., Freire, S., González-Álvarez, J. \& Antorrena, G. Uptake of phenol from aqueous solutions by adsorption in a Pinus pinaster bark packed bed. Journal of Hazardous Materials 133, 61-67 (2006).

19 Bohart, G. \& Adams, E. Some aspects of the behavior of charcoal with respect to chlorine. 1. Journal of the American Chemical Society 42, 523-544 (1920). 
20 Sarin, V., Singh, T. S. \& Pant, K. Thermodynamic and breakthrough column studies for the selective sorption of chromium from industrial effluent on activated eucalyptus bark. Bioresource Technology 97, 1986-1993 (2006).

21 Yoon, Y. H. \& Nelson, J. H. Application of gas adsorption kinetics I. A theoretical model for respirator cartridge service life. The American Industrial Hygiene Association Journal 45, 509-516 (1984).

22 Calero, M., Hernáinz, F., Blázquez, G., Tenorio, G. \& Martín-Lara, M. Study of $\mathrm{Cr}$ (III) biosorption in a fixed-bed column. Journal of Hazardous Materials 171, 886-893 (2009).

23 Ahmad, A. \& Hameed, B. Fixed-bed adsorption of reactive azo dye onto granular activated carbon prepared from waste. Journal of Hazardous Materials 175, 298303 (2010).

24 He, J., Lu, Y., Wu, L. \& Luo, G. Continuous removal of lead from aqueous solutions by $\mathrm{Ca}(\mathrm{II})$ imprinted chitosan microspheres packed column. Separation Science and Technology 50, 1127-1134 (2014).

25 Liu, G., Ma, J., Li, X. \& Qin, Q. Adsorption of bisphenol A from aqueous solution onto activated carbons with different modification treatments. Journal of Hazardous Materials 164, 1275-1280 (2009).

26 Tsai, W. T., Lai, C. W. \& Su, T. Y. Adsorption of bisphenol-A from aqueous solution onto minerals and carbon adsorbents. Journal of Hazardous Materials 134, 169-175 (2006).

27 Dąbrowski, A., Podkościelny, P., Hubicki, Z. \& Barczak, M. Adsorption of phenolic compounds by activated carbon-a critical review. Chemosphere 58, 1049-1070 (2005).

28 Pollard, S. J. T., Fowler, G. D., Sollars, C. J. \& Perry, R. Low-cost adsorbents for waste and wastewater treatment: a review. Science of The Total Environment 116, 31-52 (1992).

29 Yin, C. Y., Aroua, M. K. \& Daud, W. M. A. W. Review of modifications of activated carbon for enhancing contaminant uptakes from aqueous solutions. Separation and Purification Technology 52, 403-415 (2007).

30 Blocki, S. W. Hydrophobic zeolite adsorbent: A proven advancement in solvent separation technology. Environmental Progress 12, 226-230 (1993).

31 Zhou, Y., Lu, P. \& Lu, J. Application of natural biosorbent and modified peat for bisphenol a removal from aqueous solutions. Carbohydrate Polymers 88, 502-508 (2012).

32 Lazim, Z. M., Hadibarata, T., Puteh, M. H. \& Yusop, Z. Adsorption characteristics of bisphenol a onto low-cost modified phyto-waste material in aqueous solution. Water Air Soil Pollut 226, 1-11 (2015).

33 Dong, Y., Wu, D., Chen, X. \& Lin, Y. Adsorption of bisphenol A from water by surfactant-modified zeolite. Journal of colloid and interface science 348, 585-590 (2010).

34 Zhou, Y., Chen, L., Lu, P., Tang, X. \& Lu, J. Removal of bisphenol A from aqueous solution using modified fibric peat as a novel biosorbent. Separation and Purification Technology 81, 184-190 (2011).

35 Mondal, D. K., Nandi, B. K. \& Purkait, M. K. Removal of mercury (II) from aqueous solution using bamboo leaf powder: Equilibrium, thermodynamic and 
kinetic studies. Journal of Environmental Chemical Engineering 1, 891-898 (2013).

36 Bai, R. S. \& Abraham, T. E. Studies on enhancement of Cr(VI) biosorption by chemically modified biomass of Rhizopus nigricans. Water Research 36, 12241236 (2002).

37 Baughman, R. H., Zakhidov, A. A. \& de Heer, W. A. Carbon nanotubes--the route toward applications. Science 297, 787-792 (2002).

38 Mauter, M. S. \& Elimelech, M. Environmental applications of carbon-based nanomaterials. Environmental Science \& Technology 42, 5843-5859 (2008).

39 Iijima, S. Helical microtubules of graphitic carbon. Nature 354, $56-58$ (1991).

40 Iijima, S. \& Ichihashi, T. Single-shell carbon nanotubes of 1-nm diameter. Nature 363, 603-605 (1993).

41 Hone, J. et al. Electrical and thermal transport properties of magnetically aligned single wall carbon nanotube films. Applied Physics Letters 77, 666-668 (2000).

42 Kuo, C. Y. Comparison with as-grown and microwave modified carbon nanotubes to removal aqueous bisphenol A. Desalination 249, 976-982 (2009).

43 Long, R. Q. \& Yang, R. T. Carbon nanotubes as superior sorbent for dioxin removal. Journal of the American Chemical Society 123, 2058-2059 (2001).

44 Lin, D. \& Xing, B. Adsorption of phenolic compounds by carbon nanotubes: role of aromaticity and substitution of hydroxyl groups. Environmental Science \& Technology 42, 7254-7259 (2008).

45 Lin, W. Homochiral porous metal-organic frameworks: Why and how? Journal of Solid State Chemistry 178, 2486-2490 (2005).

$46 \mathrm{Wu}$, Y.-n. et al. Facile fabrication of photonic MOF films through stepwise deposition on a colloid crystal substrate. Chemical Communications 47, 1009410096 (2011).

47 Férey, G. et al. A Chromium terephthalate-based solid with unusually large pore volumes and surface Area. Science 309, 2040-2042 (2005).

48 Park, E. Y., Hasan, Z., Khan, N. A. \& Jhung, S. H. Adsorptive removal of bisphenol-a from water with a metal-organic framework, a porous chromiumbenzenedicarboxylate. Journal of Nanoscience and Nanotechnology 13, 27892794 (2013).

49 Pera-Titus, M. \& Farrusseng, D. Guest-induced gate opening and nreathing phenomena in soft porous crystals: building thermodynamically consistent isotherms. The Journal of Physical Chemistry C 116, 1638-1649 (2012).

50 Zhou, M. et al. The removal of bisphenol A from aqueous solutions by MIL53(Al) and mesostructured MIL-53(Al). Journal of colloid and interface science 405, 157-163 (2013).

51 Qin, F. X., Jia, S. Y., Liu, Y., Li, H. Y. \& Wu, S. H. Adsorptive removal of bisphenol A from aqueous solution using metal-organic frameworks. Desalination and Water Treatment 54, 93-102 (2015).

52 Fan, X., Tu, B., Ma, H. \& Wang, X. Adsorption behavior of environmental hormone Bisphenol A onto mesoporous silicon dioxide. Bulletin of the Korean Chemical Society 32, 2560-2564 (2011). 
53 Kim, Y. H., Lee, B., Choo, K. H. \& Choi, S. J. Selective adsorption of bisphenol A by organic-inorganic hybrid mesoporous silicas. Microporous and Mesoporous Materials 138, 184-190 (2011).

54 Davis, M. E. \& Lobo, R. F. Zeolite and molecular sieve synthesis. Chemistry of Materials 4, 756-768 (1992).

55 Baerlocher, C., Meier, W. M. \& Olson, D. H. Atlas of Zeolite Framework Types. (Elsevier, 2001).

56 Fukahori, S., Ichiura, H., Kitaoka, T. \& Tanaka, H. Photocatalytic decomposition of bisphenol $\mathrm{A}$ in water using bomposite $\mathrm{TiO}_{2}$-zeolite sheets prepared by a papermaking technique. Environmental Science \& Technology 37, 1048-1051 (2003).

57 Xie, J., Meng, W., Wu, D., Zhang, Z. \& Kong, H. Removal of organic pollutants by surfactant modified zeolite: comparison between ionizable phenolic compounds and non-ionizable organic compounds. Journal of Hazardous Materials 231-232, 57-63 (2012).

58 Tsai, W. T., Hsu, H. C., Su, T. Y., Lin, K. Y. \& Lin, C. M. Adsorption characteristics of bisphenol-A in aqueous solutions onto hydrophobic zeolite. Journal of colloid and interface science 299, 513-519 (2006).

59 Tsai, W. T., Hsien, K. J. \& Hsu, H. C. Adsorption of organic compounds from aqueous solution onto the synthesized zeolite. Journal of Hazardous Materials 166, 635-641 (2009).

60 Kitaoka, M. \& Hayashi, K. Adsorption of Bisphenol A by Cross-Linked $\beta$ Cyclodextrin Polymer. Journal of Inclusion Phenomena 44, 429-431 (2002).

61 Gong, R., Liang, J., Chen, J. \& Huang, F. Removal of bisphenol A from aqueous solution by hydrophobic sorption of hemimicelles. International Journal of Environmental Science and Technology 6, 539-544 (2009).

62 Tsai, W.-T., Lai, C.-W. \& Su, T.-Y. Adsorption of bisphenol-A from aqueous solution onto minerals and carbon adsorbents. Journal of Hazardous Materials 134, 169-175 (2006).

$63 \mathrm{Xu}$, J., Wang, L. \& Zhu, Y. Decontamination of bisphenol A from aqueous solution by graphene adsorption. Langmuir 28, 8418-8425 (2012).

$64 \mathrm{Xu}$, J. \& Zhu, Y. F. Elimination of bisphenol A from water via graphene oxide adsorption. Wuli Huaxue Xuebao/ Acta Physico - Chimica Sinica 29, 829-836 (2013).

65 Dehghani, M. H. et al. Adsorption of bisphenol A (BPA) from aqueous solutions by carbon nanotubes: kinetic and equilibrium studies. Desalination and Water Treatment 54, 84-92 (2015).

66 Bohdziewicz, J. \& Kamińska, G. Kinetics and equilibrium of the sorption of bisphenol A by carbon nanotubes from wastewater. Water Science and Technology 68, 1306-1314 (2013).

67 Gupta, V. K., Kumar, R., Nayak, A., Saleh, T. A. \& Barakat, M. Adsorptive removal of dyes from aqueous solution onto carbon nanotubes: a review. Advances in colloid and interface science 193, 24-34 (2013).

68 Pan, B. \& Xing, B. Competitive and complementary adsorption of bisphenol a and 17a-ethinyl estradiol on carbon nanomaterials. Journal of Agricultural and Food Chemistry 58, 8338-8343 (2010). 
69 Joseph, L., Heo, J., Park, Y. G., Flora, J. R. V. \& Yoon, Y. Adsorption of bisphenol A and 17 $\alpha$-ethinyl estradiol on single walled carbon nanotubes from seawater and brackish water. Desalination 281, 68-74 (2011).

70 Joseph, L. et al. Removal of bisphenol A and 17 $\alpha$-ethinyl estradiol from landfill leachate using single-walled carbon nanotubes. Water Research 45, 4056-4068 (2011).

71 Bohdziewicz, J. \& Kamińska, G. Kinetics and equilibrium of the sorption of bisphenol A by carbon nanotubes from wastewater. Water Science \& Technology 68, 1306-1314 (2013).

72 De Volder, M. F., Tawfick, S. H., Baughman, R. H. \& Hart, A. J. Carbon nanotubes: present and future commercial applications. Science 339, 535-539 (2013).

73 Smart, S., Cassady, A., Lu, G. \& Martin, D. The biocompatibility of carbon nanotubes. Carbon 44, 1034-1047 (2006).

74 Kang, S., Herzberg, M., Rodrigues, D. F. \& Elimelech, M. Antibacterial effects of carbon nanotubes: size does matter! Langmuir 24, 6409-6413 (2008).

$75 \mathrm{Su}, \mathrm{Y}$. et al. Risks of single-walled carbon nanotubes acting as contaminantscarriers: potential release of phenanthrene in Japanese Medaka (Oryzias latipes). Environmental Science \& Technology 47, 4704-4710 (2013).

$76 \mathrm{Li}, \mathrm{S}$. et al. Recyclable $\mathrm{CNTs} / \mathrm{Fe}_{3} \mathrm{O}_{4}$ magnetic nanocomposites as adsorbents to remove bisphenol A from water and their regeneration. Chemical Engineering Journal 260, 231-239 (2015).

77 Martinsen, A., Storrø, I. \& Skjårk-Bræk, G. Alginate as immobilization material: III. Diffusional properties. Biotechnology and Bioengineering 39, 186-194 (1992).

78 Kierstan, M. \& Bucke, C. The immobilization of microbial cells, subcellular organelles, and enzymes in calcium alginate gels. Biotechnology and Bioengineering 19, 387-397 (1977).

79 Park, H. G., Kim, T. W., Chae, M. Y. \& Yoo, I. K. Activated carbon-containing alginate adsorbent for the simultaneous removal of heavy metals and toxic organics. Process Biochemistry 42, 1371-1377 (2007).

80 Jodra, Y. \& Mijangos, F. Phenol adsorption in immobilized activated carbon with alginate gels. Separation Science and Technology 38, 1851-1867 (2003).

81 Lin, Y. B., Fugetsu, B., Terui, N. \& Tanaka, S. Removal of organic compounds by alginate gel beads with entrapped activated carbon. Journal of Hazardous Materials 120, 237-241 (2005).

82 Choi, J. W., Chung, S. G., Hong, S. W., Kim, D. J. \& Lee, S. H. Development of adsorbent for the simultaneous removal of organic and inorganic contaminants from aqueous solution. Water Science and Technology 64, 1821-1827 (2011).

83 Ngomsik, A. F. et al. Co(II) removal by magnetic alginate beads containing Cyanex 272@. Journal of Hazardous Materials 166, 1043-1049 (2009).

84 Ngomsik, A. F., Bee, A., Siaugue, J. M., Cabuil, V. \& Cote, G. Nickel adsorption by magnetic alginate microcapsules containing an extractant. Water Research 40, 1848-1856 (2006).

$85 \mathrm{Li}, \mathrm{H}$. et al. A novel technology for biosorption and recovery hexavalent chromium in wastewater by bio-functional magnetic beads. Bioresource Technology 99, 6271-6279 (2008). 
86 Bée, A., Talbot, D., Abramson, S. \& Dupuis, V. Magnetic alginate beads for Pb(II) ions removal from wastewater. Journal of colloid and interface science 362, 486492 (2011).

87 Rocher, V., Siaugue, J. M., Cabuil, V. \& Bee, A. Removal of organic dyes by magnetic alginate beads. Water Research 42, 1290-1298 (2008).

88 Fugetsu, B. et al. Encapsulation of multi-walled carbon nanotubes (MWCNTs) in $\mathrm{Ba} 2+$-alginate to form coated micro-beads and their application to the preconcentration/elimination of dibenzo-p-dioxin, dibenzofuran, and biphenyl from contaminated water. Analyst 129, 565-566 (2004).

89 Weng, S. Y. et al. Thermokinetics simulation for multi-walled carbon nanotubes with sodium alginate by advanced kinetics and technology solutions. Journal of Thermal Analysis and Calorimetry 113, 1603-1610 (2013).

90 Zhang, C. et al. Aerobic degradation of bisphenol A by Achromobacter xylosoxidans strain B-16 isolated from compost leachate of municipal solid waste. Chemosphere 68, 181-190 (2007).

91 Masuda, M., Yamasaki, Y., Ueno, S. \& Inoue, A. Isolation of bisphenol Atolerant/degrading Pseudomonas monteilii strain N-502. Extremophiles 11, 355362 (2007).

92 Yamanaka, H., Moriyoshi, K., Ohmoto, T., Ohe, T. \& Sakai, K. Degradation of bisphenol A by Bacillus pumilus isolated from kimchi, a traditionally fermented food. Appl Biochem Biotechnol 136, 39-51 (2007).

93 Oshiman, K.-i., Tsutsumi, Y., Nishida, T. \& Matsumura, Y. Isolation and characterization of a novel bacterium, Sphingomonas bisphenolicum strain AO1, that degrades bisphenol A. Biodegradation 18, 247-255 (2007).

94 Sasaki, M., Maki, J.-i., Oshiman, K.-i., Matsumura, Y. \& Tsuchido, T. Biodegradation of bisphenol A by cells and cell lysate from Sphingomonas sp. strain AO1. Biodegradation 16, 449-459 (2005).

95 Matsumura, Y. et al. Isolation and characterization of novel bisphenol-A-degrading bacteria from soils. Biocontrol science 14, 161-169 (2009).

$96 \mathrm{Li}, \mathrm{G}$. et al. Biodegradation and detoxification of bisphenol A with one newlyisolated strain Bacillus sp. GZB: Kinetics, mechanism and estrogenic transition. Bioresource Technology 114, 224-230 (2012).

97 Kamaraj, M., Sivaraj, R. \& Venckatesh, R. Biodegradation of bisphenol A by the tolerant bacterial species isolated from coastal regions of Chennai, Tamil Nadu, India. International Biodeterioration \& Biodegradation 93, 216-222 (2014).

98 Dorn, P. B., Chou, C.-S. \& Gentempo, J. J. Degradation of bisphenol A in natural waters. Chemosphere 16, 1501-1507 (1987).

99 Ike, M., Jin, C.-S. \& Fujita, M. Isolation and Characterization of a novel bisphenol A-degrading bacterium Pseudomonas paucimobilis Strain FJ-4. 日本水 処理生物学会誌 31, 203-212 (1995).

100 Sheeja, R. Y. \& Murugesan, T. Studies on biodegradation of phenol using response surface methodology. Journal of Chemical Technology \& Biotechnology 77, 1219-1230 (2002).

101 Massalha, N., Basheer, S. \& Sabbah, I. Effect of adsorption and bead xize of immobilized biomass on the rate of biodegradation of phenol at high 
concentration levels. Industrial \& Engineering Chemistry Research 46, 68206824 (2007).

102 Dong, L., Henderson, A. \& Field, C. Antimicrobial activity of single-walled carbon nanotubes suspended in different surfactants. Journal of Nanotechnology 2012, 7 (2012).

103 Yang, C., Mamouni, J., Tang, Y. \& Yang, L. Antimicrobial activity of singlewalled carbon nanotubes: length effect. Langmuir 26, 16013-16019 (2010).

104 Chen, H. et al. Broad-Spectrum antibacterial activity of carbon nanotubes to human gut bacteria. Small 9, 2735-2746 (2013).

105 Vecitis, C. D., Zodrow, K. R., Kang, S. \& Elimelech, M. Electronic-structuredependent bacterial cytotoxicity of single-walled carbon nanotubes. Acs Nano 4, 5471-5479 (2010).

106 Arias, L. R. \& Yang, L. Inactivation of bacterial pathogens by carbon nanotubes in suspensions. Langmuir 25, 3003-3012 (2009).

107 Zhao, F. et al. Preparation of single-walled carbon nanotubes/polyvinylchloride membrane and its antibacterial property. Water Science and Technology 66, 22752283 (2012).

108 Zhang, C., Li, M., Xu, X. \& Liu, N. Effects of carbon nanotubes on atrazine biodegradation by Arthrobacter sp. Journal of Hazardous Materials 287, 1-6 (2015).

109 Krishnan, A. V., Stathis, P., Permuth, S. F., Tokes, L. \& Feldman, D. BisphenolA: an estrogenic substance is released from polycarbonate flasks during autoclaving. Endocrinology-Philadelphia- 132, 2279-2279 (1993).

110 Ben-Jonathan, N. \& Steinmetz, R. Xenoestrogens: the emerging story of bisphenol A. Trends in Endocrinology \& Metabolism 9, 124-128 (1998).

111 Deblonde, T., Cossu-Leguille, C. \& Hartemann, P. Emerging pollutants in wastewater: A review of the literature. International Journal of Hygiene and Environmental Health 214, 442-448 (2011). 


\section{Chapter 3}

\section{Experimental Methodology}

This chapter describes the materials, characterization and experimental procedures utilized in this work. The details of adsorbent materials and reagents, including their product code and supplier, are presented. The analytical instruments used to probe the physical and chemical properties of the adsorbent materials before and after modifications are elaborated. The method section describes the preparation of the sorbent materials, namely: the pre-treatment of bamboo fiber powder and fabrication of hybrid beads comprising of MWCNTs and isolated bacteria strain PBPA2, as well as the $B P A$ removal experiments in batch and column reactors. 


\subsection{Materials}

\subsubsection{Reagents and Solvents}

The chemicals used in this study are of analytical grade. Table 3.1 lists all chemicals used in the study. Distilled deionized water was used for dilution.

Table 3.1 List of chemicals and products used in the study

\begin{tabular}{|c|c|c|c|}
\hline Compounds & $\begin{array}{l}\text { Product } \\
\text { code }\end{array}$ & Supplier & Abbreviation \\
\hline Activated carbon & 242276 & Sigma & $\mathrm{AC}$ \\
\hline $\begin{array}{l}\text { Alginic acid sodium salt } \\
\text { from brown algae }\end{array}$ & A2158 & Sigma & Alg \\
\hline Ammonium nitrate & 221244 & Sigma & $\mathrm{NH}_{4} \mathrm{NO}_{3}$ \\
\hline Bisphenol A & 239658 & Sigma & BPA \\
\hline Calcium chloride & C1016 & Sigma & $\mathrm{CaCl}_{2}$ \\
\hline Calcium chloride & $\mathrm{C} 2661$ & Sigma & $\mathrm{CaCl}_{2}$ \\
\hline $\mathrm{D}(+)$-Glucose & G8270 & Sigma & - \\
\hline $\begin{array}{l}\text { Hexadecyltrimethylamm } \\
\text { onium bromide }\end{array}$ & H6269 & Sigma & CTAB \\
\hline Hydrochloric acid, 37\% & 100317 & Merck & $\mathrm{HCl}$ \\
\hline Hydrogen Peroxide 35\% & L14000 & Alfa Aesar & $\mathrm{H}_{2} \mathrm{O}_{2}$ \\
\hline Iron(II) Sulfate & 215422 & Sigma & $\mathrm{FeSO}_{4} \cdot 7 \mathrm{H}_{2} \mathrm{O}$ \\
\hline Heptahydrate & & & \\
\hline Kanamycin disulfate salt & K1876 & Sigma & \\
\hline Luria bertani broth & L3022 & Sigma & LB broth \\
\hline Luria bertani agar & L2897 & Sigma & LB agar \\
\hline $\begin{array}{l}\text { Magnesium sulfate } \\
\text { heptahydrate }\end{array}$ & 230391 & Sigma & $\mathrm{MgSO}_{4} .7 \mathrm{H}_{2} \mathrm{O}$ \\
\hline N.N- dimethylformamide & D4551 & Sigma & $\mathrm{N}, \mathrm{N}-\mathrm{DMF}$ \\
\hline $\begin{array}{l}\text { P25 aeroxide titaninum } \\
\text { dioxide powder }\end{array}$ & 718467 & Aldrich & $\mathrm{TiO}_{2}$ \\
\hline Polysulfone & 428302 & Sigma & Psf \\
\hline $\begin{array}{l}\text { Potassium phosphate } \\
\text { dibasic }\end{array}$ & P8281 & Sigma & $\mathrm{K}_{2} \mathrm{HPO}_{4}$ \\
\hline $\begin{array}{l}\text { Potassium phosphate } \\
\text { monobasic }\end{array}$ & P0622 & Sigma & $\mathrm{KH}_{2} \mathrm{PO}_{4}$ \\
\hline Sodium chloride & S9888 & Sigma & $\mathrm{NaCl}$ \\
\hline Sodium dodecyl sulfate & L3771 & Sigma & SDS \\
\hline Sodium hydroxide pellets & 50112 & Schedelco & $\mathrm{NaOH}$ \\
\hline Triton X-100 & T9284 & Sigma & TX-100 \\
\hline Yeast extract & Y1625 & Sigma & - \\
\hline
\end{tabular}




\subsubsection{Adsorbent materials}

Bamboo fiber powders (BPs) of $1000 \mu \mathrm{m}$ (Grade 3), $300 \mu \mathrm{m}$ (Grade 4) and $55 \mu \mathrm{m}$ (Grade 6), particle sizes were acquired from Bamboo Fibers Technology.

Commercial carbon nanomaterials (CNMs) were incorporated directly in the experiment without additional modification ${ }^{1}$. Table 3.2 lists the key characteristics of the CNMs according to information obtained from suppliers. These materials were chosen based on their dimensional similarity.

Table 3.2 Key characteristics of CNMs used in this study

\begin{tabular}{llcl}
\hline \multicolumn{1}{c}{ Compounds } & Length & Diameter & Surface area \\
$\begin{array}{l}\text { Graphene nanoplatelets } \\
\text { (XGnP, XGScience) }\end{array}$ & $\begin{array}{l}6-8 \mathrm{~nm} \\
\text { (thickness) }\end{array}$ & $5.0 \mu \mathrm{m}$ & $120-150 \mathrm{~m}^{2} \cdot \mathrm{g}^{-1}$ \\
$\begin{array}{l}\text { Single-walled carbon } \\
\text { nanotubes }\end{array}$ & $0.45-2.3 \mu \mathrm{m}$ & $0.7-1.3 \mathrm{~nm}$ & Not stated \\
$\begin{array}{l}\text { (SWCNTs, Sigma) } \\
\begin{array}{l}\text { Multi-walled carbon } \\
\text { nanotubes } \\
\text { (MWCNTs, Showa Denko) }\end{array}\end{array}$ & $3.0 \mu \mathrm{m}$ & $10-15 \mathrm{~nm}$ & Not stated \\
\hline
\end{tabular}

\subsection{Analytical Methods}

\subsubsection{Bioluminescence Assay}

Bioluminescence bacteria provide an attractive platform for rapid screening of the bioavailability of toxic pollutant towards microorganisms due to their relatively inexpensive cost and technical simplicity. This is made possible by the insertion of a specific regulatory promoter and $\operatorname{lu} C D A B E$ gene within the plasmid. Bioluminescence bacteria strains have been used in various toxicity studies to predict the mode of action of pollutants such as antibiotics ${ }^{2}$ and metallic nanoparticles ${ }^{3}$. CNMs are suspected of inducing oxidative stress in bacteria ${ }^{4}$. In this work, a panel comprising of oxidative stress-sensitive bioluminescence bacteria DPD2511 5 was utilized as a qualitative sensor for detecting the amount of MWCNTs present in the solution.

A detailed protocol for DPD2511 bioluminescence assay has been described and adapted from a previous publication ${ }^{2}$. In general, a colony of the strain was inoculated into Luria 
Bertani (LB) broth with the addition of $50 \mu \mathrm{g} \cdot \mathrm{mL}^{-1}$ of the antibiotic Kanamycin. It was then grown for $16-18 \mathrm{~h}$ inside $37^{\circ} \mathrm{C}$ shaking incubator at $150 \mathrm{rpm}$. The overnight culture of the strain was subsequently diluted with sterile LB broth media without antibiotic to obtain approximately $10^{7}$ colony-forming units per milliliter. This was followed by static incubation at $37^{\circ} \mathrm{C}$ for a specified time. For the luminescence measurement, $90 \mu \mathrm{L}$ of this bacteria suspension was mixed with $10 \mu \mathrm{L}$ of samples $(\mathrm{n}=3)$ in 96 -wells microtiter plates. The plates were inserted to a luminometer (Luminoskan Ascent, Thermofisher Scientific) where the generated bioluminescence signal was recorded overnight in the dark at a selected monitoring temperature. The signal produced by the bioluminescence bacteria as a response to the inducer was relayed in terms of relative light units (RLU). The induction ratio (IR) was estimated as ${ }^{2}$ :

$$
\mathrm{IR}=\frac{\mathrm{RLU}_{\text {max,sample }}}{\mathrm{RLU}_{\text {max }, \text { blank }}}
$$

where $\mathrm{RLU}_{\text {max,sample }}$ corresponds to the maximum RLU produced by the sample, and $\mathrm{RLU}_{\text {max,blank }}$ refers to maximum RLU produced by the negative control (distilled water). The assay was repeated in triplicate with the value reported as the mean of the readings.

In order to achieve higher sensitivity, the bioluminescence assay method used in our study was first optimized by the inducement of the strain with its positive control, 2 $\mu \mathrm{g} \cdot \mathrm{mL}^{-1} \mathrm{H}_{2} \mathrm{O}_{2}$, while varying two parameters. The varied parameters were the length of incubation time in the refreshment media after $17 \mathrm{~h}$ in an overnight culture and the temperature used during monitoring of the bioluminescence.

Fig. 3.1 shows the bioluminescence patterns of the positive controls for DPD2511 after subtraction with bioluminescence pattern induced by negative control. Based on the pattern, it is apparent that the increase in monitoring temperature correlated with the decrease in the total quantity of bioluminescence produced by the bacteria. 

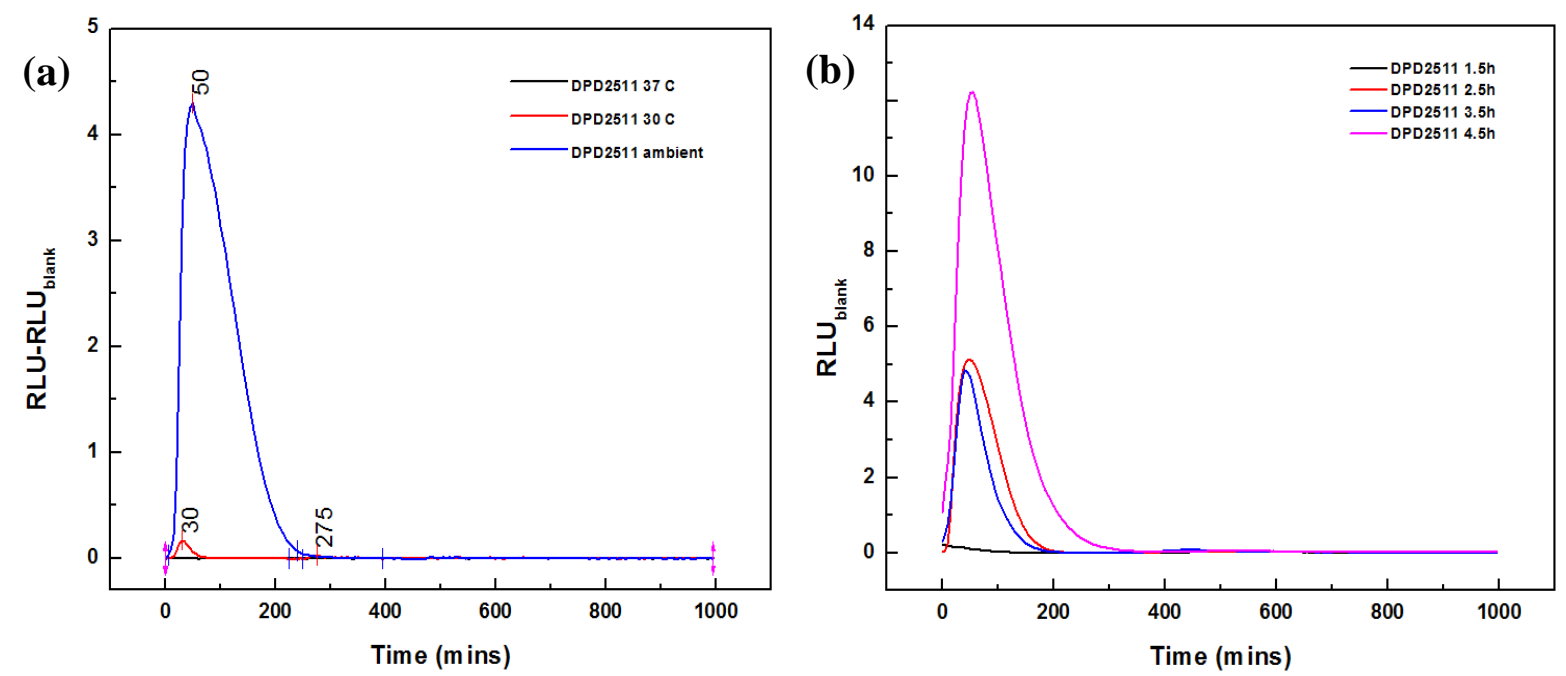

Fig. 3.1 The bioluminescence patterns produced by DPD2511 (a) after $1.5 \mathrm{~h}$ of incubation at different monitoring temperatures and (b) against a negative control after different incubation time at ambient monitoring temperature

In terms of the length of incubation time, it was observed that under the same monitoring temperature, the peak intensity of the negative control $\left(R L U_{b l a n k}\right)$, as shown in Fig. 3.1(b), increases with longer incubation time. The increase in background luminescence intensity may reduce the estimated total amount of luminescence as well as the induction ratio. These results suggested that a shorter incubation time is more appropriate for the assay due to the lower background luminescence value. In summary, both monitoring temperature and incubation time affect the bioluminescence patterns with shorter incubation time and lower monitoring temperature producing higher RLU; lower $\mathrm{RLU}_{\text {blank }}$ corresponds to higher IR. The assay in our study was therefore conducted using $1.5 \mathrm{~h}$ incubation time and an ambient monitoring temperature.

\subsubsection{Cell Viability Assay}

The viability of the cells was assessed using a plate counting method. The serial dilutions of the sample were made in a sterile broth, and $10 \mu \mathrm{L}$ of samples were spread on LB agar plates. The number of colony-forming units (CFU) was counted after overnight incubation at $30^{\circ} \mathrm{C}$. 


\subsubsection{Fourier Transforms Infrared Spectroscopy Analysis (FTIR)}

FTIR (Spectrum, Perkin Elmer) was used for the detection of the functional groups at transmission spectra of $4000-500 \mathrm{~cm}^{-1}$ at resolution of $4 \mathrm{~cm}^{-1}$. Approximately $2 \mathrm{mg}$ of powdered sample were added into $400 \mathrm{mg}$ of potassium bromide powder and grinded using a mortar and pestle to obtain finer structure. The powder was placed in a mold and pressed at $10000 \mathrm{lb}$ using a manual hydraulic press to prepare the pellet for FTIR measurement. Prior to the spectra analysis, the recorded spectrum of the sample was subtracted with the spectra of the blank pellets potassium bromide.

\subsubsection{High Performance Liquid Chromatography with Ultraviolet (HPLC-UV)}

Concentrations of BPA were estimated using HPLC (Agilent 1260) with Zorbax Eclipse Plus C18 column (Agilent, $4.6 \times 150 \mathrm{~mm}, 3.5 \mu \mathrm{m}$ ). The samples were filtered through $0.20 \mu \mathrm{m}$ pore size syringe filter (Agilent, regenerated cellulose) to remove insoluble compounds. Prior to analysis, the samples were stored at $4^{\circ} \mathrm{C}$ in a refrigerator. The mobile phase used was $0.20 \mu \mathrm{m}$-filtered $50 \%$ Acetonitrile solution with analysis time of 5 min for each sample, injection flow rate of $1.0 \mathrm{ml} \cdot \mathrm{min}^{-1}$ and volume of $50 \mu \mathrm{L}$. The absorbance was monitored using a UV detector at $280 \mathrm{~nm}$. The calibration curve was prepared based on the integration of peak area or height under BPA peak against their known standard concentrations. HPLC analysis was performed at an ambient temperature of $22^{\circ} \mathrm{C}$. Using this method, the BPA retention time was estimated at $\sim 3.8 \mathrm{~min}$. The instrument parameters and mobile phase were selected after reviewing relevant literatures $^{6-8}$ and optimization.

\subsubsection{Instron Microtester}

The mechanical strength under compression was measured on an Instron 5848 microtester connected to an Instron 5800 control unit ${ }^{9}$, using a $50-\mathrm{N}$ load cell. A minimum of six samples were tested and analyzed for each type. Anvil height was adjusted to $2.5 \mathrm{~mm}$ for all samples, followed by $40 \%$ compressive extension. Initial diameters of the sample were measured using a Mitutoyo micrometer 156-101. 


\subsubsection{Field Emission / Scanning Electron Microscopy (FE-/SEM)}

The samples were mounted on a support with carbon tape and sputter coated with platinum. The sputter time was adjusted to prevent a charging effect to about $\sim 20-40 \mathrm{sec}$. SEM was conducted on JEOL 6360 under typical acceleration voltages of $5.0-10 \mathrm{kV}$ in secondary electron imaging mode with exposure time to the environment after sputtering (prior to loading) at around $10 \mathrm{~min}$.

\subsubsection{Surface Area Analysis}

Nitrogen adsorption/desorption measurements were conducted using a Quantachrome Nova $3200 \mathrm{E}$ at liquid nitrogen temperature of $77.35 \mathrm{~K}$. The surface area was measured using the Brunauer-Emmett-Teller (BET) method and the pore size was estimated using the Barrett-Joyner-Halenda (BJH) method. The samples were degassed at $125^{\circ} \mathrm{C}$ in vacuum condition for at least $2 \mathrm{~h}$ prior to analysis. The volume of nitrogen gas adsorbed onto the adsorbent was then measured at different pressures with the resulted hysteresis fitted into the BET equation to obtain surface area information. The desorption hysteresis was used to calculate the pore size distribution based on the BJH equation.

\subsubsection{Ultraviolet-Visible (UV-Vis) Spectrophotometer}

BPA concentrations were determined using a UV-Vis spectrophotometer (UV3600, Shimadzu) at a wavelength of $276 \mathrm{~nm}^{10}$, and the concentration was calculated from a calibration curve based on the absorbance value (Fig. 3.2). The spectrophotometer was set for absorbance spectrum measurement using direct detection mode with medium speed at the wavelength of 200-300 nm, interval of $0.5 \mathrm{~nm}$ and slit width of 1.0. Blank measurement was performed prior to sample measurement to eliminate background signal contribution. 


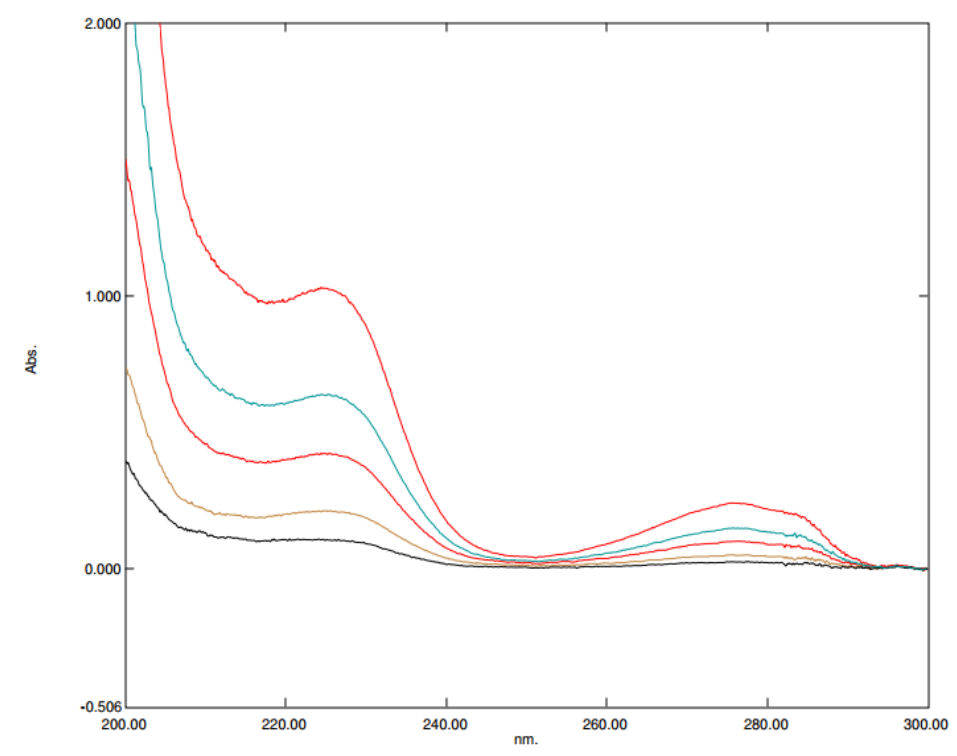

Fig.3.2 Absorbance spectra of BPA at different concentrations (top-down: 100, 80, 60, 40 and 20 mg. $\mathrm{L}^{-1}$ ) showing characteristic peaks at the wavelength of $225 \mathrm{~nm}$ and $276 \mathrm{~nm}$

The spectrophotometer was also used to estimate the optical density (OD) value for the turbidity of bacteria strains by monitoring their absorbance at a wavelength of $600 \mathrm{~nm}$.

\subsubsection{Zeta Potential Measurement}

The zeta potential of the sorbent particles was measured using a Malvern Zetasizer Nano ZS. The ability to infer the charge potential of the adsorbent particle is essential in order to predict the adsorption behavior under different $\mathrm{pH}$ values due to electrostatic interaction. In general, samples were added at a specified dosage into distilled water solutions of differing $\mathrm{pH}$. The $\mathrm{pH}$ of the solution was attuned using $0.1 \mathrm{M} \mathrm{HCl}$ or $\mathrm{NaOH}$. After vortex, approximately $750 \mu \mathrm{L}$ of the solution was injected into capillary cells for measurement. The measurements were conducted at least 5 times per sample. 


\subsection{Equipment and Procedures}

This section describes the general guidelines employed in the study. The detailed parameters as well as the sub-experiment relevant to each study are discussed further in the relevant results chapters.

\subsubsection{Preparation of Adsorbent Materials}

\subsubsection{Modification of Bamboo Fiber Powder}

The BPs used for the experiment were acquired by sieving the sawdust from 5-year old Dendrocalamus strictus Nees and Thysostachys siamensis Gamble bamboo species through meshes to obtain uniform size distribution of the powder particles. Solutions of $0.1 \mathrm{~N} \mathrm{NaOH}$ and $\mathrm{HCl}$ were used for alkali and acid treatments. Aqueous solutions of SDS, CTAB and TX-100 at their respective critical micelle concentrations of 8.0, 0.9, and 0.2 $\mathrm{mM}$ were selected and used for the treatments.

In brief, 2 grams of BPs were added into the acid/alkali/surfactant solutions and stirred for $24 \mathrm{~h}$ at an ambient temperature. After treatment, dry powder was prepared by centrifugation of the solution at $9,000 \mathrm{rpm}$ for $5 \mathrm{~min}$ in $50 \mathrm{~mL}$ tubes. Next, the supernatant was removed, and the powder was washed with distilled deionized water. The centrifuge-washing process was repeated at least twice. The obtained powder was then placed in a glass petri dish and dried at $80^{\circ} \mathrm{C}$ overnight.

\subsubsection{Fabrication of Hybrid Beads}

Calcium alginate based composite beads ( $\mathrm{Ca}-\mathrm{Alg} / \mathrm{MWCNTs}$ or $\mathrm{Ca}-\mathrm{Alg} / \mathrm{MWCNTs}-\mathrm{TiO}_{2}$ or Ca-Alg/MWCNTs-bacteria) were prepared by the addition of MWCNTs and/or $\mathrm{TiO}_{2}$ at a specified amount. This was followed by sonication (Elmasonic) and overnight stirring. The resulting mixture was dripped into a magnetically stirred $0.5 \mathrm{M} \mathrm{CaCl}_{2}$ solution using a syringe pump (KDS) at $50 \mathrm{~mL} \cdot \mathrm{h}^{-1}$. The beads were cured in the calcium solution, washed and stored in distilled water.

The addition of a Psf layer into the resultant beads relies on the phase-inversion process for solidification of $\mathrm{Psf}^{11,12}$. So, Psf at $10-\mathrm{wt} \%$ was prepared by dissolving Psf pellets into N,N-DMF. A shaking incubation of the mixture at $37^{\circ} \mathrm{C}$ shortened the dissolution time. 
Each swollen composite bead was touched to filter paper and dropped into the Psf solution for about 20s before collection and immersion in distilled water to complete the polymerization. The resulting beads were then washed and stored in distilled water at room temperature. For a dry weight to wet weight conversion, several batches of swollen beads were prepared and heated at $80^{\circ} \mathrm{C}$. The dry to wet weight conversion was calculated by measuring the average of the dry weight divided by the initial wet weight prior to drying. All calculations for data analysis were then performed based on the dry weight of the beads.
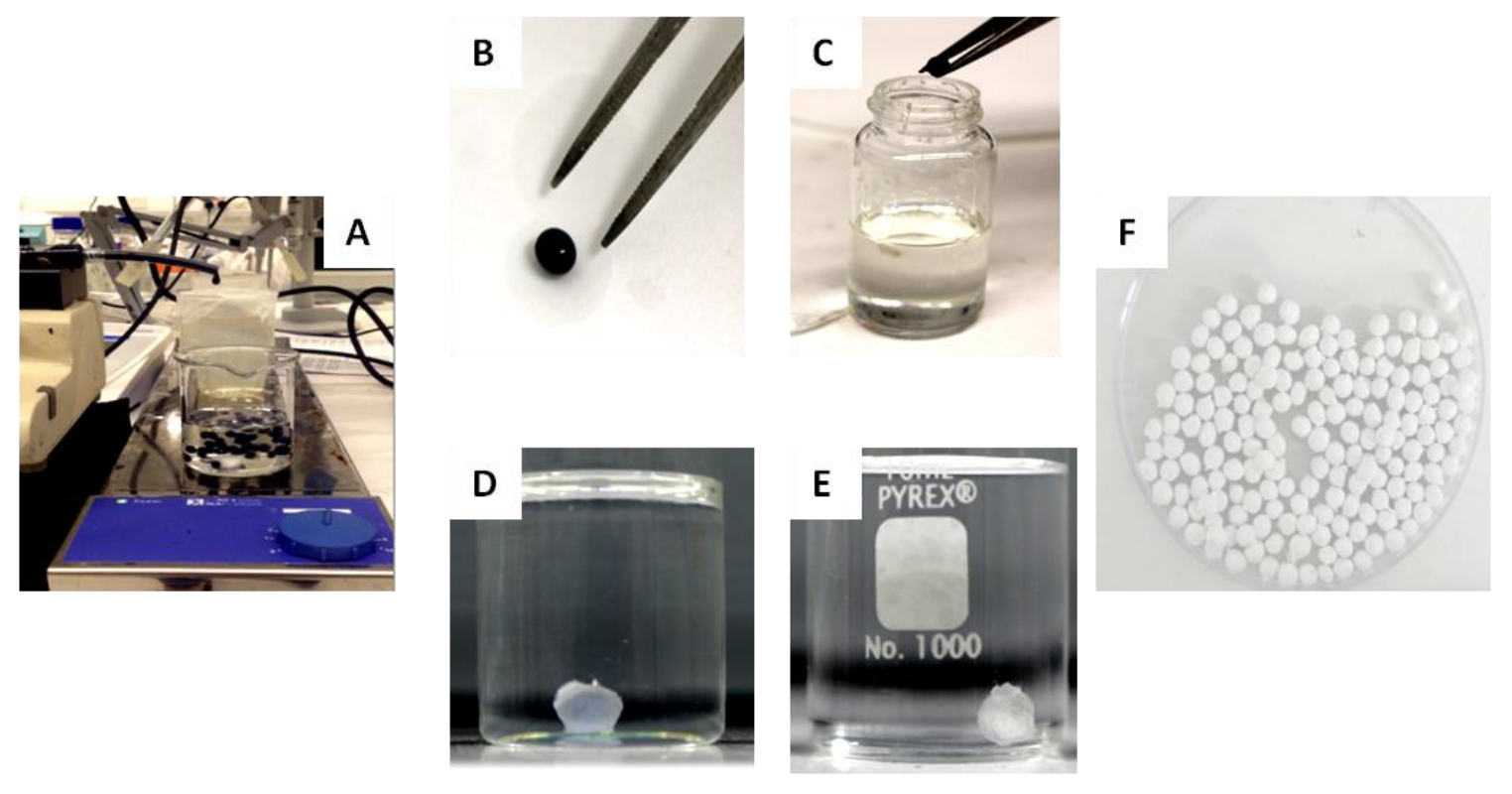

Fig. 3.3 The hybrid bead fabrication process (a) alginate-MWCNT mixture was dropped into stirred calcium chloride solution, (b) the swollen composite bead was touched to filter paper; (c) the dried bead was dropped into Psf solution; (d) phase-inversion process caused Psf layer to be formed; (e) immersion into distilled water completed the polymerization and (f) the resultant hybrid beads 


\subsubsection{Adsorption studies}

\subsubsection{Batch Reactor - Adsorption}

The methodology for adsorption experiments used in this work was adapted from previously published guidelines ${ }^{13}$. In brief, a specified dosage of sorbent was added to a BPA solution at different concentrations in glass containers and placed inside a temperature-controlled incubator shaker (NBiotek NB-205LF) at a specified temperature and shaking speed.

The BPA removal efficiency was calculated as ${ }^{13}$ :

$$
\mathrm{R}_{\mathrm{t}}(\%)=\left(1-[\mathrm{BPA}]_{\mathrm{t}} /[\mathrm{BPA}]_{0}\right) \times 100 \%
$$

$\mathrm{R}_{\mathrm{t}}(\%)$ represents the removal ratio of BPA at time $\mathrm{t}$; $[\mathrm{BPA}]_{0}\left(\mathrm{mg} . \mathrm{L}^{-1}\right)$ is the initial concentration of the BPA solution; and $[\mathrm{BPA}]_{\mathrm{t}}\left(\mathrm{mg} \cdot \mathrm{L}^{-1}\right)$ is the concentration of BPA at time t.

The adsorption capacity was calculated as ${ }^{13}$ :

$$
\mathrm{q}_{\mathrm{t}}=\left([\mathrm{BPA}]_{\mathrm{t}}-[\mathrm{BPA}]_{0}\right) \times \mathrm{V} / \mathrm{m}
$$

where $\mathrm{q}_{\mathrm{t}}\left(\mathrm{mg} \cdot \mathrm{g}^{-1}\right)$ represents the amount of BPA adsorbed at time $\mathrm{t} ; \mathrm{V}(\mathrm{L})$ is the volume of the BPA solution; and $\mathrm{m}(\mathrm{g})$ is the dry weight of the adsorbent added. Batch experiments were done in duplicate (at a minimum), with the mean of the readings as the reported value.

\subsubsection{Batch Reactor-Desorption}

The solvent extraction experiment was performed using ethanol. Beads with known adsorbed amounts of BPA were placed in ethanol in a glass container for $5 \mathrm{~h}$ at a room temperature of $22^{\circ} \mathrm{C}$. The percentage of desorption was calculated as ${ }^{13}$ :

$$
\text { Desorption }(\%)=\left([\mathrm{BPA}]_{\mathrm{liq}} /\left([\mathrm{BPA}]_{\mathrm{sol}} \times 100 \%\right.\right.
$$

$[\mathrm{BPA}]_{\text {liq }}$ represents the amount of BPA remaining in the solution $(\mathrm{mg})$ and $[\mathrm{BPA}]_{\mathrm{sol}}$ refers to the amount of BPA in the adsorbent $(\mathrm{mg}) \times 100 \%$. 


\subsubsection{Column Reactor}

Column adsorption studies were performed using a column made of borosilicate glass with an attached flow adaptor, which was connected to a pump. The column was filled with the sorbent using the tapping method until a specified bed height was reached. The BPA solution of predetermined concentration was injected in an up-flow direction into the column at specified flow rate (in order to reduce the channeling effect). A fraction of the effluent was collected as a function of time. Breakthrough curves were constructed by plotting time against the removal efficiency of BPA from the influent. Desorption was conducted by either injecting ethanol into the column or immersing the beads into an ethanol solution as described in section 3.3.2.2. Prior to the start of a new cycle, the column was flushed with distilled water to remove any trace of ethanol, and the solution, which remained inside the column, was drained by pumping air through the column. All experiments were carried out at ambient conditions.

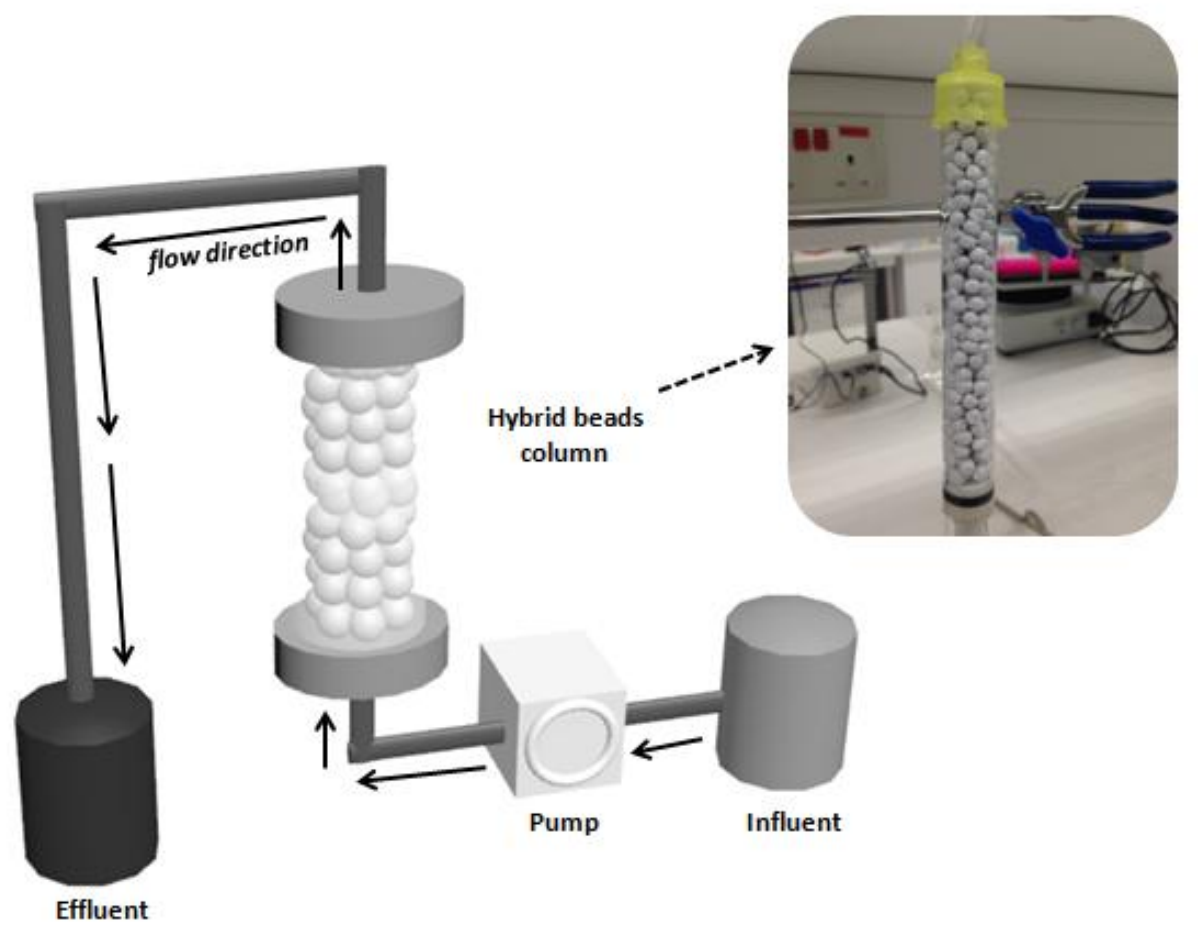

Fig. 3.4 Illustration of an up-flow packed bed column set-up used in the column experiment (Illustration by author) 


\subsubsection{Photolytic Degradation Study}

The batch mode was chosen due to the ease of quantification of adsorption capacity of the beads as it allows equilibrium to be achieved with the treated solution. The adsorption experiment was conducted according to section 3.3.2.1; desorption was conducted by immersing the exhausted beads in ethanol. Irradiations were conducted after equilibrium using a Xenon light source (Asahi Spectra, Horiba MAX-303) for $3 \mathrm{~h}$ using above 350 nm longpass filter (Asahi Spectra, ZUL0350).

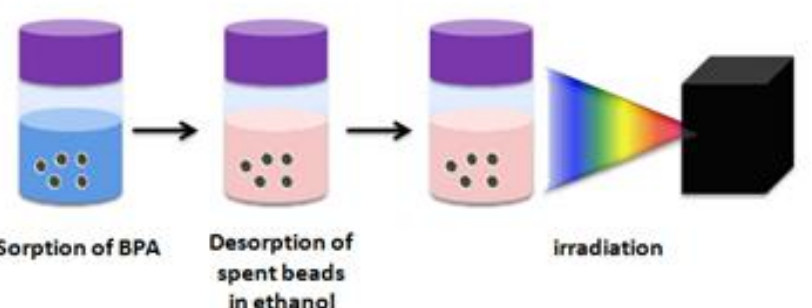

in ethanol

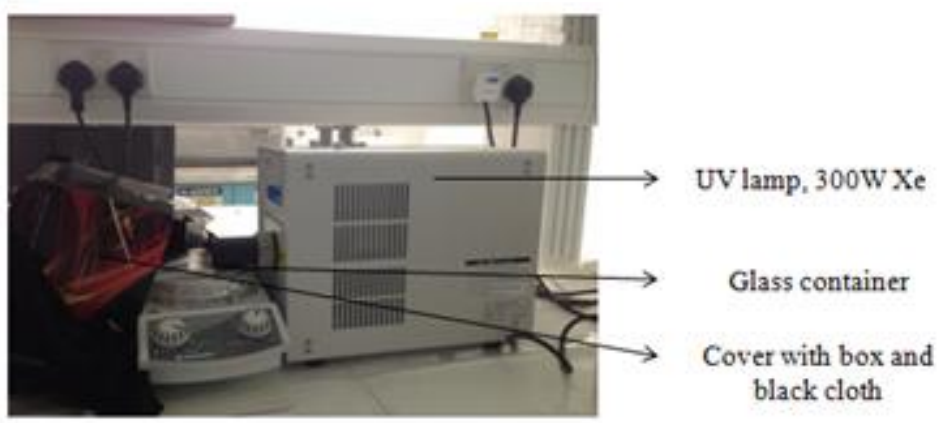

Fig. 3.5 Set-up of photolytic degradation study (Illustration by author) 


\subsubsection{Combined Biodegradation-Adsorption}

\subsubsection{Microorganism isolation and enrichment culture condition}

BPA tolerant strain PBPA2 was isolated from wastewater using an enrichment method with BPA as the sole carbon source according to the media composition by Lobos et al. ${ }^{15}$ (V. Pavlov, personal communication). In brief, the enrichment culture was comprised of 1.0 g.L $\mathrm{L}^{-1} \mathrm{NH}_{4} \mathrm{NO}_{3}, 0.2$ g.L $\mathrm{L}^{-1} \mathrm{MgSO}_{4} .7 \mathrm{H}_{2} \mathrm{O}, 1.0$ g.L $\mathrm{L}^{-1} \mathrm{~K}_{2} \mathrm{HPO}_{4}, 0.1$ g.L $\mathrm{L}^{-1} \mathrm{CaCl}_{2} .2 \mathrm{H}_{2} \mathrm{O}, 0.15$ g.L $\mathrm{L}^{-1} \mathrm{KCl}, 0.001$ g. $\mathrm{L}^{-1} \mathrm{FeSO}_{4} \cdot 6 \mathrm{H}_{2} \mathrm{O}, 0.001$ g.L $\mathrm{L}^{-1} \mathrm{ZnSO}_{4} .7 \mathrm{H}_{2} \mathrm{O}, 0.001$ g. $\mathrm{L}^{-1} \mathrm{MnSO}_{4}$ and 5.0 g. $\mathrm{L}^{-1}$ BPA. The liquid media were sterilized by autoclaving at $121^{\circ} \mathrm{C}$ for 20 mins. The strain was re-isolated and grown in nutrient agar and sent to NTU, Singapore.

\subsubsection{Batch Reactor - Biodegradation by PBPA2 strain}

Prior to the degradation study, the strain was pre-cultured overnight in $100 \mathrm{ml}$ of a sterilized mineral medium ${ }^{16}$ containing glucose, yeast extract and BPA (MYGB) which is comprised of 1.5 g.L $\mathrm{L}^{-1} \mathrm{KH}_{2} \mathrm{PO}_{4}, 0.5$ g.L ${ }^{-1} \mathrm{~K}_{2} \mathrm{HPO}_{4}, 0.5$ g.L $\mathrm{L}^{-1} \mathrm{NaCl}, 0.5$ g.L $\mathrm{L}^{-1} \mathrm{MgSO}_{4} .7 \mathrm{H}_{2} \mathrm{O}$, 3.0 g. $\mathrm{L}^{-1} \mathrm{NH}_{4} \mathrm{NO}_{3}, 0.5$ g. $\mathrm{L}^{-1}$ glucose and 2.0 g. $\mathrm{L}^{-1}$ yeast extract, $100 \mathrm{mg} . \mathrm{L}^{-1}$ BPA, 0.02 g. $\mathrm{L}^{-1} \mathrm{FeSO}_{4} .7 \mathrm{H}_{2} \mathrm{O}, 0.02$ g. $\mathrm{L}^{-1} \mathrm{CaCl}_{2} .2 \mathrm{H}_{2} \mathrm{O}$ at $30^{\circ} \mathrm{C}$ and $150 \mathrm{rpm}$ shaking platform. Stationary phase was reached after $8 \mathrm{~h}$ incubation with $\mathrm{OD}_{600 \mathrm{~nm}}$ of $0.4-0.5$. The cells were centrifuged at 4,500 rpm for $10 \mathrm{~min}$, washed, and suspended in $10 \mathrm{ml}$ sterile distilled water. The bacteria suspension was then either added directly, as free cells, or to be immobilized in bead forms, which was then placed into a mineral medium with the addition of yeast extract and BPA (MYB) of specified concentrations and cell density, followed by incubation at $30^{\circ} \mathrm{C}$ and $150 \mathrm{rpm}$. Aliquots of solutions were taken at different incubation periods to identify the degradation capability of the strain.

For reference purpose, Table 3.3 summarizes the medium recipes used in this study. 
Table 3.3 Recipes of the media used in BPA degradation study

\begin{tabular}{|c|c|c|c|c|c|}
\hline $\begin{array}{c}\text { Assigned name } \\
\text { (Abbrev.) }\end{array}$ & $\begin{array}{c}\text { BPA-enriched } \\
\text { media }\end{array}$ & $\begin{array}{c}\text { Mineral media with glucose, } \\
\text { yeast extract and BPA } \\
\text { (MYGB) }\end{array}$ & $\begin{array}{l}\text { Mineral media } \\
\text { with BPA (MB) }\end{array}$ & $\begin{array}{c}\text { Mineral media } \\
\text { with yeast extract } \\
\text { (MY) }\end{array}$ & $\begin{array}{c}\text { Mineral media } \\
\text { with yeast extract } \\
\text { and BPA (MYB) }\end{array}$ \\
\hline Purpose & $\begin{array}{l}\text { Isolation of BPA } \\
\text { tolerant strains }\end{array}$ & $\begin{array}{l}\text { Nutrient-rich media for pre- } \\
\text { culture of PBPA2 }\end{array}$ & $\begin{array}{c}\text { Biodegradation } \\
\text { study }\end{array}$ & $\begin{array}{c}\text { Biodegradation } \\
\text { study }\end{array}$ & $\begin{array}{c}\text { Biodegradation } \\
\text { study }\end{array}$ \\
\hline Reference & Lobos et al. ${ }^{15}$ & Sheeja et al. ${ }^{16}$ & Sheeja et al. ${ }^{16}$ & $\begin{array}{l}\text { Modified from } \\
\text { Sheeja et al. }\end{array}$ & $\begin{array}{l}\text { Modified from } \\
\text { Sheeja et al. }{ }^{16}\end{array}$ \\
\hline \multicolumn{6}{|c|}{ Compositions $\left(\right.$ g. $\left.L^{-1}\right)$} \\
\hline BPA & 5.0 & 0.1 & Varied & - & Varied \\
\hline $\mathrm{NH}_{4} \mathrm{NO}_{3}$ & 1.0 & 3.0 & 3.0 & 3.0 & 3.0 \\
\hline $\mathrm{MgSO}_{4} \cdot 7 \mathrm{H}_{2} \mathrm{O}$ & 0.2 & 0.5 & 0.5 & 0.5 & 0.5 \\
\hline $\mathrm{KH}_{2} \mathrm{PO}_{4}$ & - & 1.5 & 1.5 & 1.5 & 1.5 \\
\hline $\mathrm{K}_{2} \mathrm{HPO}_{4}$ & 1.0 & 0.5 & 0.5 & 0.5 & 0.5 \\
\hline $\mathrm{CaCl}_{2} \cdot 2 \mathrm{H}_{2} \mathrm{O}$ & 0.1 & 0.02 & 0.02 & 0.02 & 0.02 \\
\hline $\mathrm{NaCl}$ & - & 0.5 & 0.5 & 0.5 & 0.5 \\
\hline $\mathrm{KCl}$ & 0.15 & - & - & - & - \\
\hline $\mathrm{FeSO}_{4}-6 \mathrm{H}_{2} \mathrm{O}$ & 0.001 & 0.02 & 0.02 & 0.02 & 0.02 \\
\hline $\mathrm{ZnSO} 4.7 \mathrm{H}_{2} \mathrm{O}$ & 0.001 & - & - & - & - \\
\hline $\mathrm{MnSO}_{4}$ & 0.001 & - & - & - & - \\
\hline Yeast extract & - & 2.0 & - & 0.5 & 0.5 \\
\hline Glucose & - & 0.5 & - & - & - \\
\hline
\end{tabular}




\subsubsection{Immobilization of PBPA2 within hybrid bead}

The isolated PBPA2 strain was thereupon immobilized into hybrid carbon nanotubealginate-Psf beads. In brief, $350 \mathrm{mg}$ of MWCNTs were added into $50 \mathrm{~mL}$ of $2.5 \mathrm{wt} \%$ sodium alginate solution. The solution mixture was sonicated, stirred overnight and autoclaved. A 10-wt\% Psf solution was prepared separately by dissolving $5.0 \mathrm{~g}$ Psf in 50 $\mathrm{mL} \mathrm{N}, \mathrm{N}-\mathrm{DMF}$ solvent. The cells grown overnight were centrifuged at 4,500 rpm for 10 min, washed and suspended in $10 \mathrm{ml}$ of sterile distilled water with $\mathrm{OD}_{600 \mathrm{~nm}}=\sim 2.0$. The cell suspension in distilled water was centrifuged 4,500 rpm for $10 \mathrm{~min}$, the supernatant removed and the cell pellet mixed with autoclaved MWCNTs/alginate mixture and vortexed to adjust the final $\mathrm{OD}_{600 \mathrm{~nm}}$. The resultant solution was dripped using syringe pump into a sterile $0.5 \mathrm{M} \mathrm{CaCl}_{2}$ solution while stirring. The resultant beads were washed in sterile distilled water, touched to filter paper and immersed in Psf solution for $20 \mathrm{~s}$. Subsequent immersion in distilled water was performed for complete formation of the Psf layer. The resulting beads were washed and stored in sterile mineral medium prior to degradation study.

\subsubsection{Batch Reactor - BPA removal by immobilized PBPA2 strain}

For the batch degradation study, the cells grown overnight were centrifuged at 4,500 rpm for $10 \mathrm{~min}$, washed, and suspended in $10 \mathrm{~mL}$ sterile distilled water $\left(\mathrm{OD}_{600 \mathrm{~nm}}=\sim 2.0\right)$. The bacteria suspension was then added either as free cells or in the immobilized bead forms into $10 \mathrm{~mL}$ mineral medium with the addition of $0.05 \%$ yeast extract and BPA (MYB) at specified concentrations, followed by incubation in a $50 \mathrm{~mL}$ tube at $30^{\circ} \mathrm{C}$ and $150 \mathrm{rpm}$. The yeast extract was added into the mineral medium to improve the removal of BPA. Aliquots of solutions were taken at different intervals for analysis. 


\subsubsection{Column Reactor}

Column studies were performed using a borosilicate glass column of $15 \mathrm{~mm}$ internal diameter. The column was filled with the beads by tapping method until final height of 50 $\mathrm{mm}$ with an empty bed volume of $\sim 8.8 \mathrm{~mL}$ and a packing porosity estimated at 0.39 . Approximately 100 beads were freshly prepared and used in each column. The synthetic MYB medium containing $0.05 \%$ yeast and $10 \mathrm{mg} . \mathrm{L}^{-1}$ of BPA solution and MB medium containing only $10 \mathrm{mg} . \mathrm{L}^{-1} \mathrm{BPA}$ in mineral media were fed alternatively into the column up-flow direction using a peristaltic pump with a flow rate of $\sim 63 \mu \mathrm{L} \cdot \min ^{1}$ (Fig. 3.6).

Columns filled with hybrid Ca-alg/MWCNTs/Psf and Ca-alg/MWCNTs-bacteria/Psf were run in parallel. Aeration was provided by purging the feed bottle with sterile air. Aliquots of $1.5 \mathrm{ml}$ were collected from the outlet at different intervals at an ambient condition of $22^{\circ} \mathrm{C}$. Mineral media with $0.05 \%$ yeast extract (MY) was used in the regeneration study. 


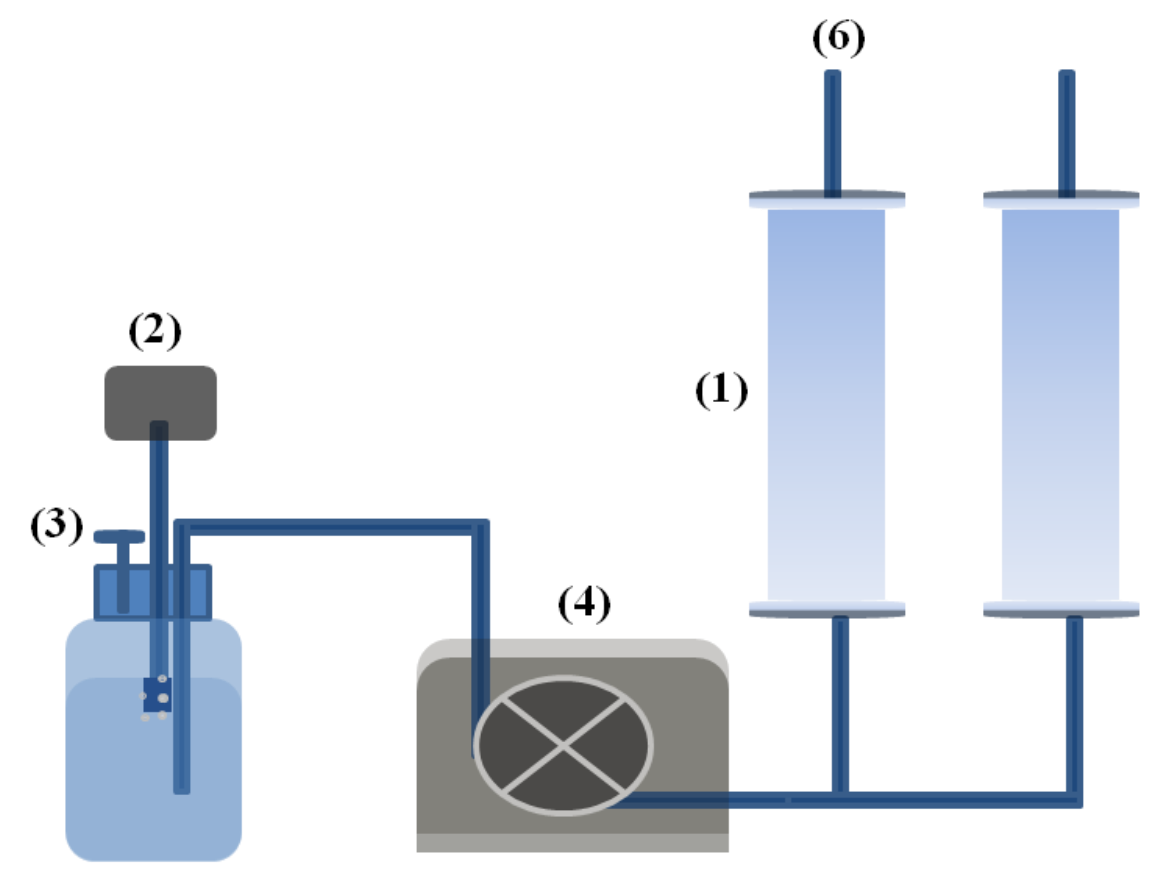

(5)

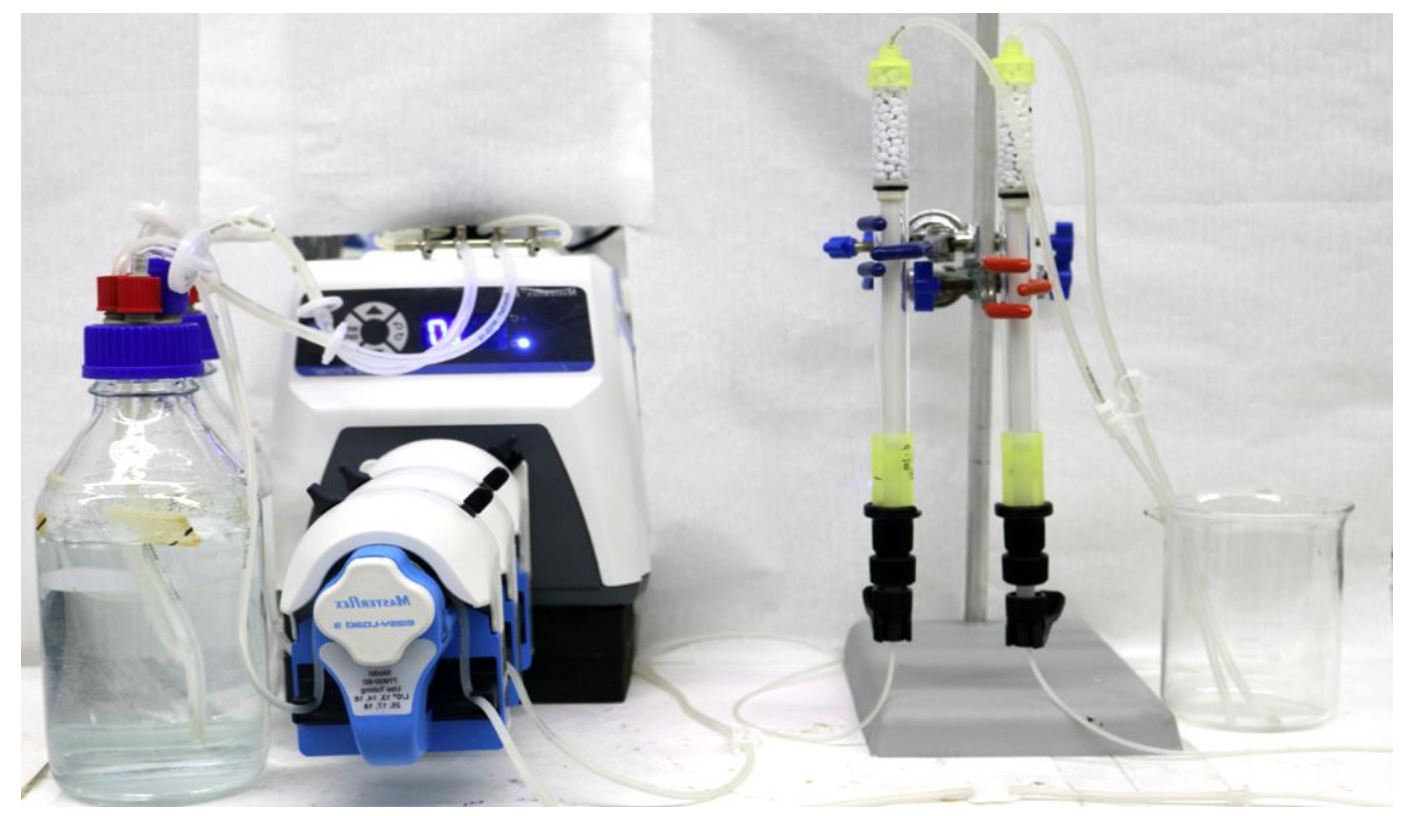

Fig. 3.6 Illustration on the set-up of the column study: (1) columns filled with hybrid beads with and without bacteria addition; (2) sterile air purging; (3) filter; (4) peristaltic pump; (5) feed and (6) outlets (Illustration by author) 


\subsection{Overview of Experiment Methodology}

In summary, adsorbent materials, namely bamboo fiber powder and CNMs were prepared as potential BPA adsorbents.

A bioluminescence assay using a genetically modified E.coli DPD2511 strain was adapted from a previous method to be used for detection of CNTs. Based on its induction response with positive control, it was observed that a shorter incubation time and luminescence monitoring at an ambient temperature optimized the luminescence production. A cell viability assay was performed to count the number of viable colonyforming bacteria. A UV-Vis spectrophotometer and HPLC were used mainly for the detection of any BPA concentration remaining in the solution. An Instron microtester was used to test the mechanical strength of the bead. SEM and a BET surface area analyzer were used for physical characterization of the bead and in determining its surface area after modification with different MWCNT loading. FTIR and a Zeta-potential analyzer were used for characterization of the surface charges under different $\mathrm{pH}$.

The hybrid bead fabrication method was adapted from a previous encapsulation method developed by our group ${ }^{11}$, whereas the batch and column-scale adsorption studies were performed according to accepted guidelines ${ }^{13}$. For BPA biodegradation experiments, the media recipes were generally based on relevant studies ${ }^{15,16}$ and modified by the addition of $0.05 \%$ yeast extract in order to improve the degradation performance of the isolated strain. 


\section{References}

1 Dehghani, M. H. et al. Adsorption of bisphenol A (BPA) from aqueous solutions by carbon nanotubes: kinetic and equilibrium studies. Desalination and Water Treatment 54, 84-92 (2015).

2 Eltzov, E., Ben-Yosef, D. Z., Kushmaro, A. \& Marks, R. Detection of subinhibitory antibiotic concentrations via luminescent sensing bacteria and prediction of their mode of action. Sensors and Actuators B: Chemical 129, 685692 (2008).

3 Li, F. et al. Analysis of copper nanoparticles toxicity based on a stress-responsive bacterial biosensor array. Nanoscale 5, 653-662, doi:10.1039/c2nr32156d (2013).

4 Olivi, M. et al. Inhibition of microbial growth by carbon nanotube networks. Nanoscale 5, 9023-9029 (2013).

5 Van Dyk, T. K. et al. Rapid and sensitive pollutant detection by induction of heat shock gene-bioluminescence gene fusions. Applied and Environmental Microbiology 60, 1414-1420 (1994).

6 Kang, J.-H., Aasi, D. \& Katayama, Y. Bisphenol A in the aquatic environment and its endocrine-disruptive effects on aquatic organisms. Critical Reviews in Toxicology 37, 607-625 (2007).

7 Kang, J.-H. \& Kondo, F. Bisphenol A degradation in seawater is different from that in river water. Chemosphere 60, 1288-1292 (2005).

8 Zhang, C. et al. Aerobic degradation of bisphenol A by Achromobacter xylosoxidans strain B-16 isolated from compost leachate of municipal solid waste. Chemosphere 68, 181-190 (2007).

9 Chee Kimling, M., Scales, N., Hanley, T. L. \& Caruso, R. A. Uranyl-sorption properties of amorphous and crystalline $\mathrm{TiO}_{2} / \mathrm{ZrO}_{2}$ millimeter-sized hierarchically porous beads. Environmental Science \& Technology 46, 7913-7920 (2012).

10 Mao, M. et al. Polysulfone-activated carbon hybrid particles for the removal of BPA. Separation Science and Technology 41, 515-529 (2006).

11 Ben-Dov, E., Kramarsky-Winter, E. \& Kushmaro, A. An in situ method for cultivating microorganisms using a double encapsulation technique. FEMS Microbiology Ecology 68, 363-371 (2009).

12 Loeb, S. \& Sourirajan, S. in Saline Water Conversion II Vol. 38 Advances in Chemistry Ch. 9, 117-132 (American Chemical Society, 1963).

13 Volesky, B. Biosorption and me. Water Research 41, 4017-4029 (2007).

14 Lin, S. et al. Silver nanoparticle-alginate composite beads for point-of-use drinking water disinfection. Water Research 47, 3959-3965 (2013).

15 Lobos, J. H., Leib, T. \& Su, T.-M. Biodegradation of bisphenol A and other bisphenols by a gram-negative aerobic bacterium. Applied and Environmental Microbiology 58, 1823-1831 (1992).

16 Sheeja, R. \& Murugesan, T. Mass transfer studies on the biodegradation of phenols in up-flow packed bed reactors. Journal of Hazardous Materials 89, 287301 (2002). 


\section{Chapter 4}

\section{Characterization and BPA Removal Performance by Bamboo Fiber Powder}

In this chapter, the application of $B P$ as an alternative biosorbent for sorption of BPA was investigated. The raw BP was pre-treated with alkali, ionic and non-ionic surfactants. The best improvement in BPA removal efficiency, with up to $3 x$ higher removal, was obtained after treatment using cationic surfactant. The effects of contact time, sorbent dosage and particle

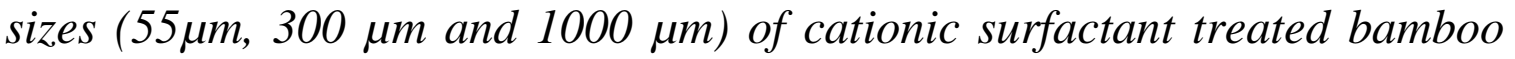
fiber powders for the removal of bisphenol A were further assessed in a batch system with an optimum removal observed for a $55 \mu$ m particle size.

*M.R. Hartono, A. Assaf, G. Thouand, A. Kushmaro, R.S. Marks and X. Chen; Use of Bamboo Powder Waste for Removal of Bisphenol A in Aqueous Solution; Water, Air, \& Soil Pollution 226 (2015):1-11 Reproduced for dissertation with permission from Springer $\bigodot 2015$ 


\subsection{Introduction}

The limitations presented by $\mathrm{AC}$ as a sorbent ${ }^{1}$ have fuelled research efforts in the exploration of alternative materials for the removal of organic aromatic pollutants ${ }^{2-10}$. Among the many types of emerging sorbent materials currently being developed, the utilization of a biosorbent originating from waste products is an attractive option because of the relatively low capital investment as well as its versatility and abundance ${ }^{11}$. Most of the research done on the utilization of waste products as sorbent materials has focused on their conversion to $\mathrm{AC}$, but little has been done with respect to their direct usage as biosorbents. This is expected, as biosorbents have inferior adsorptive capability in pure form, which often necessitates physical or chemical pre-processing prior to their employment as sorbent materials ${ }^{12,13}$.

Prior studies utilizing agricultural wastes have reported improved BPA adsorption after chemical treatment using concentrated sulphuric acid at an adsorption capacity of about $\sim 4 \mathrm{mg} \cdot \mathrm{g}^{-114}$. Another study involves modification of peat waste with a reported BPA sorption capacity of $31.40 \mathrm{mg} \cdot \mathrm{g}^{-115}$.

Diverse species of bamboo forest are ubiquitous in Asia-Pacific regions ${ }^{16}$ and hold important roles in achieving sustainability in economic, ecological and social platforms. Many industries employ bamboo as manufacturing or construction materials, which contribute to the large amounts of bamboo waste in the region. Research has been done in the application of bamboo-derived material in its pure form as a biosorbent for removal of heavy metals ${ }^{17-20}$. A common strategy in these studies is the utilization of electrostatic attraction between the negatively charged surface of a bamboo sorbent (optimized further through the adjustment of $\mathrm{pH}$ ) with the positively charged metal ions. However, few studies have been conducted on the use of bamboo-based materials for the elimination of aromatic organic pollutants such as $\mathrm{BPA}^{21}$.

Bamboo fiber powders (BPs) are a common byproduct of the construction industrymainly from the slicing and sanding of bamboo poles. BPs are treated as waste and are 
generally discharged without further processing. In this work, the potential use of BPs as as a biosorbent for the removal of BPA was evaluated. Previously, surfactant-treated biomass sorbents were reported to demonstrate higher sorption capacity towards heavy metals ${ }^{19,22}$. In this work, a comparison study on the effects of chemical modification of BPs with different types of surfactants, alkali and acid solutions was conducted with the goal being improved sorption capacity. The treated BPs were characterized by means of BET, FTIR-PCA and Zeta-potential analysis. The treatment generating the best enhancement in sorption capacity was chosen and investigated in a batch reactor. Their adsorption isotherm profile at different particle sizes was evaluated.

\subsection{Experimental}

This section provides additional details relevant to this study, which were not covered in Chapter 3 - experimental methodology

\subsubsection{Methods}

\section{Preparation of bamboo fiber sorbents}

The procedure for pre-treatment of bamboo fiber powder has been described in section

\subsubsection{1.}

\section{$B P A$ removal experiments}

The BPA removal experiments were performed in a batch reactor according to the procedures outlined in section 3.3.2.1. Bamboo fiber powder was added into BPA solutions of known concentrations in glass containers. The containers were agitated at $150 \mathrm{rpm}$ at $30^{\circ} \mathrm{C}$ with an incubator shaker. The experiments were performed independently and in duplicate with the mean value of the readings presented on the graphs. 


\subsubsection{Analytical Methods}

\section{Zeta potential measurements}

Zeta potential measurements were performed using Malvern Zetasizer Nano ZS. A 1.0 g. $\mathrm{L}^{-1}$ dosage of BP particles was added into tubes containing distilled water. The $\mathrm{pH}$ of the solution was adjusted using $0.1 \mathrm{~N} \mathrm{HCl}$, and $0.1 \mathrm{~N} \mathrm{NaOH}$. $750 \mu \mathrm{L}$ of the sample was placed into the capillary cell and run $5 \mathrm{x}$ with 10 measurements for each run.

\section{FTIR measurements}

FTIR (Perkin Elmer Spectrum) was operated within the transmission spectra of 4000-400 $\mathrm{cm}^{-1}$ at a resolution of $4 \mathrm{~cm}^{-1}$ and each sample scanned 60x. To prepare the pellet, $2.0 \mathrm{mg}$ of each BP sample was mixed with $400 \mathrm{mg}$ of potassium bromide powder. Triplicate pellets were prepared per sample.

Principal component analysis (PCA), a chemometric method for handling multi-variable data sets, enables the grouping of multiple variables into principal components, which portray the variability of the data $\operatorname{sets}^{23}$. Application of PCA on FTIR spectrum will facilitate discrimination of interchangeable spectra from multiple data sets as well as classification of the bands responsible for the discrimination. Matlab (v.2012b) and "Saisir package" 24 was used to perform "PCA function" and the analysis of variance (ANOVA) “Anova1 function". Before classification, spectra were centered by subtraction of the mean of each group. The discrimination between spectra was based on PC1 and PC2 scores because these first principal components clarify the majority of variance of the data set. 


\subsection{Results \& Discussions}

\subsubsection{Effect of chemical treatments of bamboo powder on removal of BPA}

The effect of chemical treatments of bamboo powders with different surfactants, acid and alkali for the removal of BPA is also shown in Fig. 4.1. It can be seen that untreated BP is able to remove BPA with an average percentage removal of $13 \pm 0.40 \%$ from an initial BPA solution of $100 \mathrm{mg} . \mathrm{L}^{-1}$. The pre-treatment of bamboo powders has been observed to generally improve BPA removal according to the following order: CTAB-treated bamboo powders $(39 \pm 2.97 \%)>$ SDS-treated bamboo powders $(33 \pm 1.49 \%)>\mathrm{NaOH}$-treated bamboo powders $(29 \pm 0.78 \%) \approx \mathrm{TX}-100$ treated bamboo powders $(28 \pm 2.23 \%)>\mathrm{HCl}$ treated bamboo powders $(15 \pm 0.40 \%)>$ untreated bamboo powders $(13 \pm 0.40 \%)$. Based on the result in the preliminary batch experiment, the CTAB-treated bamboo powder (CBPs) showed the highest improvement in BPA removal and was selected for subsequent adsorption experiments.

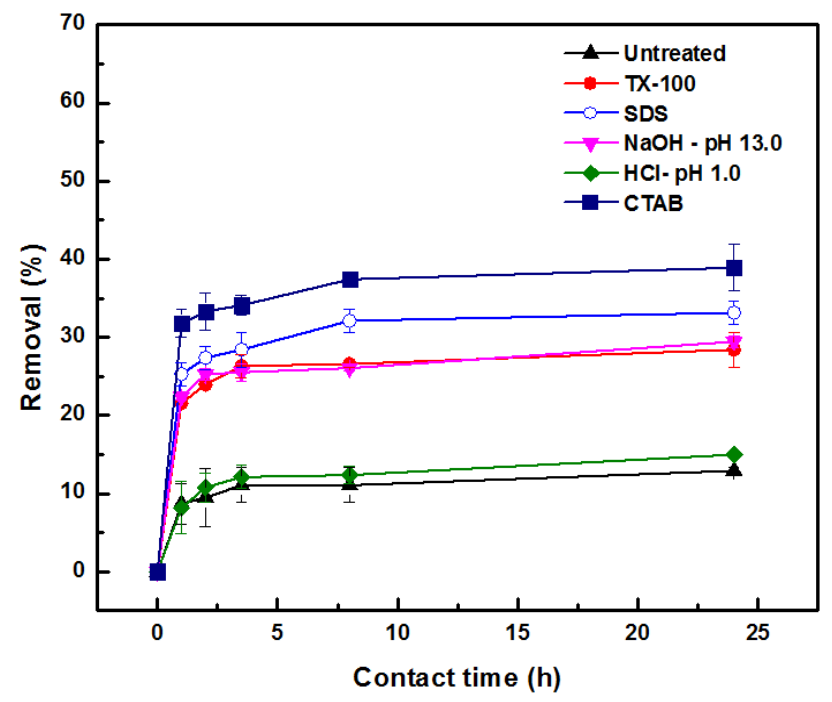

Fig. 4.1 Removal of BPA by chemically treated bamboo powders. (BPA concentration $=100$ $\mathrm{mg} . \mathrm{L}^{-1} ; \mathrm{pH}=6.0$, adsorbent dosage $=4 \mathrm{~g} . \mathrm{L}^{-1}$, particle size $=300 \mu \mathrm{m}$, error bars represent standard deviation)

\subsubsection{Effect of bamboo powders dosage in BPA removal}

The adsorption profile of BPA at different CBP dosages of 2, 4, 8, 15 and 30 g.L $\mathrm{L}^{-1}$ is shown in Fig. 4.2. It is apparent that the percentage of BPA removal increased with the 
increase in CBP dose. This pattern can be attributed to the increase in surface area and availability of active sites for adsorption with the increase in adsorbent dose $\mathrm{e}^{25}$.

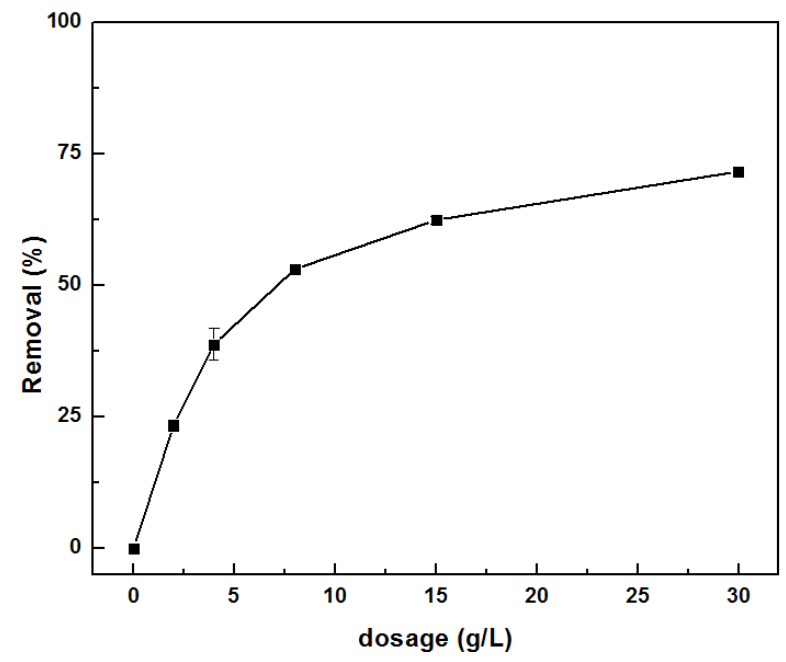

Fig. 4.2 Effect of CBP dosage on removal of BPA (BPA concentration $=100 \mathrm{mg} \cdot \mathrm{L}^{-1} ; \mathrm{pH}=6.0$, particle size $=300 \mu \mathrm{m}$, error bars represent standard deviation)

\subsubsection{Sorption isotherm at different particle size}

The isotherm result of BPA adsorption in an aqueous solution onto CBPs is shown in Fig. 4.3. It can be deduced that the adsorbed amount of BPA per $g$ of CBPs at equilibrium is in proportional relationship with the residual BPA concentration in the solution for the particle sizes tested with reasonable linearity over the range of tested concentrations. In this study, the linear and Freundlich adsorption isotherm models were used to provide a quantitative evaluation of the system. 


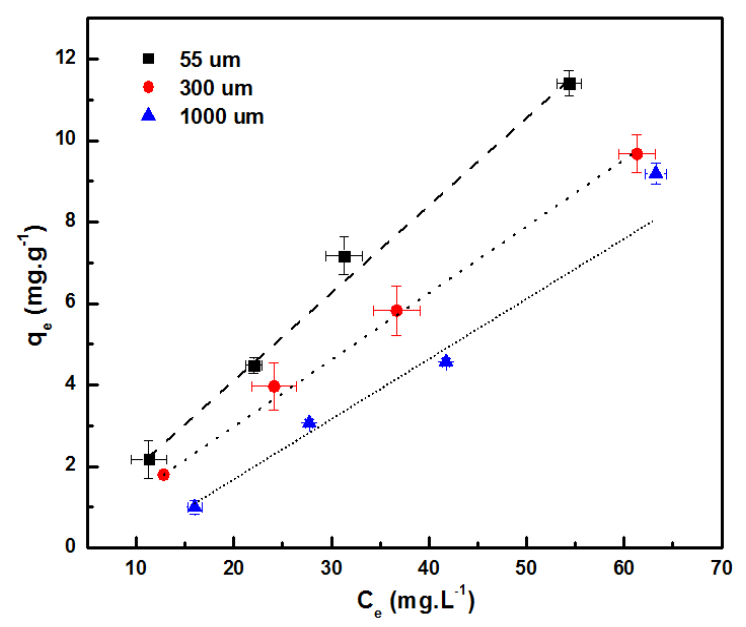

Fig. 4.3 Sorption isotherm of BPA on the CTAB treated bamboo powder at equilibrium (BPA concentrations $=20-100 \mathrm{mg} \cdot \mathrm{L}^{-1} ; \mathrm{pH}=6.0$, contact time $=24 \mathrm{~h}$, adsorbent dosage $=4 \mathrm{~g} \cdot \mathrm{L}^{-1}$, particle sizes $=55 \mu \mathrm{m}, 300 \mu \mathrm{m}$, and $1000 \mu \mathrm{m}$, error bars represent standard deviation)

Table 4.1 Parameters of linear and Freundlich isotherm models

\begin{tabular}{lllllll}
\hline $\begin{array}{l}\text { Particle size of } \\
\text { CBPs }\end{array}$ & \multicolumn{2}{c}{ Linear } & & \multicolumn{3}{c}{ Freundlich } \\
\cline { 2 - 3 } \cline { 6 - 7 } & $\mathbf{K}_{\mathbf{d}}\left(\mathbf{L} \cdot \mathbf{g}^{-1}\right)$ & $\mathbf{r}^{2}$ & & $\mathbf{K}_{\mathbf{F}}\left(\mathbf{m g}^{1-1 / \mathbf{n}} \mathbf{g}^{-1} \cdot \mathbf{L}^{1 / \mathbf{n}}\right)$ & $\mathbf{l} / \mathbf{n}$ & $\mathbf{r}^{2}$ \\
$55 \mu \mathrm{m}$ & 0.206 & 0.991 & & 0.164 & 1.073 & 0.994 \\
$300 \mu \mathrm{m}$ & 0.158 & 0.998 & & 0.123 & 1.069 & 0.995 \\
$1000 \mu \mathrm{m}$ & 0.129 & 0.914 & & 0.014 & 1.569 & 0.984 \\
\hline
\end{tabular}

The data from the adsorption isotherm study (as shown in Fig. 4.3 and Table 4.1) follow both the linear and Freundlich models with correlation coefficient values above 0.910. High correlation with the Freundlich model suggests that the neutral BPA molecules were adsorbed on the surface of the CBPs in this system in multi-layered fashion. It was observed that the $\mathrm{K}_{\mathrm{F}}$ values indicate that the adsorption capacity declined at bigger particle sizes. It is expected that higher BPA removal can be attained using a smaller particle size due to the higher surface area available for the attachment of surfactant molecules during treatment (and consequently higher BPA retention) such that a smaller particle size of CBPs will exhibit better adsorption capacity. The linearity of the isotherm indicated the role of a hydrophobic partitioning process in the system ${ }^{26}$.

The value of sorption intensity (1/n) from the Freundlich model at $\mathrm{pH} 6.0$ for a particle size of $55 \mu \mathrm{m}$ is close to unity, which further supported the notion of linearity of the 
system. Similar linear behavior has been reported in other sorption systems with natural organic materials (or biosorbents) such as in the case of pentachlorophenol adsorption on pine bark whereby the $1 / \mathrm{n}$ constant value is also close to unity ${ }^{27}$. From the sorption isotherm data attained at equilibrium for different particle sizes at $\mathrm{pH} 6.0$, the value of linear distribution coefficient $\mathrm{K}_{\mathrm{d}}$ for larger particles was lower in comparison to smaller particle size. This poorer sorption performance demonstrated under the same dosage, particles with smaller size will have increased available surface areas for attachment of surfactant (and consequently the available binding sites) to interact with BPA or any other organic compounds.

The maximum sorption capacity of CBPs used in our study was determined based on the sorption at an initial BPA concentration of $100 \mathrm{mg} . \mathrm{L}^{-1}$, which was the highest BPA concentration tested in our study. While direct comparison with the results of previous studies is difficult due to the difference in experimental parameters such as initial concentrations, dosage and temperature, the maximum BPA sorption capacities of CBPs in our study are similar in values to carbonaceous materials reported in the literature ${ }^{12,14,28,29}$. Nevertheless, it should be noted that most of these bio-derived sorbent materials require preparation at high temperatures of $400^{\circ} \mathrm{C}-1000^{\circ} \mathrm{C}$ for carbonization. The exclusion of the need for preparative treatment at high temperature makes our CBPs simpler to prepare in comparison to sorbent derived activated carbon. It is worth noting that previous reports indicate that cationic surfactant modified peat ${ }^{15}$ (another low-cost sorbent) has a high BPA sorption capacity of up to $31.40 \mathrm{mg} \cdot \mathrm{g}^{-1}$. However the concentration of surfactant used during the modification was much higher (0.1 M and 50 $\mathrm{mM}$ ), which in itself may be a potential source of pollution (unlike the one used in our study $(0.9 \mathrm{mM}))$. Moreover, bamboo based sorbents have a demonstrated affinity towards heavy metal pollutants ${ }^{17,18}$. Their ability to be used for the adsorption of a diverse range of pollutant species will enable them to be used in a column reactor for simultaneous removal of multiple pollutants from water. Since bamboo powder waste is abundant and can be easily prepared, the low-cost adsorbent proposed may have application potential for the removal of non-polar aromatic pollutants in developing countries. 


\subsubsection{Proposed mechanism}

Bamboo is a type of lignocellulosic biomass which is composed of a porous structure of hemicelluloses, cellulose and lignin in layered formations ${ }^{30}$. Table 4.2 shows the surface analysis results of bamboo powders before and after treatment. It is known that the physical characteristics of biosorbents differ with the source of plant materials used. In this study, the BET surface area of untreated bamboo fiber powders with $300 \mu \mathrm{m}$ particle size was estimated to be $6.682 \mathrm{~m}^{2} \cdot \mathrm{g}^{-1}$. The measured surface area for untreated bamboo powders is slightly higher than the reported surface area for water-bamboo husk particles with a BET of $1.866 \mathrm{~m}^{2} / \mathrm{g}^{17}$.

Table 4.2 Surface analysis measurements of treated bamboo powders of $300 \mu \mathrm{m}$ particle size

\begin{tabular}{lcccc}
\hline Sample & $\begin{array}{c}\text { BET } \\
\text { surface area } \\
\left(\mathbf{m}^{2} \cdot \mathbf{g}^{-1}\right)\end{array}$ & $\begin{array}{c}\text { Surface } \\
\text { area }\left(\mathbf{m}^{2} \cdot \mathbf{g}^{-1}\right)\end{array}$ & $\begin{array}{c}\text { Pore volume } \\
\left(\mathbf{c m}^{3} \cdot \mathbf{g}^{-1}\right)\end{array}$ & $\begin{array}{c}\text { Pore radius } \\
(\mathbf{n m})\end{array}$ \\
Untreated bamboo powders & 6.682 & 5.330 & 0.014 & 1.866 \\
Triton X-100 treated & 3.010 & 3.021 & 0.013 & 1.862 \\
SDS treated & 6.530 & 5.726 & 0.009 & 1.655 \\
CTAB treated & 25.787 & 21.069 & 0.041 & 1.658 \\
$0.1 \mathrm{~N} \mathrm{NaOH}$ treated & 4.404 & 4.120 & 0.009 & 1.661 \\
$0.1 \mathrm{~N} \mathrm{HCl}$ treated & 7.068 & 5.870 & 0.018 & \\
\hline
\end{tabular}

Surface analysis measurements of pre-treated bamboo powders (Table 4.2) depict a significant increase in surface area for CTAB treated bamboo powders. While it can be deduced that removal of BPA by CTAB treated bamboo powders is enhanced by the higher available adsorption sites in comparison to untreated bamboo fiber powders, the surface area measurements of bamboo powders treated with non-ionic, anionic surfactants and alkali solutions do not differ much in comparison with untreated bamboo powders, suggesting the presence of other factor influencing the adsorption of BPA besides surface area.

The PCA analysis of FTIR spectrums for treated and untreated bamboo powders is shown in Fig. 4.4. The obtained results show that the acid treatment with $\mathrm{HCl}$ does not affect the 
bamboo surfaces (results are similar to untreated surfaces). According to these results, $\mathrm{HCl}$ spectra were eliminated and not used in the statistical methods (PCA and ANOVA).

The plot of PCA scores (PC1 and PC2) in Fig. 4.4(a) shows the presence of 3 distinct groups with $80.2 \%$ variance explained by PC1 scores. Spectra of CTAB and $\mathrm{NaOH}$ treatment are classified in separate groups while spectra of untreated, SDS and Tx-100 treatment were classified in the same. This result indicates that interactions between the reactants and bamboo powders have taken place after pre-treatment of bamboo powders; ANOVA test performed on the first PCA score in Fig. 4.4(b) confirms that CTAB and $\mathrm{NaOH}$ treatments are different from the other treatment. The analysis of the first PCA loading in Fig. 4.4(c) attributes the observed discrimination to 5 bands with strong contribution of the $820 \mathrm{~cm}^{-1}$ and $2910 \mathrm{~cm}^{-1}$ regions, corresponding to the asymmetric $\mathrm{C}-\mathrm{H}$ bending of $\mathrm{CH}_{2}$ group and $\mathrm{CH}_{2}$ stretching and bending, respectively. Taken together with the surface area measurement results, the FTIR analysis supported the notion that BPA removal by treated bamboo fiber powders may be influenced by other factors besides surface area. 
(a)

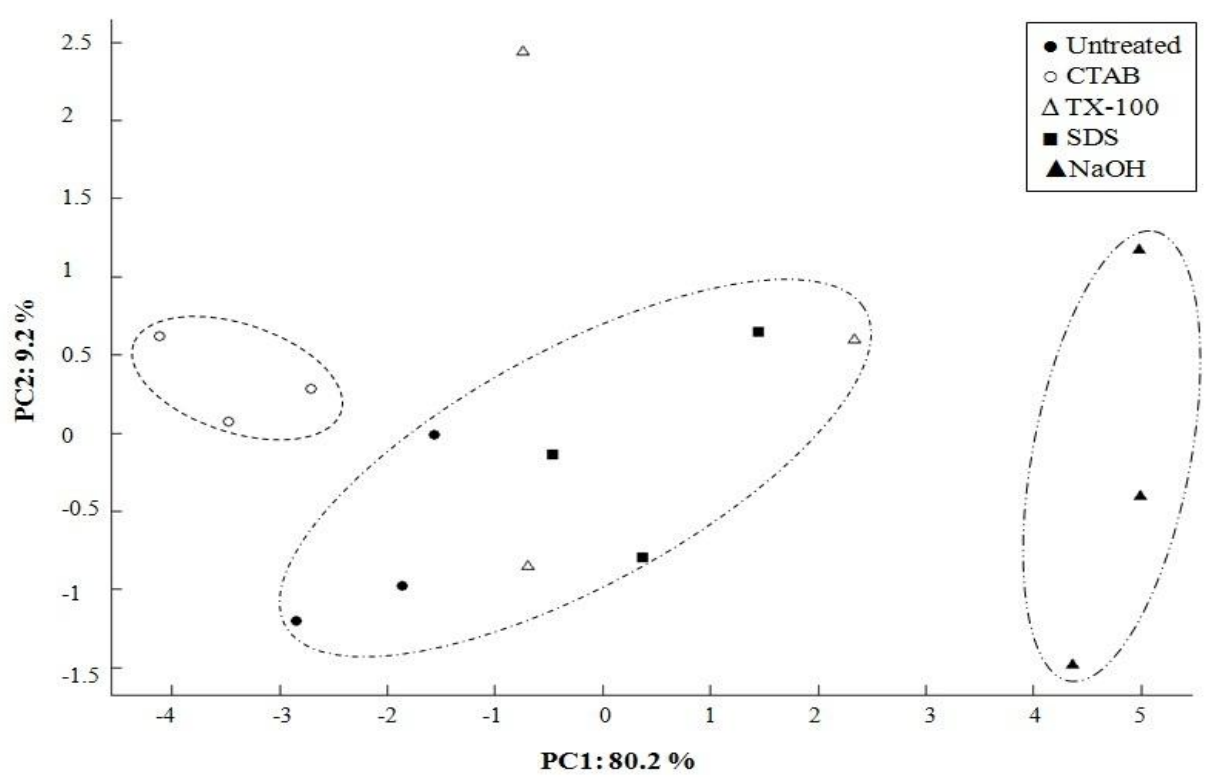

(b)

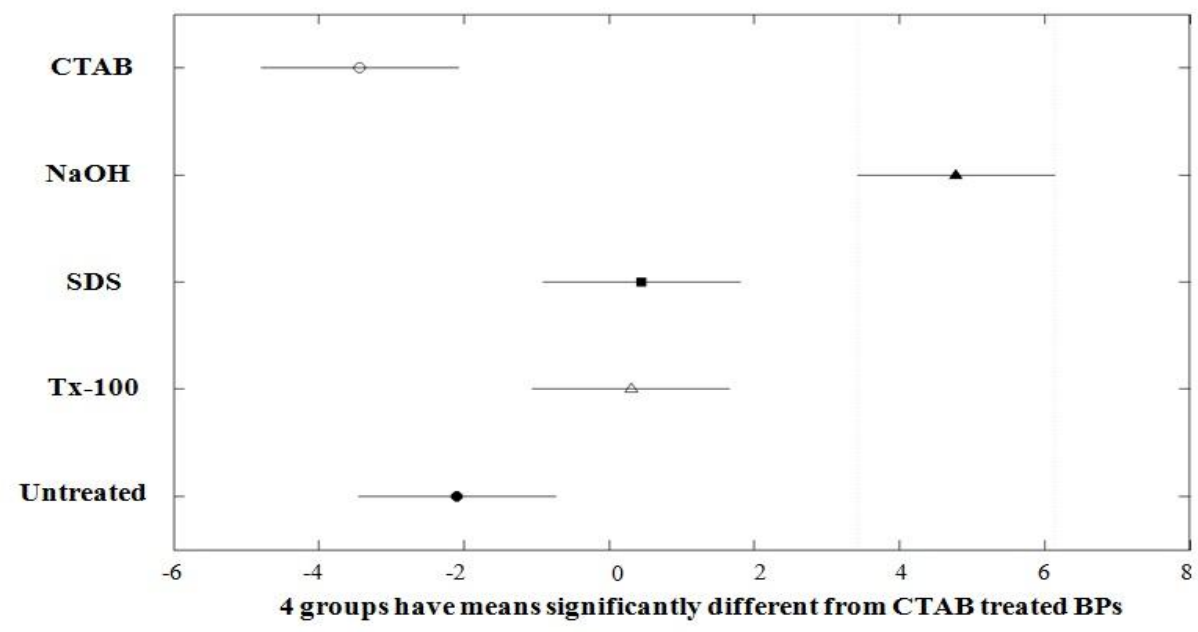

(c)

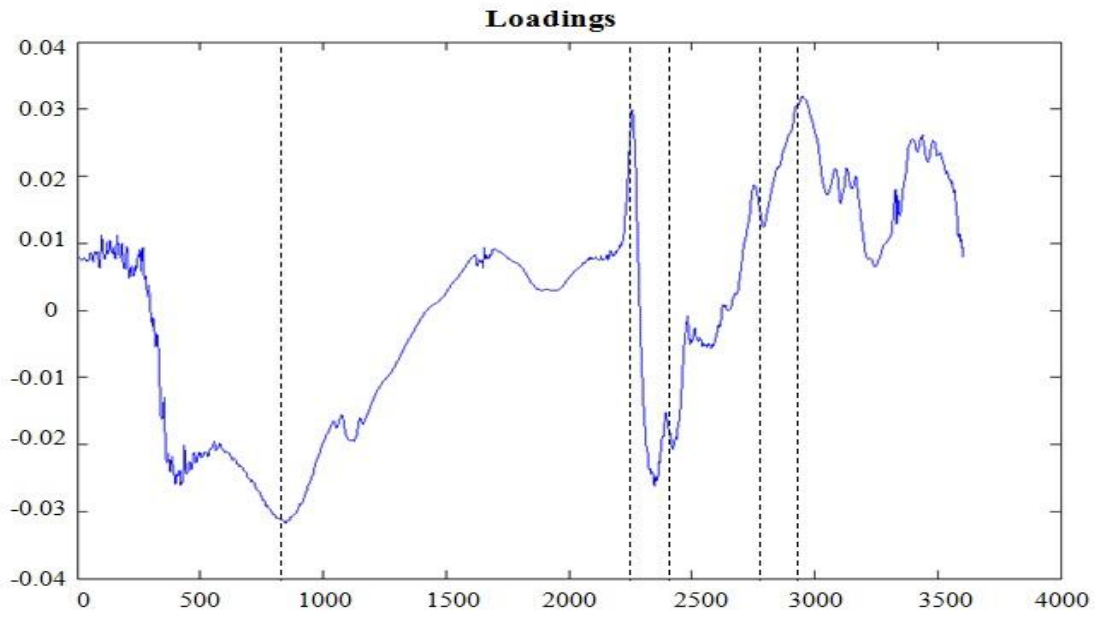

Fig. 4.4 (a) Principal component analysis showing the distribution of spectra, (b) ANOVA showing the distribution of different groups, ANOVA table: $p$-value $=1.77 \times 10^{-5}$ indicating that the samples are statistically different, (c) First loading of PCA scores 


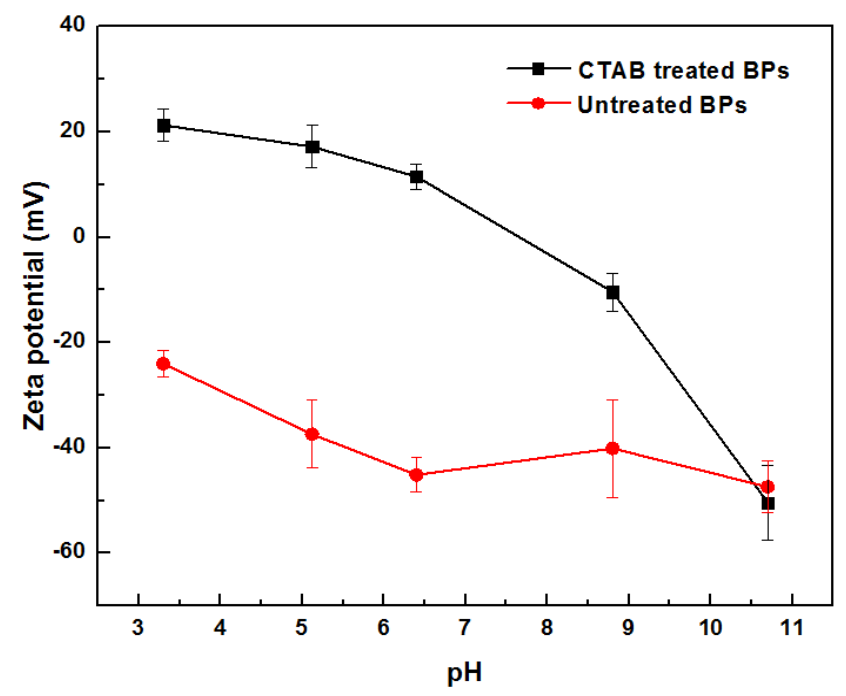

Fig. 4.5 Zeta-potential measurements of untreated and CTAB-treated BPs used in this study (dosage used for measurements: $1 \mathrm{~g} . \mathrm{L}^{-1}$, particle size: $55 \mu \mathrm{m}$ )

Fig. 4.5 shows the Zeta potential measurements of untreated and CTAB treated bamboo fiber powders. It appeared that the surface of untreated bamboo fiber powders is negatively charged within a $\mathrm{pH}$ range of 3-11, while its treatment with CTAB generally resulted in an increase to a more positive surface Zeta potential at a $\mathrm{pH}$ lower than 10.5 , which may be due to the displacement of natural counter-ions on the surface of untreated bamboo powders with cationic head of CTAB.

Inspired by a previous $\operatorname{study}^{10}$ and aforementioned observations, we proposed the possible interactions that occurred during pre-treatment of bamboo fiber powders and their resultant surface modifications after washing in Fig. 4.6(a) and 4.6(b). These surface modifications may have inadvertently contributed to the improvement in BPA removal by the treated bamboo powders. Fig. 4.6(a) depicts the surface of untreated bamboo fiber powders during chemical treatment with cationic surfactant CTAB. The positively charged head of the surfactant was oriented towards the negatively charged surface of bamboo fiber powders due to electrostatic attraction. The lipophilic tail adopted either a perpendicular orientation or became adsorbed on their surface due to hydrophobic interaction with aromatic groups, adopting a flat or tilted orientation. In this experiment, the $\mathrm{pH}$ of the BPA solution was adjusted to 6.0, less than the $\mathrm{pKa}$ of BPA which is reported to be in a $\mathrm{pH}$ range of $9.6-10.2^{31}$ in which case, the BPA will exist in 
its anion form. At a $\mathrm{pH}$ less than its $\mathrm{pKa}$, the BPA molecule presents itself in its neutral form and may act as a moderately hydrophobic organic compound with $\log \mathrm{K}_{\mathrm{ow}}$ of $3.4^{32}$. The increase in BPA removal by pre-treated bamboo fiber powders may be attributed to the loading of surfactants. The surfactants may exist in a monolayer or bilayer form at sufficient concentrations and thus, create a hydrophobic environment. The interaction of the surfactant with BPA is influenced by Van Der Walls and London forces and is supported by a partitioning process of hydrophobic BPA into the organic hydrophobic phase constructed by a lipophilic tail of the surfactant. The two hydrophobic benzene rings in BPA molecules will thus interact with the lipophilic tail of the surfactant and improve the affinity to BPA, which together result in hydrophobic sorption ${ }^{33}$. In addition to the hydrophobic interaction, the neutral form of BPA may interact with the positively charged head of the surfactant due to the presence of oxygen as an electron donor in the phenol group of BPA with a positively charged head of the surfactant acting as electron acceptor.

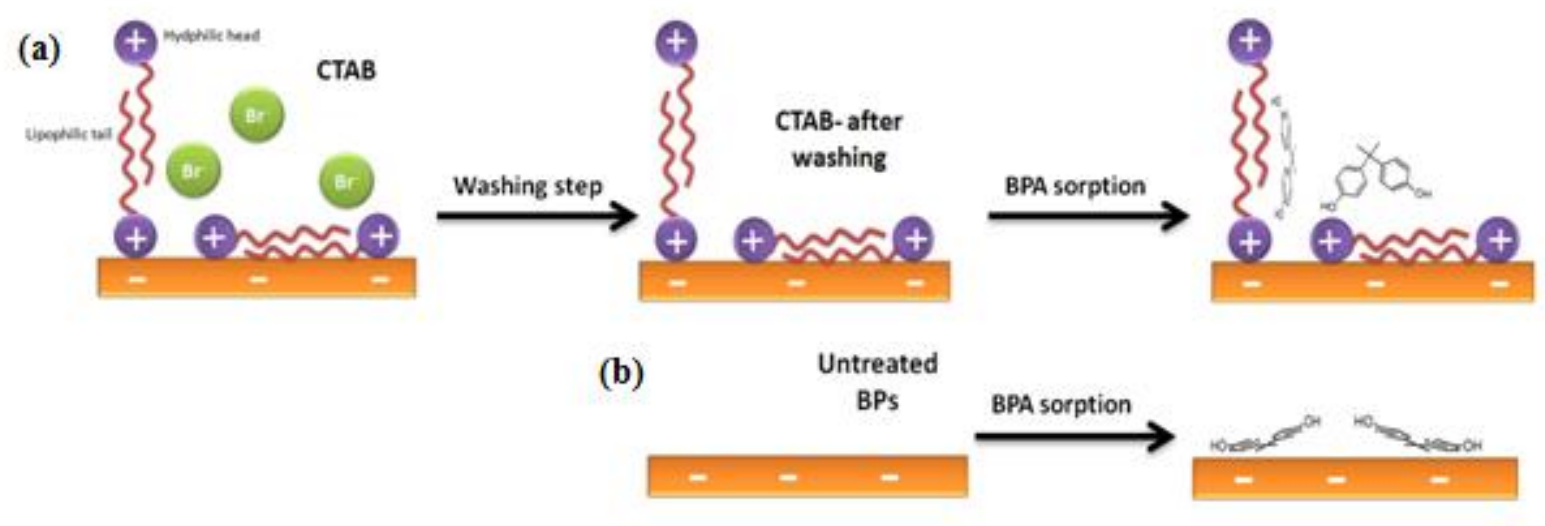

Fig. 4.6 Illustration on the possible interactions involved during the chemical treatment of BPs with (a) Cationic surfactant CTAB and (b) untreated.

In this regard, the highest improvement in BPA removal exhibited by CBPs was postulated as resulting from the presence of both a positively charged cationic head and a lipophilic tail, both of which contribute to BPA retention. The ability of untreated bamboo fiber powders to remove BPA from the solution, as shown in Fig. 4.6(b) may be attributed to the amount of surface area available as adsorption sites in the bamboo 
powders through a pore-filling mechanism and the hydrophobic interaction between aromatic groups in bamboo fiber powders and benzene rings in BPA.

\subsection{Conclusion}

BPs have been assessed as an alternate sorbent for the elimination of aromatic organic pollutant from aqueous solutions. Pre-retreatment with surfactants and alkali solutions were shown to enhance their sorption capacity with the best improvement shown by cationic surfactant-treated BPs. The adsorption process in this system was shown to be both particle-size and dosage dependent and occurs in a multi-layered fashion. The omission of preparative treatment at an elevated temperature (such as in the case of carbonaceous AC) makes preparation of modified BPs simpler.

\subsection{Performance comparison with CNMs}

The comparison of adsorption performance of XGnPs, SWCNTs and MWCNTs with CBPs of BPA are shown in Fig. 4.7. The adsorption capacities and initial sorption rates were predicted based on pseudo-second order kinetic models. In all cases, pseudo equilibrium state was rapidly achieved after $1 \mathrm{~h}$ of agitation. It is evident that despite improvement in BPA removal (in comparison to untreated BPs), CBPs performance was still considered inferior with respect to CNMs. XGnPs possessed the lowest adsorption capacity among the CNMs tested with the high BPA adsorption capacity exhibited by SWCNTs and MWCNTs. 


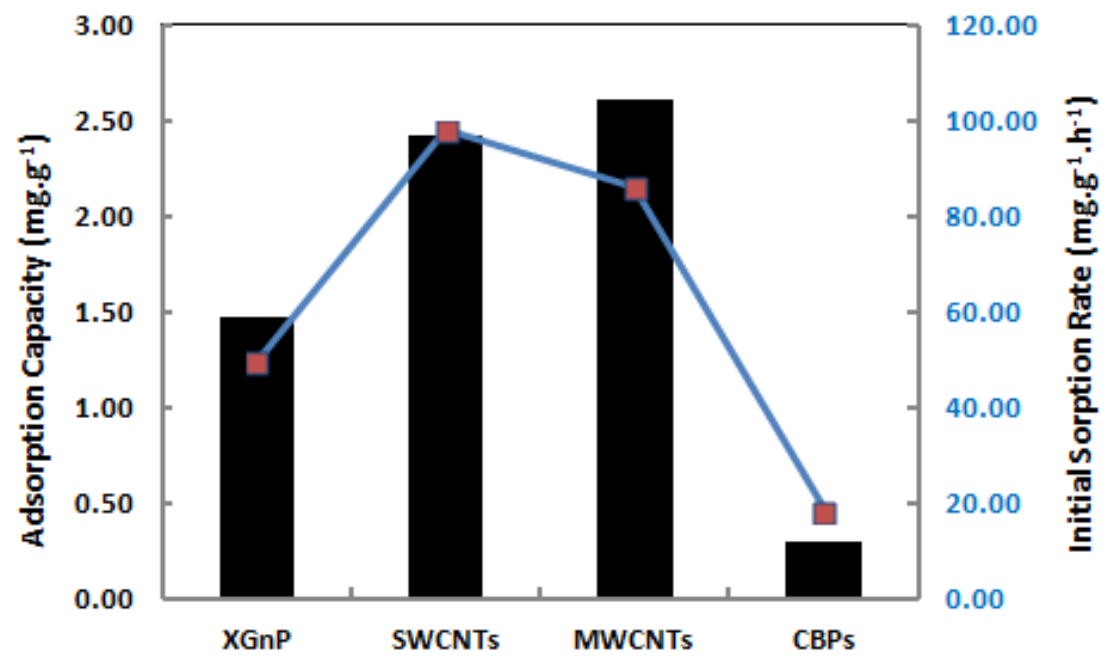

Fig. 4.7 BPA adsorption capacity and initial sorption rate of CBPs and tested CNMs (Dosage = 0.4 g. $\mathrm{L}^{-1}$, BPA concentration of $10 \mathrm{mg} . \mathrm{L}^{-1}$, shaking speed: $150 \mathrm{rpm}$ at $22^{\circ} \mathrm{C}$ and proceeded by 20 s sonication).

Dehghani et al. $^{34}$ highlighted a higher adsorption capacity of BPA by MWCNTs in comparison to SWCNTs, however a differing result was also reported ${ }^{35}$. Based on our observation and taking into consideration the overall high cost of SWCNTs, MWCNTs were selected as potential CNMs to be further evaluated as a sorbent for BPA. Due to their small size however, there is concern regarding their eco-toxicity when released into the environment ${ }^{36}$. This prompts the need for fabrication of an appropriate immobilization compartment in order to minimize their discharge into the effluent.

In this chapter, we evaluated the effect of pre-treatment of low cost bamboo powder fiber waste as a potential biosorbent to remove BPA. Treatment with cationic surfactant (CBPs) was shown to provide the best improvement in comparison to acid, alkali, anionic and non-ionic surfactants. Despite the enhancement, the sorption performance of CBPs was still inferior in comparison to CNMs such as MWCNTs. In the next chapter, MWCNTs are immobilized in calcium-alginate beads as a means to reduce their leakage into effluent and provide ease of handling. 


\section{References}

1 Blocki, S. W. Hydrophobic zeolite adsorbent: A proven advancement in solvent separation technology. Environmental Progress 12, 226-230 (1993).

2 Lin, D. \& Xing, B. Adsorption of phenolic compounds by carbon nanotubes: role of aromaticity and substitution of hydroxyl groups. Environmental Science \& Technology 42, 7254-7259 (2008).

3 Zhao, W., Tang, Y., Xi, J. \& Kong, J. Functionalized graphene sheets with poly(ionic liquid)s and high adsorption capacity of anionic dyes. Applied Surface Science 326, 276-284 (2015).

4 Park, E. Y., Hasan, Z., Khan, N. A. \& Jhung, S. H. Adsorptive removal of bisphenol-a from water with a metal-organic framework, a porous chromiumbenzenedicarboxylate. Journal of Nanoscience and Nanotechnology 13, 27892794 (2013).

5 Qin, F. X., Jia, S. Y., Liu, Y., Li, H. Y. \& Wu, S. H. Adsorptive removal of bisphenol A from aqueous solution using metal-organic frameworks. Desalination and Water Treatment 54, 93-102 (2015).

6 Kim, Y. H., Lee, B., Choo, K. H. \& Choi, S. J. Selective adsorption of bisphenol A by organic-inorganic hybrid mesoporous silicas. Microporous and Mesoporous Materials 138, 184-190 (2011).

7 Fan, X., Tu, B., Ma, H. \& Wang, X. Adsorption behavior of environmental hormone Bisphenol A onto mesoporous silicon dioxide. Bulletin of the Korean Chemical Society 32, 2560-2564 (2011).

8 Wang, Z. M. et al. Matrix-enhanced adsorption removal of trace BPA by controlling the interlayer hydrophobic environment of montmorillonite. Applied Clay Science 104, 81-87 (2015).

9 Tsai, W. T., Hsien, K. J. \& Hsu, H. C. Adsorption of organic compounds from aqueous solution onto the synthesized zeolite. Journal of Hazardous Materials 166, 635-641 (2009).

10 Dong, Y., Wu, D., Chen, X. \& Lin, Y. Adsorption of bisphenol A from water by surfactant-modified zeolite. Journal of colloid and interface science 348, 585-590 (2010).

11 Pollard, S. J. T., Fowler, G. D., Sollars, C. J. \& Perry, R. Low-cost adsorbents for waste and wastewater treatment: a review. Science of The Total Environment 116, 31-52 (1992).

12 Zhou, Y., Lu, P. \& Lu, J. Application of natural biosorbent and modified peat for bisphenol a removal from aqueous solutions. Carbohydrate Polymers 88, 502-508 (2012).

13 Zhao, R.-S. et al. Preconcentration and determination of polybrominated diphenyl ethers in environmental water samples by solid-phase microextraction with $\mathrm{Fe}_{3} \mathrm{O}_{4}$-coated bamboo charcoal fibers prior to gas chromatography-mass spectrometry. Analytica Chimica Acta 769, 65-71 (2013).

14 Lazim, Z. M., Hadibarata, T., Puteh, M. H. \& Yusop, Z. Adsorption characteristics of bisphenol a onto low-cost modified phyto-waste material in aqueous solution. Water Air Soil Pollut 226, 1-11 (2015). 
15 Zhou, Y., Chen, L., Lu, P., Tang, X. \& Lu, J. Removal of bisphenol A from aqueous solution using modified fibric peat as a novel biosorbent. Separation and Purification Technology 81, 184-190 (2011).

16 Bystriakova, N., Kapos, V., Lysenko, I. \& Stapleton, C. M. A. Distribution and conservation status of forest bamboo biodiversity in the Asia-Pacific Region. Biodiversity \& Conservation 12, 1833-1841(2003).

17 Asberry, H. B., Kuo, C.-Y., Gung, C.-H., Conte, E. D. \& Suen, S.-Y. Characterization of water bamboo husk biosorbents and their application in heavy metal ion trapping. Microchemical Journal 113, 59-63 (2014).

18 Hsu, F.-L., Peng, Y. C. \& Lee, H. L. Removal of heavy metal ions from aqueous solutions by bamboo wastes. Taiwan Jornal of Forest Science 24, 159-168 (2009).

19 Mondal, D. K., Nandi, B. K. \& Purkait, M. K. Removal of mercury (II) from aqueous solution using bamboo leaf powder: Equilibrium, thermodynamic and kinetic studies. Journal of Environmental Chemical Engineering 1, 891-898 (2013).

20 Luo, A. K., Luo, X. G. \& Lin, X. Y. The Adsorption of Cd(II) Ions on Sodium Hydroxide-Treated Bamboo Powder. Materials Science Forum 695, 73-76 (2011).

21 Jiang, X. L., Jiang, Y. H. \& Cai, C. G. Study of adsorption process and performance of neutral red dye wastewater by bamboo shoot hulls. Applied Mechanics and Materials 295-298, 1647-1653 (2013).

22 Bai, R. S. \& Abraham, T. E. Studies on enhancement of Cr(VI) biosorption by chemically modified biomass of Rhizopus nigricans. Water Research 36, 12241236 (2002).

23 Jolliffe, I. T. Principal Component Analysis. Second edn, (Springer, 2002).

24 Cordella, C. B. \& Bertrand, D. SAISIR: A new general chemometric toolbox. TrAC Trends in Analytical Chemistry 54, 75-82 (2014).

25 Sari, A. \& Tuzen, M. Removal of mercury(II) from aqueous solution using moss (Drepanocladus revolvens) biomass: Equilibrium, thermodynamic and kinetic studies. Journal of Hazardous Materials 171, 500-507 (2009).

26 Site, A. D. Factors affecting sorption of organic compounds in natural sorbent/water systems and sorption coefficients for selected pollutants. A review. Journal of Physical and Chemical Reference Data 30, 187-439 (2001).

27 Brás, I., Lemos, L., Alves, A. \& Pereira, M. F. R. Sorption of pentachlorophenol on pine bark. Chemosphere 60, 1095-1102 (2005).

28 Nakanishi, A., Tamai, M., Kawasaki, N., Nakamura, T. \& Tanada, S. Adsorption characteristics of bisphenol A onto carbonaceous materials produced from wood chips as organic waste. Journal of colloid and interface science 252, 393-396 (2002).

29 Asada, T. et al. Study of removal effect of bisphenol A and BETA-estradiol by porous carbon. Journal of health science 50, 588-593 (2004).

30 Liese, W. Anatomy and properties of bamboo. Proceedings of the International Bamboo Workshop,Hangzhou, China, 196-208 (1985).

31 Dorn, P. B., Chou, C.-S. \& Gentempo, J. J. Degradation of bisphenol A in natural waters. Chemosphere 16, 1501-1507 (1987). 
32 Munari, S., Bottino, A., Capannelli, G., Moretti, P. \& Petit Bon, P. Preparation and characterization of polysulfone-polyvinylpyrrolidone based membranes. Desalination 70, 265-275 (1988).

33 Choi, J. W., Chung, S. G., Hong, S. W., Kim, D. J. \& Lee, S. H. Development of adsorbent for the simultaneous removal of organic and inorganic contaminants from aqueous solution. Water Science and Technology 64, 1821-1827 (2011).

34 Dehghani, M. H. et al. Adsorption of bisphenol A (BPA) from aqueous solutions by carbon nanotubes: kinetic and equilibrium studies. Desalination and Water Treatment 54, 84-92 (2015).

35 Bohdziewicz, J. \& Kamińska, G. Kinetics and equilibrium of the sorption of bisphenol A by carbon nanotubes from wastewater. Water Science \& Technology 68, 1306-1314 (2013).

36 Smart, S., Cassady, A., Lu, G. \& Martin, D. The biocompatibility of carbon nanotubes. Carbon 44, 1034-1047 (2006). 


\section{Chapter 5}

\section{Characterization and BPA Removal Performance by Ca-alginate/MWCNTs-TiO 2 beads}

In this chapter, the preparation of composite calciumalginate/MWCNTs $/ \mathrm{TiO}_{2}$ beads was discussed. The sorption potential of the composite beads for the removal of bisphenol A was inspected using a fixedbed sorption column, while varying specific parameters such as bed height $(15$ - $20 \mathrm{~cm})$, flow rate $\left(2.0-6.0 \mathrm{~mL} \cdot \mathrm{min}^{-1}\right)$ and inlet bisphenol A concentration $\left(10-30 \mathrm{mg} \cdot \mathrm{L}^{-1}\right)$. The highest sorption capacity of $5.46 \mathrm{mg} \cdot \mathrm{g}^{-1}$ was achieved at $10 \mathrm{mg} . \mathrm{L}^{-1}$ bisphenol A concentration, $2.0 \mathrm{~mL} . \mathrm{min}^{-1}$ flow rate and $20 \mathrm{~cm}$ bed height at saturation. The Adam-Bohart, Yoon-Nelson and dose-response isotherm models were applied to evaluate the performance of the column at different inlet concentrations. The experimental data applied satisfactorily to the dose-response model with a high correlation $r^{2}>0.97$ across the breakthrough curve. The desorbed pollutant degradation from the used adsorbent beads in a desorption solvent after $1.5 \mathrm{~h}$ light irradiation was demonstrated with high regeneration efficiency.

* M.R Hartono, A. Kushmaro, R.S. Marks and X. Chen, "Calcium-Alginate/MWCNTs/TiO 2 composite beads for the removal of bisphenol-A"; Water Science \& Technology (In press, doi:10.2166/wst.2016.354) Reproduced for dissertation with permission from IWA Publishing @2016 


\subsection{Introduction}

Carbon nanomaterials have gained interest due to their superior adsorption performance and better re-usability in comparison to conventional activated carbon ${ }^{1}$. Recently, a higher adsorption capacity of BPA by multi-walled carbon nanotubes (MWCNTs) in comparison to single-walled carbon nanotubes has been reported in a batch study ${ }^{2}$. Despite CNMs' superior adsorption performance, it is important to note that their toxicity effects are still argued ${ }^{3}$. The entrapment of CNMs is, therefore, essential to limit their leakage and further realize their practical application as a sorbent material in wastewater treatment.

Heterogeneous photocatalysts such as $\mathrm{TiO}_{2}$ are able to oxidize and subsequently degrade organic compounds through photocatalysis oxidation (PCO) process ${ }^{4}$. Complete PCO results in the mineralization of the organic pollutant-essentially to $\mathrm{CO}_{2}, \mathrm{H}_{2} \mathrm{O}, \mathrm{NO}_{3}{ }^{-}$, $\mathrm{PO}_{4}{ }^{3-}$ and halide ions ${ }^{5}$. This mineralization capability of titania plays a prominent role in various applications, including removal of noxious organic pollutants in wastewater. In wastewater treatment, titania has been generally applied in suspension form. However, additional processing steps are often required for the reclamation of titania powder after each batch of PCO reaction.

A myriad of studies have focused on the immobilization of sorbent materials to prevent their release into the environment. One of the commonly used materials for this purpose is based on alginate. Alginate is a family of linear biopolymers comprised of 1,4-linked p-D-mannuronic and a-L-guluronic acid residues ${ }^{6}$ which become cross-linked in the presence of divalent ions, resulting in the formation of a hydrogels matrix ${ }^{7}$. Our current study focuses on the entrapment of MWCNTs and $\mathrm{TiO}_{2}$ inside alginate beads as a composite sorbent based on the notion of integrating adsorption and photocatalytic oxidation in the beads form to ease the recovery of the used sorbent.

Most of the adsorption studies involving CNTs reported in the literature were performed in a batch system ${ }^{8}$. However, wastewater treatment plants are operated in continuous 
mode with limited contact time to reach equilibrium in comparison to batch mode ${ }^{9}$. It is, therefore, necessary to assess the capability of a sorbent in continuous flow mode to assess the practical application of CNTs. Although a native form of CNTs has been employed recently in a fixed-bed study ${ }^{10}$, as far as the author knows, studies involving BPA removal in a packed-bed column using hydrogel encapsulated CNTs are still limited $^{11}$. An increase in mechanical strength and stability is achieved through immobilization; it also serves to a certain degree as a barrier to prevent the leakage of CNTs.
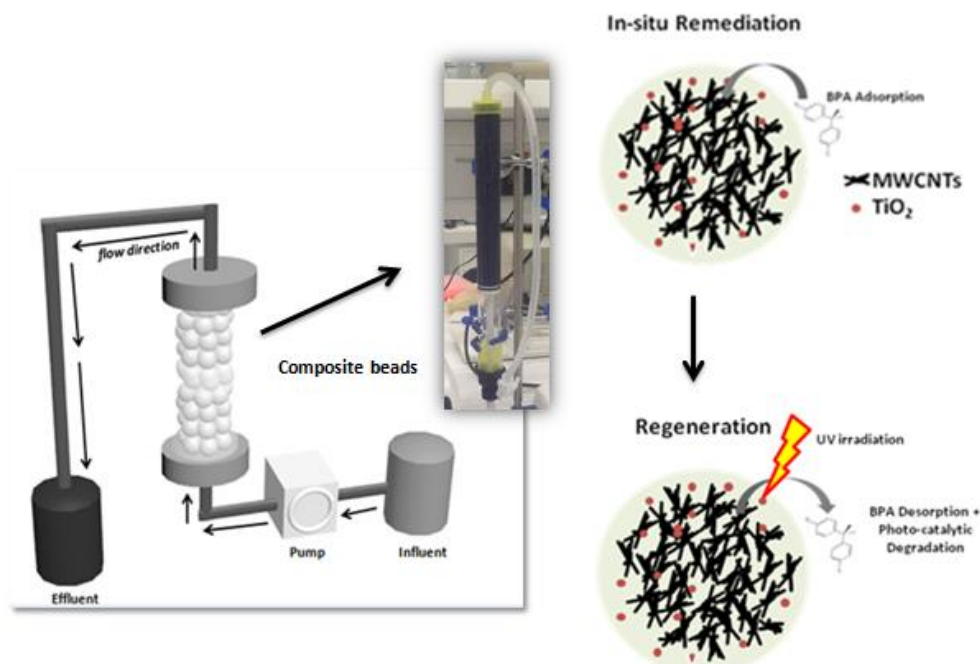

Fig 5.1 Simplified illustration on the pollutant sorption and subsequent regeneration of the spent composite carbon nanotube- $\mathrm{TiO}_{2}$ hydrogel beads (Illustration by author)

The study is divided into two parts. For the first part, we applied the composite MWCNTs/TiO 2 alginate beads in a laboratory-scale fixed-bed column reactor for the treatment of BPA-spiked feed in continuous flow mode. The effect of important parameters such as flow rates, initial feed concentrations and bed heights on BPA removal were evaluated. Further, dynamic sorption analysis using several sorption models frequently used in the design of a fixed-bed system, namely Adam-Bohart ${ }^{12}$, Yoon-Nelson $^{13}$ and dose-response models ${ }^{14-16}$, were performed on the obtained experimental data in order to compare the correlational fit between them and eventually to predict the dynamic behaviors of the column sorption. In the second part of this study, we demonstrated the consequent photolytic BPA removal via a batch reactor. The composite beads were added into a solution of known BPA concentration until it reached 
equilibrium. The used beads were then immersed in a desorption solution and irradiated to induce the degradation of desorbed BPA (Fig. 5.1). The developed composite adsorbent may be beneficial for in situ remediation where a wastewater treatment facility is not readily available. The polluted water could be injected into the column in-situ; the spent beads are capable of being regenerated with simultaneous BPA degradation using light irradiation.

\subsection{Experimental}

This section provides additional details relevant to this study, which were not covered in Chapter 3 - experimental methodology

\subsubsection{Methods}

\section{Preparation of the sorbent beads}

The preparation of composite carbon nanotube-alginate- $\mathrm{TiO}_{2}$ beads was modified from our previous work ${ }^{17}$, the adjustment of sodium alginate and $\mathrm{TiO}_{2}$ weight percentage ratio is described in Appendix A. In brief, $400 \mathrm{mg}$ of P25 powder and $350 \mathrm{mg}$ of MWCNTs were added into $50 \mathrm{ml}$ of $2.5 \mathrm{wt} \%$ sodium alginate solution. The solution mixture was sonicated for 20 mins and stirred overnight. The mixture was dripped using a syringe pump into stirred $0.5 \mathrm{M} \mathrm{CaCl}_{2}$ solution for curing. The resultant beads were then washed twice with distilled water to remove the remaining $\mathrm{CaCl}_{2}$ from the surface of the beads and stored in distilled water prior to application. The average diameter of the beads produced was $2.70 \pm 0.15 \mathrm{~mm}$ with a wet weight to dry weight conversion ratio of $0.093 \mathrm{~g} \cdot \mathrm{g}^{-1}$.

\section{Column study}

The column system was constructed using a glass column of $2.5 \mathrm{~cm}$ internal diameter and $30 \mathrm{~cm}$ length (Biorad, Econo-column 7372532). A flow adapter (Biorad, 7380017) was attached at the bottom of the column and connected to a peristaltic pump (Cole Parmer, Masterflex 07528-30). A BPA solution of pre-specified concentration was injected into

the column at varying flow rates $\left(2.0,4.0\right.$ and $\left.6.0 \mathrm{~mL} \cdot \mathrm{min}^{-1}\right)$ and bed heights $(15,20 \mathrm{~cm})$ 
at an ambient laboratory temperature $\left(22^{\circ} \mathrm{C}\right)$ without any $\mathrm{pH}$ adjustment. For a bed height of $20 \mathrm{~cm}$, porosity of packing was estimated at 0.39 with apparent volume of 98.1 $\mathrm{mL}$ and estimated pore volume of $38.2 \mathrm{~mL}$. Thus for a flow rate of $2 \mathrm{~mL} \cdot \mathrm{min}^{-1}$, the retention time in the column was around $19 \mathrm{~min}$. Aliquots of $1.5 \mathrm{ml}$ were collected from the outlet at predetermined times for analysis of residual BPA concentration. Operation of the column was stopped when the BPA concentration in the effluent reached saturation point, or at least 0.90 of the initial feed concentration.

\section{Photolytic bisphenol A degradation}

A sorbent of 2.0 g. $\mathrm{L}^{-1}$ dosage was added into a BPA solution of known concentration in a glass container and agitated at $120 \mathrm{rpm}$ in ambient condition. Aliquots of the solution were taken to monitor the putative removal of BPA from the aqueous solution over time. BPA adsorption capacity in the batch study was calculated as follows:

$$
q_{e, b a t c h}=\frac{C_{i-} C_{e}}{m} \times V
$$

where $\mathrm{q}_{\mathrm{e}, \text { batch }}\left(\mathrm{mg}_{\mathrm{g}} \mathrm{g}^{-1}\right)$ represents the adsorption capacity of the composite bead sorbent at equilibrium; $\mathrm{C}_{\mathrm{e}}\left(\mathrm{mg} . \mathrm{L}^{-1}\right)$ represents the concentration of BPA in the solution at equilibrium and $\mathrm{V}(\mathrm{L})$ is the volume of the solution in the batch experiment. To ensure that the adsorption equilibrium was reached, the beads were immersed in the BPA solution for at least $8 \mathrm{~h}$. Desorption was conducted by immersing the exhausted beads in ethanol for at least $5 \mathrm{~h}$ to allow optimum BPA desorption from the beads. Irradiations were conducted afterwards using a Xenon light source (Asahi Spectra, Horiba MAX-303) without filter.

\subsection{Results \& Discussions}

\subsubsection{Influence of design parameters on bisphenol A removal}

\section{Effect of flow rate}

The effect of flow rate on the removal of BPA in a fixed-bed sorption column was studied by injecting the column with the influent feed flow of $2.0-6.0 \mathrm{~mL} \cdot \mathrm{min}^{-1}(0.12-$ $0.36 \mathrm{~L}^{-\mathrm{h}^{-1}}$ ) at a constant BPA concentration of $10 \mathrm{mg} . \mathrm{L}^{-1}$ and bed height of $20 \mathrm{~cm}$. It was apparent that BPA sorption was significantly affected by the flow rate. As shown in Fig. 
5.2(a), based on experimental observation, the $50 \%$ breakthrough times were estimated at $8 \mathrm{~h}, 1 \mathrm{~h}$ and less than $0.5 \mathrm{~h}$ for $2.0,4.0$ and $6.0 \mathrm{~mL} \cdot \mathrm{min}^{-1}$ flow rates, respectively. In accordance, the exhaustion of the column occurred faster at a higher flow rate with $90 \%$ breakthrough times estimated at $90 \mathrm{~h}, 22 \mathrm{~h}$ and $6 \mathrm{~h}$ for 2.0, 4.0 and $6.0 \mathrm{~mL} \cdot \mathrm{min}^{-1}$ flow rates. The sorption capacity of the composite beads decreased from $5.46 \mathrm{mg}^{-\mathrm{g}^{-1}}$ at 2.0 $\mathrm{mL} \cdot \mathrm{min}^{-1}$ flow rate to $2.91 \mathrm{mg} . \mathrm{g}^{-1}$ and $2.04 \mathrm{mg} . \mathrm{g}^{-1}$ at 4.0 and $6.02 \mathrm{~mL} \cdot \mathrm{min}^{-1}$ flow rates, respectively. It is evident that saturation of the column occurred more rapidly with a higher flow rate. At a higher flow rate, the mass transfer rate increased with shorter contact time, which led to faster saturation of the column ${ }^{18}$ and decreased sorption capacity, while longer contact time with the sorbent was achieved at a lower flow rate, which facilitated a higher removal of BPA. The lowest flow rate of $2.0 \mathrm{~mL} \cdot \mathrm{min}^{-1}$ was, therefore, chosen for the next experiments.

\section{Effect of bed height}

The influence of bed height or the amount of composite sorbent used on BPA removal over time was tested at a height of $15 \mathrm{~cm}$ (5.65 g dry weight) and $20 \mathrm{~cm}$ (7.46 g dry weight) at an initial influent BPA concentration of $10 \mathrm{mg} . \mathrm{L}^{-1}$ under a constant feed flow rate of $2.0 \mathrm{~mL} \cdot \mathrm{min}^{-1}\left(0.12 \mathrm{~L}^{-1} \mathrm{~h}^{-1}\right.$. The results are shown in Fig. 5.2(b). The breakthrough curves suggest that a lower bed height resulted in much less BPA removal and a rapid exhaustion of the column due to shorter contact time with the composite sorbent. Increases in the dosage of the composite beads with a higher bed depth resulted in an increase of surface area available as binding sites for attachment of the pollutant ${ }^{19}$. In our study, the $90 \%$ breakthrough time for a $15 \mathrm{~cm}$ bed height was reached after only $7.5 \mathrm{~h}$ of column operation time in comparison to $90 \mathrm{~h}$ for a $20 \mathrm{~cm}$ bed height. The sorption capacity of the composite beads significantly increased from $0.55 \mathrm{mg} \cdot \mathrm{g}^{-1}$ for a $15 \mathrm{~cm}$ bed height to $5.46 \mathrm{mg} . \mathrm{g}^{-1}$ for $20 \mathrm{~cm}$ bed height. Based on the results, it was apparent that a lower feed flow rate and a higher bed height are favorable for extending the operation time of the column. 
(a)

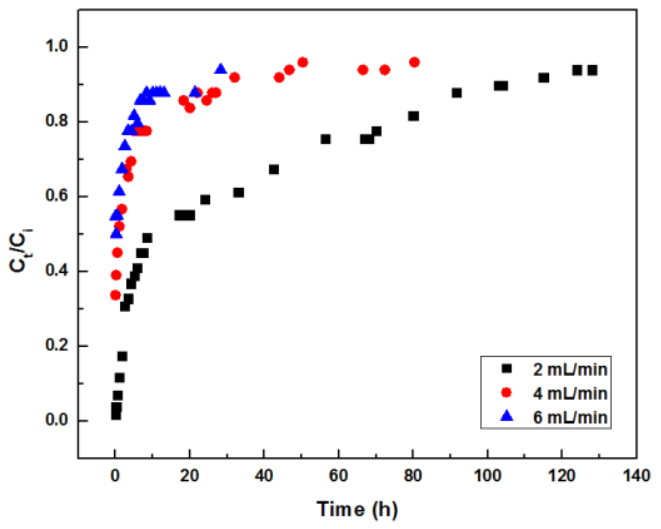

(b)

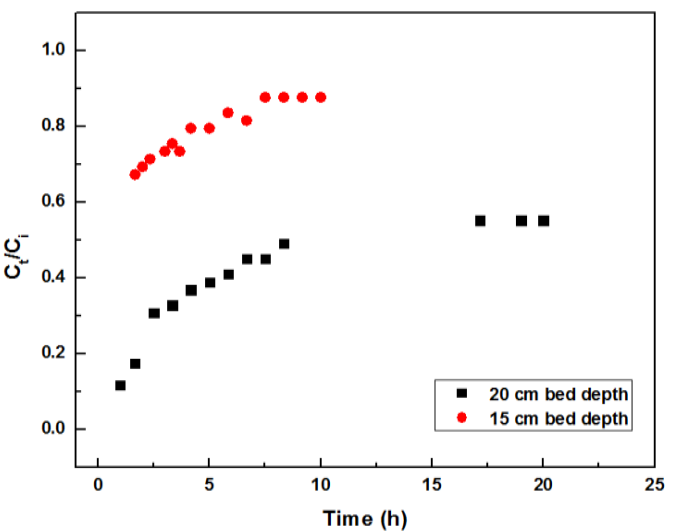

Fig. 5.2 BPA sorption curves by the column under different (a) flow rates and (b) bed depths

\section{Effect of bisphenol A concentration}

The influence of initial BPA concentrations on the performance of the column was assessed by varying inlet concentrations from $10-30 \mathrm{mg} \cdot \mathrm{L}^{-1}$ at a fixed-bed height of 20 $\mathrm{cm}$ and flow rate of $2.0 \mathrm{~mL} \cdot \mathrm{min}^{-1}$. The experimental setting used in this study and calculated sorption parameters are listed in Table 5.1(a) and Table 5.1(b).

Table 5.1(a) Experimental setting in the breakthrough study

\begin{tabular}{ll}
\hline Column diameter & $0.025 \mathrm{~m}$ \\
Column length & $0.20 \mathrm{~m}$ \\
Adsorbent weight (dry) & $7.45 \mathrm{~g}$ \\
Average beads diameter & $2.7 \times 10^{-3} \mathrm{~m}$ \\
Inlet flow rate & $0.12 \mathrm{~L} \cdot \mathrm{h}^{-1}$ \\
& $\left(2.0 \mathrm{~mL} \cdot \mathrm{min}^{-1}\right)$ \\
Temperature & ambient $\left(22^{\circ} \mathrm{C}\right)$ \\
\hline
\end{tabular}

For each concentration, the column was run until it reached saturation. It should be noted that the percentage of BPA removal after 1 bed volume at $10 \mathrm{mg} . \mathrm{L}^{-1}$ initial BPA concentration was only $98 \%\left(C_{t} / C_{i}=0.02\right)$, which decreased to $90 \%\left(C_{t} / C_{i}=0.1\right)$ after 1 $\mathrm{h}$ of operation. According to experimental observations (as shown in Fig. 5.3(a)), the 50\% breakthrough time for $10 \mathrm{mg} . \mathrm{L}^{-1}, 20 \mathrm{mg} . \mathrm{L}^{-1}$ and $30 \mathrm{mg} . \mathrm{L}^{-1}$ inlet BPA concentrations was estimated to be $8 \mathrm{~h}, 7 \mathrm{~h}$ and $5 \mathrm{~h}$, respectively. The $90 \%$ breakthrough time was estimated 
at $90 \mathrm{~h}, 50 \mathrm{~h}$ and $33 \mathrm{~h}$ for $10 \mathrm{mg} . \mathrm{L}^{-1}, 20 \mathrm{mg} . \mathrm{L}^{-1}$ and $30 \mathrm{mg} \cdot \mathrm{L}^{-1}$ inlet BPA concentrations. The adsorption capacity was estimated at $5.46 \mathrm{mg} . \mathrm{g}^{-1}, 5.20 \mathrm{mg} \cdot \mathrm{g}^{-1}$ and $4.74 \mathrm{mg} . \mathrm{g}^{-1}$ for 10 mg.L. $\mathrm{L}^{-1}, 20 \mathrm{mg} . \mathrm{L}^{-1}$ and $30 \mathrm{mg} . \mathrm{L}^{-1}$ inlet BPA concentrations with similar totals of adsorbed BPA, $\mathrm{q}_{\text {total }}$, across the different inlet concentrations tested. A steeper slope of breakthrough curve was evident with an increase in inlet concentration, suggesting that concentration gradient affects the saturation time of the column. The decline in the breakthrough time, adsorption capacity and percentage of BPA removal in the column may be attributed to the increased diffusion rate due to the enhanced concentration gradient introduced by the higher inlet concentration, which subsequently resulted in the rapid saturation of the available binding sites ${ }^{20}$. Similar results have been observed in other fixed-bed systems before ${ }^{19}$. The adsorption capacity obtained in this study is higher in comparison to previous fixed-bed studies for BPA removal using modified sericite ${ }^{21}$, but it is lower than its adsorption capacity in a batch reactor ${ }^{17}$ (Appendix), which was expected due to insufficient contact time to reach equilibrium.
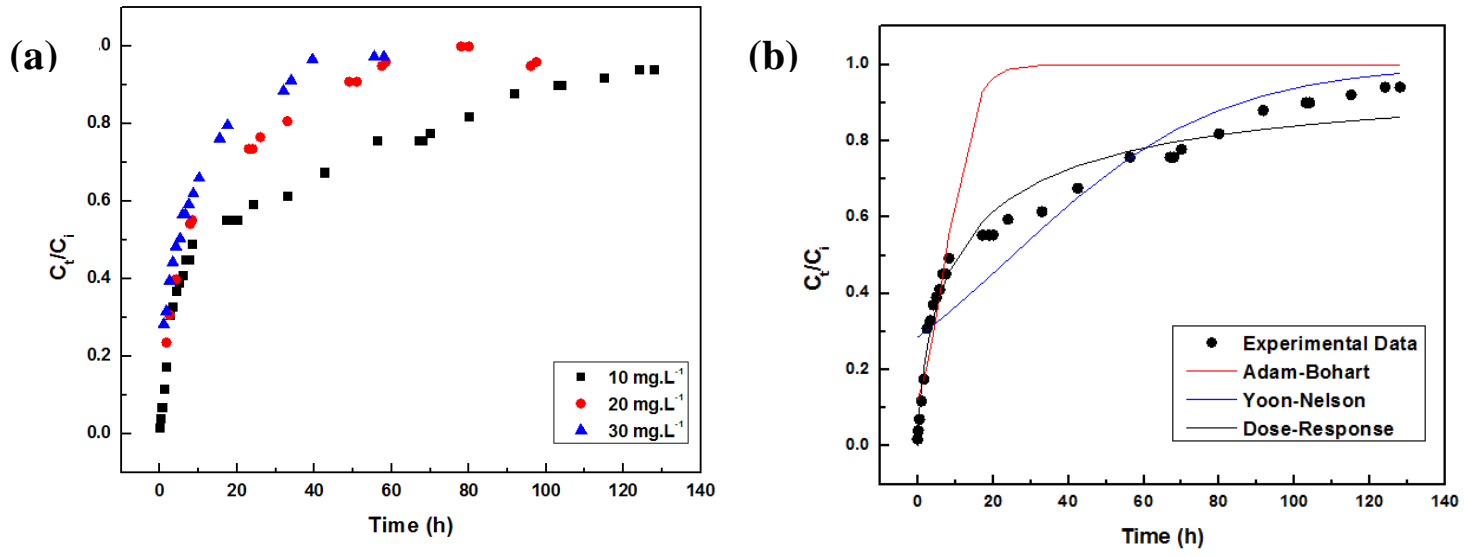

Fig. 5.3 BPA sorption curves by the column subjected to different (a) inlet BPA concentrations and (b) Predicted concentration-time profile based on sorption models for $10 \mathrm{mg} . \mathrm{L}^{-1}$ inlet BPA concentration

The Adam-Bohart, Yoon-Nelson and dose-response models were then used to predict the concentration-time profile based on the sorption data obtained at a $2.0 \mathrm{~mL}$. $\mathrm{min}^{-1}$ flow rate and $20 \mathrm{~cm}$ bed height at different inlet BPA concentrations. 
Table 5.1(b). Parameters of sorption models at different initial BPA concentrations

\begin{tabular}{|c|c|c|c|}
\hline \multirow[t]{2}{*}{ Parameters } & \multicolumn{3}{|c|}{ BPA concentrations $\left(\mathrm{mg} \cdot \mathrm{L}^{-1}\right)$} \\
\hline & 10 & 20 & 30 \\
\hline $\mathrm{m}_{\text {total }}(\mathrm{mg})$ & 154 & 230 & 205 \\
\hline$q_{\text {total }}(\mathrm{mg}) /$ Removal (\%) & $40.8 / 26.5 \%$ & $38.8 / 16.9 \%$ & $35.4 / 17.3 \%$ \\
\hline$q_{e, t s}\left(\mathrm{mg} \cdot \mathrm{g}^{-1}\right)$ & 5.46 & 5.20 & 4.74 \\
\hline \multicolumn{4}{|l|}{ Adam-Bohart Model $\left(\mathrm{t}_{0}-\mathrm{t}_{0.5 \mathrm{Ci}}\right)$} \\
\hline$K_{A B}\left(\mathrm{~L} \cdot \mathrm{h}^{-1} \cdot \mathrm{mg}^{-1}\right)$ & 0.026 & 0.010 & 0.007 \\
\hline No $\left(\mathrm{mg} \cdot \mathrm{L}^{-1}\right)$ & 95.6 & 196.84 & 228.13 \\
\hline$r^{2}$ & 0.92 & 0.99 & 0.98 \\
\hline \multicolumn{4}{|l|}{ Yoon-Nelson Model $\left(\mathrm{t}_{0}-\mathrm{t}_{0.9 \mathrm{Ci}}\right)$} \\
\hline$k_{y n}\left(\mathrm{~h}^{-1}\right)$ & 0.04 & 0.07 & 0.13 \\
\hline$\tau(\mathrm{h})$ & 25.3 & 10.5 & 5.47 \\
\hline$q_{\text {total }}(\mathrm{mg})$ & 40.7 & 37.4 & 30.1 \\
\hline$r^{2}$ & 0.92 & 0.97 & 0.99 \\
\hline \multicolumn{4}{|c|}{ Dose-Response Model $\left(\mathrm{t}_{0}-\mathrm{t}_{0.9 \mathrm{C}}\right)$} \\
\hline A & 0.74 & 1.00 & 0.94 \\
\hline $\mathrm{V}_{\text {eff50\% }}(\mathrm{L})$ & 1.28 & 0.78 & 0.52 \\
\hline$q_{\text {total, cal }}(\mathrm{mg})$ & 40.9 & 40.9 & 40.9 \\
\hline$q_{e, t s c a l}\left(\mathrm{mg} \cdot \mathrm{g}^{-1}\right)$ & 5.48 & 5.48 & 5.48 \\
\hline$r^{2}$ & 0.99 & 0.97 & 0.99 \\
\hline
\end{tabular}

Adam-Bohart is applicable to model the initial stage of the breakthrough curve when the pollutant concentration in the effluent is less than $0.5 \mathrm{C}_{\mathrm{i}}^{22}$. Therefore in this study, the model was applied to the experimental data set for the initial portion of the breakthrough curve. As shown in Table 5.1(b), the Adam-Bohart model could predict with good fit $\left(\mathrm{r}^{2}\right.$ $>0.92$ ) the initial part of the curves under different inlet BPA concentrations. The volumetric sorption capacity $\mathrm{N}_{\mathrm{o}}$ increased from $95.6 \mathrm{mg} . \mathrm{L}^{-1}$ to $228.1 \mathrm{mg} . \mathrm{L}^{-1}$, while the kinetics constant decreased from $0.026 \mathrm{~L} \cdot \mathrm{h}^{-1} \cdot \mathrm{mg}^{-1}$ to $0.007 \mathrm{~L} \cdot \mathrm{h}^{-1} \cdot \mathrm{mg}^{-1}$ with the increase in inlet concentrations. This trend is similar to other reported sorption studies involving different adsorption-column systems ${ }^{23}$. When all the range of concentrations was used for modeling $\left(\mathrm{t}=0\right.$ until $\left.\mathrm{t}=\mathrm{t}_{\mathrm{s}}\right)$, however, both the Adam-Bohart and Yoon-Nelson produced similar breakthrough curves. Indeed, the mathematical expression of the Yoon-Nelson model is equivalent to the Adam-Bohart model ${ }^{12-13}$ with $k_{Y N} \cong k_{A B} C_{i}$ (Appendix A). 
The values for rate constant $k_{Y N}$ and $50 \%$ breakthrough time $\tau$ obtained from the YoonNelson model are presented in Table 5.1(b). Based on the model, it was predicted that the increase in inlet concentrations would result in an increased rate constant $k_{Y N}$ and a decreased breakthrough time by $50 \%$, which indicated more rapid saturation of the column with the increase in inlet concentrations. The $\tau$ values obtained from the YoonNelson model differed from the experimental observation, with considerable discrepancy predicted for the $10 \mathrm{mg} . \mathrm{L}^{-1}$ BPA concentration. As shown in Fig. 5.3(b), the YoonNelson model could not satisfactorily reproduce the experimental data at initial operation time. However, the $\tau$ values at 20 and $30 \mathrm{mg} . \mathrm{L}^{-1}$ BPA concentrations were similar to experimental observations.

As shown in Fig. 5.3(b) and Table 5.1(b), the breakthrough curve of the dose-response model can be utilized to predict the removal profile of BPA with relatively good correlation $\left(\mathrm{r}^{2}>0.97\right)$ with the experimental data. The calculated value of the sorption capacity based on the predicted breakthrough curve produced by the dose-response model, $q_{e, t s c a l}$, is similar to the sorption capacity calculated from the experimental data. Similar findings regarding the relatively good fit of the dose-response model in reproducing the breakthrough curve in a fixed-bed column study has been reported by other researchers 14,16. The correlation coefficient values $\left(\mathrm{r}^{2}\right)$ obtained from the Yoon-Nelson and doseresponse models can be considered a good fit $\left(r^{2}>0.92\right)$ to the experimental data set under different inlet BPA concentrations with the best fit produced by dose-response model. The Adam-Bohart model is useful in predicting the initial stage of the breakthrough curve of up to $50 \%$ breakthrough time.

\subsubsection{Photolytic degradation}

The potential for BPA degradation in the desorption solution was tested in a batch study because of the ease of quantification for the amount of BPA sorbed at equilibrium. Fig. 5.4(a) shows the full cycle of adsorption-desorption-photolytic removal of BPA. The initial BPA solution in the batch reactor was $50 \mathrm{mg} . \mathrm{L}^{-1}$. After $48 \mathrm{~h}$ of contact with 2.0 g. $\mathrm{L}^{-1}$ dosage of composite beads, an equilibrium condition was established with the 
concentration of BPA remaining in the solution estimated at $25 \mathrm{mg} . \mathrm{L}^{-1}$ and equilibrium adsorption capacity estimated at $\sim 11 \mathrm{mg} \cdot \mathrm{g}^{-1}$.

(a)

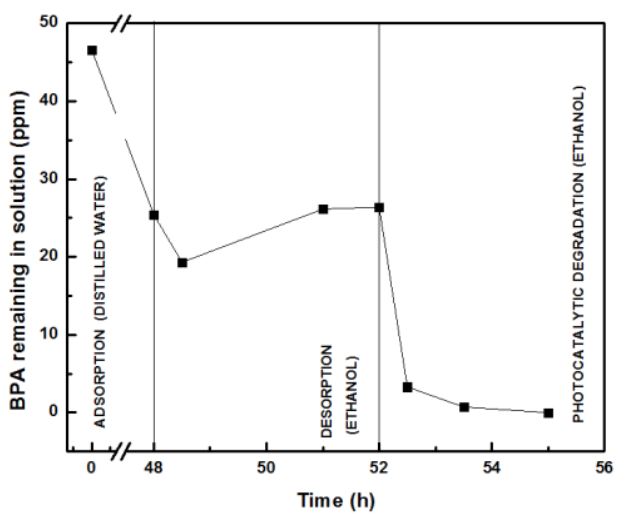

(b)

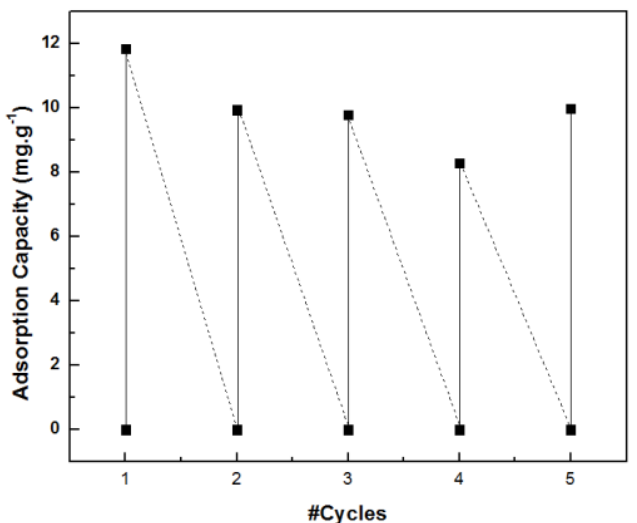

Fig.5.4 (a) Adsorption-desorption-photocatalytic removal of BPA by the composite calciumalginate/MWCNTs/TiO 2 beads (b) Adsorption performance of the beads after 5 cycles of adsorption-desorption- irradiation

The used beads were then immersed in an ethanol solution, which resulted in up to $90 \%$ BPA recovery. Subsequent irradiation of the solution in the presence of the beads eliminated the remaining BPA after 1.5h. It is postulated that the inclusion of $\mathrm{TiO}_{2}$ into the composite beads assisted subsequent BPA degradation through light irradiation of the spent beads in their desorption solution. The re-usability of the beads after 5 cycles of adsorption-desorption-irradiation is shown in Fig. 5.4 (b). Slight variability in adsorption capacity is apparent, but not significant, which concedes the potential for the composite beads to be used in multiple regeneration cycles.

\subsection{Conclusion}

In this study, composite carbon nanotube-alginate- $\mathrm{TiO}_{2}$ hydrogel beads were fabricated and used for the sorption of BPA in a fixed-bed column reactor. BPA removal is affected by the feed flow rate, bed height and initial inlet concentrations. It was observed that maximum sorption was achieved at the lowest flow rate and highest bed height tested. The breakthrough time was extended with higher bed height, lower flow rate and lower inlet pollutant concentration. The sorption capacity of the composite sorbent at $10 \mathrm{mg} . \mathrm{L}^{-1}$ inlet BPA concentration, $2.0 \mathrm{~mL} \cdot \mathrm{min}^{-1}$ flow rate and $20 \mathrm{~cm}$ bed height was $5.46 \mathrm{mg} \cdot \mathrm{g}^{-1}$. 
The modeling study shows that the experimental breakthrough curve could be depicted with satisfactory correlation using the dose-response model. Photolytic oxidation of BPA desorbed from the beads is possible under irradiation. Thus, the regeneration of the spent adsorbent beads and eventual photolytic degradation of bisphenol A can be achieved simultaneously.

In this chapter, we evaluated the potential of MWNCT encapsulation within calcium-alginate beads and its application for bisphenol A removal in a column reactor. Despite the ease of fabrication, the fragility of the beads may lead to potential release of the CNTs. In the next chapter, we proposed a design for a compartment for carbon nanotubes immobilization by introducing the addition of a polysulfone coating on the surface of alginate beads. 


\section{References}

1 Lu, C., Chiu, H. \& Bai, H. Comparisons of adsorbent cost for the removal of zinc (II) from aqueous solution by carbon nanotubes and activated carbon. Journal of Nanoscience and Nanotechnology 7, 4-5 (2007).

2 Dehghani, M. H. et al. Adsorption of bisphenol A (BPA) from aqueous solutions by carbon nanotubes: kinetic and equilibrium studies. Desalination and Water Treatment, 1-9, doi:10.1080/19443994.2013.876671 (2014).

3 Bottini, M. et al. Multi-walled carbon nanotubes induce T lymphocyte apoptosis. Toxicology Letters 160, 121-126 (2006).

4 Fujishima, A. \& Honda, K. Photolysis-decomposition of water at surface of an irradiated semiconductor. Nature 37, 238-245 (1972).

5 Carp, O., Huisman, C. L. \& Reller, A. Photoinduced reactivity of titanium dioxide. Progress in Solid State Chemistry 32, 33-177 (2004).

6 Martinsen, A., Skjåk-Bræk, G. \& Smidsrød, O. Alginate as immobilization material: I. correlation between chemical and physical properties of alginate gel beads. Biotechnol. Bioeng. 33, 79-89 (1989).

7 Kierstan, M. \& Bucke, C. The immobilization of microbial cells, subcellular organelles, and enzymes in calcium alginate gels. Biotechnol. Bioeng. 19, 387397 (1977).

8 Lin, D. \& Xing, B. Adsorption of phenolic compounds by carbon nanotubes: role of aromaticity and substitution of hydroxyl groups. Environmental Science \& Technology 42, 7254-7259 (2008).

9 Low, K. \& Lee, C. Cadmium uptake by the moss, Calymperes delessertii, Besch. Bioresource Technology 38, 1-6 (1991).

10 Dichiara, A. B., Harlander, S. F. \& Rogers, R. E. Fixed bed adsorption of diquat dibromide from aqueous solution using carbon nanotubes. RSC Advances 5, 61508-61512 (2015).

11 Fugetsu, B. et al. Encapsulation of multi-walled carbon nanotubes (MWCNTs) in $\mathrm{Ba} 2+$-alginate to form coated micro-beads and their application to the preconcentration/elimination of dibenzo-p-dioxin, dibenzofuran, and biphenyl from contaminated water. Analyst 129, 565-566 (2004).

12 Bohart, G. \& Adams, E. Some aspects of the behavior of charcoal with respect to chlorine. 1. Journal of the American Chemical Society 42, 523-544 (1920).

13 Yoon, Y. H. \& Nelson, J. H. Application of gas adsorption kinetics I. A theoretical model for respirator cartridge service life. The American Industrial Hygiene Association Journal 45, 509-516 (1984).

14 Calero, M., Hernáinz, F., Blázquez, G., Tenorio, G. \& Martín-Lara, M. Study of $\mathrm{Cr}$ (III) biosorption in a fixed-bed column. Journal of Hazardous Materials 171, 886-893 (2009).

15 Yan, G., Viraraghavan \& Chen, M. A new model for heavy metal removal in a biosorption column. Adsorption Science \& Technology 19, 25-43 (2001).

16 He, J., Lu, Y., Wu, L. \& Luo, G. Continuous removal of lead from aqueous solutions by $\mathrm{Ca}(\mathrm{II})$ imprinted chitosan microspheres packed column. Separation Science and Technology 50, 1127-1134 (2014). 
17 Hartono, M. R., Marks, R. S., Chen, X. \& Kushmaro, A. Hybrid multi-walled carbon nanotubes-alginate-polysulfone beads for adsorption of bisphenol-A from aqueous solution. Desalination and Water Treatment 54, 1167-1183 (2015).

18 Ko, D. C., Porter, J. F. \& McKay, G. Optimised correlations for the fixed-bed adsorption of metal ions on bone char. Chemical engineering science 55, 58195829 (2000).

19 Ahmad, A. \& Hameed, B. Fixed-bed adsorption of reactive azo dye onto granular activated carbon prepared from waste. Journal of Hazardous Materials 175, 298303 (2010).

20 Jain, M., Garg, V. \& Kadirvelu, K. Cadmium (II) sorption and desorption in a fixed bed column using sunflower waste carbon calcium-alginate beads. Bioresource Technology 129, 242-248 (2013).

21 Thanhmingliana, Lee, S. M. \& Tiwari, D. Use of hybrid materials in the decontamination of bisphenol A from aqueous solutions. RSC Advances 4, 4392143930 (2014).

22 Sarin, V., Singh, T. S. \& Pant, K. Thermodynamic and breakthrough column studies for the selective sorption of chromium from industrial effluent on activated eucalyptus bark. Bioresource Technology 97, 1986-1993 (2006).

23 Aksu, Z. \& Gönen, F. Biosorption of phenol by immobilized activated sludge in a continuous packed bed: prediction of breakthrough curves. Process Biochemistry 39, 599-613 (2004). 


\section{Chapter 6}

\section{Characterization and BPA Removal Performance by Ca-alginate/MWCNTs/Polysulfone beads}

In this study, we immobilized MWCNTs within calcium alginate beads coated with a polysulfone layer, both to provide an additional barrier to prevent MWCNTs release into the effluent and also to improve bead mechanical integrity. The hybrid beads were tested for their capacity to remove bisphenol $A$ in a batch reactor. The adsorption of BPA followed both the Langmuir and Freundlich isotherm models with high correlation. A maximum adsorption capacity of the hybrid beads was obtained using the Langmuir model at $24.69 \mathrm{mg} \cdot \mathrm{g}^{-1}$. The addition of the polysulfone layer, together with MWCNTs, improved mechanical performance of the bead. This study showed that a hybrid alginate-polysulfone bead may serve as a compartment for encapsulation of MWCNTs for the removal of BPA.

* M.R. Hartono, R.S. Marks, X. Chen, A. Kushmaro; Hybrid multi walled carbon nanotube-alginatepolysulfone beads for removal of bisphenol A; Desalination and Water Treatment vol. 54 no.4 (2014): 1167-1183

Reproduced for dissertation with permission from Taylor \& Francis @2015 


\subsection{Introduction}

To date, only a few studies have addressed the containment of carbon nanomaterials (CNMs) for their application in water or wastewater treatment to prevent their elution into the effluent ${ }^{1}$. A possible strategy for such containment exploits their entrapment in a hydrophilic alginate matrix. The physical degradation of alginate beads due to abrasion

effects, however, has been reported by several authors in different applications ${ }^{2,3}$. This degradation may lead to the eventual release of entrapped materials into the solution. The addition of a robust secondary layer onto alginate beads is necessary to provide an additional barrier. Polysulfone (Psf) is a good candidate for this secondary layer as it possesses superior mechanical, oxidative, thermal and hydrolytic stabilities ${ }^{4}$. In addition, several studies have reported the affinity of pollutants with high oil-water partition coefficient towards Psf ${ }^{5-7}$.

To the best of our knowledge, the containment of CNMs in double-encapsulated beads for removal of pollutant has not been previously explored. In this study, we immobilized multi-walled carbon nanotubes (MWCNTs), one of CNMs variants, within calciumalginate gel beads, which were coated with a Psf layer to provide an additional barrier to prevent MWCNTs release and to improve the bead stability. The simplified illustration of our proposed hybrid Ca-Alg/MWCNTs/Psf bead is shown in Fig. 6.1.

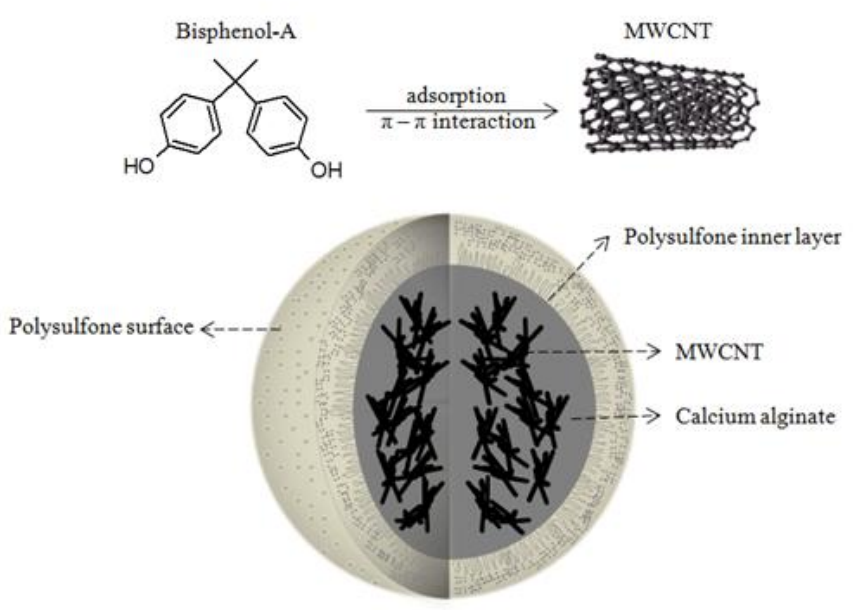

Fig. 6.1 Simplified illustration of the composite bead with Psf layer (Ca-Alg/MWCNTs/Psf) 
The hybrid beads were characterized using FTIR, BET surface area analysis and SEM. The effects of an additional Psf layer on the leakage containment of MWCNTs and the stability of the hybrid beads were evaluated by means of a bioluminescence toxicity assay and a compression test. The batch and column adsorption studies onto the hybrid beads were conducted using synthetic BPA solutions by considering parameters such as solution $\mathrm{pH}$, adsorbent dosage, initial BPA concentrations and contact time. The suitability of adsorption models was assessed and maximum adsorption capacity was derived based on the Langmuir isotherm model. Adsorption kinetics was studied using pseudo-first- and pseudo-second order models to determine the rate constants.

\subsection{Experimental}

This section provides additional details relevant to this study, which was not covered in Chapter 3 - experimental methodology

\subsubsection{Methods}

\section{Fabrication of composite beads}

The general procedure for preparation of composite beads in this study is described in section 3.3.1.2. Calcium alginate-MWCNTs composite beads (Ca-Alg/MWCNTs) were prepared by adding a known amount of MWCNTs into a 2.5-wt\% alginate solution as seen in Table 6.1. This was followed by sonication (Elmasonic) and overnight stirring. The resulting mixture was dripped into a magnetically stirred $0.5 \mathrm{M}$ calcium chloride solution using a syringe pump (KDS) at $50 \mathrm{~mL} / \mathrm{h}$ through a polyurethane tube with a 3.5$\mathrm{mm}$ diameter opening. The beads were aged in the calcium solution overnight then were washed and stored in distilled water. 
Table 6.1 Summary of experimental conditions for bead fabrication

\begin{tabular}{ccccc}
\hline Sample & $\begin{array}{c}\text { Volume } \\
(\mathbf{m L})\end{array}$ & $\begin{array}{c}\text { Alginic } \\
\text { acid }(\mathbf{g})\end{array}$ & $\begin{array}{c}\text { MWCNTs } \\
(\mathbf{m g})\end{array}$ & Treatments \\
\hline Ca-Alg & 50 & 1.25 & 0 & Stir overnight \\
Ca-Alg/ 2\%-MWCNTs & 50 & 1.25 & 25 & \\
Ca-Alg/ 7\%-MWCNTs & 50 & 1.25 & 100 & $\begin{array}{c}\text { Sonicate }(2 \text { mins })-\text { stir } 1.5 \mathrm{hrs} \\
\text { - sonicate } 20 \text { mins }- \text { stir } \\
\text { Ca-Alg/ 14\%- }\end{array}$ \\
$\begin{array}{c}\text { MWCNTs } \\
\text { Ca-Alg/ 22\%- }\end{array}$ & 50 & 1.25 & 200 & \\
MWCNTs & 50 & 1.25 & 350 & sonicate \\
\hline
\end{tabular}

The fabrication procedure for $\mathrm{Ca}-\mathrm{Alg} / \mathrm{MWCNTs}$ beads with a Psf layer addition (CaAlg/MWCNTs/Psf) was adapted from previous studies ${ }^{8,9}$. Psf at $10-\mathrm{wt} \%$ was prepared by dissolving Psf pellets into N,N-DMF. Each swollen bead was touched to filter paper and dropped into the Psf solution for about 20s before collection and immersion in distilled water to complete the polymerization. The resulting beads were then washed and stored in distilled water at room temperature. For wet weight to dry weight conversion, several batches of swollen beads (wet weight of each $0.5 \mathrm{~g}$ ) were prepared and heated at $80^{\circ} \mathrm{C}$. The dry to wet weight conversion was calculated by measuring the average of the dry weight divided by the initial wet weight prior to drying. All calculations for data analysis were then performed based on the dry weight of the beads.

\section{Adsorption and Desorption Experiments}

The procedures for batch adsorption and desorption experiments have been described in sections 3.3.2.1 and 3.3.2.2

\section{Column Adsorption}

Column adsorption studies were performed using a column made of borosilicate glass with a $1.5 \mathrm{~cm}$ internal diameter. The column was filled with the hybrid beads by tapping method until a final beads height of $12.5 \mathrm{~cm}$. A BPA solution of $100 \mathrm{mg} . \mathrm{L}^{-1}$ concentration was injected in an up-flow direction (in order to reduce the channeling effect) into the column at flow rate of $0.5 \mathrm{ml} . \mathrm{min}^{-1}$. A fraction of the effluent was collected as a function of time. Breakthrough curves were constructed by plotting the time against removal efficiency of BPA from the influent. Desorption of the column was conducted by injecting ethanol at a flow rate of $0.5 \mathrm{ml} \cdot \mathrm{min}^{-1}$. Prior to the start of a new 
cycle, the column was flushed with distilled water to remove traces of ethanol, and the remaining solution inside the column was drained by pumping air through the column. All experiments were carried out at ambient conditions.

\subsubsection{Analytical Methods}

\section{Bioluminescence assay}

The experimental procedure for the preparation of DPD2511 bioluminescence assay is discussed in section 3.2.1. In order to study the effect of the addition of Psf layer onto Ca$\mathrm{Alg} / 22 \%$-MWCNTs beads to enhance the containment of MWCNTs, a total of $10 \mathrm{Ca}-$ Alg/22\%-MWCNTs beads with and without the addition of a Psf layer were immersed in $2 \mathrm{~mL}$ of distilled water and subjected to vigorous vortex at a high rate for $10 \mathrm{mins}$. The aliquots before and after vortex were then tested using the DPD2511 assay. As a control, samples of solutions containing MWCNTs of different concentrations were freshly prepared and sonicated for $1 \mathrm{~h}$ in an ultrasonic bath before use.

\section{FTIR measurement}

FTIR was utilized to assess the functional groups that were present before and after modification. The FTIR spectra of MWCNTs, calcium-alginate beads and composite Caalg/MWCNTs beads were analyzed. The beads were dried and crushed to powder form using mortar and pestle.

\section{Scanning electron microscopy}

Samples of the composite beads for SEM imaging were dried in an oven at $80^{\circ} \mathrm{C}$ prior to mounting on a conductive support and coating.

\section{Zeta-potential measurements}

Calcium alginate beads ( $\mathrm{Ca}-\mathrm{Alg}$ ) were crushed into small particles using mortar and pestle followed by drying at $70^{\circ} \mathrm{C} .1 \mathrm{~g} / \mathrm{L} \mathrm{Ca}$-Alg particles and $0.05 \mathrm{~g} / \mathrm{L}$ MWCNTs were added into tubes containing distilled water of different $\mathrm{pH}$ values. 


\subsection{Results and discussion}

\subsubsection{Characterization of the hybrid beads}

FTIR spectrums of MWCNTs, Ca-Alg, and Ca-Alg/MWCNTs are shown in Fig. 6.2. As shown in Fig. 6.2(a), no significant band is observed for MWCNTs. The IR spectra of $\mathrm{Ca}-\mathrm{Alg}$ at 3426, 1637, 1435 and $1032 \mathrm{~cm}^{-1}$ are contributed by $-\mathrm{OH}, \mathrm{C}=\mathrm{O}, \mathrm{C}-\mathrm{OH}$ and $\mathrm{OC}-$ $\mathrm{OH}$ vibrations. Little discrepancy in the IR spectrum is apparent between Ca-Alg and $\mathrm{Ca}-\mathrm{Alg} / 22 \%$-MWCNTs, perhaps due to lower amount of MWCNTs entrapped within the bead.

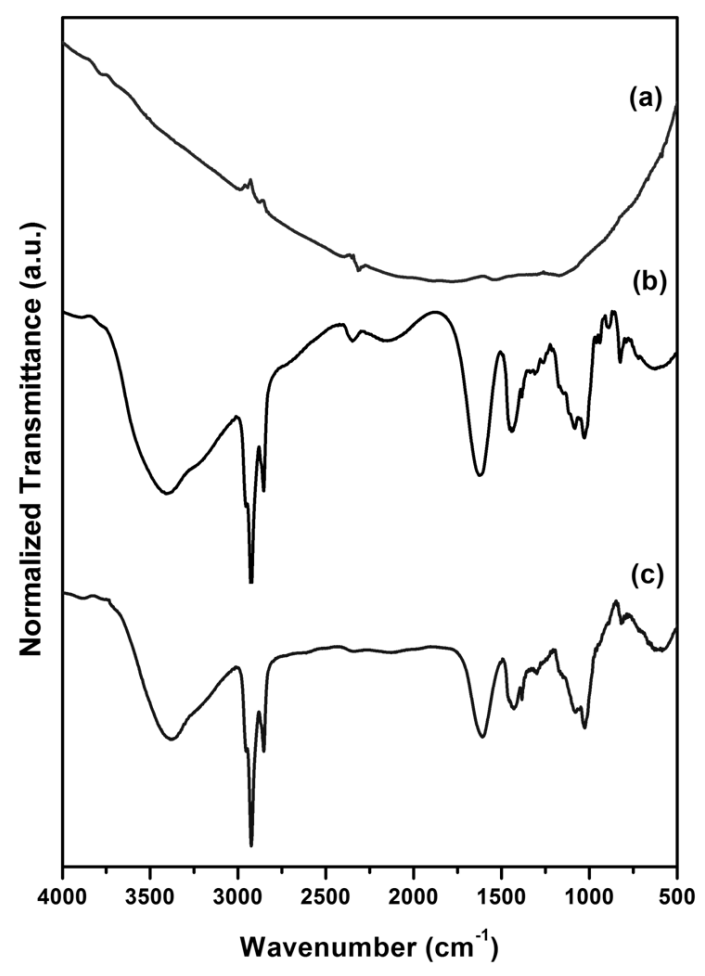

Fig. 6.2. FTIR spectrum of (a) MWCNTs (b) Ca-Alg (c) Ca-Alg/22\%MWCNTs

Fig. 6.3a and Fig. 6.3b show the SEM images of calcium alginate beads without addition of MWCNTs (Ca-Alg) and calcium alginate beads with addition of MWCNTs (Ca$\mathrm{Alg} / \mathrm{MWCNTs}$ ). It appears that $\mathrm{Ca}-\mathrm{Alg} / \mathrm{MWCNTs}$ bead has a rougher surface in comparison to $\mathrm{Ca}-\mathrm{Alg}$. The dimension of MWCNTs used in the study was $10-15 \mathrm{~nm}$ in diameter and $3 \mu \mathrm{m}$ in length. The pore radius of $\mathrm{Ca}-\mathrm{Alg}$ used in our study was estimated using $\mathrm{BJH}$ adsorption method to be $1.67 \mathrm{~nm}$. Hence, it can be assumed that the pore diameter of the Ca-Alg used in our study is less than $10 \mathrm{~nm}$, which was sufficient to contain the MWCNTs within the alginate matrix. It is worth noting that one of the 
concerns in using solely alginate as an entrapment matrix is the possibility of abrasion and the resultant release of the entrapped CNMs. In this study, an additional Psf layer was introduced as secondary layer for additional protection and to improve stability. Fig. 6.3c shows the SEM image of the Psf surface on the outer layer of the bead which is covered with polydisperse pores of up to $\sim 10 \mu \mathrm{m}$ in diameter.
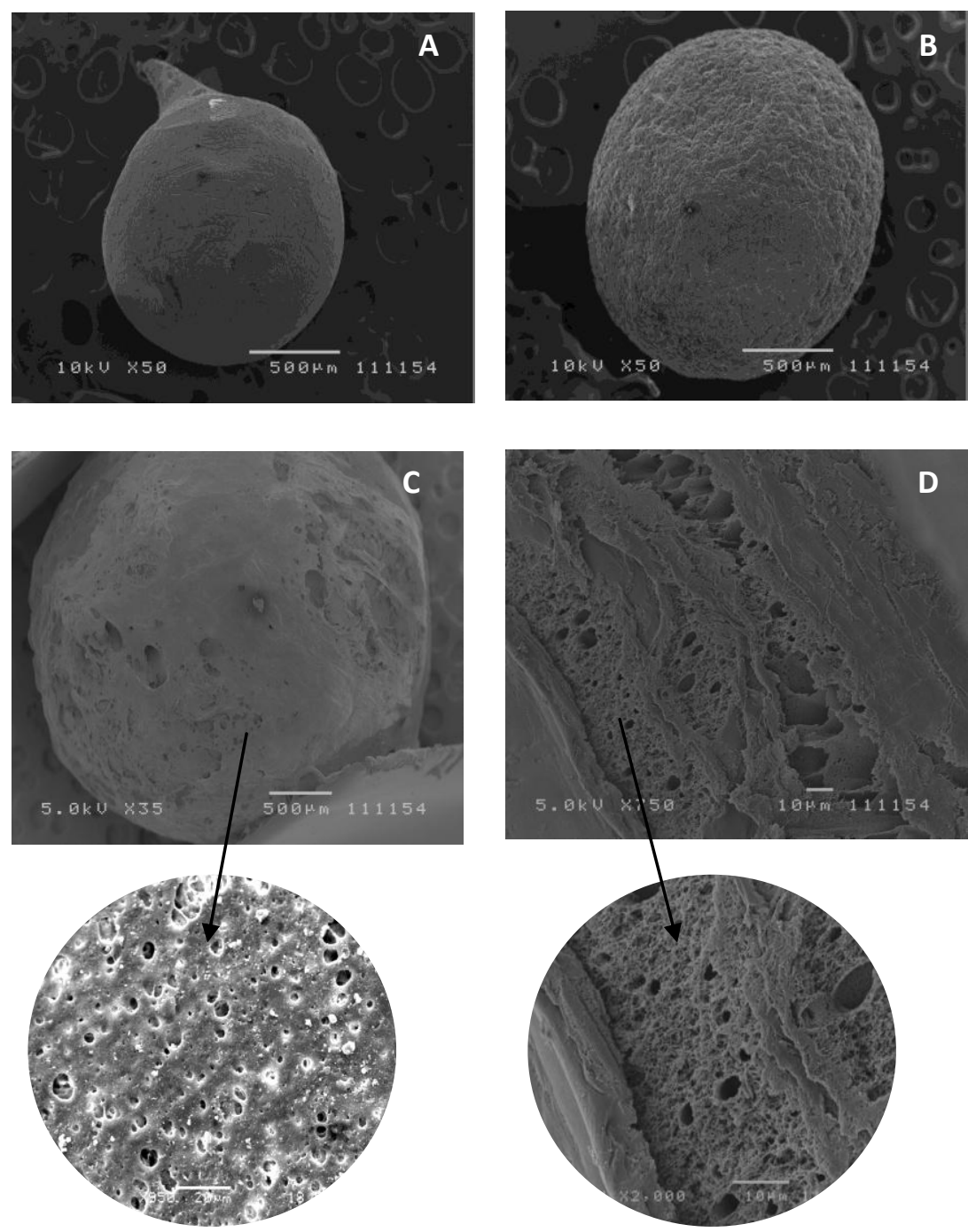

(Inset)

(Inset)

Fig. 6.3. SEM photographs of (a) surface of Ca-Alg bead (b) Ca-Alg/ 22\%-MWCNTs, (c) Psf surface, (d) Cross section of Psf layer. Scale bar for (a) and (b) is $500 \mu \mathrm{m}$; magnification is $50 \mathrm{x}$; $10 \mathrm{kV}$. Scale bar for (c) is $35 \times$; $5 \mathrm{kV}$ (Inset) is $20 \mu \mathrm{m} ; 950 \times ; 10 \mathrm{kV}$. Scale bar for (d) is $10 \mu \mathrm{m}$; $750 \times ; 5 \mathrm{kV}$ (Inset) is $10 \mu \mathrm{m} ; 2000 \times ; 5 \mathrm{kV}$ 
To coat the Ca-Alg/MWCNTs bead with Psf, the swollen bead was dropped in Psf solution and then immersed in distilled water, which propels the rapid phase separation by means of solvent outflow and/or non-solvent (water) inflow. Following this rapid exchange, dense skin layers ${ }^{10}$ were formed on the outer interface of Psf. Another thinner skin layer formed on the inner interface as the Psf solution came into contact with the surface of the swollen alginate surface, which was predominantly composed of water with porous structures formed in between these skin layers (Fig 6.3d). These macrovoid porous structures were covered with pores, which resulted from rapid phase separation.

As adsorption occurs mainly in small pores due to their higher surface area and binding affinity for adsorbate, the presence of these pore networks in the Psf layer may improve the adsorption capacity of the bead.

Table 6.2. Comparisons of BET surface area values of the hybrid beads

\begin{tabular}{lc}
\hline Sample & BET surface area $\left(\mathrm{m}^{2} \cdot \mathrm{g}^{-1}\right)$ \\
\hline Ca-Alg & 2.93 \\
$\mathrm{Ca}-\mathrm{Alg} / 22 \%-\mathrm{MWCNTs}$ & 18.63 \\
$\mathrm{Ca}-\mathrm{Alg} / 22 \%-\mathrm{MWCNTs} /$ Psf & 38.71 \\
$\mathrm{MWCNTs}$ & 325.86 \\
\hline
\end{tabular}

Table 6.2 shows the comparison of BET surface area values of the beads before and after the addition of MWCNTs and Psf layer, respectively. It is shown that the addition of MWCNTs and Psf layer increases the surface area of the beads.

\subsubsection{Influence of experiment parameters}

\section{Effect of MWCNTs content}

Before addition of a Psf layer, batch experiments were performed to select suitable MWCNT content for Ca-Alg/MWCNTs beads. The MWCNTs were dispersed at different concentrations into a $2.5 \mathrm{wt} \%$ alginate solution by varying the total sonication time. Good dispersions were shown up to a MWNCT content of $22 \%$ with 40 mins of total sonication time. Higher MWCNT contents of $30 \%$ and $50 \%$ were marked with a reduction in the MWCNTs dispersion. This reduction was observed by agglomeration of MWCNTs at the bottom of the vessel, which necessitated longer sonication time (Table 
6.3). After $3 \mathrm{~h}$ of sonication, the resulting mixture of $30 \%$ and $50 \%$ MWCNTs became more viscous and difficult to handle during the injection of the alginate mixture into calcium chloride solution. Due to the viscous nature, the cross-linked composite Ca$\mathrm{Alg} / 30 \%-\mathrm{MWCNTs}$ and $\mathrm{Ca}-\mathrm{Alg} / 50 \%$-MWCNTs adopted a bigger and more elongated form as the content of MWCNTs increased (Fig.6.4).

Table 6.3. Description of MWCNTs dispersion into alginate at different concentration

\begin{tabular}{|c|c|c|c|c|}
\hline \multirow[b]{2}{*}{$\begin{array}{c}\text { Content of MWCNTs } \\
\text { in alginate }\end{array}$} & \multicolumn{4}{|c|}{$\begin{array}{c}\text { Total sonication time } \\
\text { (degree of agglomeration: }+,++,+++ \text { ) }\end{array}$} \\
\hline & 40 mins & $60 \mathrm{mins}$ & $2 \mathrm{~h}$ & $3 \mathrm{~h}$ \\
\hline 2\%-MWCNTs & $<$ & good dispersion & $\ldots$ & \\
\hline $7 \%$-MWCNTs & $<$ & good dispersion & $\ldots$ & \\
\hline $14 \%$-MWCNTs & $<$ & good dispersion & $\ldots$ & \\
\hline $22 \%$-MWCNTs & $<$ & good dispersion & $\ldots$ & \\
\hline $30 \%$-MWCNTs & + & + & + & + \\
\hline 50\%-MWCNTs & ++ (thick paste) & H+ & H+ & H+ \\
\hline
\end{tabular}
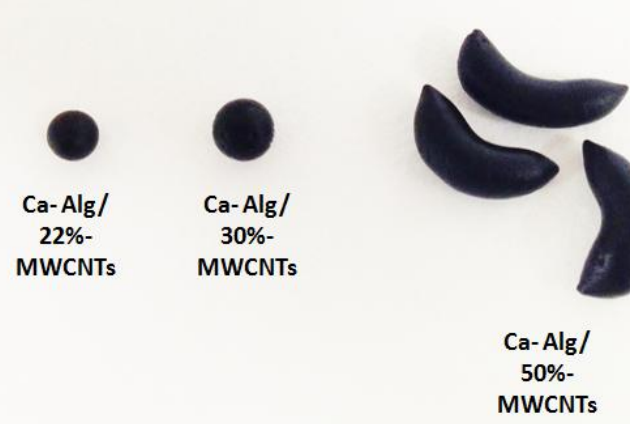

Fig. 6.4. Structures formed after cross-linking of alginate/MWCNTs mixture with calcium chloride

Since the presence of agglomeration caused frequent obstruction in the syringe's nozzle, the MWCNT content within Ca-Alg/MWCNTs beads was not increased beyond $22 \%$ MWCNTs for this study. The effects of MWCNT content immobilized within the alginate beads, without the addition of Psf layer, on the removal of BPA are shown in Fig. 5. The BPA removal efficiency of $\mathrm{Ca}-\mathrm{Alg} / \mathrm{MWCNT}$ beads is higher than pure $\mathrm{Ca}-\mathrm{Alg}$ beads but lower than pure MWCNTs. It can be seen that the amount of BPA adsorbed 
positively correlated with the increase in amount of MWCNTs embedded inside the alginate beads. Hereafter, the $\mathrm{Ca}-\mathrm{Alg} / \mathrm{MWCNTs} / \mathrm{Psf}$ beads for subsequent experiments were prepared using $\mathrm{Ca}-\mathrm{Alg} / 22 \%$-MWCNTs.

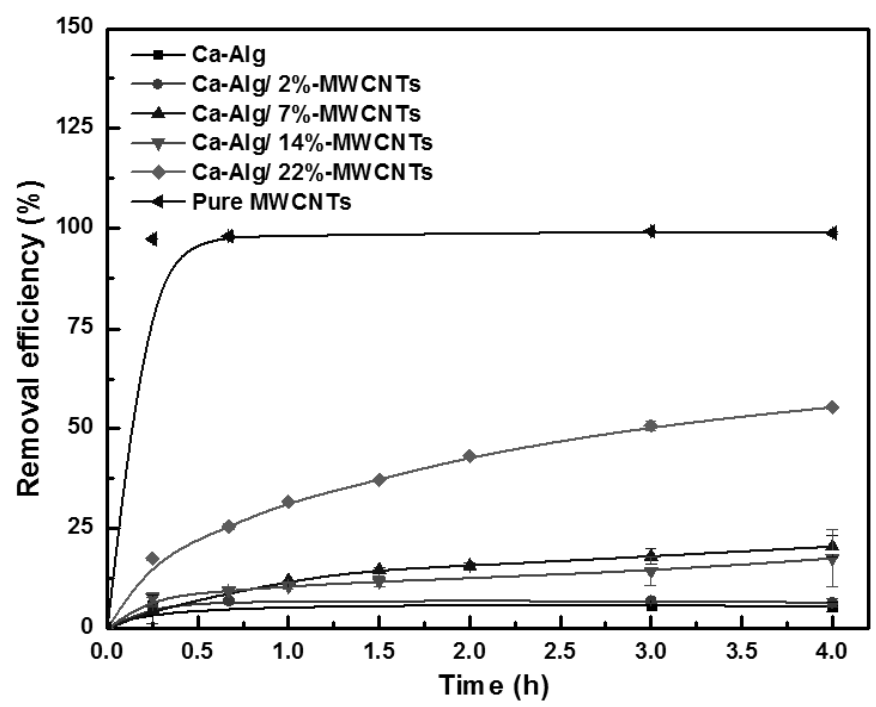

Fig. 6.5. Effect of amount of MWCNTs immobilized in alginate beads on BPA removal (Dosage $=4 \mathrm{~g} \cdot \mathrm{L}^{-1}$ dry weight, $\mathrm{pH}=6.0, \mathrm{BPA}$ concentration $\left.=100 \mathrm{mg} . \mathrm{L}^{-1}\right)$. Data are expressed as mean \pm standard error.

As seen on Fig. 6.5, the removal rates of $\mathrm{Ca}-\mathrm{Alg} / \mathrm{MWCNT}$ beads are inferior in comparison to pure MWCNTs. For pure MWCNTs of the same dry weight dosage, the equilibrium was reached within $1 \mathrm{~h}$ of agitation; whereas, contact time of more than $4 \mathrm{~h}$ was required for equilibrium to be established when MWCNTs were encapsulated within the calcium alginate beads. This result was expected as the porous network of the bead may have limited the diffusion rate of the pollutant ${ }^{11}$. Despite the slower removal associated with the Ca-Alg/MWCNT beads in comparison to pure MWCNTs, containment of MWNCTs is still important to prevent its elution into purified effluent.

\section{Effect of addition of Psf layer on MWCNTs containment}

The effect of a Psf layer addition on the containment of the MWCNTs was assessed by subjecting $\mathrm{Ca}-\mathrm{Alg} / 22 \%-\mathrm{MWCNTs}$ and $\mathrm{Ca}-\mathrm{Alg} / 22 \%-\mathrm{MWCNTs} / \mathrm{Psf}$ beads, immersed in distilled water, to a high degree of vortex, which could have resulted in the abrasion of the beads. The solution was then tested using a bioluminescence assay to detect the presence of MWCNTs. The induction factor of bioluminescence released by DPD2511 
at different concentrations of MWCNTs is shown in Fig. 6.6(a). It can be observed that the strain was able to detect the presence of MWCNTs at concentrations as low as $10^{-7}$ $\mu \mathrm{g} / \mathrm{mL}$ with a maximum induction factor at MWCNT concentration of $0.005 \mu \mathrm{g} / \mathrm{mL}$. This finding shows that, indeed, the presence of MWCNTs induce oxidative stress on E.coli. The oxidative stress-sensitive DPD2511 strain, therefore, can be used to indicate the presence of MWCNTs in the solution.
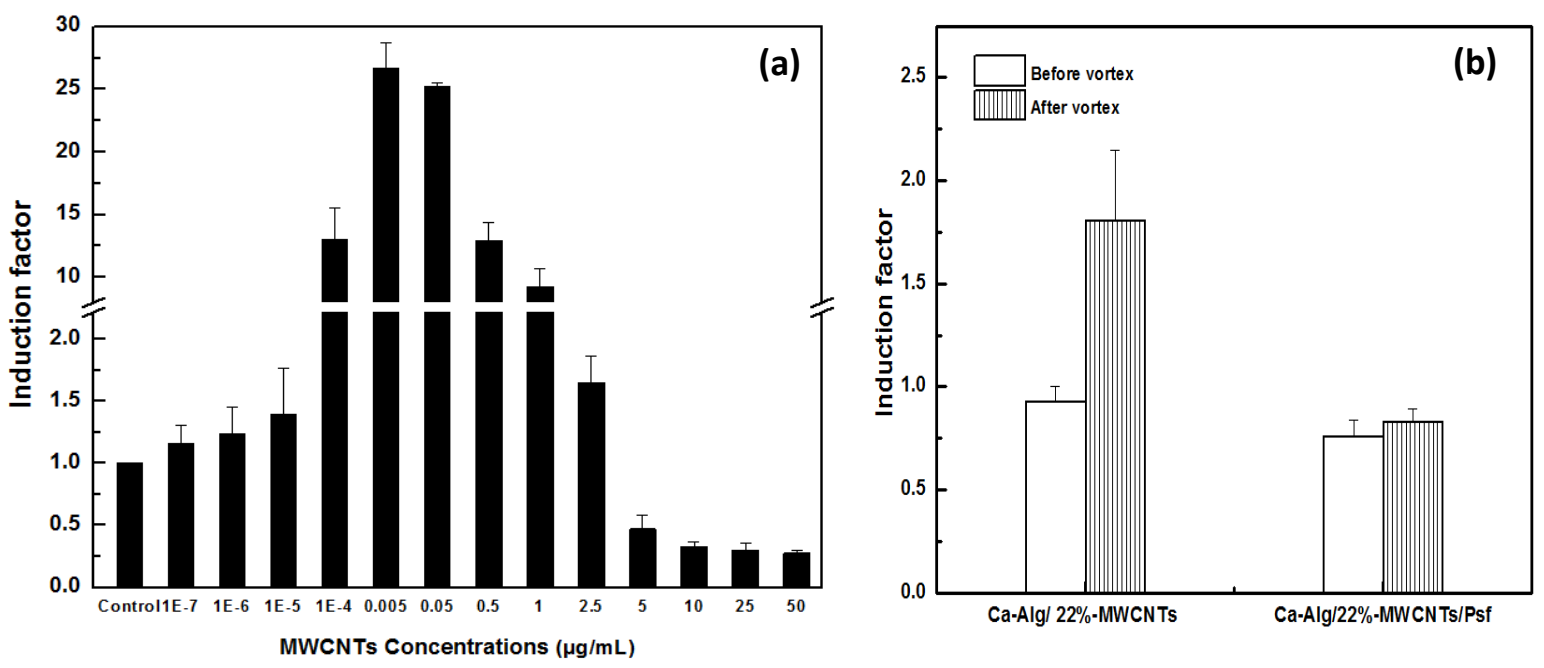

Fig. 6.6. (a) Induction factor produced by DPD 2511 after being subjected to (a) MWCNT solutions at different concentrations and (b) aliquots taken before and after vortex for CaAlg/22\%-MWCNTs and Ca-Alg/22\%-MWCNTs/Psf beads. Data are expressed as mean \pm standard deviation.

Fig. 6.6b shows the induction factor of luminescence released by DPD2511 after its exposure to the aliquots taken before and after vortex. It can be seen that the induction factor of the solution, immersed with $\mathrm{Ca}-\mathrm{Alg} / 22 \%$-MWCNTs beads and without the addition of a Psf layer, was higher after vortex, indicating the release of MWCNTs from the bead into the solution. However, the induction factor was maintained for $\mathrm{Ca}-$ $\mathrm{Alg} / 22 \%-\mathrm{MWCNTs} / \mathrm{Psf}$ beads. Fig. 6.7a and 6.7b depict the surface of Ca-Alg/22\%MWCNT beads before and after vortex, it can be seen that several voids were evident on the surface of the beads after vortex due to abrasion. 

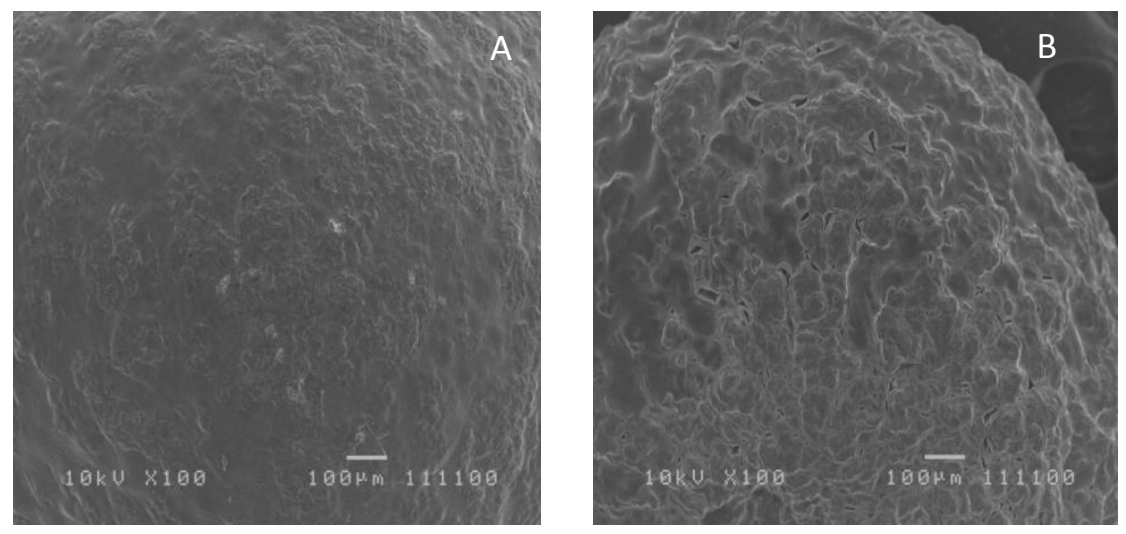

Fig. 6.7. SEM photographs of (a) surface of Ca-Alg/ 22\%-MWCNTs beads (a) before and (b) after vortex. Scale bar for (a) and (b) is $100 \mu \mathrm{m}$; magnification is $100 \times$; $10 \mathrm{kV}$.

The results of bioluminescence assay, as well as observation of the surface of the beads using SEM, indicate that the addition of a Psf layer onto Ca-Alg/MWCNT beads is beneficial to provide better MWCNTs containment.

\section{Effect of addition of Psf layer on BPA adsorption and bead stability}

The effect of a Psf-layer addition on the adsorption of BPA was analyzed by comparing the adsorption capacity of $\mathrm{Ca}-\mathrm{Alg} / \mathrm{MWCNTs}$ and $\mathrm{Ca}-\mathrm{Alg} / \mathrm{MWCNTs} / \mathrm{Psf}$ beads with different MWCNT content at equilibrium (Fig. 6.8).

It is shown that the addition of the Psf layer to the Ca-Alg/2\%-MWCNT beads resulted in the adsorption of greater amounts of BPA onto $\mathrm{Ca}-\mathrm{Alg} / 2 \%$-MWCNTs/Psf beads relative to the $\mathrm{Ca}-\mathrm{Alg} / 2 \%$-MWCNTs. In comparison to the more hydrophilic alginate matrix, the hydrophobic property of Psf might have resulted in a higher affinity towards compounds with high $\mathrm{K}_{\mathrm{ow}}$ and low water solubility, such as BPA, which caused the increase in the amount of BPA adsorbed onto Ca-Alg/2\%-MWCNTs/Psf beads. However, the effect of the Psf-layer addition towards improvement in BPA adsorption was not significant when the MWCNT content within the beads was increased. As MWCNT content increased, the effect of MWCNTs as a "trap" may have dominated the adsorption process. Therefore, the improvement in BPA adsorption contributed by the addition of the hydrophobic Psf layer was less pronounced as the MWCNT's content increased. 


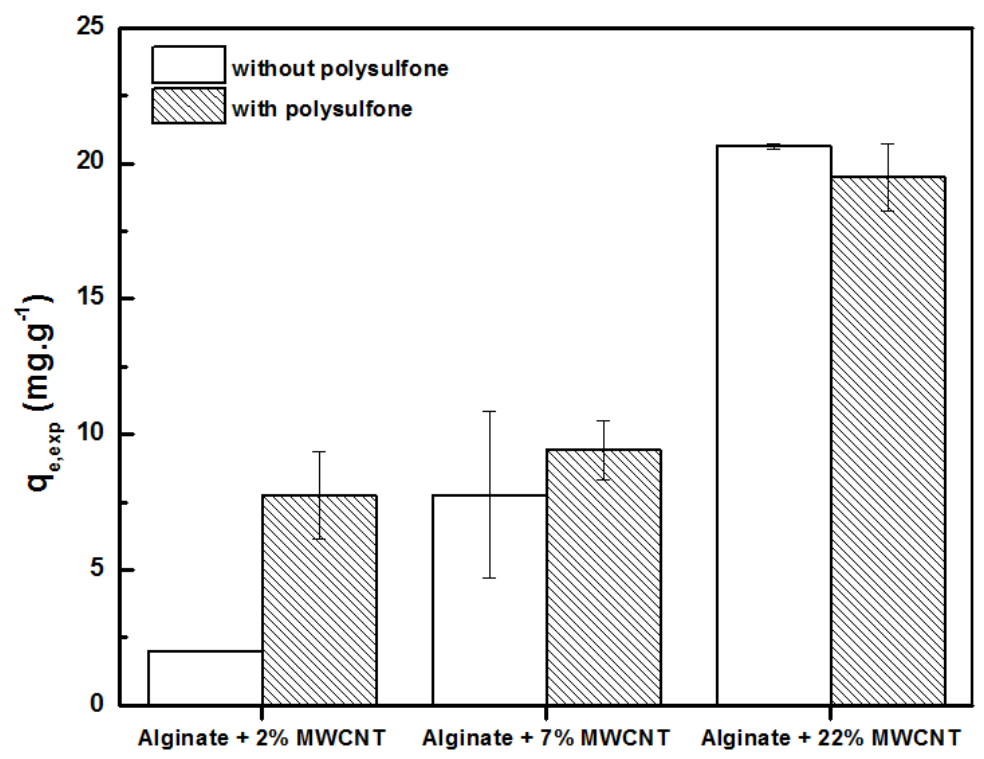

Fig. 6.8 Equilibrium amounts of BPA adsorbed to Ca-Alg/MWCNTs and Ca-Alg/MWCNTs/Psf. (Dosage $=4 \mathrm{~g} . \mathrm{L}^{-1}$ dry weight, $\mathrm{pH}=6.0$, BPA concentration $=100 \mathrm{mg} . \mathrm{L}^{-1}$ ). Data are expressed as mean \pm standard error.

Stability of the hybrid beads was examined by means of a compression test at $40 \%$ compressive extension. Table 6.4 summarizes the compression property and initial diameter of the hybrid beads before compression.

Table 6.4. Physical properties of the hybrid beads

\begin{tabular}{lcc}
\hline Sample & $\begin{array}{c}\text { compressive load at } \\
\mathbf{4 0} \% \text { extension }(\mathbf{N})\end{array}$ & ${\text { bead diameter }(\mathbf{m m})^{\mathrm{a}}}^{\mathrm{C}}$ \\
\hline $\mathrm{Ca}-\mathrm{Alg}$ & $1.10 \pm 0.02$ & $3.37 \pm 0.02$ \\
$\mathrm{Ca}-\mathrm{Alg} / \mathrm{Psf}$ & $6.46 \pm 0.39$ & $4.00 \pm 0.04$ \\
$\mathrm{Ca}-\mathrm{Alg} / 7 \%-M W C N T s$ & $1.85 \pm 0.07$ & $3.59 \pm 0.06$ \\
$\mathrm{Ca}-\mathrm{Alg} / 7 \%-\mathrm{MWCNTs} /$ Psf & $13.48 \pm 1.01$ & $3.92 \pm 0.06$ \\
$\mathrm{Ca}-\mathrm{Alg} / 22 \%-M W C N T s$ & $3.38 \pm 0.2$ & $3.53 \pm 0.03$ \\
$\mathrm{Ca}-\mathrm{Alg} / 22 \%-M W C N T s /$ Psf & $12.95 \pm 0.96$ & $4.04 \pm 0.07$ \\
\hline
\end{tabular}

${ }^{a}$ non-contracted beads were used for measurement

The results show that the compressive load capacity increased with the MWCNT content added, this observation is in accordance with the previous report, which indicated that the addition of carbon nanotubes as filler improved the mechanical property of 
hydrogel $^{12}$. The presence of Psf, together with MWCNTs, increased the compressive load capacity at $40 \%$ compressive extension up to twelvefold in comparison to pure alginate beads.

Although the addition of the Psf layer does not significantly affect the BPA adsorption (especially at higher MWCNTs content), it nevertheless improves the compressive load capacity, and hence the stability, of the swollen bead.

\section{Effect of pH on BPA adsorption to Ca-Alg/22\%-MWCNT/Psf beads}

The $\mathrm{pH}$ of the aqueous solution is one of the important parameters affecting the adsorption process because it influences the speciation and the functional groups present in the adsorbate-adsorbent system. The effect of initial solution $\mathrm{pH}$ on BPA removal using Ca-Alg/22\%-MWCNT/Psf beads is shown in Fig. 6.9(a). The pH ranged from 3 to 11.
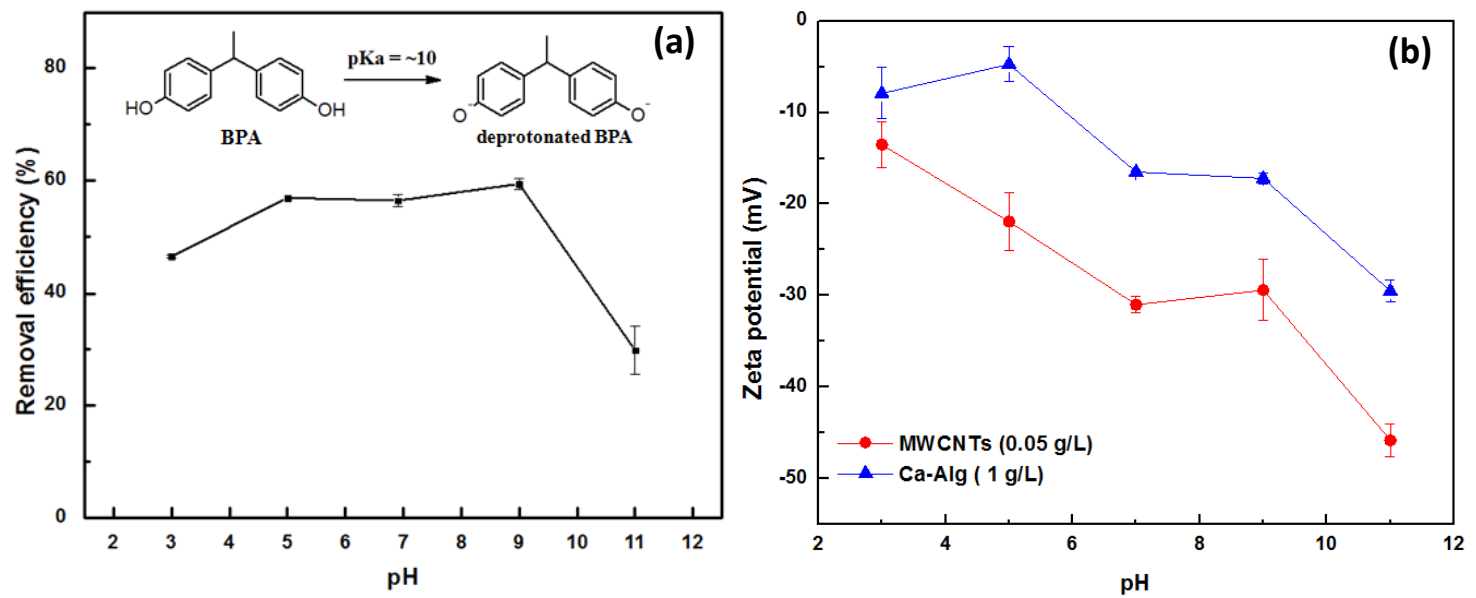

Fig. 6.9.(a) The effect of $\mathrm{pH}$ on BPA removal using Ca-Alg/ 22\%-MWCNTs/Psf beads (Dosage $=4 \mathrm{~g} \cdot \mathrm{L}^{-1}$ dry weight, BPA concentration $\left.=100 \mathrm{mg} . \mathrm{L}^{-1}\right)$ (b) Zeta-potential curves vs. $\mathrm{pH}$ of Caalginate $(\boldsymbol{\Delta})$ and MWCNTs $(\bullet)$ Data are expressed as mean \pm standard error.

The $\mathrm{pK}_{\mathrm{a}}$ value for BPA was reported to be in the range of $9.6-10.2^{13}$; thus, BPA will be negatively charged when the $\mathrm{pH}$ is higher than $\mathrm{pK}_{\mathrm{a}}$ and neutral at a $\mathrm{pH}$ lower than $\mathrm{pK}_{\mathrm{a}}$. From Fig. 6.9(a), it can be seen that there is no significant fluctuation in BPA removal observed at a $\mathrm{pH}$ less than 9; however, the removal efficiency decreased at higher $\mathrm{pH}$ levels. Zeta-potential measurements of Ca-alginate and MWCNT particles are shown in 
Fig. 6.9(b). The graph shows the trend whereby the surfaces of Ca-alginate and MWCNTs became more negatively charged as the $\mathrm{pH}$ increased. Similarly, the Psf membrane was also reported as more negatively charged with increasing $\mathrm{pH}^{7}$.

If we consider the behavior of individual components of the bead, namely $\mathrm{Ca}$-alginate, MWCNTs and Psf (which become more negatively charged with increasing $\mathrm{pH}$ ) then as $\mathrm{pH}>\mathrm{pKa}$, the electrostatic repulsion effect may have taken place as the surface of BPA became negatively charged, which resulted in less binding affinity and lower adsorption of BPA onto the hybrid beads. Based on the experimental results, the solution $\mathrm{pH}$ of subsequent experiments in this study was adjusted to 6.0, which is lower than the pKa of BPA. Hence, it can be assumed that there was no net electrical charge in the BPA molecules and that the BPA adsorption onto the hybrid bead occurred mainly via nonelectrostatic interaction - namely hydrophobic affinity with Psf and $\pi-\pi$ electron coupling between MWCNTs and the $\pi$-electrons of the aromatic compounds ${ }^{14}$.

\section{Effect of Ca-Alg/22\%-MWCNT/Psf beads dosage on BPA adsorption}

Effect of hybrid beads dosage on the removal of BPA is shown in Fig. 6.10. Experimental studies were conducted at room temperature with a $100 \mathrm{mg} . \mathrm{L}^{-1} \mathrm{BPA}$ concentration using a contact time of more than $72 \mathrm{~h}$ to ensure that an equilibrium condition was achieved.

It is evident that removal of BPA increased when increasing the dosage from 2 to 10 g. $\mathrm{L}^{-1}$ dry weight, but there was no significant increase in removal as the dosage was increased further. At the lowest dosage tested ( 2 g. $\mathrm{L}^{-1}$ dry weight), the BPA removal efficiency was $41.3 \%$. Meanwhile at the highest dosage (30 g. $\mathrm{L}^{-1}$ dry weight), the removal efficiency was $97.9 \%$. The higher adsorbent dosage provides more surface-active sites available for adsorption. A further increase in adsorption-active sites through increased dosage produces no substantial effect after equilibrium is reached. 


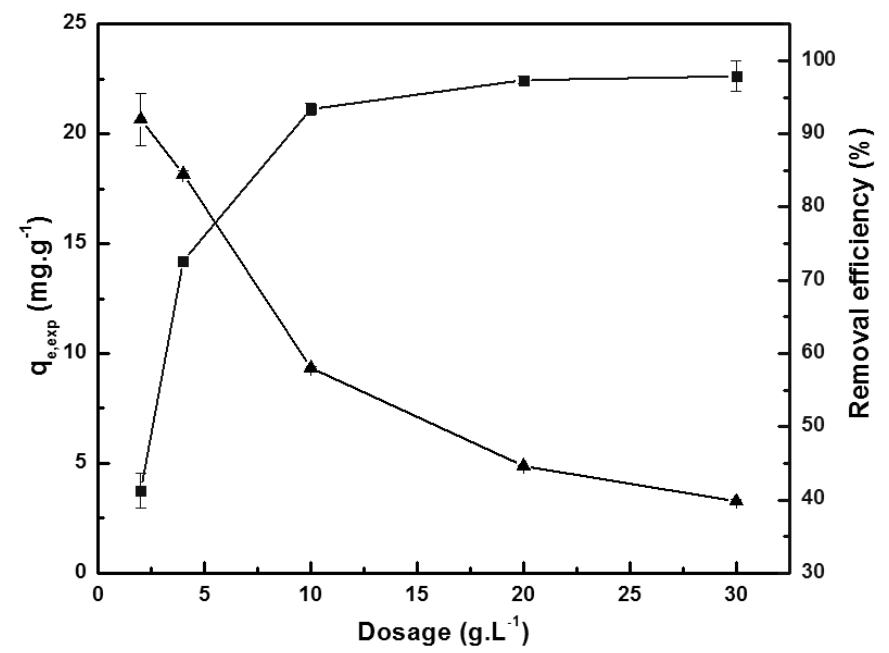

Fig.6.10. The effect of adsorbent dosage on the adsorption of BPA onto Ca-Alg/ 22\%MWCNTs/Psf beads at equilibrium $\left(\mathrm{pH}=6.0, \mathrm{BPA}\right.$ concentration $=100 \mathrm{mg} . \mathrm{L}^{-1}$, contact time $=$ $141 \mathrm{~h}),(\boldsymbol{\Delta})$ represents adsorption capacity and (a) denotes \%removal. Data are expressed as mean \pm standard error.

\subsubsection{Adsorption properties}

\section{Adsorption kinetic}

The adsorption kinetic depicts the rate of BPA adsorption on the hybrid beads and is one of the important considerations in designing a water treatment process as the kinetic parameters can be used for predicting the adsorption rate and selecting the optimum conditions for the operation of full-scale batch process. The adsorption kinetic can be distinguished by its different stages. Surface adsorption and rapid external diffusion occur at the initial stage of adsorption, which is indicated by the curved portion in the plot of adsorption capacity against time. The subsequent linear portion in the plot is attributed to steady intraparticle diffusion. The plot reaches plateau when the adsorbate-adsorbent system is in equilibrium, as the intraparticle diffusion decreases due to fewer available adsorption sites and the lower concentration of adsorbate remaining in the solution ${ }^{15}$. 


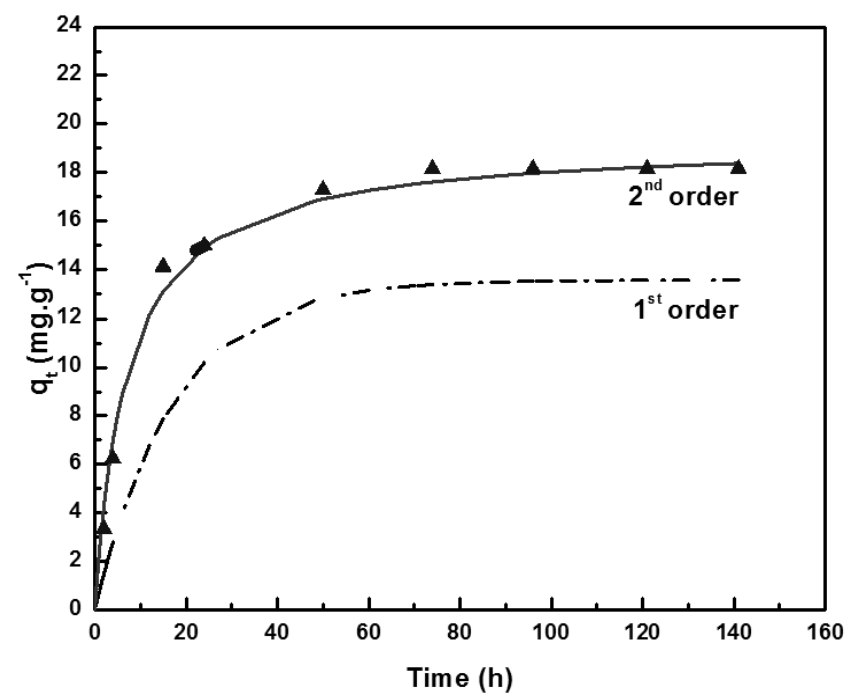

Fig. 6.11. Effect of contact time on the adsorption of BPA on the Ca-Alg/ 22\%-MWCNTs/Psf beads (Dosage $=4 \mathrm{~g} . \mathrm{L}^{-1}$ dry weight, $\mathrm{pH}=6.0$, BPA concentration $=100 \mathrm{mg} \cdot \mathrm{L}^{-1}$ ), the dotted line and solid lines correspond to simulations based on pseudo-first-order and pseudo-second-order models

The effect of contact time on the adsorption of $100-\mathrm{mg} . \mathrm{L}^{-1}$ BPA onto Ca-Alg/22\%MWCNT/Psf beads with a dosage of 4 g.L. $L^{-1}$ dry weight was analyzed and shown in Fig. 6.11. The adsorption capacity of the hybrid beads rose rapidly in the first $40 \mathrm{~h}$ and then increased at slower rate until the equilibrium was reached within $72 \mathrm{~h}$. The lengthy contact time required to achieve equilibrium might have been due to the very slow diffusion of the BPA compound from the solution into the porous network of Psf and alginate. Based on the result, a contact time of more than $72 \mathrm{~h}$ was chosen in all experiments conducted in this study to ensure that adsorption equilibrium is established.

To understand the mechanism of the adsorption, the data were analyzed by using two widely used kinetic models, namely, pseudo-first order and pseudo-second order ${ }^{16,17}$.

Table 6.5 and Fig.6.12 show the calculated kinetic parameters and plot of $t / q_{t}$ against $t$ for BPA adsorption onto Ca-Alg/22\%-MWCNT/Psf beads (dosage $=4 \mathrm{~g} . \mathrm{L}^{-1}$ dry weight, $\mathrm{pH}=6.0)$ at different initial BPA concentrations. 
Table 6.5. Kinetic parameters for BPA adsorption by Ca-Alg/ 22\%-MWCNTs/Psf at different initial BPA concentrations. (Dosage $=4 \mathrm{~g} . \mathrm{L}^{-1}$ dry weight, $\mathrm{pH}=6.0$ )

\begin{tabular}{|c|c|c|c|c|c|c|c|c|}
\hline \multirow{2}{*}{$\begin{array}{c}\text { Concentration } \\
\text { of BPA } \\
\left(\mathbf{m g} \cdot \mathbf{L}^{-1}\right)\end{array}$} & \multirow{2}{*}{$\underset{\left(\mathrm{mg} \cdot \mathrm{g}^{-1}\right)}{\left.\mathrm{q}_{\mathrm{e}}\right) \exp }$} & \multicolumn{3}{|c|}{ Pseudo-first-order } & \multicolumn{4}{|c|}{ Pseudo-second-order } \\
\hline & & $\underset{\left(\mathrm{mg} \cdot \mathrm{g}^{-1}\right)}{\mathrm{q}_{\mathrm{e}, \mathrm{cal}}}$ & $\begin{array}{c}\mathbf{k}_{1} \\
\left(\mathbf{h}^{-1}\right)\end{array}$ & $\mathbf{R}^{2}$ & $\underset{\left(\mathrm{mg} \cdot \mathrm{g}^{-1}\right)}{\mathrm{qe}_{\mathrm{e}} \mathrm{al}}$ & $\begin{array}{c}\mathrm{k}_{2} \\
\left(\mathrm{~g} \cdot \mathrm{mg}^{-1} \cdot \mathrm{h}^{-1}\right)\end{array}$ & $\underset{\left(m g \cdot g^{-1} h^{-1}\right)}{h}$ & $\mathbf{R}^{2}$ \\
\hline 100 & 18.16 & 13.6 & 0.058 & 0.9626 & 19.31 & 0.007 & 2.734 & 0.9993 \\
\hline 60 & 12.69 & 9.11 & 0.052 & 0.9847 & 13.37 & 0.012 & 2.125 & 0.9997 \\
\hline 20 & 4.75 & 4.11 & 0.082 & 0.9972 & 4.96 & 0.040 & 0.990 & 0.9994 \\
\hline
\end{tabular}

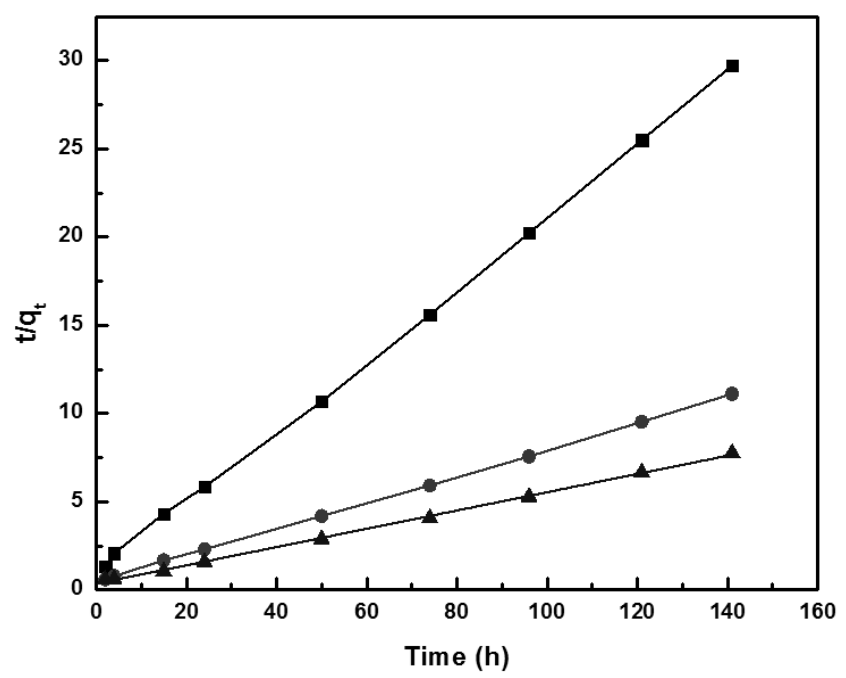

Fig. 6.12. Pseudo-second order kinetic plots for the adsorption of BPA on Ca-Alg/ 22\%MWCNTs/Psf beads (Dosage $=4 \mathrm{~g} . \mathrm{L}^{-1}$ dry weight, $\mathrm{pH}=6.0$ ) at BPA concentrations of (घ) $20 \mathrm{mg} . \mathrm{L}^{-1},(\bullet) 60 \mathrm{mg} . \mathrm{L}^{-1}$ and $(\boldsymbol{\Delta}) 100 \mathrm{mg} . \mathrm{L}^{-1}$. Data are expressed as a mean.

High correlations $\left(\mathrm{R}^{2}>0.95\right)$ were obtained for both kinetic models. However, the calculated equilibrium adsorption capacity obtained from the pseudo-second order model is closer to the experimental adsorption capacity in comparison to the equilibrium adsorption capacity calculated using pseudo-first order model. These results suggest that the pseudo-second order model should be employed to represent the adsorption of BPA onto the hybrid beads rather than the pseudo-first order model. 
It is observed that when the initial BPA concentration was increased, the pseudo-second order rate constant $\left(\mathrm{k}_{2}\right)$ decreased while the initial adsorption rate $(\mathrm{h})$ increased, which suggested that concentrations of both adsorbate and adsorbent were involved in the ratedetermining step.

The Weber-Morris kinetic model ${ }^{18}$ was utilized to further probe the rate-controlling steps in the adsorption process of BPA onto the hybrid beads. When a plot of $\mathrm{q}_{\mathrm{t}} \mathrm{vs} \mathrm{t}^{0.5}$ is linear, it means that intra-particle diffusion is involved in the adsorption process. In addition, if the plot passes through the origin, the intra-particle diffusion can be regarded as a ratedetermining step ${ }^{19}$

Fig. 6.13(a) shows the plot of $\mathrm{q}_{\mathrm{t}}$ against $\mathrm{t}^{0.5}$ for the Ca-Alg/22\%-MWCNT/Psf beads $\left(\right.$ dosage $=4$ g. $\mathrm{L}^{-1}$ dry weight, $\mathrm{pH}=6.0$, BPA concentration of $\left.100 \mathrm{mg} . \mathrm{L}^{-1}\right)$; it can be observed that the plot could be divided into three linear portions representing different sorption processes, namely external mass transfer $\left(\mathrm{K}_{\mathrm{d} 1}=4.346 \mathrm{mg} \cdot \mathrm{g}^{-1} \cdot \mathrm{h}^{-0.5}\right)$, intra-particle diffusion $\left(\mathrm{K}_{\mathrm{d} 2}=0.9987 \mathrm{mg} \cdot \mathrm{g}^{-1} \cdot \mathrm{h}^{-0.5}\right)$ and active sites binding. Since the active sites binding was considered to have occurred rapidly, it could not be a rate-determining step, which left intra-particle diffusion and external mass transfer as probable rate-controlling processes involved in the adsorption system.
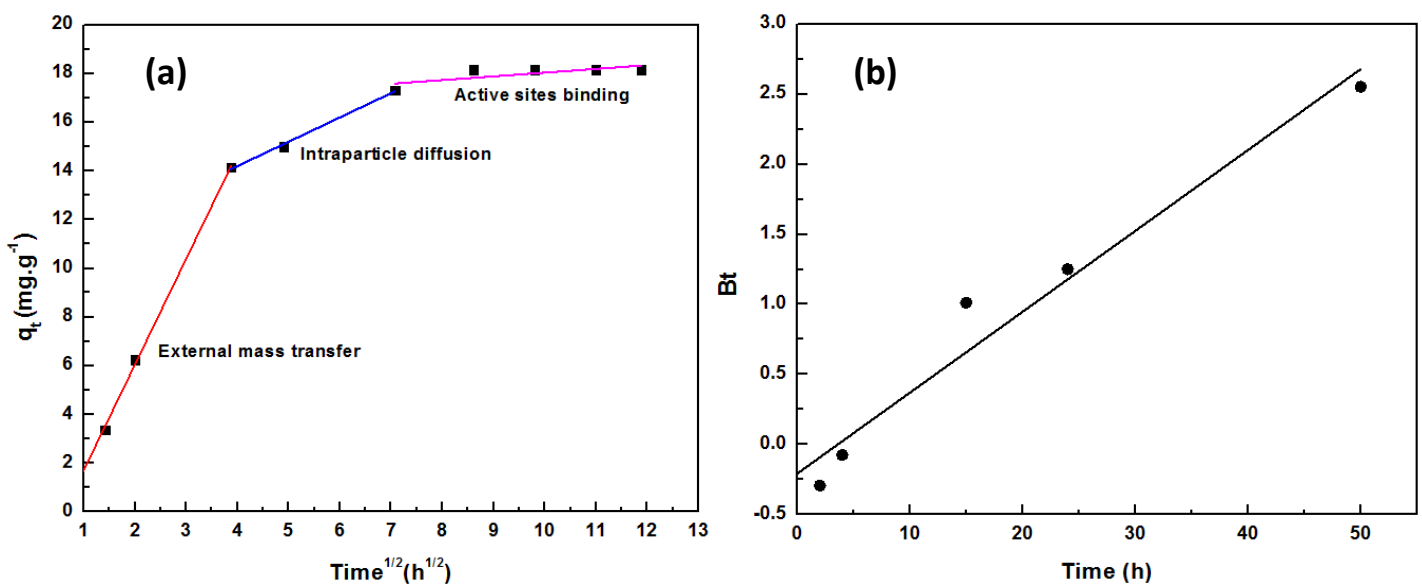

Fig. 6.13. (a) Weber-Morris graph and (b) Plot of $B_{t}$ against time for the adsorption of BPA on $\mathrm{Ca}-\mathrm{Alg} / 22 \%$-MWCNTs/Psf beads (Dosage $=4 \mathrm{~g} . \mathrm{L}^{-1}$ dry weight, $\mathrm{pH}=6.0$ at BPA concentrations of $100 \mathrm{mg} . \mathrm{L}^{-1}$ ) Data are expressed as mean. 
The plot on Fig. 6.13(a) does not pass through the origin which suggested that although intra-particle diffusion was involved in the adsorption process, it was not the initial rate controlling step.

The Boyd plot helps to determine whether the rate-controlling steps are external mass transfer or intra-particle diffusion ${ }^{20}$. If the plot of $B_{t}$ against time passes through the origin, then intra-particle diffusion controls adsorption; otherwise, external mass transfer is the rate-controlling step in the adsorption system. Fig. 6.13(b) shows the plot of $B_{t}$ against time for the Ca-Alg/22\%-MWCNT/Psf beads (dosage $=4$ g. $\mathrm{L}^{-1}$ dry weight, $\mathrm{pH}=$ 6.0, BPA concentration of $100 \mathrm{mg} . \mathrm{L}^{-1}$ ). Like the Weber-Morris model, the linearized plot did not pass through the origin, which implies that external mass transfer was the initial rate-controlling process during adsorption ${ }^{21}$. Both models suggest that intra-particle diffusion and external mass transfer held important roles in the adsorption of BPA onto the hybrid beads. The desorption of BPA released from the Ca-Alg/22\%-MWCNT/Psf beads was estimated by immersing the used hybrid beads with a known adsorbed amount of BPA into commonly used regenerative solvents. The desorption of BPA in 2-propanol and ethanol was estimated to be about $67 \% \pm 3 \%$ and $87 \pm 4 \%$ (mean \pm standard error). This preliminary result suggested the re-usability potential of the hybrid beads. Based on the result, ethanol was selected as the desorption solvent in the column reactor.

\section{Adsorption isotherm}

The adsorption isotherm correlates the concentration of adsorbate in the bulk solution and the amount of solute adsorbed per unit weight of the adsorbent under equilibrium conditions. A correlation between the batch-equilibrium experimental data and the theoretical model is an important consideration as it could be used in the design and analysis of the adsorption system. The adsorption isotherm studies were performed at fixed adsorbent dosage of 4 g. $\mathrm{L}^{-1}$ dry weight by changing the initial BPA concentrations. The equilibrium adsorption of BPA onto $\mathrm{Ca}-\mathrm{Alg} / 22 \%-\mathrm{MWCNT} / \mathrm{Psf}$ beads is shown in

Fig. 6.14. It can be observed that the adsorption capacity of the hybrid beads gradually increased with the increasing equilibrium concentration of BPA in the liquid solution as it progressively reached saturation. The equilibrium data were then analyzed using two 
well-known equilibrium models, the Langmuir $^{22}$ and Freundlich ${ }^{23}$. The sorption parameters obtained from the models helped to clarify the interaction between the adsorbate and the adsorbent as the system reached equilibrium

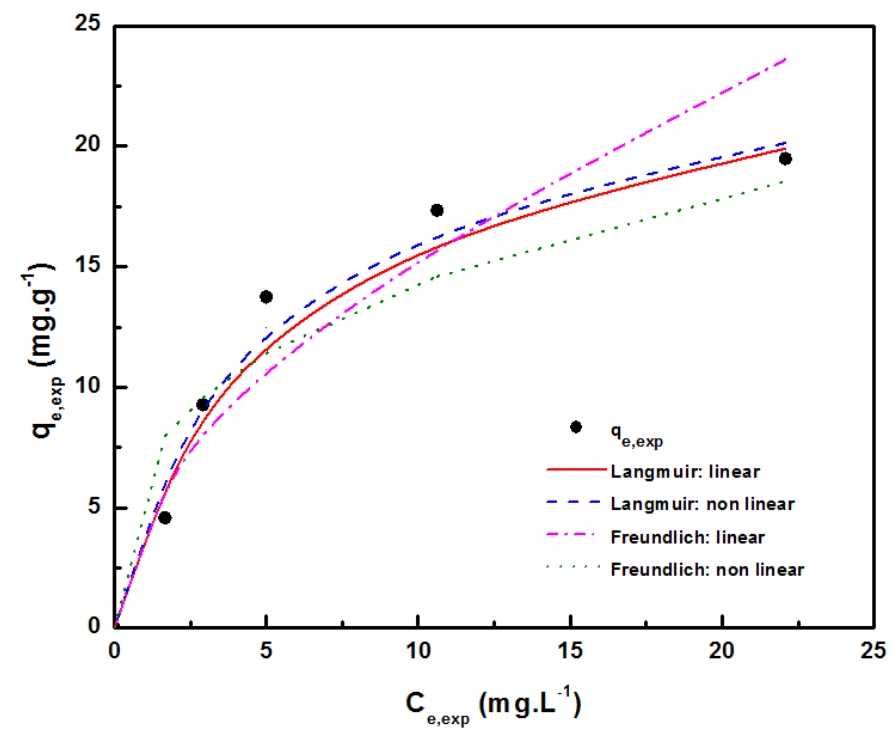

Fig. 6.14. Isotherm of BPA adsorption onto Ca-Alg/ 22\%-MWCNTs/Psf beads (Dosage $=4$ g.L $\mathrm{L}^{-1}$ dry weight, $\mathrm{pH}=6.0$, initial BPA concentrations $=20 \mathrm{mg} . \mathrm{L}^{-1}-100 \mathrm{mg} \cdot \mathrm{L}^{-1}$ ). Data are expressed as mean \pm standard error

For both isotherm models, a non-linear method based on a trial-and-error curve-fitting optimization procedure was performed using solver add-in with Microsoft's excel to determine the corresponding Langmuir and Freundlich coefficients. The Langmuir and Freundlich parameters for BPA adsorption onto Ca-Alg/ 22\%- MWCNTs/Psf beads $\left(\right.$ dosage $=4 \mathrm{~g} . \mathrm{L}^{-1}$ dry weight, $\mathrm{pH}=6.0, \mathrm{BPA}$ concentration $\left.=100 \mathrm{mg} \cdot \mathrm{L}^{-1}\right)$ are shown in Table 6.6. 
Table 6.6. Langmuir and Freundlich parameters for BPA adsorption by $\mathrm{Ca}-\mathrm{Alg} / 22 \%$ MWCNTs/Psf at equilibrium (Dosage $=4$ g.. ${ }^{-1}$ dry weight, $\mathrm{pH}=6.0$ )

\begin{tabular}{|c|c|c|c|c|c|c|c|c|}
\hline & \multicolumn{5}{|c|}{ Langmuir } & \multicolumn{3}{|c|}{ Freundlich } \\
\hline & $\underset{\left(\mathrm{mg} \cdot \mathrm{g}^{-1}\right)}{\mathrm{q}_{\mathrm{m}}}$ & $\begin{array}{c}\alpha_{\mathrm{L}} \\
\left(\mathbf{L} \cdot \mathbf{m g}^{-1}\right)\end{array}$ & $\begin{array}{c}\mathbf{K}_{\mathrm{L}} \\
\left(\mathbf{L} \cdot \mathbf{g}^{-1}\right)\end{array}$ & $\mathbf{R}_{\mathbf{L}}$ & $\mathbf{R}^{2}$ & $\mathbf{K}_{\mathbf{F}}$ & $\mathbf{n}$ & $\mathbf{R}^{2}$ \\
\hline Linear & 24.69 & 0.1883 & 4.650 & 0.050 & 0.9808 & 4.589 & 1.890 & 0.9092 \\
\hline $\begin{array}{l}\text { Non- } \\
\text { linear }\end{array}$ & 24.53 & 0.2073 & 5.085 & 0.050 & 0.9825 & 6.745 & 3.061 & 0.9297 \\
\hline
\end{tabular}

The calculated values of $\mathrm{n}$ coefficients, which represents adsorption strength, in both linear and non-linear Freundlich models are between 1 and 10, which indicated favorable adsorption $^{24}$. The results are also supported by the value of the coefficients obtained from the Langmuir model. The maximum adsorption capacity $\mathrm{q}_{\mathrm{m}}$ of the hybrid beads at an adsorbent dosage of 4 g. $\mathrm{L}^{-1}$ dry weight was predicted, using the non-linear and linear Langmuir models, to be $24.53 \mathrm{mg} \cdot \mathrm{g}^{-1}$ and $24.69 \mathrm{mg} \cdot \mathrm{g}^{-1}$, respectively. The $\mathrm{R}_{\mathrm{L}}$ value, calculated for the initial concentration of BPA $100 \mathrm{mg} \cdot \mathrm{L}^{-1}$ in this study, was 0.05 ; it has been suggested that a value of $\mathrm{R}_{\mathrm{L}}$ between 0 and 1 indicates favorable adsorption ${ }^{25}$.

The adsorption mechanism of BPA on the hybrid beads is complex as the bead is comprised of more than two materials. However, the correlation coefficients attained from both adsorption isotherm models indicated a strong affinity for BPA adsorption onto the hybrid beads. The correlation coefficients for both the linear and non-linear Langmuir models were higher than the Freundlich's model, which suggested that the Langmuir model fit the adsorption equilibrium data better and suggested that BPA adsorption by the hybrid beads occurred in a monolayer behavior. 


\subsubsection{Reusability of the Column}

The adsorption isotherm data may not be a good representative of scale-up data. To better understand the adsorption behavior of the hybrid beads under continuous flow, a packedbed column was constructed. A continuous flow of $100 \mathrm{mg} \cdot \mathrm{L}^{-1}$ of BPA was injected to the column for up to $8 \mathrm{~h}$, followed by desorption before the subsequent cycle started. The breakthrough curves are shown in Fig.6.15.
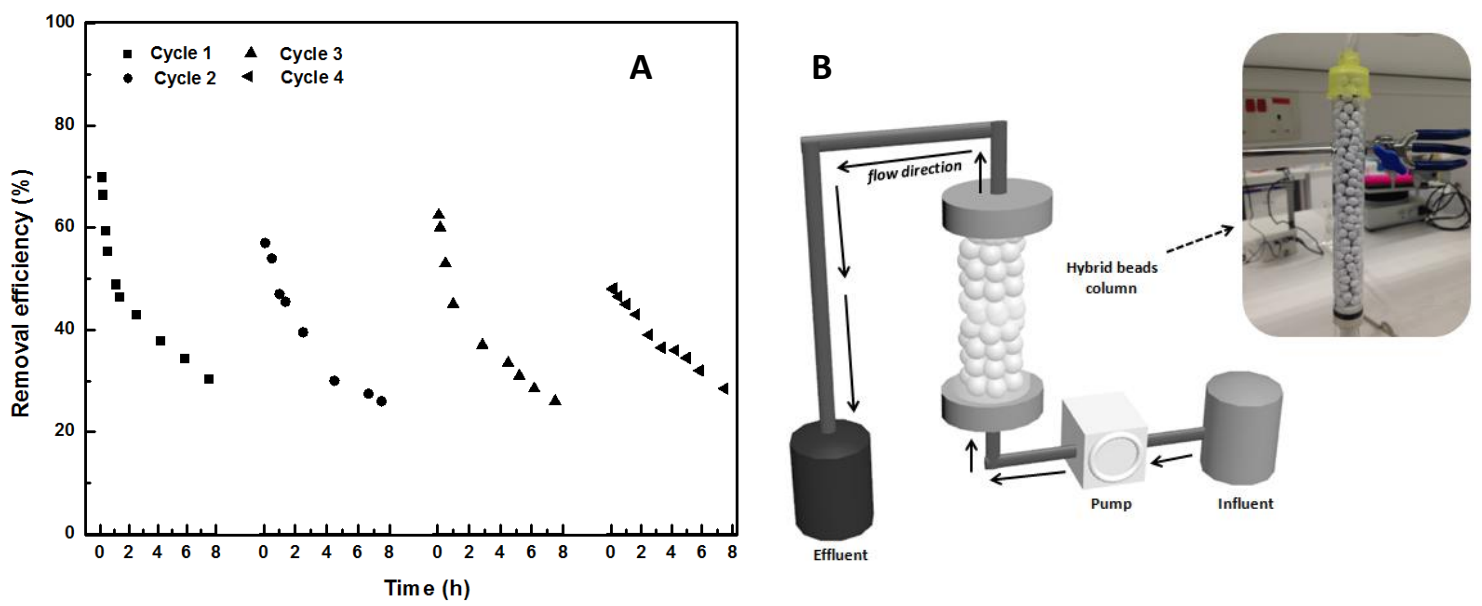

Fig. 6.15. (a) Breakthrough curve in continuous-flow column reactor for adsorption of $100 \mathrm{mg} . \mathrm{L}^{-1}$ BPA on Ca-Alg/22\%-MWCNTs/Psf beads and (b) Illustration of up-flow packed-bed column setup used in the continuous flow experiment

Since the column study was conducted using high concentrations of BPA, it was not possible to remove all of the BPA in the solution initially. Using the current set-up (beads height $=12.5 \mathrm{~cm}$ and flow rate $\left.0.5 \mathrm{ml} \cdot \mathrm{min}^{-1}, \mathrm{BPA}=100 \mathrm{mg} \cdot \mathrm{L}^{-1}\right)$, it appeared that longer contact time was needed for the column to achieve complete saturation. Similar removal patterns with slight discrepancies were observed for the first three cycles, but at the fourth cycle, the adsorption capacity started to decrease, which was indicated by a lower removal percentage in the beginning of the cycle. This behavior might be attributed to the decline in desorption efficiency. Nevertheless, the result highlighted the re-usability of the packed-hybrid beads column under continuous flow. 


\subsection{Conclusion}

Novel hybrid beads comprised of alginate and MWCNT core and enveloped in a Psf layer were proposed and fabricated in this study. Addition of a Psf layer improved the adsorbed BPA amount at lower MWCNT amounts but was less significant at higher MWCNTs. The hybrid beads were relatively stable at wide range of $\mathrm{pH}$ levels. The adsorption profile followed the pseudo-second order kinetic and Langmuir isotherm models with high correlation. The addition of a Psf layer on composite beads that contained MWCNTs improved the compressive load capacity of the composite beads. This has the potential for shielding and improving the stability of the composite beads in reactors where they may be subjected to abrasion, which could affect the beads' integrity.

In this chapter, we fabricated and characterized a novel alginate-based platform for encapsulation of MWCNTs with addition of a polysulfone coating to reduce the leakage of MWCNTs. In the next chapter, we elaborate on our attempted incorporation of BPA-degrading bacteria into hybrid $\mathrm{Ca}$ alginate/MWCNTs/Polysulfone beads in order to improve BPA removal efficiency through combination of adsorption-biodegradation processes. 


\section{References}

1 Fugetsu, B. et al. Encapsulation of multi-walled carbon nanotubes (MWCNTs) in $\mathrm{Ba} 2+$-alginate to form coated micro-beads and their application to the preconcentration/elimination of dibenzo-p-dioxin, dibenzofuran, and biphenyl from contaminated water. Analyst 129, 565-566 (2004).

2 Albarelli, J. Q., Santos, D. T., Murphy, S. \& Oelgemoller, M. Use of Ca-alginate as a novel support for $\mathrm{TiO} 2$ immobilization in methylene blue decolorisation. Water Science and Technology 60, 1081 (2009).

3 Lee, K. Y., Bouhadir, K. H. \& Mooney, D. J. Controlled degradation of hydrogels using multi-functional cross-linking molecules. Biomaterials 25, 2461-2466 (2004).

4 El-Hibri, M. J. \& Weinberg, S. A. in Encyclopedia of Polymer Science and Technology (John Wiley \& Sons, Inc., 2002).

5 Mao, M. et al. Polysulfone-activated carbon hybrid particles for the removal of BPA. Separation Science and Technology 41, 515-529 (2006).

6 Zhao, C. et al. Preparation of porous polysulfone beads for selective removal of endocrine disruptors. Separation and Purification Technology 40, 297-302 (2004).

7 Su-Hua, W., Bing-zhi, D. \& Yu, H. Adsorption of bisphenol A by polysulphone membrane. Desalination 253, 22-29 (2010).

8 Ben-Dov, E., Kramarsky-Winter, E. \& Kushmaro, A. An in situ method for cultivating microorganisms using a double encapsulation technique. FEMS Microbiology Ecology 68, 363-371 (2009).

9 Loeb, S. \& Sourirajan, S. in Saline Water Conversion II Vol. 38 Advances in Chemistry Ch. 9, 117-132 (American Chemical Society, 1963).

10 Matsuura, T. Progress in membrane science and technology for seawater desalination - a review. Desalination 134, 47-54 (2001).

11 Jodra, Y. \& Mijangos, F. Phenol adsorption in immobilized activated carbon with alginate gels. Separation Science and Technology 38, 1851-1867 (2003).

12 Tong, X., Zheng, J., Lu, Y., Zhang, Z. \& Cheng, H. Swelling and mechanical behaviors of carbon nanotube/poly(vinyl alcohol) hybrid hydrogels. Materials Letters 61, 1704-1706 (2007).

13 Staples, C. A., Dome, P. B., Klecka, G. M., Oblock, S. T. \& Harris, L. R. A review of the environmental fate, effects, and exposures of bisphenol A. Chemosphere 36, 2149-2173 (1998).

14 Long, R. Q. \& Yang, R. T. Carbon nanotubes as superior sorbent for dioxin removal. Journal of the American Chemical Society 123, 2058-2059 (2001).

15 Guibal, E., McCarrick, P. \& Tobin, J. M. Comparison of the sorption of anionic dyes on activated carbon and chitosan derivatives from dilute solutions. Separation Science and Technology 38, 3049-3073 (2003).

16 Ho, Y. S. \& McKay, G. The kinetics of sorption of divalent metal ions onto sphagnum moss peat. Water Research 34, $735-742$ (2000).

17 Blanchard, G., Maunaye, M. \& Martin, G. Removal of heavy metals from waters by means of natural zeolites. Water Research 18, 1501-1507 (1984).

18 Weber, W. J. \& Morris, J. C. Kinetics of adsorption on carbon from solution. Journal of the Sanitary Engineering Division 89 (1963). 
19 Özacar, M. \& Şengil, İ. A. Application of kinetic models to the sorption of disperse dyes onto alunite. Colloids and Surfaces A: Physicochemical and Engineering Aspects 242, 105-113 (2004).

20 Boyd, G. E., Adamson, A. W. \& Myers, L. S. The exchange adsorption of ions from aqueous solutions by organic zeolites. II. Kinetics1. Journal of the American Chemical Society 69, 2836-2848 (1947).

21 Gupta, V. K., Kumar, R., Nayak, A., Saleh, T. A. \& Barakat, M. Adsorptive removal of dyes from aqueous solution onto carbon nanotubes: a review. Advances in colloid and interface science 193, 24-34 (2013).

22 Langmuir, I. The adsorption of gases on plane surfaces of glass, mica and platinum. Journal of the American Chemical Society 40, 1361-1403 (1918).

23 Freundlich, H. Over the adsorption in solution. J. Phys. Chem 57, 1100-1107 (1906).

24 Aksu, Z. \& Gönen, F. Biosorption of phenol by immobilized activated sludge in a continuous packed bed: prediction of breakthrough curves. Process Biochemistry 39, 599-613 (2004).

25 McKay, G., Blair, H. S. \& Gardner, J. R. Adsorption of dyes on chitin. I. Equilibrium studies. Journal of Applied Polymer Science 27, 3043-3057 (1982). 


\section{Chapter 7}

\section{Characterization and BPA Removal Performance by Ca-alginate/MWCNTs-Bacteria/Polysulfone beads}

This study reports the integration of the bacteria strain PBPA2 into a hybrid bead compartment comprised of multi-walled carbon-nanotube-embedded calcium-alginate beads with a polysulfone layer for the removal of bisphenol $A$ in a batch or packed-bed reactor. The inclusion of bacteria in calciumalginate/multi-walled carbon nanotubes/polysulfone beads improves BPA removal up to $20 \%$ in a batch reactor and extends the operation time in a continuous column flow.

* M.R. Hartono, R.S. Marks, X. Chen, A. Kushmaro; Hybrid Calcium-alginate/MWCNTsbacteria/polysulfone beads for removal of bisphenol A (in preparation) 


\subsection{Introduction}

Microbial-mediated degradation of BPA has been evaluated for the remediation of BPA. In the past three decades, BPA-tolerant and-degrading strains have been isolated from various sources in the environment ${ }^{1,2}$. Most of the identified strains belong to Sphingomonas $s p^{3,4}$, Pseudomonas $s .^{5}$ and Bacillus $s p^{6}$. Although it is cost-effective, biological treatment is usually limited by both toxicity and a slow degradation process with a high concentration of noxious waste. Immobilizing the microorganism increases its efficiency in biological wastewater treatment due to high density of bacteria. It also assists in the separation of liquid and solid and reduces the likelihood for washout ${ }^{7}$.

Since the 1970s, the biological activated carbon (BAC) process, which combines the adsorption capability of activated carbon with bacteria for the removal of organic pollutants, has been developed ${ }^{8,9}$. Greater adsorption and biological oxidation capacity in the combined process (as compared to their independent performance) has been observed in several studies ${ }^{10,11}$. As far as our knowledge, a limited number of studies have been reported in the literature regarding the integration and application of pollutant-degrading microorganisms with carbon nanomaterials for the removal of noxious contaminants ${ }^{12}$. In the previous chapter, we demonstrated the capability of hybrid calcium-alginate-multi walled carbon nanotube beads with an added polysulfone layer for the adsorption of BPA in a batch reactor ${ }^{13}$. In this follow-up study, we investigated the feasibility of incorporating BPA-degrading bacteria within the hybrid beads matrix. Performance of pollutant-degrading bacteria in contact with MWCNTs may be influenced by several factors. First is the inhibition of biodegradation due to bactericidal nature of CNTs ${ }^{14}$. Next is the decrease in bioavailability of pollutant due to strong and fast adsorption of MWCNTs, which may lower the degradation rate $^{15}$ and subsequently minimize the contribution of biodegradation. 


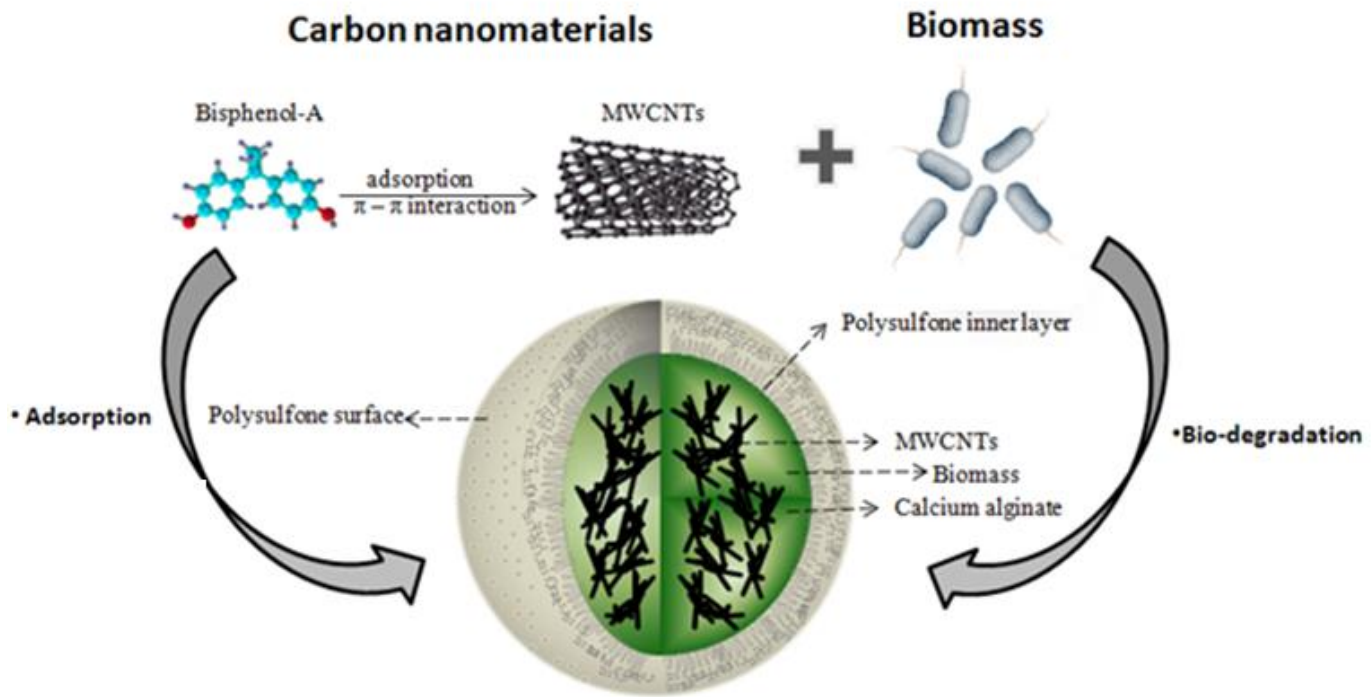

Fig. 7.1 Illustration of the proposed hybrid beads. Both bacteria and MWCNTs are embedded inside the calcium alginate bead and finally coated with a layer of polysulfone (Illustration by author)

Our initial premise was that by combining the superior adsorption ability of MWCNTs with bacteria degradation, a more efficient treatment could be constructed (Fig. 7.1). The work is divided into three parts: (1) Isolation of novel BPA-tolerant and-biodegrading bacteria PBPA2 from the environment, (2) Optimization of culture media for the degradation of BPA was conducted and (3) Testing the BPA removal performance in both batch and continuous column reactors.

\subsection{Experimental}

This section provides additional details relevant to this study, which were not covered in Chapter 3 - experimental methodology

\subsubsection{Methods}

Microorganism isolation and enrichment culture condition

The description of microorganism isolation and culture media was presented in section 3.3.4. In brief, BPA-tolerant bacteria PBPA2 was isolated from wastewater using an enrichment method with 2.0 g. $\mathrm{L}^{-1} \mathrm{BPA}$ as the sole carbon source ${ }^{16}$. The isolated PBPA2 
strain was not able to be regrown in the enrichment media; hence, culture media comprised of glucose, yeast extract, and $100 \mathrm{mg} \cdot \mathrm{L}^{-1}$ BPA (MYGB) was adapted ${ }^{17}$. PBPA2 was grown overnight in the MYGB culture media prior to immobilization.

\section{Beads immobilization process}

The detailed procedure of the immobilization of PBPA2 into hybrid carbon nanotubealginate-Psf beads was described in section 3.3.4.3 and was adapted from our previous work $^{13}$.

\section{Batch reactor - BPA removal}

BPA removal in a batch reactor by isolated PBPA2, either by free cells or immobilized form, was assessed based on the procedure described in section 3.3.4.4.

\section{Column Reactor}

Column studies were performed according to the procedure described in section 3.3.4.5. In this study, mineral media with BPA and $0.05 \%$ yeast extract (MYB) and mineral media with BPA (MB) were injected into the columns. Mineral media with $0.05 \%$ yeast extract (MY) was used in the regeneration study.

\subsubsection{Analytical Method}

BPA concentrations were estimated using HPLC as described in section 3.2.4.

\subsection{Results and discussion}

\subsubsection{Characterization of the isolated strain PBPA2}

The 16s rRNA genes from isolated strain PBPA2 were sequenced and identified with a 100\% homology match as Pseudomonas aeruginosa based on screening with the Basic Local Alignment Search Tool (BLAST).

\section{Effect of yeast extract addition to mineral media on BPA removal}

The BPA-tolerant and-biodegrading $\mathrm{PBPA}_{2}$ strain was isolated from the enrichment

culture media containing 2.0 g. $\mathrm{L}^{-1} \mathrm{BPA}$ as its sole carbon source, as adapted from Lobos 
et al. ${ }^{16}$. Utilizing the same media, this team was able to isolate strain MV1, which is capable of degrading BPA in a BPA-enriched medium; however, the loss of BPA degradation capacity was noted after the strain was regrown on nutrient media. This presents difficulty in recultivation of the strain outside of the enrichment culture. In this study, the isolated strain $\mathrm{PBPA}_{2}$ was acclimatized overnight in a mineral medium containing 0.5 g. $1^{-1}$ glucose, 2.0 g. $1^{-1}$ yeast extract and $100 \mathrm{mg} . \mathrm{l}^{-1}$ BPA. The strain grew rapidly in this media due to the presence of additional carbon sources besides BPA. It reached stationary phase after $8 \mathrm{~h}$ of incubation with a final $\mathrm{OD}_{600 \mathrm{~nm}}=\sim 0.4$ (as shown on Fig. 7.2(a)). For this BPA removal study, this same culture was inoculated into mineral media containing only BPA as the sole carbon source in a batch reactor. The initial $\mathrm{OD}_{600 \mathrm{~nm}}$ of the culture was $\sim 0.04$. Similar to the result reported by Lobos et al. ${ }^{16}$, we observed that $\mathrm{PBPA}_{2}$ was not able to remove BPA efficiently in the mineral mediumwith only around $0.6 \%$ BPA removed from the initial concentration of $20 \mathrm{mg} . \mathrm{l}^{-1}$ after 6 days of incubation. As shown in Fig. 7.2(b), the cell growth was slow with almost no improvement seen in the final $\mathrm{OD}_{600 \mathrm{~nm}}$. A similar finding was also reported by Zhang et al. $^{18}$, which reported slow cell growth for Achromobacter xylosoxidans strain B-16 grown in mineral media with BPA as the sole carbon source.
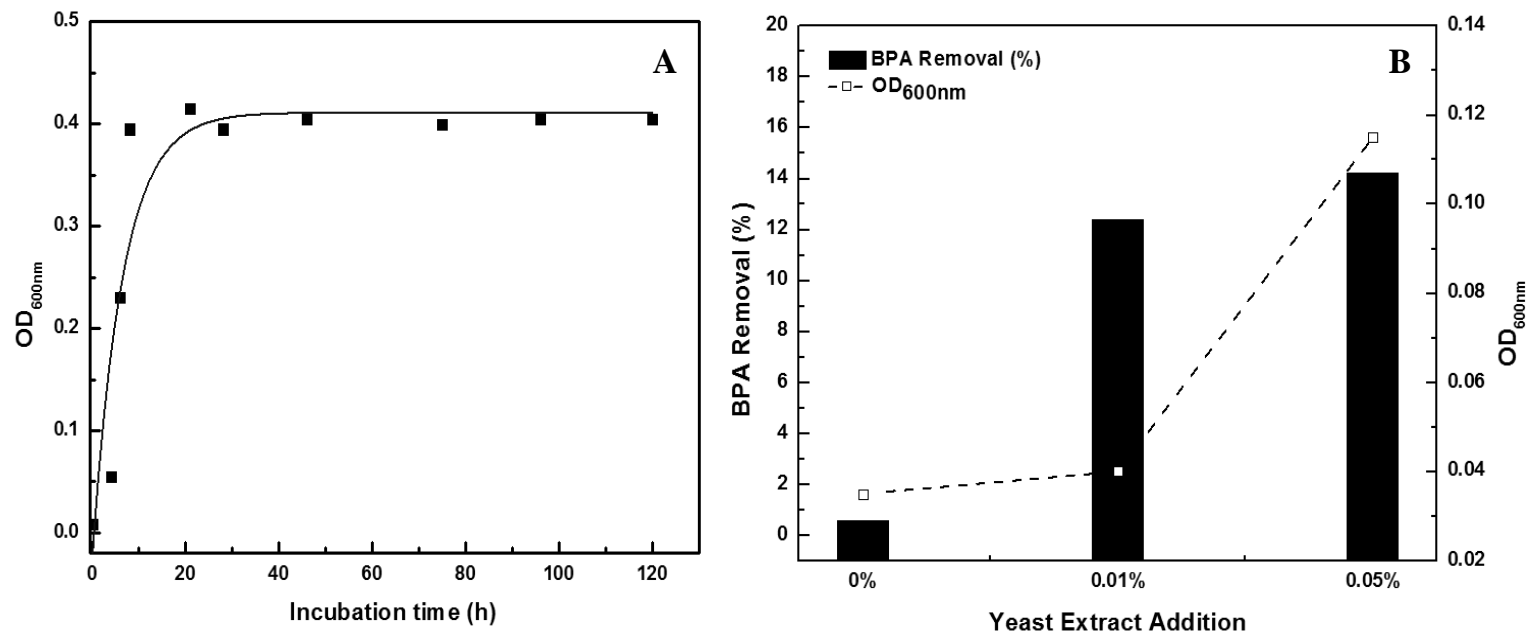

Fig. 7.2 (a) $\mathrm{OD}_{600 \mathrm{~nm}}$ of $\mathrm{PBPA}_{2}$ against incubation time in acclimatization medium supplied with high amounts of glucose and yeast extract and (b) Percentage of BPA removal and $\mathrm{OD}_{600 \mathrm{~nm}}$ of $\mathrm{PBPA}_{2}$ in mineral media with addition of different concentrations of yeast extract (Initial $\mathrm{OD}_{600 \mathrm{~nm}}$ $=\sim 0.04$ or $19.6 \mathrm{mg} \mathrm{dw} . \mathrm{L}^{-1}$, initial BPA concentration $=20 \mathrm{mg} \cdot \mathrm{l}^{-1}, 30^{\circ} \mathrm{C}, 150 \mathrm{rpm}, \sim 6$ days $)$ 
Prior studies have reported the improvement in BPA degradation in nutrient rich mediums $^{3,4,19}$, so we attempted to improve BPA removal through the addition of yeast extract into the mineral medium at $0.01 \%$ and $0.05 \%$ concentrations, at a starting BPA concentration of $20 \mathrm{mg} \cdot \mathrm{l}^{-1}$. As shown in Fig. 7.2(b), we observed an improvement in BPA removal, as well as $\mathrm{OD}_{600 \mathrm{~nm}}$ of the culture, in the presence of yeast extract. The increase in yeast extract concentration appeared to correlate with the increase in cell growth and percentage of BPA removal. After 6 days of incubation, up to $12 \%$ and $14 \%$ of BPA were removed in the culture with addition of $0.01 \%$ and $0.05 \%$ yeast extract, respectively. Based on this result, $0.05 \%$ yeast extract was added into the mineral media for the subsequent BPA removal experiments, utilizing the BPA tolerant strain $\mathrm{PBPA}_{2}$.

\section{Effect of starting cell density on BPA removal}

The effect of initial cell density on BPA removal over time is shown in Fig 7.3. Negligible BPA removal was observed at $20 \mathrm{mg} . \mathrm{L}^{-1} \mathrm{BPA}$ concentration by nonimmobilized PBPA2 cells after 2 days incubation.

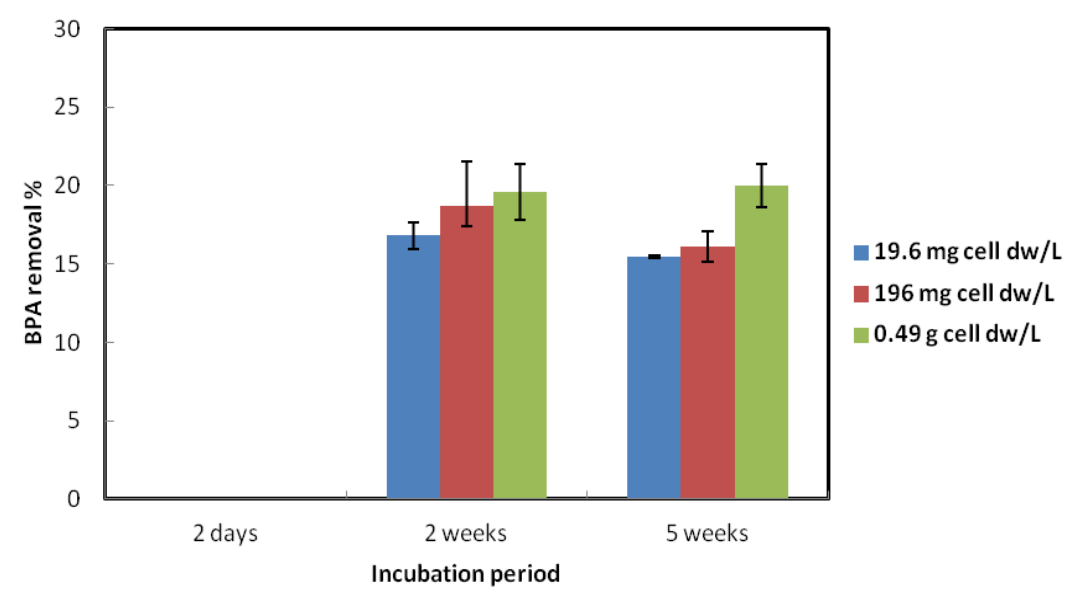

Fig. 7.3 Percentage of BPA removed by strain PBPA2 in the free culture form (Initial $\mathrm{OD}_{600 \mathrm{~nm}}=$ $\sim 0.04$ or $19.6 \mathrm{mg} \mathrm{dw} . \mathrm{L}^{-1}, \sim 0.4$ or $196 \mathrm{mg} \mathrm{dw} . \mathrm{L}^{-1}$, and $\sim 1.0$ or $0.49 \mathrm{~g} \mathrm{dw} . \mathrm{L}^{-1}$, BPA concentration = $20 \mathrm{mg} . \mathrm{l}^{-1}, 30^{\circ} \mathrm{C}, 150 \mathrm{rpm}$, ANOVA p-value $>0.05$ indicating insignificant difference)

This could be due to the yeast extract being consumed, instead of BPA, during early stages of growth. Once the yeast was depleted, BPA began to be utilized as a carbon source with the continuous incubation revealing $~ 18 \%$ removal after 5 weeks of incubation irrespective of starting cell density. This result also shows that, at the current 
level of BPA concentration and initial cell density, BPA does not inhibit the degradation capability of the free cell.

\section{Effect of MWCNTs towards viability of PBPA2}

A viability test was performed to understand the possible toxic effect of MWCNTs towards strain PBPA2. PBPA2 was incubated in MY media without BPA in the presence of different concentrations of MWCNTs (Fig. 7.4). No significant toxic effect was observed at 0.1 g.L ${ }^{-1}$ MWCNTs. Interestingly, when compared to the control, a $17 \%$ increase in the mean viable cell count was recorded. This finding is similar to previous studies, which suggests the stimulation effect of MWCNTs (at a certain level) for the upregulation of genes involved in bacteria growth ${ }^{12}$. However, a noticeable decrease in viable cells was seen upon exposure to higher MWCNT concentrations. Addition of 1.0 g.L $\mathrm{L}^{-1}$ MWCNTs showed a $3.5 \%$ decrease in the mean viable cell count, and further exposure to $10 \mathrm{~g} . \mathrm{L}^{-1}$ MWCNTs resulted in a $69 \%$ decrease in the mean of viable PBPA2 cells in comparison to the control. In comparison to the control, the ANOVA p-value for exposure to 0.1 g.L $\mathrm{L}^{-1}$ and 1.0 g. $\mathrm{L}^{-1}$ MWCNTs was 0.40 and 0.89 , respectively. The pvalues for both concentrations were $>0.05$, which indicated an insignificant difference with the control. However, the ANOVA p-value was 0.009 after exposure to $10 \mathrm{~g} . \mathrm{L}^{-1}$ MWCNTs, which indicated a statistically significant difference with the control. This observation suggested the toxic effect of MWCNTs at high concentrations towards PBPA2.

Previous research on the antimicrobial activity of MWNCTs suggests that Pseudomonas genera, in general, exhibits tolerance towards MWCNTs ${ }^{20}$ with an eventual toxic effect caused by the wrapping of microbial cells by the MWCNT network, which results in a decrease in both their capacity to form colonies and their ability to induce oxidative stress $^{21}$. Hence, the relatively high percentage of MWCNTs embedded within the beads ( 22 wt \%, which correlated to about 7 g.L L $^{-1}$ MWCNTs) may inadvertently affect the viability of PBPA2 and inhibit biodegradation activity. 


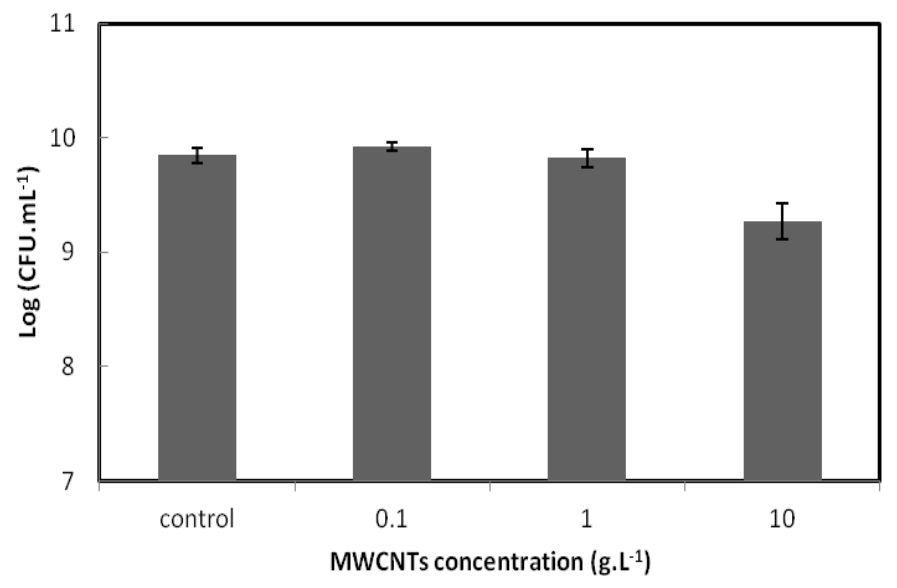

Fig. 7.4 Effect of MWCNT dosages towards viability of PBPA2 strain after 3 days incubation (Initial $\mathrm{OD}_{600 \mathrm{~mm}}=\sim 0.4$ or $196 \mathrm{mg} \mathrm{dw} \cdot \mathrm{L}^{-1}, 30^{\circ} \mathrm{C}, 150 \mathrm{rpm}$ )

\subsubsection{BPA removal by hybrid beads- immobilized PBPA2 in batch reactor}

In comparison to free cells, entrapment of PBPA2 within the hybrid bead increased the BPA removal at the early incubation period. This behavior can be attributed chiefly to the adsorption of BPA by the beads matrix. As shown in Fig. 7.5, removal of BPA by control beads of $2 \mathrm{~mm}$ diameter without the addition of PBPA2 after 2 days incubation was about the same as that exhibited by beads $2 \mathrm{~mm}$ in diameter with PBPA2. BPA removal by the $\mathrm{Ca}-\mathrm{alg} / \mathrm{MWCNTs} / \mathrm{Psf}$ control beads reached equilibrium within 3 days $^{13}$ at $10.54 \%$ removal; whereas, removal by Ca-alg/PBPA2-MWCNTs/Psf beads was about 14\%. This result suggests that, despite the high MWCNTs loading, integration of PBPA2 into the hybrid Ca-alg/MWCNTs/Psf bead enhanced its performance and resulted in more than a $20 \%$ increase in BPA removal in the batch study.

One may argue that immobilization in the alginate matrix played a role in "shielding" and preventing direct contact between PBPA2 and MWCNTs therefore minimizing their toxic effect ${ }^{22}$. 


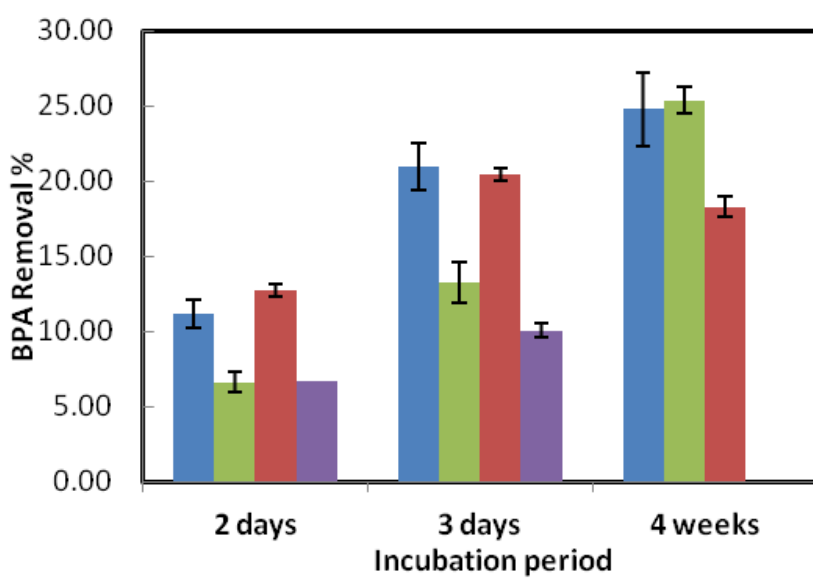

$1 \mathrm{~mm}$ diameter

$2 \mathrm{~mm}$ diameter

$4 \mathrm{~mm}$ diameter

control $2 \mathrm{~mm}$ diameter

Fig. 7.5 Percentage of BPA removed by hybrid Ca-alginate/MWCNTs-PBPA2/Psf beads (BPA concentration $=20 \mathrm{mg} \cdot \mathrm{l}^{-1}$, Initial $\mathrm{OD}_{600 \mathrm{~nm}}=\sim 1.0$ or $0.49 \mathrm{~g} \mathrm{dw} \cdot \mathrm{L}^{-1}$ beads dosage $=1.6 \mathrm{~g} . \mathrm{L}^{-1}, 30^{\circ} \mathrm{C}$, $150 \mathrm{rpm})$

Continued incubation showed that removal by hybrid Ca-alginate/22\%MWCNTs PBPA2/Psf beads reached to more than $\sim 18 \%$ after 4 weeks of incubation, irrespective of the beads' size ( $\mathrm{p}$-value $=0.08$ suggesting insignificant difference). A smaller hybrid bead diameter appeared to improve BPA removal efficiency, which may be attributed to the higher surface area available for sorption and subsequent degradation. In this case, the BPA removal reached $23 \%$ for $1 \mathrm{~mm}$ diameter beads after 4 weeks of incubation. The prolonged incubation appeared to produce similar results, in terms of BPA removal, as those achieved by free cells.

It was, therefore, tempting to conclude that the immobilization of PBPA2 within the hybrid beads was able to produce a similar performance as those of free cells. However, the probability that the entrapped cells were leaking out of the beads and proliferating in the batch reactor over time, which subsequently contributed towards the enhancement in BPA removal, could not be discarded. To minimize the influence of cell leakage during removal, the hybrid beads were applied in a fixed-bed column reactor. In this set-up, the leaked cells would be washed with the continuous feed. 


\subsubsection{BPA removal by immobilized PBPA2 in column reactor}

To assess whether the BPA adsorbed into hybrid beads could be degraded by immobilized PBPA2, the removal of BPA with the hybrid Ca-alginate/MWCNTsPBPA2/Psf beads was carried out in a continuous column reactor and compared to the control beads without PBPA2 for 2 weeks. For this application, beads of $4 \mathrm{~mm}$ in diameter were selected due to their ease of fabrication. During the first 5 days, a mineral MYB medium with $10 \mathrm{mg} . \mathrm{L}^{-1}$ BPA was injected into both columns simultaneously in order to acclimatize the bacteria. From day 6 to day 14, only MB media with $10 \mathrm{mg} . \mathrm{L}^{-1}$ BPA was used as a feed into the columns. The data points were then subjected to doseresponse modeling, as previously reported in Chapter 5 and plotted in Figure 7.6.

Table 7.1 Dose-response model parameters (mass of beads $=0.67 \mathrm{~g}$, flow rate $=0.00378 \mathrm{~L} \cdot \mathrm{h}^{-1}$ )

\begin{tabular}{ccc}
\hline Parameters & Hybrid beads with PBPA2 & $\begin{array}{c}\text { Hybrid beads without } \\
\text { PBPA2 }\end{array}$ \\
A & 0.979 & 1.889 \\
$\mathrm{~V}_{\text {eff50\% }}(\mathrm{L})$ & 0.24 & 0.22 \\
$r^{2}$ & 0.94 & 0.98 \\
\hline
\end{tabular}

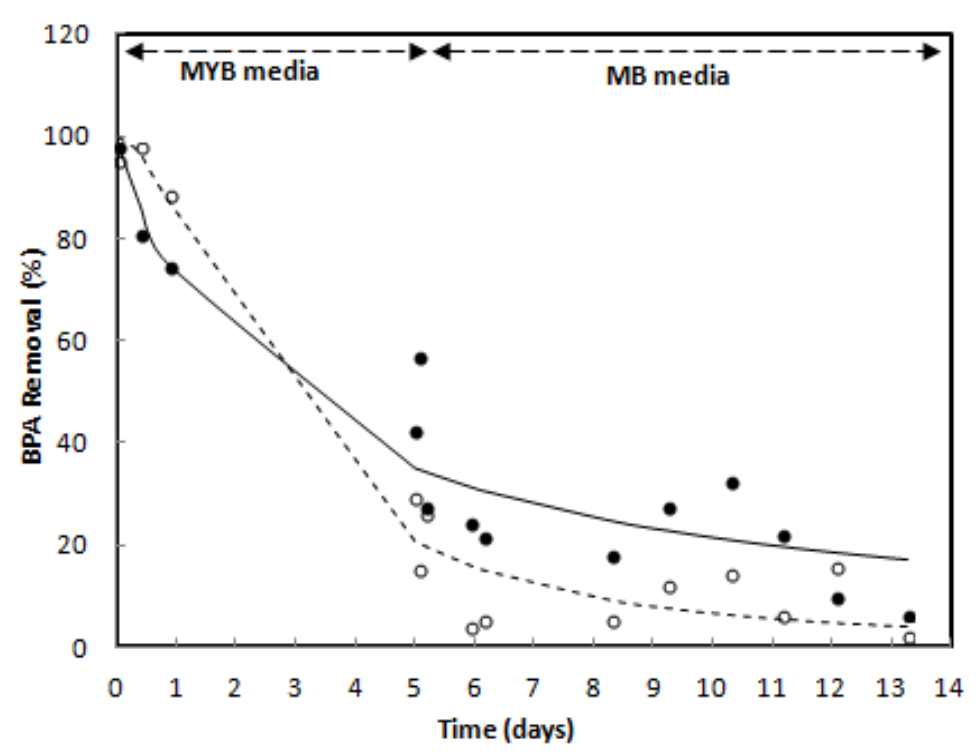

Fig. 7.6 BPA removed by hybrid Ca-alginate/MWCNTs-PBPA2/Psf beads $(\bullet)$ in continuous column reactor in comparison to control beads without PBPA2 (०) (Inlet BPA concentration $=10$ $\mathrm{mg} . \mathrm{l}^{-1}$, \#beads $=100$, line graphs are their corresponding dose-response models) 
It was shown that the exhaustion time for the Ca-alginate/MWCNTs-PBPA2/Psf column was longer than the hybrid beads without PBPA2. For instance, based on the modeling parameters obtained, the $80 \%$ breakthrough time for Ca-alginate/MWCNTs-PBPA2/Psf is stipulated to be 11 days in comparison to 5 days for beads without PBPA2. The discrepancy suggests that the adsorbed BPA is available for degradation by PBPA2, hence extending the lifetime of the beads. The exhaustion eventually occurred since the adsorption rate can be considered higher than the degradation rate by PBPA2. Further studies are required to optimize the performance of the beads by adjusting the MWCNT loading in order to achieve longer operating time.

\section{Regeneration prospect of the beads using bacteria}

Despite the improvement in operation time, the regeneration of the spent hybrid Caalginate/MWCNTs-PBPA2/Psf beads is challenging since the solvent extraction (as depicted in Chapters 3 and 4) is toxic to the bacteria. Inspired by the mechanism of biological regeneration in the BAC process $^{23}$, an exploration study was conducted by utilizing the desorption of BPA from MWCNTs and the degradation capability of the bacteria. Exposing the spent beads to a solution absent of BPA should induce desorption of BPA due to a reverse concentration gradient ${ }^{12}$, which may in turn increase the bioavailability of the previously adsorbed BPA to the bacteria within the beads.
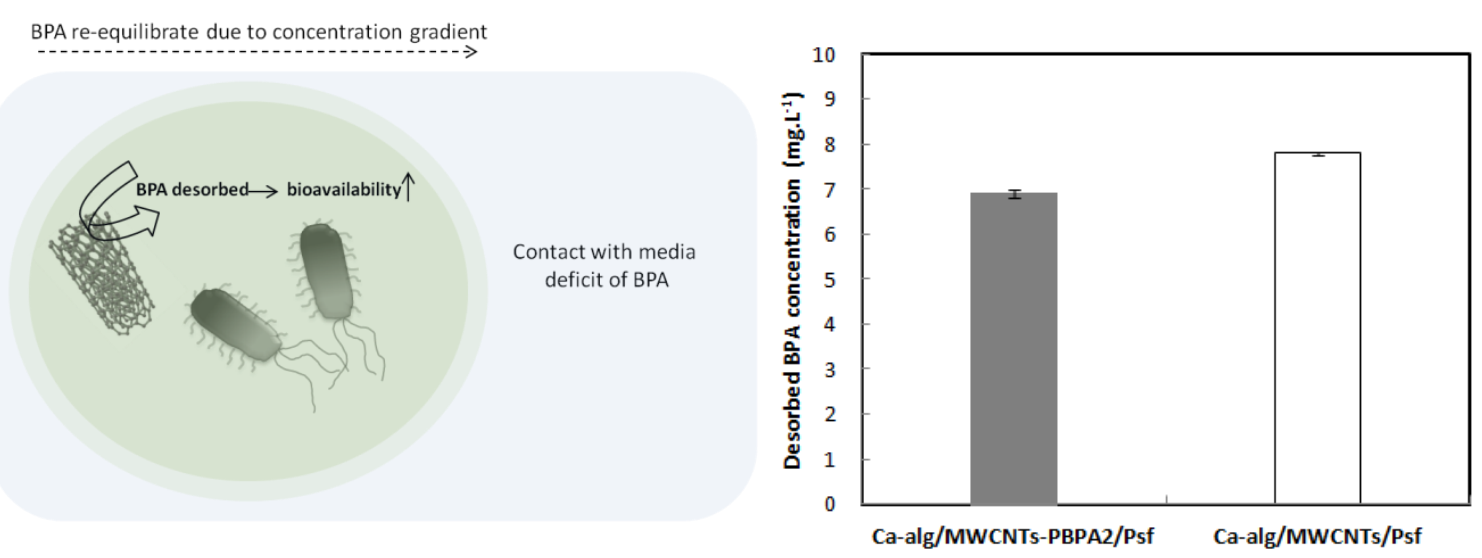

Fig. 7.7 Amount of BPA extracted from the hybrid beads after solvent extraction using ethanol. Data is presented as mean \pm standard error (ANOVA p-value $=0.011$, for $p$-value $<0.05$ the result is statistically significant). 
To clarify the efficiency of this procedure, solvent extraction of BPA from the spent beads in the column was performed. Prior to the extraction, mineral media with $0.05 \%$ yeast extract (MY media) was injected into the columns for 1 week to induce desorption of BPA through decreasing the solute concentration. After this process, 15 beads from each column were immersed into a 10-ml ethanol solution for 2 days. As shown in Fig. 7.7, the amount of BPA desorbed from Ca-alg/MWCNTs-PBPA2/Psf was lower in comparison to the beads without PBPA2, which may indicate the availability of the desorbed BPA for degradation. This preliminary work suggests the possibility of regenerating the beads by exposing them into media deficit of BPA for a longer period. However, it is important to note that (as described in Chapter 5) solvent extraction of BPA from the spent beads was not able to fully recover the total amount of BPA adsorbed. This hysteresis was possibly due to the BPA becoming entrapped in unextractable sites during desorption.

\subsection{Conclusion}

This study demonstrates the feasibility of combining MWCNTs, a known bactericidal, with novel BPA-biodegrading bacteria within beads compartment for the removal of a pollutant in an aqueous solution. BPA-tolerant Pseudomonas aeruginosa strain, PBPA2, was isolated, and its culture medium for the degradation of BPA was optimized by the addition of yeast extract. The batch study shows that BPA removal performance by the free cells was not affected by the initial starting cell density. Immobilization of PBPA2 within hybrid Ca-alg/MWCNTs/Psf beads improves its removal performance at the early incubation stage and makes the bead capable of demonstrating a similar removal performance as that of free cells - with up to a $20 \%$ increase in comparison to beads without PBPA2. The column reactor study shows extension in breakthrough time, which supports the notion of biodegradation within the beads. Further studies are required to optimize the MWCNT loading within the bead and to study how it affects the biodegradation rate of the pollutant. 


\section{References}

1 Dorn, P. B., Chou, C.-S. \& Gentempo, J. J. Degradation of bisphenol A in natural waters. Chemosphere 16, 1501-1507 (1987).

2 Ike, M., Jin, C.-S. \& Fujita, M. Isolation and characterization of a novel bisphenol A-degrading bacterium Pseudomonas paucimobilis Strain FJ-4. 日本水処理生物 学会誌 31, 203-212 (1995).

3 Oshiman, K.-i., Tsutsumi, Y., Nishida, T. \& Matsumura, Y. Isolation and characterization of a novel bacterium, Sphingomonas bisphenolicum strain AO1, that degrades bisphenol A. Biodegradation 18, 247-255 (2007).

4 Sasaki, M., Maki, J.-i., Oshiman, K.-i., Matsumura, Y. \& Tsuchido, T. Biodegradation of bisphenol A by cells and cell lysate from Sphingomonas sp. strain AO1. Biodegradation 16, 449-459 (2005).

$5 \quad$ Kamaraj, M., Sivaraj, R. \& Venckatesh, R. Biodegradation of bisphenol A by the tolerant bacterial species isolated from coastal regions of Chennai, Tamil Nadu, India. International Biodeterioration \& Biodegradation 93, 216-222 (2014).

6 Yamanaka, H., Moriyoshi, K., Ohmoto, T., Ohe, T. \& Sakai, K. Degradation of bisphenol A by Bacillus pumilus isolated from kimchi, a traditionally fermented food. Appl Biochem Biotechnol 136, 39-51 (2007).

7 Brodelius, P. \& Vandamme, E. J. Immobilized cells systems biotechnology. Vol. 7a 405-464 (VCH Verlag, Weinheim 1987).

8 Martin, M. J., Serra, E., Ros, A., Balaguer, M. D. \& Rigola, M. Carbonaceous adsorbents from sewage sludge and their application in a combined activated sludge-powdered activated carbon (AS-PAC) treatment. Carbon 42, 1389-1394 (2004).

9 Sirotkin, A. S., Koshkina, L. Y. \& Ippolitov, K. G. The BAC-process for treatment of waste water containing non-ionogenic synthetic surfactants. Water Research 35, 3265-3271 (2001).

10 Orshansky, F. \& Narkis, N. Characteristics of organics removal by PACT simultaneous adsorption and biodegradation. Water Research 31, 391-398 (1997).

11 Morinaga, H., Nehijima, W. \& Okada, M. Stimulation of bacterial activity by the addition of different PACS. Environmental Technology 24, 179-186 (2003).

12 Zhang, C., Li, M., Xu, X. \& Liu, N. Effects of carbon nanotubes on atrazine biodegradation by Arthrobacter sp. Journal of Hazardous Materials 287, 1-6 (2015).

13 Hartono, M. R., Marks, R. S., Chen, X. \& Kushmaro, A. Hybrid multi-walled carbon nanotubes-alginate-polysulfone beads for adsorption of bisphenol-A from aqueous solution. Desalination and Water Treatment 54, 1167-1183 (2015).

14 Young, Y.-F. et al. Toxicity mechanism of carbon nanotubes on Escherichia coli. Materials Chemistry and Physics 134, 279-286 (2012).

15 Xia, X., Li, Y., Zhou, Z. \& Feng, C. Bioavailability of adsorbed phenanthrene by black carbon and multi-walled carbon nanotubes to Agrobacterium. Chemosphere 78, 1329-1336 (2010).

16 Lobos, J. H., Leib, T. \& Su, T.-M. Biodegradation of bisphenol A and other bisphenols by a gram-negative aerobic bacterium. Applied and Environmental Microbiology 58, 1823-1831 (1992). 
17 Sheeja, R. \& Murugesan, T. Mass transfer studies on the biodegradation of phenols in up-flow packed bed reactors. Journal of Hazardous Materials 89, 287301 (2002).

18 Zhang, C. et al. Aerobic degradation of bisphenol A by Achromobacter xylosoxidans strain B-16 isolated from compost leachate of municipal solid waste. Chemosphere 68, 181-190 (2007).

19 Matsumura, Y. et al. Isolation and characterization of novel bisphenol-A-degrading bacteria from soils. Biocontrol science 14, 161-169 (2009).

20 Shrestha, B. et al. An evaluation of the impact of multiwalled carbon nanotubes on soil microbial community structure and functioning. Journal of Hazardous Materials 261, 188-197 (2013).

21 Olivi, M. et al. Inhibition of microbial growth by carbon nanotube networks. Nanoscale 5, 9023-9029 (2013).

22 Liu, S. et al. Sharper and faster "nano darts" kill more bacteria: a study of antibacterial activity of individually dispersed pristine single-walled carbon nanotube. Acs Nano 3, 3891-3902 (2009).

23 Yamanaka, H., Moriyoshi, K., Ohmoto, T., Ohe, T. \& Sakai, K. Efficient Microbial Degradation of Bisphenol A in the Presence of Activated Carbon. Journal of Bioscience and Bioengineering 105, 157-160 (2008). 


\section{Chapter 8}

\section{Discussion and Future Work}

This chapter discusses the findings from the thesis that are relevant to the extension of the current body of knowledge. The contributions mainly involve the treatment of sorbent material to enhance their adsorption performance as well as development of encapsulation strategy to reduce the likelihood of sorbent leakage while enabling integration with pollutant degrading bacteria. The recommendations for future studies include optimization of the developed MWCNTs-bacteria macro bead platform by the means of statistical method and further exploration on the toxicity interaction between CNMS and bacteria through utilization of bioluminescence bacteria panel assay. 


\subsection{General Discussion}

This thesis presents the development of a novel composite sorbent material for the removal of BPA and elucidates its sorption mechanisms and efficiencies.

The first contribution generated from this thesis was the investigation of different chemical treatments on bamboo powder biosorbent in its natural state to enhance the removal of the emerging pollutant BPA. The modified biosorbent with the highest improvement was produced with the use of cationic surfactant (which possesses a positively charged hydrophilic head and a long hydrophobic aliphatic chain) as a pretreatment, which then allowed for a combination of electrostatic attraction and hydrophobic affinity for sorption of aromatic compounds. The increase in BPA removal by pre-treated bamboo fiber powders may be attributed to the loading of surfactants which, at layered forms, would create a hydrophobic environment. The interaction of the surfactant with BPA is influenced by van der walls and London forces and is supported by a partitioning process of hydrophobic BPA into the organic hydrophobic phase constructed by a lipophilic tail of the surfactant. The adsorption isotherm study shows that the adsorption followed both Freundlich and linear models with high correlation, which suggests that BPA molecules were adsorbed in multi-layered fashion whereas the linearity supported the notion of hydrophobic partitioning. Other treatments involving anionic, non-ionic and alkali solutions also showed improvement in BPA removal, which individually suggest the role of hydrophobic partitioning and electrostatic interaction in improving sorption capability. This hypothesis was further supported by the FTIR analysis and Zeta-potential measurements of the modified bamboo powder. CBPs' adsorption of BPA is dosage-and particle-size dependent and follows both the linear and Freundlich models with a high correlation. Although the performance of the modified biosorbent is promising, kinetic studies, which compare its performance to other emerging adsorbents (such as CNM variants), show that its sorption capacity is still inferior. 
Despite a great deal of literature dedicated to reporting the adsorption performance of a variety of CNMs structures, an area rarely researched involves the practical application of CNMs as an adsorbent in wastewater treatment while limiting the possibility of their release into the environment. Our immobilization matrix of choice was alginate, a biocompatible material, which has been utilized as immobilization media in wastewater treatment $^{1}$ and a biosorbent (for the removal of heavy metals) due to its high affinity for divalent cations, ease of manufacturing and mechanical stability ${ }^{2}$.

In its pure form, MWCNTs and SWCNTs exhibited higher BPA adsorption capacity in comparison to XGnPs. The second contribution in this thesis assessed pollutant removal behavior by calcium-alginate encapsulated MWCNTs in a fixed-bed reactor. Due to their hydrophobic nature, however, only certain concentrations of unmodified MWCNTs could be loaded into the beads, as the viscosity of the alginate-MWCNTs mixture increases at higher concentrations. In our case, $22 \%$ MWCNTs was deduced as the optimal loading. It was deduced that BPA adsorption onto the hybrid bead occurred mainly through $\pi$ - $\pi$ electron coupling between MWCNTs and the $\pi$-electrons of the aromatic compounds in BPA. The adsorption mechanism of BPA on the hybrid beads is complex as the bead is comprised of more than two materials. However, the correlation coefficients for Langmuir model were higher than the Freundlich model, which suggested that BPA adsorption by the hybrid beads occurred in a monolayer behavior. In an effort to integrate the adsorption performance of MWCNTs with photocatalytic removal, $\mathrm{P} 25 \mathrm{TiO}_{2}$ powder was combined with the mixture to form $\mathrm{Ca}-\mathrm{Alg} / \mathrm{MWCNTs}-\mathrm{TiO}_{2}$ beads. The adsorption kinetics of BPA was studied at ambient conditions to understand the design parameters influencing BPA removal in a column reactor. It was observed that the breakthrough time was affected by the bed height, initial BPA concentration in the feed, and flow rate. The dose-response model could predict the removal behavior in our fixed-bed column system with high correlation. In the most recent published study in this field, CNMs in bare form were applied into a continuous column reactor without any encapsulation ${ }^{3}$. In terms of BPA removal, the adsorption capacity obtained in our study was higher than other reported material ${ }^{4}$ but lower than the capacity in the batch study. The photocatalytic removal of BPA and regeneration of the beads was performed by desorption of BPA from 
the spent beads using the organic solvent ethanol while simultaneously irradiating the container with light. Our results suggested that up to $90 \%$ of BPA was desorbed from the bead, with subsequent irradiation of the solution showing removal of BPA after $1.5 \mathrm{~h}$. During the photolytic study, the abrasion of the composite-alginate beads was observed. Similar phenomena have been reported previously ${ }^{5}$. In order to improve the containment stability of the MWCNTs, the addition of a secondary layer to minimize the leakage of MWCNTs was proposed.

Our third contribution entailed the development of a hybrid bead platform consisted of an alginate-MWCNT core and a Psf secondary layer and an assessment of its characterization for the adsorption of BPA. Only a few studies have addressed the encapsulation of CNMs for the removal of pollutants ${ }^{6,7}$. Psf is a good candidate for a secondary layer as it possesses superior mechanical stabilities ${ }^{8}$ and an affinity towards pollutants with a high oil-water partition coefficient ${ }^{9-11}$. After the additional layer of Psf, MWCNTs' containment property was tested by means of genetically modified bioluminescence bacteria, which are sensitive to oxidative stress. We observed that the bioluminescence signal produced, measured under luminometer, after contact of the DPD2511 bacteria with solution originating from composite beads after rigorous vortex was higher than the solution originating from the beads with the Psf layer. This finding suggested that the Psf layer assisted in minimizing the amount of MWCNT leakage due to abrasion. Results of the FTIR study, BET characterization and batch adsorption using hybrid beads (with and without Psf coating) indicated that the BPA affinity on the hybrid beads is controlled by the availability of surface area for adsorption at low MWCNT loading and $\pi-\pi$ hydrophobic attraction between the benzene rings in MWCNTs and BPA at high MWCNTs loading. The pseudo-second order model was suitable for predicting the adsorption kinetics for $\mathrm{Ca}-\mathrm{Alg} / \mathrm{MWCNTs} / \mathrm{Psf}-\mathrm{BPA}$ system in the batch reactor. The Weber and Boyd models suggested that intra-particle diffusion and external mass transfer hold important roles in the adsorption of BPA onto the hybrid beads. The Langmuir model fit the adsorption equilibrium data and indicated that BPA adsorption by the hybrid beads occurs in a monolayer behavior. The re-usability of the packed-hybrid beads column of up to 3 cycles under continuous flow was demonstrated 
Integration of bacteria degradation with CNMs may enhance pollutant removal and offer the possibility for the complete mineralization of the recalcitrant pollutant. Unlike activated carbon, few studies have been dedicated to investigating CNMs' integration with biodegradation. One reason for this involves the antibacterial capacity that has been reported for various CNMs (such as fullerenes ${ }^{12,13}$ and carbon nanotubes $(\mathrm{CNTs})^{14,15}$ ), which may have discouraged such endeavors. Most of the reported studies on the integration of $\mathrm{CNMs}$ and bacteria were performed without encapsulation ${ }^{16-18}$. Encapsulation has been shown to cultivate and protect strains from native microorganisms ${ }^{1,2}$ as well as enable their practical application in water treatment. To our best knowledge, no study has been conducted on the integration of bacteria and MWCNTs through encapsulation.

The last part of this thesis has contributed to the literature regarding the effect of the addition of pollutant-degrading bacteria into a hybrid bead containing MWCNTs for the removal of BPA. To answer this question, a BPA-tolerant and-degrading wild bacteria strain Pseudomonas aeruginosa (PBPA2) was successfully isolated and identified. Prior to integration with the hybrid beads, we addressed the difficulty in the re-cultivation of the isolated bacteria in the enrichment media and the absence of BPA degradation in mineral media when BPA was the sole carbon source. This problem was reported previously in other studies utilizing the same enrichment media ${ }^{19}$. We observed that the addition of $0.05 \%$ yeast extract in the BPA-degradation media was beneficial for increasing cell density as well as the subsequent removal of BPA by free cells in a batch reactor. Although a toxic effect was seen when PBPA2 was exposed to a high concentration of MWCNTs, our study revealed that BPA could be removed through the integration of the strain into the hybrid Ca-alg/MWCNTs-bacteria/Psf beads and demonstrated up to a $20 \%$ performance improvement in a batch study when compared to the control. Further application of the hybrid Ca-alg/MWCNTs-bacteria/Psf beads in a column reactor showed an extension in bed exhaustion time, as predicted with doseresponse model, in comparison to the control. A regeneration study of the spent beads was proposed by injecting the media deficits of BPA in order to induce desorption (due to 
the concentration gradient). The solvent extraction of the remaining BPA showed a lower concentration of BPA desorbed Ca-alg/MWCNTs-bacteria/Psf beads, which suggests the occurrence of biodegradation.

All things considered, our results demonstrated the feasibility of immobilizing CNMs (such as MWCNTs) with pollutant-degrading bacteria within a bead compartment in order to improve their performance for the removal of a recalcitrant organic pollutant such as BPA. The shielding effect provided by the alginate matrix may have alleviated the antibacterial capacity of the otherwise toxic load of MWCNTs within the beads, while simultaneously enabling the combination of superior MWCNTs adsorption with bacterial degradation for pollutant removal. A question arising from the study is the possibility of employing the same encapsulation strategy to other bacteria strains, preferably facultative anaerob, which is of interest for degrading other emerging recalcitrant pollutants. It has been shown that Pseudomonas genera exhibited tolerance towards high concentrations of MWCNTs $^{20}$, thus our current finding might only be applicable to specific genera and CNMs variants. The encapsulated nature also made it difficult to quantify the amount of bio-available BPA in the system after adsorption to MWCNTs. However, the lower rate of bed exhaustion as indicated through dose-response modeling indirectly implies the role that biodegradation activity plays in extending operation time.

\subsection{Future Works}

Based on the obtained results, further research might focus on the following subtopics:

\subsubsection{Structural characterization of surfactant treated lignocellulosic fiber}

Bamboo fiber is one of the highly crystalline natural lignocellulosic fibers ${ }^{21}$. In our study, it was observed that treatment of bamboo fiber with organic surfactant enhances its adsorption capacity towards BPA. Although several studies have been dedicated on the investigation and simulation of intercalation pattern of surfactant molecules on clay and zeolite structures $^{22,23}$, there is still lack of literature that focuses on the arrangement of surfactant molecules in interlayer space of plant-based lignocellulosic fiber materials and its corresponding microstructures. It was predicted that the manner of arrangement of 
surfactant would affect the microstructures and subsequent adsorption capacity of the modified fiber. Future characterization studies on bamboo fiber treated at different surfactant concentrations by BET, X-ray diffraction and X-ray photoelectron spectroscopy could be used to gain information on discrepancy in terms of surface area, lattice spacing, crystallinity index and elemental analysis of bamboo fiber after treatment. These information, coupled with molecular modeling simulation, may provide valuable perspective on the relationship between surfactant arrangement, the resultant microstructures and the adsorption mechanisms of the modified fiber.

\subsubsection{Optimization of integrated MWCNTs-bacteria bead}

Statistical methods ${ }^{24,25}$ could be employed for the optimization of conditions for multiple parameters such as MWCNT loading, bacteria concentration, BPA concentration and bead diameter in order to achieve optimal BPA removal and reduce the number of experiments to be performed. The optimization for regeneration conditions could be similarly performed. The application of real wastewater effluent and a long-term operation study into the optimized column is of importance to test their performance.

\subsubsection{Toxicity effect of CNTs}

Carbon nanotubes (CNTs) have emerged as potential adsorbent materials with an antimicrobial property. The antimicrobial property of purified SWCNTs was first reported by Kang et al. ${ }^{14}$ and appears to be affected by their concentrations, length ${ }^{26}$, buffer, surface functional group and shapes of the bacteria ${ }^{27}$ and are less influenced by the charge of the functional group on the carbon nanotubes ${ }^{28}$. The antimicrobial property of SWCNTs was observed to increase with the fraction of metallic SWNCTs, which was attributed to the induced oxidative stress ${ }^{29}$. It was proposed that direct contact with SWCNTs was the probable cause of the cell-membrane damage, which resulted in the leakage of cytoplasmic materials - with thinner SWCNTs being more effective in piercing the membrane of the bacteria than MWCNTs ${ }^{30}$. It was also suggested in a prior study that the antibacterial activity of SWCNTs was propelled by the uptake of SWCNTs, which interfered with bacterial cellular processes ${ }^{31}$, rather than direct contact with SWCNTs. Liu et al. ${ }^{15}$ utilized the Atomic Force Microscopy to visualize the effect of SWCNTs 
collisions on morphological and mechanical changes in gram negative E.coli and gram positive B.substilis. They reported the unlikely possibility for direct piercing of the bacteria membrane by individual SWCNTs during incubation and proposed that the bacterial death was caused by the accumulated effects of the agglomerated nanotubes network covering the surface of the cells, which enhanced cellular stress in the bacteria. This is supported by Olivi et al. ${ }^{32}$, who found that a network of CNTs inhibits microbial growth.

Our observations suggested that the encapsulated MWCNTs do not restrict the biodegradation activity of the Pseudomonas aeruginosa PBPA2, as they were integrated together inside the same compartment despite the exhibited toxic effect in the free cells viability assay. Based on these studies, it is apparent that the interactions of CNTs with bacteria cells is complex and require further exploration. A better understanding of the toxicity mechanism governing CNTs' antimicrobial capability will enable the development of much improved CNT-based materials for potential use in wastewater treatment.

Bioluminescene bacteria provide an attractive platform for a rapid screening of the bioavailability of toxic pollutants towards microorganisms due to their relatively inexpensive cost and technical simplicity. For future work, a bioluminescence bacteria panel could be considered to elucidate the toxicity mechanism involved during the interaction of the recombinant E.coli bacteria with SWCNTs and MWCNTs. The panel would comprised a series of genetically engineered recombinant E.coli strains sensitive to different sources of toxic stressors (Fig. 8.1), such as protein, DNA, oxidative and membrane damages. This is made possible by insertion of specific regulatory promoter and luxCDABE gene within the plasmid, which have been used in various toxicity studies to predict the mode of action of pollutants such as antibiotics and metallic nanoparticles ${ }^{33,34}$. Although the usage of bioluminescence bacteria for toxicity detection of CNMs has been reported previously, these studies emphasized the development of a general toxicity sensor rather than the mode of action of the toxicity itself ${ }^{35,36}$. 


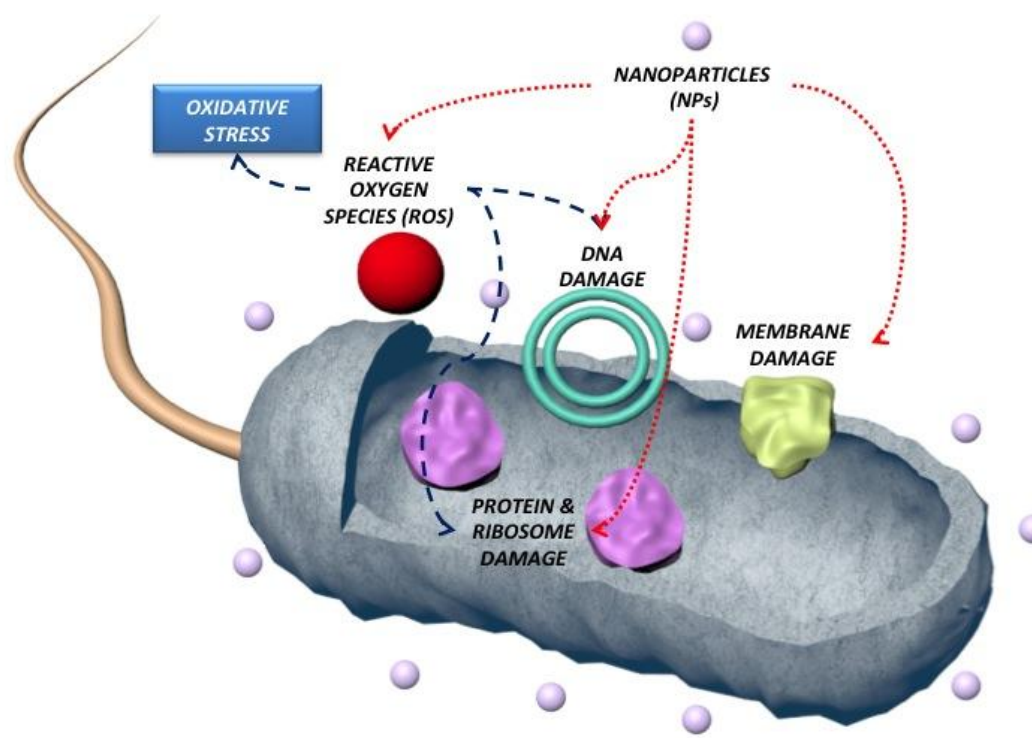

Fig. 8.1 Nanoparticles such as CNMs may be toxic to prokaryotic cells (bacteria) through a variety of cellular pathways (Illustration by author and Dr. Cai Pinqiang)

An exploration study to investigate the mechanism involved in the toxicity of SWCNTs and MWCNTs towards gram-negative E.coli by utilizing the stress-responsive E.coli bioluminescence strains would be beneficial in providing information in the adjustment of the concentration of CNTs during their integration with pollutant-degrading bacteria in order to minimize its toxic effect and achieve optimum pollutant removal.

\subsection{Conclusion}

In this thesis, several designs of sorbent materials were proposed, namely surfactant modified bamboo fiber powder and encapsulated CNMs sorbent, which utilized alginate as the main immobilization matrix for the removal of BPA. The adsorption performance of these adsorbents was studied in batch and column reactors. Integration of a biological component, in the form of novel isolated strain PBPA2, into alginate-encapsulated MWCNTs appeared to improve the BPA removal performance. Although our result is preliminary, it opens up potential research inquiries, which hopefully surmount our current limitations towards the application of encapsulated nanomaterials for the removal of aromatic organic pollutants. 


\section{References}

1 Covarrubias, S. A., de-Bashan, L. E., Moreno, M. \& Bashan, Y. Alginate beads provide a beneficial physical barrier against native microorganisms in wastewater treated with immobilized bacteria and microalgae. Appl Microbiol Biotechnol 93, 2669-2680 (2011).

2 Jen, A. C., Wake, M. C. \& Mikos, A. G. Review: Hydrogels for cell immobilization. Biotechnology and Bioengineering 50, 357-364 (1996).

3 Dichiara, A. B., Harlander, S. F. \& Rogers, R. E. Fixed bed adsorption of diquat dibromide from aqueous solution using carbon nanotubes. RSC Advances 5, 61508-61512 (2015).

4 Thanhmingliana, Lee, S. M. \& Tiwari, D. Use of hybrid materials in the decontamination of bisphenol A from aqueous solutions. RSC Advances 4, 4392143930 (2014).

5 Albarelli, J. Q., Santos, D. T., Murphy, S. \& Oelgemoller, M. Use of Ca-alginate as a novel support for $\mathrm{TiO}_{2}$ immobilization in methylene blue decolorisation. Water Science and Technology 60, 1081 (2009).

6 Fugetsu, B. et al. Encapsulation of multi-walled carbon nanotubes (MWCNTs) in $\mathrm{Ba}^{2+-}$ alginate to form coated micro-beads and their application to the preconcentration/elimination of dibenzo-p-dioxin, dibenzofuran, and biphenyl from contaminated water. Analyst 129, 565-566 (2004).

7 Weng, S.-Y. et al. Thermokinetics simulation for multi-walled carbon nanotubes with sodium alginate by advanced kinetics and technology solutions. Journal of thermal analysis and calorimetry 113, 1603-1610 (2013).

8 El-Hibri, M. J. \& Weinberg, S. A. in Encyclopedia of Polymer Science and Technology (John Wiley \& Sons, Inc., 2002).

9 Mao, M. et al. Polysulfone-activated carbon hybrid particles for the removal of BPA. Separation Science and Technology 41, 515-529 (2006).

10 Zhao, C. et al. Preparation of porous polysulfone beads for selective removal of endocrine disruptors. Separation and Purification Technology 40, 297-302 (2004).

11 Su-Hua, W., Bing-zhi, D. \& Yu, H. Adsorption of bisphenol A by polysulphone membrane. Desalination 253, 22-29 (2010).

12 Lyon, D. Y. \& Alvarez, P. J. J. Fullerene water suspension (nC60) exerts antibacterial effects via ROS-independent protein oxidation. Environmental Science \& Technology 42, 8127-8132 (2008).

13 Lyon, D. Y., Fortner, J. D., Sayes, C. M., Colvin, V. L. \& Hughes, J. B. Bacterial cell association and antimicrobial activity of a C60 water suspension. Environmental toxicology and chemistry 24, 2757-2762 (2005).

14 Kang, S., Herzberg, M., Rodrigues, D. F. \& Elimelech, M. Antibacterial effects of carbon nanotubes: size does matter! Langmuir 24, 6409-6413 (2008).

15 Liu, S. et al. Antibacterial action of dispersed single-walled carbon nanotubes on Escherichia coli and Bacillus subtilis investigated by atomic force microscopy. Nanoscale 2, 2744-2750 (2010).

16 Zhang, C., Li, M., Xu, X. \& Liu, N. Effects of carbon nanotubes on atrazine biodegradation by Arthrobacter sp. Journal of Hazardous Materials 287, 1-6 (2015). 
17 Xia, X., Li, Y., Zhou, Z. \& Feng, C. Bioavailability of adsorbed phenanthrene by black carbon and multi-walled carbon nanotubes to Agrobacterium. Chemosphere 78, 1329-1336 (2010).

18 Shrestha, B., Anderson, T. A., Acosta-Martinez, V., Payton, P. \& Cañas-Carrell, J. E. The influence of multiwalled carbon nanotubes on polycyclic aromatic hydrocarbon (PAH) bioavailability and toxicity to soil microbial communities in alfalfa rhizosphere. Ecotoxicology and Environmental Safety 116, 143-149 (2015).

19 Lobos, J. H., Leib, T. \& Su, T.-M. Biodegradation of bisphenol A and other bisphenols by a gram-negative aerobic bacterium. Applied and Environmental Microbiology 58, 1823-1831 (1992).

20 Shrestha, B. et al. An evaluation of the impact of multiwalled carbon nanotubes on soil microbial community structure and functioning. Journal of Hazardous Materials 261, 188-197 (2013).

21 Liu, Y. \& Hu, H. X-ray diffraction study of bamboo fibers treated with $\mathrm{NaOH}$. Fibers and Polymers 9, 735-739 (2008).

22 Bhardwaj, D., Sharma, P., Sharma, M. \& Tomar, R. Surfactant modified tectosilicates and phyllosilicates for 2,4-D removal and slow release formulation. RSC Advances 4, 4504-4514 (2014).

23 Park, Y. et al. Structural characterisation and environmental application of organoclays for the removal of phenolic compounds. Journal of colloid and interface science 393, 319-334 (2013).

24 Singh, L., Pavankumar, A. R., Lakshmanan, R. \& Rajarao, G. K. Effective removal of $\mathrm{Cu}^{2+}$ ions from aqueous medium using alginate as biosorbent. Ecological Engineering 38, 119-124 (2012).

25 Cestari, A. R., Vieira, E. F. S. \& Mota, J. A. The removal of an anionic red dye from aqueous solutions using chitosan beads-The role of experimental factors on adsorption using a full factorial design. Journal of Hazardous Materials 160, 337343 (2008).

26 Yang, C., Mamouni, J., Tang, Y. \& Yang, L. Antimicrobial activity of singlewalled carbon nanotubes: length effect. Langmuir 26, 16013-16019 (2010).

27 Chen, H. et al. Broad-spectrum antibacterial activity of carbon nanotubes to human gut bacteria. Small 9, 2735-2746 (2013).

28 Arias, L. R. \& Yang, L. Inactivation of bacterial pathogens by carbon nanotubes in suspensions. Langmuir 25, 3003-3012 (2009).

29 Vecitis, C. D., Zodrow, K. R., Kang, S. \& Elimelech, M. Electronic-structuredependent bacterial cytotoxicity of single-walled carbon nanotubes. Acs Nano 4, 5471-5479 (2010).

30 Liu, S. et al. Sharper and faster "nano darts" kill more bacteria: a study of antibacterial activity of individually dispersed pristine single-walled carbon nanotube. Acs Nano 3, 3891-3902 (2009).

31 Chaves, J. S. \& Chaves, S. J. in Nanotechnology 2012: Bio Sensors, Instruments, Medical, Environment and Energy Vol. 3 Chapter 5: Environmental Health \& Safety, 300-303 (2012).

32 Olivi, M. et al. Inhibition of microbial growth by carbon nanotube networks. Nanoscale 5, 9023-9029 (2013). 
33 Li, F. et al. Analysis of copper nanoparticles toxicity based on a stress-responsive bacterial biosensor array. Nanoscale 5, 653-662 (2013).

34 Eltzov, E., Ben-Yosef, D. Z., Kushmaro, A. \& Marks, R. Detection of subinhibitory antibiotic concentrations via luminescent sensing bacteria and prediction of their mode of action. Sensors and Actuators B: Chemical 129, 685692 (2008).

35 Jia, K., Marks, R. S. \& Ionescu, R. E. Influence of carbon-based nanomaterials on lux-bioreporter Escherichia coli. Talanta 126, 208-213 (2014).

36 Zheng, H. et al. Rapid determination of nanotoxicity using luminous bacteria. Analytical Sciences 26, 125-128 (2010). 


\section{Supporting Information}

\section{Derivation of Adam-Bohart equation (Chapter 5)}

Adam-Bohart equation (15) can be arranged to:

$$
\frac{\mathrm{C}_{\mathrm{i}}}{\mathrm{C}_{\mathrm{t}}}=\frac{\mathrm{e}^{\left(\frac{\mathrm{k}_{\mathrm{AB}} \mathrm{N}_{\mathrm{o}} \mathrm{Z}}{u}\right)}-1+\mathrm{e}^{\left(\mathrm{k}_{\mathrm{AB}} \mathrm{C}_{\mathrm{i}} \mathrm{t}\right)}}{\mathrm{e}^{\left(\mathrm{k}_{\mathrm{AB}} \mathrm{C}_{\mathrm{i}} \mathrm{t}\right)}}
$$

When $\mathrm{e}^{\left(\frac{\mathrm{k}_{\mathrm{AB}} \mathrm{N}_{\mathrm{OZ}}}{v}\right)}$ and $\mathrm{e}^{\left(\mathrm{k}_{\mathrm{AB}} \mathrm{C}_{\mathrm{i}} \mathrm{t}\right)}$ are considered greater than 1, the equation is simplified to:

$$
\frac{\mathrm{C}_{\mathrm{i}}}{\mathrm{C}_{\mathrm{t}}}-1=\mathrm{e}^{\left(\frac{\mathrm{k}_{\mathrm{AB}} \mathrm{N}_{\mathrm{O}} \mathrm{Z}}{u}-\mathrm{k}_{\mathrm{AB}} \mathrm{C}_{\mathrm{i}} \mathrm{t}\right)}
$$

Taking natural $\log$ on both sides,

$$
\ln \left(\frac{\mathrm{C}_{\mathrm{i}}}{\mathrm{C}_{\mathrm{t}}}-1\right)=\frac{\mathrm{k}_{\mathrm{AB}} \mathrm{N}_{\mathrm{o}} \mathrm{Z}}{u}-\mathrm{k}_{\mathrm{AB}} \mathrm{C}_{\mathrm{i}} \mathrm{t}
$$

As $u=v / \mathrm{A}$, the equation becomes:

$$
\ln \left(\frac{\mathrm{C}_{\mathrm{i}}}{\mathrm{C}_{\mathrm{t}}}-1\right)=\frac{\mathrm{k}_{\mathrm{AB}} \mathrm{N}_{\mathrm{o}} \mathrm{ZA}}{v}-\mathrm{k}_{\mathrm{AB}} \mathrm{C}_{\mathrm{i}} \mathrm{t}
$$

Where $\mathrm{N}_{\mathrm{o}} \mathrm{ZA}=\mathrm{N}_{\mathrm{o}} \mathrm{V}=\mathrm{q}_{\text {total }}=\mathrm{q}_{\mathrm{o}} \mathrm{m}_{\text {ads }}$, therefore:

$$
\ln \left(\frac{\mathrm{C}_{\mathrm{i}}}{\mathrm{C}_{\mathrm{t}}}-1\right)=\frac{\mathrm{k}_{\mathrm{AB}} \mathrm{q}_{\mathrm{o}} \mathrm{m}_{\mathrm{ads}}}{v}-\mathrm{k}_{\mathrm{AB}} \mathrm{C}_{\mathrm{i}} \mathrm{t}
$$

Equation S5 is a simplified form of Adam-Bohart model which is also known as "Thomas" model, more detailed derivation of the original Adam-Bohart model to equation S5 can be referred to paper by K.H. Chu ${ }^{[1]}$.

At $50 \%$ breakthrough, $\mathrm{C}_{\mathrm{t}} / \mathrm{C}_{\mathrm{i}}=0.5$, therefore:

$$
t_{0.5 C_{i}}=\frac{q_{o} m_{a d s}}{v C_{i}}
$$

Equation S5 can be re-arranged to:

$$
\begin{aligned}
\ln \left(\frac{\mathrm{C}_{\mathrm{i}}}{\mathrm{C}_{\mathrm{t}}}-1\right) & =\mathrm{k}_{\mathrm{AB}} \mathrm{C}_{\mathrm{i}}\left(\mathrm{t}_{0.5 \mathrm{C}_{\mathrm{i}}}-\mathrm{t}\right) \\
\frac{\mathrm{C}_{\mathrm{i}}}{\mathrm{C}_{\mathrm{t}}} & =1+\mathrm{e}^{\mathrm{k}_{\mathrm{AB}} \mathrm{C}_{\mathrm{i}}\left(\mathrm{t}_{0.5 \mathrm{C}_{\mathrm{i}}}-\mathrm{t}\right)} \\
\frac{\mathrm{C}_{\mathrm{t}}}{\mathrm{C}_{\mathrm{i}}} & =\frac{1}{1+\mathrm{e}^{\mathrm{k}_{\mathrm{AB}} \mathrm{C}_{\mathrm{i}}\left(\mathrm{t}_{0.5 \mathrm{C}_{\mathrm{i}}}-\mathrm{t}\right)}}
\end{aligned}
$$

Replacing $\mathrm{k}_{\mathrm{AB}} \mathrm{C}_{\mathrm{i}}$ with $\mathrm{k}_{\mathrm{jn}}$, the equation becomes:

$$
\frac{\mathrm{C}_{\mathrm{t}}}{\mathrm{C}_{\mathrm{i}}}=\frac{1}{1+\mathrm{e}^{\mathrm{k}_{\mathrm{jn}}\left(\mathrm{t}_{0.5 \mathrm{C}_{\mathrm{i}}}{ }^{-\mathrm{t})}\right.}}
$$

S10 is the same form as Yoon-Nelson equation (7). Therefore, it can be deduced that Adam-Bohart model is mathematically analogous to Yoon-Nelson model. Hence, similar breakthrough curve is expected when applying the whole data range to both models. 


\section{Adjustment of $\mathrm{Alg} / \mathrm{TiO}_{2}$ composition in $\mathrm{Ca}-\mathrm{Alg} / \mathrm{MWCNTs}-\mathrm{TiO}_{2}$ beads (Chapter 5)}

The influence of Alginate $(\mathrm{Alg})$ and $\mathrm{TiO}_{2}$ wt\% loading ratio towards the adsorption, desorption and regeneration in batch reactors have been investigated at fixed CNTs loading of $22 \mathrm{wt} \%$. Three [Alg/TiO $\left.{ }_{2}\right]$ ratios, namely: $3.1,5$ and 7 were tested for this purpose.

$\mathbf{A}$

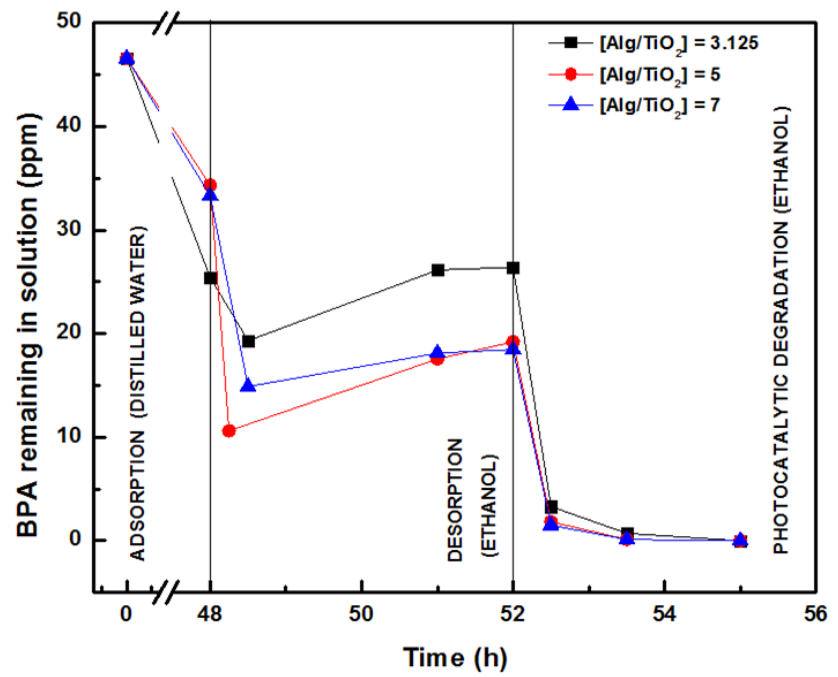

B

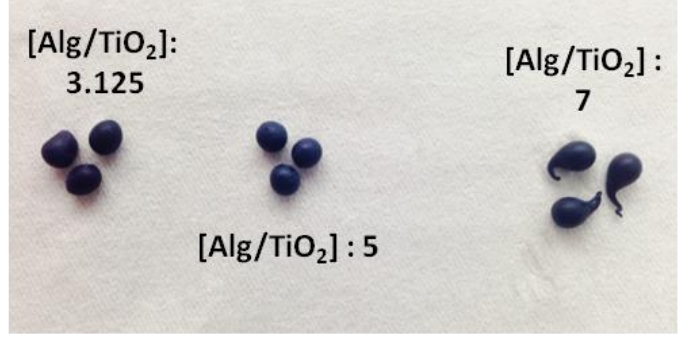

Fig. S1. (a) Adsorption-desorption-photocatalytic removal of BPA by the composite calciumalginate/MWCNTs/TiO ${ }_{2}$ beads at different $\left[\mathrm{Alg} / \mathrm{TiO}_{2}\right]$ loading ratio at $2 \mathrm{~g} . \mathrm{L}^{-1}$ beads dosage and $50 \mathrm{mg} . \mathrm{L}^{-1}$ initial BPA concentration and (b) the corresponding beads structure

As shown on Figure S1, the adsorption capacity of the beads decreased at higher $\left[\mathrm{Alg} / \mathrm{TiO}_{2}\right]$ ratio with no distinct difference in terms of desorption and regeneration capability of the beads. It might be argued that at higher loading of $\mathrm{TiO}_{2}$, higher surface area is available for adsorption of $\mathrm{BPA}^{2}$. Due to increase in solution viscosity, beads prepared from $\left[\mathrm{Alg} / \mathrm{TiO}_{2}\right]=7$ developed tail at one end which may reduce the uniformity of the beads that potentially affect the packing in column reactor. Based on these preliminary results, the beads composition with $\left[\mathrm{Alg} / \mathrm{TiO}_{2}\right]=3$ was selected. 


\section{Equilibrium adsorption capacity of Ca-Alg/MWCNTs-TiO beads $_{2}$ (Chapter 5)}

In order to estimate the adsorption capacity of the beads in batch reactor, $1.17 \mathrm{~g} . \mathrm{L}^{-1}$ dosage of composite beads were added into container filled with BPA solution of 10 mg. $\mathrm{L}^{-1}-100 \mathrm{mg} . \mathrm{L}^{-1}$ concentration and incubated at ambient temperature without shaking for three days to ensure equilibrium. The experiments were performed in duplicate and Langmuir isotherm used to predict the maximum adsorption capacity.

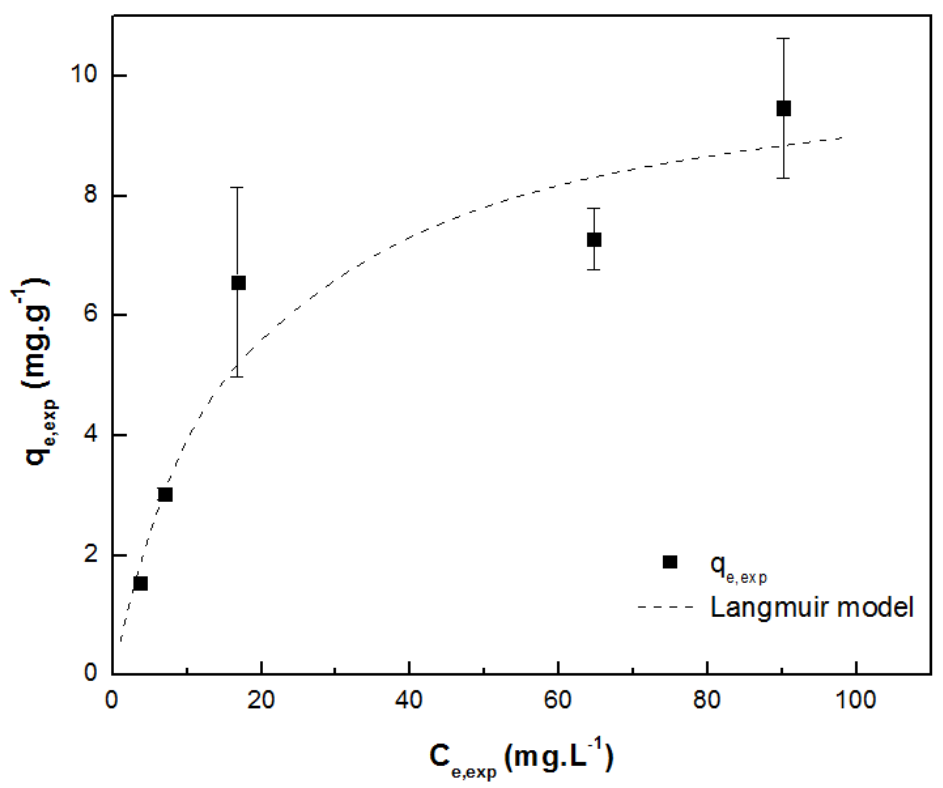

Fig. S2. BPA adsorption onto $\mathrm{Ca}-\mathrm{Alg} / 22 \%-\mathrm{MWCNTs}-\mathrm{TiO}_{2}$ beads in static incubation and its corresponding predicted adsorption capacity based on Langmuir model (Dosage $=1.17 \mathrm{~g} . \mathrm{L}^{-1}$ dry weight, $\mathrm{pH}=6.0$, initial BPA concentrations $\left.=10 \mathrm{mg} \cdot \mathrm{L}^{-1}-100 \mathrm{mg} \cdot \mathrm{L}^{-1}\right)$. Data are expressed as mean \pm standard error

According to the model, the maximum adsorption capacity of the bead in static condition

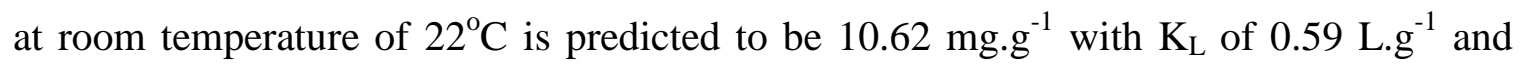
correlation coefficient of 0.959 . 


\section{16srDNA BLAST sequence of Pseudomonas aeruginosa PBPA2 (Chapter 7)}

GGAGAAGGGAGCTTGCTCCTGGATTCAGCGGCGGACGGGTGAGTAATGCCTA GGAATCTG CCTGGTAGTGGGGGATAACGTCCGGAAACGGGCGCTAATACCGCATACGTCC TGAGGGAG AAAGTGGGGGATCTTCGGACCTCACGCTATCAGATGAGCCTAGGTCGGATTA GCTAGTTG GTGGGGTAAAGGCCTACCAAGGCGACGATCCGTAACTGGTCTGAGAGGATGA TCAGTCAC ACTGGAACTGAGACACGGTCCAGACTCCTACGGGAGGCAGCAGTGGGGAAT ATTGGACAA TGGGCGAAAGCCTGATCCAGCCATGCCGCGTGTGTGAAGAAGGTCTTCGGAT TGTAAAGC ACTTTAAGTTGGGAGGAAGGGCAGTAAGTTAATACCTTGCTGTTTTGACGTTA CCAACAG AATAAGCACCGGCTAACTTCGTGCCAGCAGCCGCGGTAATACGAAGGGTGCA AGCGTTAA TCGGAATTACTGGGCGTAAAGCGCGCGTAGGTGGTTCAGCAAGTTGGATGTG AAATCCCC GGGCTCAACCTGGGAACTGCATCCAAAACTACTGAGCTAGAGTACGGTAGAG GGTGGTGG

AATTTCCTGTGTAGCGGTGAAATGCGTAGATATAGGAAGGAACACCAGTGGC GAAGGCGA

CCACCTGGACTGATACTGACACTGAGGTGCGAAAGCGTGGGGAGCAAACAG GATTAGATA

\section{Reference}

1 Chu, K.H. Fixed bed sorption: setting the record straight on the Bohart-Adams and Thomas models. Journal of Hazardous Materials 177(1), 1006-1012 (2010)

2 Ohko, Y. et al. Degradation of Bisphenol A in Water by $\mathrm{TiO}_{2}$ Photocatalyst. Environmental Science \& Technology 35, 2365-2368 (2001) 


\section{LIST OF PUBLICATIONS}

\section{Journal Publications}

1. M.R. Hartono, R.S. Marks, X. Chen, A. Kushmaro; Hybrid multi walled carbon nanotube-alginate-polysulfone beads for removal of bisphenol-A; Desalination and Water Treatment vol. 54 no.4 (2015): 1167-1183

2. M.R. Hartono, G. Thouand, A. Assaf, A. Kushmaro, X. Chen, R.S. Marks; Utilization of bamboo powder for the removal of organic pollutant in aqueous solution; Water, Air, Soil Pollution vol. 226 (2015): 1-11

3. M.R Hartono, A. Kushmaro, R.S. Marks and X. Chen, "CalciumAlginate/MWCNTs/TiO 2 composite beads for the removal of bisphenol-A"; Water Science \& Technology (In press, doi:10.2166/wst.2016.354)

4. M.R. Hartono, R.S. Marks, X. Chen, A. Kushmaro; Hybrid Calciumalginate/MWCNTs-bacteria/polysulfone beads for removal of bisphenol-A (In preparation)

\section{Conference Presentations}

1. M.R Hartono, M-J. D. Thouand, R.S. Marks and G. Thouand, "Removal of tributyltin by alginate gels in artificial seawater", in the $6^{\text {th }}$ Annual Conference on the Challenges in Environmental Science \& Engineering (CESE), 2013, Daegu South Korea (Poster)

2. M.R Hartono, R.S. Marks, X. Chen and A. Kushmaro, "Hybrid MWCNT/alginate/polysulfone beads for removal of bisphenol-A", in the $6^{\text {th }}$ Annual Conference on the Challenges in Environmental Science \& Engineering (CESE), 2013, Daegu - South Korea (Oral)

3. M.R Hartono, A. Kushmaro and R.S. Marks, "Probing nanotoxicity mechanism of single- and multi-walled carbon nanotubes via bioluminescent panel assays", in the International Water Association' $7^{\text {th }}$ Young Water Professional Conference (IWA-YWP), 2014, National Taiwan University, Taipei-Taiwan (Oral) 
4. M.R. Hartono, A. Kushmaro and R.S. Marks, "Bamboo-deTox: Bamboo Remediation of Polluted Water", in the Negev Global Issues, 2015, Ben Gurion University, Israel (Poster)

5. M.R. Hartono, A. Kuhsmaro and R.S. Marks, "Hybrid Ca-Alginate/MWCNTsBiomass/Polysulfone Beads for the Removal of Bisphenol-A in Aqueous Solution", in the $4^{\text {th }}$ Asian Conference on Civil, Material and Environmental Sciences, 2015, Osaka, Japan (Poster)

6. M.R. Hartono, A. Kuhsmaro, R.S. Marks and X. Chen, "Ca-Alginate/MWCNTs$\mathrm{TiO}_{2}$ Composite Beads for the Removal of Bisphenol-A", in the IWA $9^{\text {th }}$ Micropol \& Ecohazard Conference, 2015, National University of Singapore, Singapore (Poster) 